\title{
Sponsorship Evaluation
}

By

Norman O'Reilly
Eric Sprott School of Business

A thesis submitted to the Faculty of Graduate Studies and Research in conformity with the requirements for the degree of Doctor of Philosophy (Management)

Carleton University

June 2007

(C) Norman O'Reilly, 2007 


$\begin{array}{ll}\begin{array}{l}\text { Library and } \\ \text { Archives Canada }\end{array} & \begin{array}{l}\text { Bibliothèque et } \\ \text { Archives Canada }\end{array} \\ \begin{array}{l}\text { Published Heritage } \\ \text { Branch }\end{array} & \begin{array}{l}\text { Direction du } \\ \text { Patrimoine de l'édition }\end{array} \\ \begin{array}{l}\text { 395 Wellington Street } \\ \text { Ottawa ON K1A ON4 }\end{array} & \begin{array}{l}\text { 395, rue Wellington } \\ \text { Ottawa ON K1A ON4 } \\ \text { Canada }\end{array}\end{array}$

Your file Votre référence ISBN: 978-0-494-33506-2 Our file Notre référence ISBN: 978-0-494-33506-2

NOTICE:

The author has granted a nonexclusive license allowing Library and Archives Canada to reproduce, publish, archive, preserve, conserve, communicate to the public by telecommunication or on the Internet, loan, distribute and sell theses worldwide, for commercial or noncommercial purposes, in microform, paper, electronic and/or any other formats.

The author retains copyright ownership and moral rights in this thesis. Neither the thesis nor substantial extracts from it may be printed or otherwise reproduced without the author's permission.
AVIS:

L'auteur a accordé une licence non exclusive permettant à la Bibliothèque et Archives Canada de reproduire, publier, archiver, sauvegarder, conserver, transmettre au public par télécommunication ou par l'Internet, prêter, distribuer et vendre des thèses partout dans le monde, à des fins commerciales ou autres, sur support microforme, papier, électronique et/ou autres formats.

L'auteur conserve la propriété du droit d'auteur et des droits moraux qui protège cette thèse. $\mathrm{Ni}$ la thèse ni des extraits substantiels de celle-ci ne doivent être imprimés ou autrement reproduits sans son autorisation.
In compliance with the Canadian

Privacy Act some supporting forms may have been removed from this thesis.

While these forms may be included in the document page count, their removal does not represent any loss of content from the thesis.
Conformément à la loi canadienne sur la protection de la vie privée, quelques formulaires secondaires ont été enlevés de cette thèse.

Bien que ces formulaires aient inclus dans la pagination, il n'y aura aucun contenu manquant.

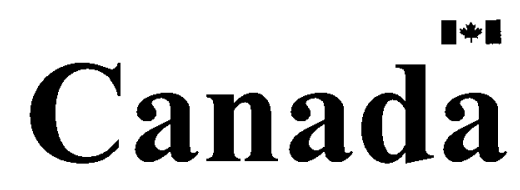




\begin{abstract}
The application of and investment in sponsorship globally has been increasing rapidly for over 20 years while the theoretical development and practical ability to evaluate the effectiveness of sponsorship has lagged behind. It is evident that a strong theoretical foundation and improved evaluation tools are required. Agency Theory has made contributions to almost every discipline and sub-discipline within organization theory, and a review of its tenets supports taking such a perspective on sponsorship evaluation. Viewing the sponsor-sponsee relationship as an example of the principalagent relationship for the purpose of evaluating sponsorship is the focus of the research. The implication that the sponsee provides a service to the sponsor in return for cash and/or in-kind product is also fundamental to this research.

This research recognizes the importance of the explicit (formal) and implicit (unwritten) objectives of both the sponsor and the sponsee in effectively evaluating a sponsorship. In this regard, the dissertation focuses on the evaluation of the sponsorship contract (Agency Theory's unit of analysis) in both its explicit and implicit forms, while considering important relationship factors (e.g. time) as external influences to the evaluation of such contracts. Specifically, a review of the literature and a series of expert interviews and consultations were used to explore the sponsor-sponsee relationship, and provide the basis for the construction and development of a sponsorship evaluation process model. The process model was then tested by adopting it to evaluate two major sponsorships: Kanatek's sponsorship of an expedition to Mount Everest, and ATB Bank's sponsorship of the Edmonton Grand Prix. Based on learning gleaned from these sponsorship evaluation case studies, a final version of the model is proposed and recommendations for future research and practice in sponsorship evaluation are presented.
\end{abstract}




\section{Dedication}

This thesis is dedicated to Dr. Sean Egan, team leader of the Kanatek Expedition to Mount Everest and close friend and mentor to the author. He passed away tragically in April 2005 during his quest to summit Everest. Sean's conscientious guidance and unconditional support of the author and his research is recognized. He was a role model to many, including the author, and is deeply missed.

\section{Special Thanks}

A successful thesis is not possible without the support of advisor, family and friends. This research is no different and two particular and equally important expressions of gratitude are noted.

The diligent and knowledgeable support of Dr. Judith Madill, thesis advisor, is thankfully recognized. She has inspired and will continue to inspire the author.

The sacrifices made, support given and understanding expressed by Nadège, Emma and Kian are especially noted. The author is a very fortunate husband and father. 


\section{Acknowledgements}

The journey that was this thesis required the support and participation of many individuals at varying levels of commitment. They are acknowledged here.

Advisor:

Dr. Judith Madill, Sprott School of Business, Carleton University

Committee:

Dr. Lorraine Dyke, Sprott School of Business, Carleton University

Dr. George Haines, Sprott School of Business, Carleton University

Dr. Louise Heslop, Sprott School of Business, Carleton University

External Reviewers:

External/external: Dr. George Foster, Graduate School of Business, Stanford University

External/internal: Dr. Christopher Waddell, School of Journalism, Carleton University

Expert Interviewees

Sincere thanks are expressed to each of the expert interviewees who shared a few hours of their valuable time and their vast knowledge.

- David Bedford

- Christine Boon

- Cheri Bradish

- Bernie Colterman

- Carol Gardner

- Mark Harrison

- Terry Kell

- Brian Levine

- Tim Maloney

- Jim Mintz

- Gavin Roth

- Kelly Rudan

- Hari Sihvo

- Scott Smith

\section{ATB Bank}

The support of Mr. Kelly Rudan, Marketing Manager, is acknowledged - particularly his belief in the value of this work. Without his support, the thesis would not have been completed.

Kanatek Expedition to Mount Everest

A special thank you is expressed to title sponsor Kanatek and its President Terry Kell, and to all members of the expedition including the organizing team of Dr. Sean Egan (University of Ottawa), Mr. Harold Mah (City of Toronto Event Support Manager), and Dr. Dave Valliere (Ryerson University).

Ireland-Canada Scholarship Fund:

A special thank you is expressed to the Ireland-Canada Scholarship Board for their support, Mr. Eric Sprott for his financial assistance, and the Kemmy Business School, particularly Dr. John Fahy, at the University of Limerick, for their generous hospitality and support. 


\section{TABLE OF CONTENTS}

Abstract

Dedication iii

Special Thanks $\quad$ iii

Acknowledgements iv

Table of Contents $\mathrm{V}$

List of Tables $\quad \mathbf{x}$

List of Figures $\quad$ xii

List of Appendices - xiii

1.0 Introduction 1

1.1 Purpose and Relevance 1

$\begin{array}{ll}1.2 \text { Outline of Dissertation } & 7\end{array}$

1.3 Contribution of Dissertation: Objectives 8

$\begin{array}{ll}2.0 \text { Sponsorship } & 11\end{array}$

2.1 Introducing Sponsorship $\quad 11$

2.1.1 The Origin of Sponsorship 13

2.1.2 Defining Sponsorship $\quad 14$

2.1.2.1 Sponsorship Involvement 17

2.1.2.2 Leveraging 18

2.1.2.3 Sponsorship and Exclusivity 19

2.1.2.4 Sponsorship and Image Transfer 20

2.1.2.5 Sponsee Scenarios $\quad 22$

2.1.2.6 Working Definition of Sponsorship 24

2.1.3 The Process of Establishing a Sponsorship 26

2.2 Sponsorship Industry Growth and Key Industry Segments 28

2.3 Sponsorship and Marketing Theory 31

$\begin{array}{ll}\text { 2.4 Summary: Sponsorship } & 36\end{array}$

$\begin{array}{ll}\text { 3.0 Sponsorship Evaluation } & 37\end{array}$

$\begin{array}{ll}3.1 \text { Introducing Sponsorship Evaluation } & 37\end{array}$

3.1.1 The Attribution Issue 38

3.1.2 Demand for Improved Sponsorship Evaluation $\quad 40$

$\begin{array}{ll}3.2 \text { Evaluation } & 42\end{array}$

3.3 Performance Measurement 43 
3.4 Sponsorship Evaluation $\quad 46$

3.4.1 The Challenges of Sponsorship Evaluation 46

3.4.2 The Sponsorship Evaluation Literature 48

3.4.3 Sponsorship Evaluation Practice 50

3.4.4 Implementing Sponsorship: The Role of Evaluation $\quad 59$

3.4.4.1 Objective Setting $\quad 60$

3.4.4.2 Pre-Sponsorship Measurement 64

3.4.4.3 Choose Promotional Tactics 65

3.4.4.4 Sponsorship Implementation 66

3.4.4.5 Post-Sponsorship Measurement and Results 67

3.5 Summary: Sponsorship Evaluation $\quad 71$

$\begin{array}{ll}4.0 \text { Theoretical Framework } & 73\end{array}$

4.1 Selecting and Introducing Agency Theory 73

4.1.1 The Scope of Agency Theory 75

4.1.2 An Overview of Agency Theory 77

4.2 Key concepts in Agency Theory 78

4.2.1 The Contract as Unit of Analysis $\quad 78$

4.2.2 Assumptions in Agency Theory $\quad 78$

4.2.3 Monitoring in Agency Theory 80

4.2.4 Agency Theory in Economics, Marketing and Management 80

4.2.5 Information and Agency Theory 85

4.2.6 Risk Preference and the Variables in Agency Theory 85

4.2.7 Incentives and Self-Interest in Agency Theory $\quad 88$

4.2.8 The Two Branches of Agency Theory 88

4.2.8.1 Principal-Agent research $\quad 89$

4.2.8.1.2 Pre-Contractual Problems 91

4.2.8.1.2 Post-Contractual Problems 92

4.2.8.2 The Positivist Branch of Agency Theory 95

4.2.8.3. Comparison of the Branches 97

4.3 Theory Development: Agency Theory and Sponsorship 98

4.3.1 Agency Theory, Mega-Sponsees and Typical Sponsees $\quad 99$

4.3.2 Agency Theory, the Contract, and the Relationship 99

4.3.3 Agency Theory Phases in Sponsorship 101

4.3.4 Agency Theory, Risk and Sponsorship 101

4.3.5 Agency Theory, Imperfect Surveillance and Sponsorship $\quad 102$

4.3.6 A Model of Agency Theory in Sponsorship 103

4.3.7 Sponsorship Evaluation and Agency Theory 104 4.3.7.1 Draft Process model for Sponsorship Evaluation $\quad 105$

$\begin{array}{lll}4.4 & \text { Chapter Summary } & 110\end{array}$ 
6.1.1 Background on Interviewees 122

6.1.2 Background Sponsorship Information Results 127

6.1.3 Understanding the Sponsor-Sponsee Relationship 127

6.1.3.1 How Sponsorships Begin and End 128

6.1.3.2 Frequency of Sponsor-Sponsee Communication 131

6.1.3.3 Agency Theory and Sponsorship 133

6.1.3.3.1 Formal Sponsorship Contract 134

6.1.3.3.2 Evidence of Sponsee Monitoring 134

6.1.3.3.3 Sponsee Compliance 135

6.1.3.4 Sponsor and Sponsee Objectives 136

6.1.3.5 Frequency of Intermediary Involvement $\quad 137$

6.1.3.6 The Importance of Exclusivity 138

6.1.3.7 The Importance of Leveraging $\quad 140$

6.1.4 Understanding Current Practice in Spon. Evaluation 141

6.1.4.1 Sponsorship Evaluation Experience 141

6.1.4.2 Frequency of Sponsorship Evaluation $\quad 142$

6.1.4.3 Identification of Sponsorship Evaluation Practices 143

6.1.4.4 Mega-Sponsee Evaluation Practice 144

6.1.4.5 Forecasting Future Practice 146

6.1.5 Barriers, Fears and Benefits of Evaluation 147

6.1.5.1 Belief in Sponsorship Evaluation $\quad 147$

6.1.5.2 Senior Management Motivations $\quad 147$

6.1.5.3 Resource Allocation and Sponsorship Evaluation 149

6.1.5.4 Barriers to Effective Sponsorship Evaluation $\quad 150$

6.1.5.5 Identification of Fears in Sponsorship Evaluation 151

6.1.5.6 Benefits of Evaluation $\quad 152$

6.1.5.7 Frequency of Dually-Supported Evaluation $\quad 152$

6.1.6 Understanding the Timing of Evaluation 153

6.1.7 Updated Sponsorship Evaluation Process model 154 
6.2 Phase 2: Sponsorship Evaluation Case Studies 159

6.2.1 ATB Bank and the Edmonton Grand Prix 159

$\begin{array}{ll}\text { 6.2.1.1 Setting the Stage } & 160\end{array}$

6.2.1.1.1 Identify Sponsorship 160

6.2.1.1.2 Build Relationships 166

6.2.1.1.3 Cost-Benefit Pre-Test 166

6.2.1.1.4 Decision 167

6.2.1.2 Collect Data $\quad 167$

6.2.1.2.1 Data Gathering 167

6.2.1.2.2 Attributes of the Relationship 170

$\begin{array}{ll}\text { 6.2.1.3 Articulate Objectives } & 173\end{array}$

6.2.1.4 Establish Metrics $\quad 175$

6.2.1.5 Determine Metrics for Resources and Shirking $\quad 180$

6.2.1.5.1 Resources and Activities 181

6.2.1.5.2 Shirking 183

6.2.1.6 Collect Data and Analyze $\quad 185$

6.2.1.6.1 Data Collection Exercises 186

6.2.1.6.1.1 Additional Information Gathered 206

6.2.1.6.2 Data Analysis: Objectives 208

6.2.1.6.3 Data Analysis: Shirking Behaviours 238

6.2.1.7 Outcomes and Impacts 249

6.2.1.7.1 Recommendations to Organizations 253

6.2.2 Kanatek and the 2005 Everest Expedition 257

6.2.2.1 Setting the Stage $\quad 257$

6.2.2.1.1 Identify Sponsorship 260

6.2.2.1.2 Build Relationships 266

6.2.2.1.3 Cost-Benefit Pre-Test 267

6.2.2.1.4 Decision 267

6.2.2.2 Collect Data $\quad 268$

6.2.2.2.1 Data Gathering - 268

6.2.2.2.2 Attributes of the Relationship 271

6.2.2.3 Articulate Objectives $\quad 273$

6.2.2.4 Establish Metrics $\quad 274$

6.2.2.4.1 Observations on Research Process $\quad 278$

6.2.2.5 Determine Metrics for Resources and Shirking $\quad 278$

6.2.2.5.1 Resources and Activities 279

6.2.2.5.2 Shirking 280

6.2.2.6 Collect Data and Analyze $\quad 281$

6.2.2.6.1 Data Collection Exercises $\quad 281$

6.2.2.7 Outcomes and Impacts 289

6.2.3 Summary: Sponsorship Evaluation Case Studies 290

viii 
7.1 Research Conclusions: Sponsorship Evaluation Case Studies

7.1.1 Summary Findings

7.1.2 Updated Process model

7.1.3 Methods and Implementation

7.2 Contributions to Practice

7.3 Contributions to Theory and the Literature

7.3.1 Contributions to Agency Theory

7.3.2 Contributions to Sponsorship Theory 304

7.3.3 Contributions to Sponsorship Evaluation Theory 306

7.3.4 Contributions to the Literature related to Objectives 307

7.4 Limitations of this Research 


\section{List of Tables}

Table 1: Sponsorship Arrangements 26

Table 2: Global Sponsorship Values $\quad 29$

Table 3: Sponsorship's Distinction from Advertising 32

Table 4: Models, Methods and Frameworks of Sponsorship Evaluation 51

Table 5: Measurable Promotional Tactics 58

Table 6: Summary Groupings of Sponsorship Objectives 63

Table 7: Top 10 Sponsorship Best Practices 67

Table 8: Agency Relationships Example: NFL Franchise and QB 76

Table 9: Agency Theory Overview 77

Table 10: Comparison of Agency Theory Assumptions and Perspectives 79

Table 11: Cases of the Simple Model of Principal-Agent Research 89

Table 12: Two Propositions of Positivist Theory 95

Table 13: Principal-Agent Research versus Positivist Theory 97

Table 14: Scenarios of the Sponsor-Sponsee Relationships 99

Table 15: Basic Typology of Sponsors, Sponsees \& Intermediaries $\quad 100$

Table 16: Agency Theory Phases in Sponsorship 101

Table 17: Proposed Cases \& Dimensions of Operational Definition $\quad 116$

Table 18: Research Plan for Dissertation Objectives 121

Table 19: Roster and Expertise of Interviewees 123

Table 20: Sponsorship Relationships: Methods of Termination $\quad 130$

Table 21: Top Sponsor Objectives $\quad 136$

Table 22: Top Sponsee Objectives 137

Table 23: Estimates of the Frequency of Sponsorship Evaluation $\quad 142$

Table 24: Sponsorship Evaluation-Themes Observed in Current Practices 143

Table 25: Barriers to Effective Sponsorship Evaluation 150

Table 26: List: Fears about Sponsorship Evaluation 151

Table 27: Process Model Refinements 156

Table 28: Financial Institution Market Share, Alberta 1992 \& 1993

Table 29: 2006 EGP Sponsors 162

Table 30: 2006 EGP Ticket Prices 163

Table 31: ATB-EGP Sponsorship and Working Definition . 165

Table 32: Secondary Data Sources 168

Table 33: ATB-EGP Sponsorship: Articulation of Objectives 174

Table 34: ATB-EGP Sponsorship: Metrics 176

Table 35: Data Collection Details 179

Table 36: ATB financial/ATB MasterCard Sponsorship Budget Expenses 182

Table 37: Sponsee Shirking in the ATB-EGP Sponsorship 184

Table 38: Impact of EGP Sponsorship on Positive Opinion of ATB 188

Table 39: ATB Internal Customer Data, 4 Branches $\quad 190$

Table 40: ATB Internal Customer Data, Aggregate 191

Table 41: Edmonton versus Calgary Branch Comparison, in-branch 193

Table 42: Customer Opinion of Impacts on ATB 194

Table 43: Age of Mass Market Survey Respondents 197

Table 44: Household Income of Mass Market Survey Respondents 198 
Table 45: Title Sponsor Recognition 199

Table 46: Financial Institution Sponsor Recognition 199

Table 47: Frequency Responses, EGP Sponsorship Effectiveness 200

Table 48: General Results: Post-Event Employee Interviews 203

Table 49: Impacts on Decisions to Join or Increase ATB Business 210

Table 50: Summary Results, Objective 5 ANOVA 217

Table 51: Correlation Matrix: Objective 12 Questions 228

Table 52: Evaluation Research Expenses 250

Table 53: Summary Results 251

Table 54: KEME Sponsorship and Working Definition 261

Table 55: 2005 KEME Sponsors $\quad 262$

Table 56: 2005 KEME Planned Itinerary 264

Table 57: Secondary Data Sources 269

Table 58: KEME: Articulation of Objectives, Reach, Activities, Outputs 274

Table 59: KEME Sponsorship Evaluation: Metrics and Methods 276

Table 60: Data Collection Details 277

Table 61: Research Output To Date and Forecasted 286

Table 62: Summary Results: Outcomes per Objectives 290

Table 63: Changes Made to Process Model Version D3 from Version D2 295 


\section{List of Figures}

Figure 1: Models for Performance Measurement 45

Figure 2: Steps to Successful Implementation of a Sponsorship 60

Figure 3: Framework of Agency Theory Variables $\quad 87$

$\begin{array}{ll}\text { Figure 4: The Sponsorship Relationship } & 100\end{array}$

Figure 5: Agency Theory adapted to the Sponsorship Relationship 103

Figure 6: Draft Process Model of Sponsorship Evaluation: Process model D1 109

Figure 7: Defining Metrics and Methods 119

Figure 8: Frequency of Sponsor-Sponsee Contact 132

Figure 9: Histogram of Frequency of Intermediary Involvement 138

Figure 10: Draft Process Model VERSION D2 158

Figure 11: FI Market Share (Alberta Only) 162

Figure 12: Process Model of Sponsorship Evaluation: Process Model D3 298 


\section{List of Appendices}

Appendix_Footnote: Summary of Evaluation Application 351

Appendix A: List of Sponsorship Objectives $\quad 355$

Appendix B: Script for Expert Interviews 357

Appendix C: Online, Pre-Event Survey 359

Appendix D: In-Branch questionnaire $\quad 361$

Appendix E: Hospitality Suite Survey 366

Appendix F: Interview: Hospitality Hostess/Host - Template 368

Appendix G: Mass-market Questionnaire $\quad 369$

Appendix H: Post-event Employee Interview Template 373

Appendix I: Internal Data Request, Kanatek Staff 374

Appendix J: Kanatek Staff Survey $\quad 376$

Appendix K: Expedition Member Survey 378

Appendix L: Current Sponsorship Industry Trends 380

Appendix M: Expert Interviewee Description of own Evaluation Model 381 


\subsection{INTRODUCTION}

\subsection{Purpose and Relevance}

A sponsorship occurs when a "corporation [or other investor] creates a link with an outside issue or event, hoping to influence the audience by the connection" (Rifon, Choi, Trimble, \& Li, 2004, p. 30). This 'link' or 'association' with a specific property (known as the 'sponsee' as a way to consider all forms of properties from athletes to events to clubs to facilities) is the key to differentiating sponsorship from other promotional strategies. It enables the investor (known as the 'sponsor') not only to receive the related promotional benefits (television exposure, print exposure, branding opportunity, etc.), but also to be associated, in the minds of consumers, with the sponsee. For example, Irwin, Lachowetz, Cornwell and Clark (2003), in their survey of 500 spectators at the 2000 FedEx St. Jude Classic Golf Tournament, found evidence which suggests that spectator response to the sponsor (FedEx) was influenced positively by their affinity to the cause which the tournament benefits - the St. Jude's Children's Research Hospital. In fact, the association between a sponsor and a sponsee has proven to be longer-lasting than the sponsorship itself, as it carries on even when the sponsorship relationship is terminated (Wright, 1988). For example, the long-running sponsorship between Gatorade and the Hawaii Ironman Triathlon has now ended, yet the benefits for both parties continue as consumers continue to associate the Hawaii Ironman Triathlon and Gatorade. Akin to other promotional strategies, sponsorship also enables a sponsor to efficiently reach its target market (Rodgers, 2003; Pham \& Johar, 2001). 
In a typical sponsorship transaction, the sponsor provides cash and/or in-kind ${ }^{1}$ product/service to a sponsee in return for promotional opportunities and the ability to leverage the association. The following two examples of Ottawa-based sponsorships illustrate this relationship. First, the 2006 ING-National Capital Marathon was a sponsorship where ING bank, as sponsor, provides cash to the National Capital Marathon event, the sponsee, in return for promotional value. Second, Scotiabank Place is a sponsorship relationship where Scotiabank has invested significant financial resources in order to be the title sponsor of the arena facility, the sponsee, and the exposure it provides.

International sporting goods conglomerate Adidas' sponsorship of the 2004 European Football Championship provides a good example of a large international sponsorship. This sponsorship involved the use of Adidas' silver and black 'Roteiro' ball in every game of the month long tournament. In demonstrating the significant potential of a well planned sponsorship, the promotional value provided to Adidas in exchange for cash led to the sale of over 6 million Roteiro balls in the weeks following the event (Ewing, 2004). The use of data from the sales of Roteiro balls in the Adidas case exemplifies a typical sponsorship evaluation measure. Current sponsorship evaluation practice often involves the use of 'eyeballs', ' footsteps' ${ }^{3 \text { ' }}$ or sales projections. Such evaluation measures lack specificity in terms of how objectives are addressed and, typically, these projections overstate or include factors that do not indicate whether the sponsor or the sponsee will achieve their objectives.

\footnotetext{
1 "In-kind" refers to the contribution of product or services in lieu of cash by a sponsor. For example, an athletic apparel company provides the volunteer $T$-shirts and draw prizes for a running event.

${ }^{2}$ The number of people who viewed the promotion, often measured by impressions.

${ }^{3}$ The number of people who frequented a store as a result of the promotions, often measured by coupon retrieval or questionnaires.
} 
In today's competitive marketplace, sponsees compete for limited sponsorship opportunities from a variety of sources in an environment where the demand from sponsees for sponsorship resources is significantly greater than the supply of interested sponsors (e.g., Nike, General Motors, Coca-Cola). Because of this competitive environment, the sponsor is placed in a position of power when dealing with all but the most valuable sponsees, such as the Olympic Games, Expo, Academy Awards, World Cup of Soccer, Super Bowl, and well-known athletes like Tiger Woods. Although these 'super-valuable' or 'mega' sponsees are in the enviable business position of having interested sponsors bidding for their property rights, the majority of sponsees seeking resources struggle to attract, satisfy and maintain sponsors (Hoek \& Gendall, 2002). Sponsors generally seek promotional means through which they can enhance their brand and build their networks, creating loyal customers and attracting new business as a consequence.

The sponsor-sponsee relationship is a marketing relationship which can develop in many ways and may be viewed from a variety of perspectives. No two sponsorsponsee relationships are the same: power structures vary, the size and scope of the parties vary, the objectives differ, the stage of the relationship between the sponsor and the sponsee changes, the length of the sponsorship varies, and in some instances the relationship involves intermediaries. The literature establishes sponsorship as "a strategic activity with the potential to generate a sustainable competitive advantage in the marketplace" (Fahy, Farrelly, \& Quester, 2004, p. 1013). This implies a divergence from philanthropy and supports the role of sponsorship as part of marketing strategy where sponsors garner promotional value, and sponsees obtain resources. 
Sponsorship has developed from its roots in philanthropy where sponsors provided resources to third parties based on altruism, to the current situation where sponsorship is used by practitioners to achieve the goals of their respective organizations (Dolphin, 2003). In today's dynamic marketplace, sponsorship is viewed as an effective and efficient promotional tool that is capable of cutting through the existing advertising clutter (Rodgers, 2003; Pham \& Johar, 2001) and achieving competitive advantage (Fahy, Farrelly, \& Quester, 2004). According to Cornwell and Maignan (1998), sponsorship continues to be in the early stages of its development and Meenaghan (1998) notes that sponsorship has received more attention from industry than it has received within academic circles. This lack of academic attention has been described as an "empirical chasm" (Westerbeek \& Smith, 2002, p. 141).

Three general sponsorship related themes have developed in the sponsorship literature. The first theme centers on the definition of sponsorship (e.g., Rifon, Choi, Trimble \& Li, 2004; Gardiner \& Shuman, 1988; Sandler \& Shani, 1993; Meenaghan, 1983). In addition to research focusing on sponsorship definition issues, this theme includes research concerning the managerial aspects of sponsorship such as sponsors' objectives, target audiences and media objectives (Cornwell \& Maignan, 1998). A second major theme might be termed 'methods to obtain corporate donations'. Research in this theme focuses on sponsorship's complementary yet distinct position with respect to philanthropy and cause-related-marketing (CRM) (e.g., Polonsky \& Speed, 2001; Webb $\&$ Mohr, 1998). Third, a significant stream of literature has evolved regarding the implementation side of sponsorship. Topics within this stream focus on sponsor/sponsee selection (Cornwell \& Maignan, 1998), the link to corporate objectives (Gardiner \& 
Shuman, 1988), the ability to measure the effectiveness of a sponsorship (e.g., Farrelly, Quester, \& Burton, 1997), the legal and ethical considerations in sponsorship (Cornwell \& Maignan, 1998), the magnitude of the association between the sponsor and the property (e.g., Giannelloni, 1993), sponsorship's influence on consumer attitudes (Parker, 1991), and the sponsor's commitment to leveraging their investment (Gwinner \& Eaton, 1999).

While considerable investigation into sponsorship has taken place during the past 15 years (e.g., Amis, 2003; Bennett, Henson \& Zhang, 2002; Javalgi, Traylor, Gross, \& Lampman, 1994), practitioners and academic researchers have recognized that evaluation remains one of the greatest challenges facing sponsorship development (Crompton, 2004a; Harvey, 2001; Bowey, 1998; Copeland, Frisby, \& McCarville, 1996). While several evaluation tools exist in the literature (Irwin \& Asimakopoulos, 1992), they suffer from a number of deficiencies including failure to assess return on investment $\left(\mathrm{ROI}^{4}\right)$ and reliance on simple measures that do not take the objectives of the sponsorship, such as sales increases and brand equity, into account (Crompton, 2004a; Berrett \& Slack, 1995; Gardiner \& Shumman, 1988).

As investment in sponsorship continues to increase (Kolah, 2003) so will the incentives for both sponsors and sponsees to evaluate sponsorships. Sponsors will question the resulting effects of an investment in the sponsee as a means of validating its selection, compared to alternative promotional strategies and/or tactics it did not pursue. Similarly, the sponsee will want to demonstrate its ability to both attract and maintain investment by sponsors as well as to provide evaluation of the value provided to

\footnotetext{
${ }^{4} \mathrm{ROI}$ is a commonly used term in business to refer to the ratio of money earned or lost on an investment to the amount of money invested in that activity. It is typically measured as a percentage annualized return.
} 
sponsors. Clearly, evaluation is vital to a sponsorship's continuing growth and is the focus of this dissertation. Specifically, this research is focused on utilizing an Agency Theory perspective to develop and test a process model for sponsorship evaluation.

Agency Theory, where the sponsor-sponsee relationship is viewed as a principalagent relationship and where the agent acts on behalf of the interests of the principal (Bahli \& Rivard, 2003), is adopted as the theoretical foundation for the dissertation. In this context, Agency Theory provides a way to view cooperative effort where one entity (the principal) engages another (the agent) to act on their behalf; where the sponsee as agent is seen as offering a service to the sponsor as principal. Given that "Agency Theory provides a unique, realistic, and empirically testable perspective on problems of cooperative effort" (Eisenhardt, 1989, p. 72), and that agency relationships have been shown to pervade marketing (Bergen, Dutta, \& Walker, 1992), the application of an agency perspective on the sponsor-sponsee relationship, particularly with respect to the evaluation of its success, may be useful.

This dissertation focuses on designing, developing and testing a process model that could be used for the evaluation of sponsorship in a variety of settings. The author could not uncover a similar approach in the available literature, suggesting that no such model or approach currently exists. This process model was developed by reviewing the current literature on sponsorship evaluation and evaluation in general. This first phase of development is outlined in a preliminary model (Version D1) developed from a review of the literature and presented in Chapter 4.3.7.1.

A number of knowledge gaps concerning sponsorship evaluation were identified in the review of the literature. These include the limited research and understanding of (i) 
the sponsor-sponsee relationship, (ii) current evaluation practices, (iii) barriers to evaluation, and (iv) when and how evaluation occurs. Therefore, the second phase of the dissertation research involved in-depth qualitative interviews with 14 experts. The purpose of these interviews was to improve understanding of sponsorship, focusing on areas where gaps in the literature are most prevalent. The preliminary sponsorship evaluation process model was then revised on the basis of knowledge gained from these expert interviews, and the revised model (Version D2) is presented in Chapter 6.1.6.

The third phase of the research involved the implementation of the process model in two sponsorship evaluation case studies. In this phase of the research, the process outlined in the model was applied in evaluating both sponsorships. After applying the process model in these two sponsorship case studies, it was once again revised and Version D3 is presented in Chapter 6.2.3.

\subsection{Outline of Dissertation}

This dissertation is organized into seven chapters. The current chapter introduces the concept of sponsorship and outlines its importance. This chapter also describes the purpose, objectives and structure of the document. The second chapter describes sponsorship in detail. First, it includes its definition, descriptions of the important players in the sponsorship relationship, and its distinction from philanthropy and other forms of corporate donations. Second, the varying views around the position of sponsorship in marketing theory are presented. Third, the sponsorship literature is reviewed briefly. The third chapter focuses on sponsorship evaluation and includes a review of general evaluation theory, a review of literature on sponsorship implementation and evaluation, 
and an assessment of current practice. The fourth chapter models the sponsor-sponsee relationship as an occurrence of a principal-agent relationship. This process involves, first, introducing Agency Theory as the framework by which to view sponsorship; second, reviewing the literature on Agency Theory; and, finally, viewing sponsorship from an Agency Theory perspective. The fifth chapter outlines the preliminary sponsorship evaluation process model, and then describes the research methodology which details the two-phase research protocol. The sixth chapter presents the results of both phases of the research, as well as revisions to the sponsorship evaluation process model, while the seventh chapter discusses the results, limitations and suggestions for future research.

\subsection{Contribution of Dissertation: Objectives}

Given (i) the increasing use of sponsorship, (ii) the calls for improved sponsorship evaluation in the literature, (iii) the demand for effective evaluation tools by practitioners of sponsorship, (iv) the limited available literature on sponsorship evaluation, and (v) the proprietary nature of evaluation methodologies in practice, a number of steps were undertaken to provide the foundations necessary to build the sponsorship evaluation model. These steps comprise an iterative process of developing the initial process model from the literature, gathering needed information from sponsorship experts and revising the model, applying the model in two sponsorship cases, and once again revising the model. Specifically, these steps address the major objective of this dissertation as described below. 
Major Dissertation Objective: To propose and test a sponsorship evaluation process model. A preliminary model is developed based on existing literature. Data on existing sponsorship evaluation practices were gathered from interviews with sponsorship experts, and the model was revised in light of this enhanced understanding. The model was then utilized/put into practice in order to evaluate two different sponsorships. Based on the knowledge and experience gained through the implementation of the model, the process model is revised once again and offered as a model to be used and adapted by others in evaluating sponsorships.

To achieve this objective, four important sub-objectives must also be addressed as follows:

1. Dissertation Sub-Objective \#1: To achieve a deeper understanding of the sponsorsponsee relationship. Typical and common objectives of the sponsor as principal and sponsee as agent must be identified and understood. Further, an understanding of the inner workings of the sponsor-sponsee relationship, both the formal contract (explicit) and the informal understandings (implicit), must be developed and enhanced.

2. Dissertation Sub-Objective \#2: To achieve a deeper understanding of current evaluation practices. Without a clear understanding of what practitioners are currently doing to evaluate sponsorships, it is very difficult to develop a relevant and legitimate process model. 
3. Dissertation Sub-Objective \#3: To develop an understanding of the perceptions of barriers, benefits, and fears regarding evaluation in order to allow for effective evaluation.

4. Dissertation Sub-Objective \#4: To develop knowledge about whether and when evaluation occurs in practice in sponsorship. In order to evaluate sponsorships, measurement metrics for each sponsor/sponsee objective must be developed with knowledge of the timing and depth of analysis that occurs in practice. 


\subsection{SPONSORSHIP}

The purpose of this chapter is to introduce and describe the promotional activity known as sponsorship. In doing so, it provides the necessary understanding around the concept to allow for the research that follows regarding the evaluation of sponsorship. Included within the chapter is content on the historical development of sponsorship, a review of its growth, its definition and the definitions of its key variables (e.g. sponsor, sponsee, intermediary), and the key concepts of sponsorship (e.g. involvement, leveraging, exclusivity, mega-sponsees, and image transfer). This content led to the identification of important issues in the related literatures, including the absence of a consensus definition, the conflicting views on sponsorship's place in marketing theory, and the limited understanding of the development of sponsorship relationships. In turn, the chapter also includes sections devoted to clarifying these important issues, including (i) constructing a proposed working definition of sponsorship, (ii) articulating the common sponsee scenarios, (iii) reviewing the process of establishing a sponsorship relationship, and (iv) presenting the literature related to sponsorship's place in marketing theory.

\subsection{Introducing Sponsorship}

A sponsor 5 (e.g., Coke, Jim's Hardware Store, the Government of Ontario, and Eric Sprott) is an investor who invests resources in a sponsee and in return seeks promotional value and other objectives from their association with that sponsee. The sponsee (e.g., Olympic Games, Michael Jordan, the Tulip Festival, a fundraising dinner,

\footnotetext{
${ }^{5}$ In most cases, the sponsor is a corporation, however a sponsor can also be a charity, a not-for-profit organization, a partnership or an individual.
} 
Winterlude) is the property which receives resources and seeks to achieve their own objectives from the association. Affiliated entities are intermediaries who support the sponsor-sponsee relationship, such as a benefiting charity, a sponsorship sales agent, an event manager, or a facility provider.

Sponsorship is attractive to these stakeholders for several reasons. First, faced with the challenge of a cluttered marketplace (Arthur, Dolan, \& Cole, 1998), it is no longer sufficient for an organization to promote through advertising alone. Sponsorship may provide an efficient way to differentiate a company from its competitors (Fahy, Farrelly \& Quester, 2004; Amis, Slack \& Berrett, 1999). Second, anecdotal evidence concerning the attractiveness of sponsorship relative to other promotional tools is supported by sponsors who have bolstered their initial sponsorship investment with additional funds to leverage that investment (Berrett \& Slack, 2001). It is the ability to leverage a sponsorship extensively as part of an integrated marketing communications mix that makes it more attractive than other promotional tools such as advertising and publicity (Cornwell, Pruitt, \& Clark, 2005; Belch \& Belch, 2001; Shimp, 1997; Cornwell, 1995). Leveraging, used in this context, refers to strategies that the sponsor or sponsee funds in addition to what was outlined in the contract and then implements in order to increase the effectiveness of the sponsorship. These techniques are varied and include such things as the title sponsor of a televised event, and/or developing commercials for that event and paying for their diffusion leading up to, during, and following the event (Nicholls, Roslow \& Dublish, 1999). Reebok's recent decision to increase its annual budget to leverage its sponsorship investments to US\$12.6 million (Kolah, 2003) emphasizes the importance of leveraging. 


\subsubsection{Origin of Sponsorship}

There is extensive debate among researchers over the exact origins of sponsorship. It has been linked to the banning of cigarette advertisements in Britain in 1965 and the subsequent interest of tobacco companies in promoting themselves and their products through association with televised sporting events (Mason, 1999). Arthur, Scott, Woods and Booker (1998) claim that sponsorship has been around for thousands of years since the gladiator days of ancient Rome. Cornwell, Pruitt and Clark (2005) trace its formal beginnings to the 1984 Olympic Summer Games. Still, others give credit to the late Mark McCormack, the legendary founder of the sport marketing firm IMG. ${ }^{6}$ McCormack's vision that athletes could secure sponsorship and endorsement deals led him to convince legendary golfer Arnold Palmer to allow him to manage his affairs (Kolah, 2003). Wilkinson (1993) believes that the first true use of sponsorship was in the 1960s when corporations began to seek a return on their donations to sport and other social service associations. These were known as "Philanthropic Sponsorships" (Wilkinson, 1993). Media sponsorship (product mentions on radio programming), a precursor to sponsorship as we know it today, was first practiced during the 1930's in the United States by industry giants Coca-Cola and General Foods (Bloxam, 1998). While these views are divergent, most authors suggest that modern sponsorship has been around for at least the last $40-50$ years.

It is widely agreed that sponsorship has moved from its roots in philanthropy to a promotional activity that has mutual benefits for both the sponsor and the sponsee

\footnotetext{
${ }^{6}$ IMG is one of the world's largest and most successful sport marketing firms. Headquartered in Cleveland, USA the firm has 70 offices in 30 countries, including one in Toronto. For more information see www.imgworld.com.
} 
through a relationship where their association is key in the resulting promotional strategy (Rifon, Choi, Trimble \& Li, 2004; Mason, 1999; Mack, 1999; Arthur, Scott, Woods \& Booker, 1998; Scott, 1998; Hoffman, 1998; Thwaites \& Carruthers, 1998; Mullen, 1997; Wilson, 1997; Howard \& Crompton, 1995; Smith, 1994; Collins, 1994; Kuzma \& Shanklin, 1994; Irwin, 1993; Shaw \& Post, 1993; Sandler \& Shani, 1993; Wilkinson, 1993; Woods, 1993; Witcher, Craigen, Culligan \& Harvey, 1991; Abratt \& Grobler, 1989; Sleight, 1989; Armstrong, 1988; Gross, Traylor \& Shuman, 1987). Others are less convinced of sponsorship's evolution. For example, Meenaghan (1991a) dubbed sponsorship the "Chairman's Choice Syndrome," suggesting that sponsorship development was often based on the CEO or President of a given firm supporting his or her favourite sport so that he/she and his/her colleagues could sit in the crowd and watch. However, the prevalent view today is that sponsorship is now distinct from philanthropy, and is utilized as a promotional strategy tied to an organization's marketing communications activities (Dolphin, 2003; Cornwell and Maignan, 1998; Meenaghan, 1998; Brooks, 1990).

\subsubsection{Defining Sponsorship}

Sponsorship is not easily defined. A review of the literature reveals that definitions of sponsorship - although rarely identical - often contain the same key elements (Olkkonen, 2001). These key elements include the mutually beneficial exchange of sponsor resources (cash or in-kind product/services) in return for promotional value, and - most importantly - the association with the sponsee. The associations made between sponsor and sponsee can influence consumer perceptions of both (Brown \& 
Dacin, 1997; Aaker, 1996). Each sponsorship relationship has its own distinct personality and a unique transfer of image values to the sponsor leads to the positive rub-off of image from the sponsee to the sponsor, or the halo-effect of the association (Meenaghan, 1983). The modern term for the halo-effect is congruency (Meenaghan, 2001) where it is the consumer's perception ${ }^{7}$ of the congruency between the sponsor, the sponsee and the association that is important. The fact that the sponsor receives the right to promote the association (the sponsee also has this right) is either stated or implied in most definitions of sponsorship (e.g., Dean, 1999; d'Astous \& Bitz, 1995).

The first widely accepted definition of sponsorship (Meenaghan, 1983) still included the concept of philanthropy, while more recent definitions (Polonsky \& Speed, 2001; Cornwell \& Maignan, 1998; Sandler and Shani, 1993; Otker \& Hayes, 1987) do not include philanthropy in their definitions, indicating sponsorship's evolution into a communications strategy/tactic. Gardiner and Shuman (1988) describe sponsorship as a form of promotion, but indicate that it differs from advertising in that the medium and creative messages are not as tightly controlled by the sponsor as they would be by an advertiser. Interestingly, this definition focused on differentiating sponsorship from advertising, which was a major challenge for the field in the mid-1980's. The importance of the 'association' was also common in sponsorship definitions around this time (Sandler \& Shani, 1989, p. 12):

[Sponsorship is] the provision of resources (e.g., money, people, equipment) by an organization directly to an event or activity in exchange for a direct association to the event or activity. The providing organization can then use this direct association to achieve either their corporate, marketing or media objectives.

\footnotetext{
${ }^{7}$ Consumer's perception of congruence has been shown to be determined by their prior knowledge of the sponsor and the sponsee, and how logically they view the connection between the two (Meenaghan, 2001; Jagre, Watson \& Watson, 2001).
} 
Integral to this definition as well as others (Sandler and Shani, 1993; Meenaghan, 1991a; Sleight, 1989) is the implied relationship between the sponsor and sponsee, and that both parties expect to benefit from the sponsorship. Similarly, McCarville and Copeland (1994, p. 103) positioned sponsorship as a promotional strategy that "involves an exchange of resources with an independent partner in hopes of gaining a corresponding return for the sponsor". Ukman's (1995, p. 2) definition emphasizes the fact that sponsorship can be paid in cash or via in-kind product, and introduces the notion of leveraging: "[Sponsorship is] a cash and/or in-kind fee paid to a property...in return for access to the exploitable commercial potential associated with that property."

Newer definitions of sponsorship focus primarily on the relationship aspects of sponsorship and leveraging. For example, Cornwell and Maignan (1998, p. 12) provide this view on sponsorship:

On the basis of the definitions found in the literature, we propose that sponsorship involves two main activities: (1) an exchange between a sponsor and a sponsee whereby the latter receives a fee and the former obtains the right to associate itself with the activity sponsored, and (2) the marketing of the association by the sponsor. Both activities are necessary if the sponsorship fee is to be a meaningful investment.

Specific to the sport industry, Shank's (1999) definition moves emphasis away from the concept of the exchange towards taking an investment perspective on sponsorship (i.e., a sponsor-focused definition). Further, Shank's definition emphasizes the expansion of the definition of the sponsee beyond an event or activity to include sports properties such as athletes, leagues, and events.

Recent publications on sponsorship have moved away from re-defining sponsorship to accepting past definitions. Cornwell, Pruitt and Clark (2005) adopt the 
definition of sponsorship-linked marketing as "the orchestration and implementation of marketing activities for the purpose of building and communicating an association to a sponsorship" (Cornwell, 1995, p. 13) while Crompton (2004a, p. 268) defines sponsorship as an example of exchange theory where "(i) two or more parties exchange resources, and (ii) the resources offered by each party must be equally valued by the reciprocating parties". Further, Jalleh, Donovan, Giles-Corti, and Holman (2002) defined sponsorship in the context of a Hierarchical Communications Model, and Madrigal (2001) reverts to Meenaghan's definition of sponsorship (1991a).

Intermediaries are entities outside of the sponsor and sponsee (i.e., third parties) who exert influence on the relationship. They may include player agents, contractors, event managers, media organizations, security groups and municipalities. From their point of view, a formal sponsor-sponsee relationship is a means by which to achieve their specific goals, such as profit, promotion, networking, etc. In this regard, an agent representing the sponsor or the sponsee, the manager of the facility in which the event will occur, or the sub-contractor carrying out some task (e.g., advertising design, signage, etc.) will receive their due share and potentially benefit from the association. For example, TrojanOne, a Toronto-based sport marketing firm, acts as Coca-Cola's agent in determining how to best allocate their promotional dollars for certain marketing objectives.

\subsubsection{Sponsorship Involvement}

Involvement is "the personal, social, and economic significance of the purchase to the consumer" (Crane, Kerin, Hartley, Berkowitz \& Rudelius, 2006, p. 206). Anne and 
Cheron (1991) find that consumers are more likely to recall a sponsor (i) if they are more involved with the sponsee, (ii) if they have prior knowledge about the sponsor, and (iii) if they have interest in the sponsee. D'Astous and Bitz (1995) and Pham (1992) narrow the list to two key points: (i) an exciting sponsee and (ii) achieving a high level of consumer involvement in the sponsorship. In either case, the high level of involvement leads to an increase in information-processing by the consumer and more interest in the sponsorship.

\subsubsection{Leveraging}

Leveraging activities can be defined as any marketing or promotional tactic implemented with the goal of promoting a sponsee or a sponsor-sponsee association (Cornwell, Pruitt \& Van Ness, 2001; Quester \& Thompson, 2001; Crimmins \& Horn, 1996). A number of authors (Otker, 1988, Abratt \& Grobler, 1989, Meenaghan, 1991a; 1991b; 1998; Sandler \& Shani, 1993, 1998) prescribe that it is good practice for sponsors to leverage their sponsorship by investing additional resources in complementary promotional activities that strengthen the association. The argument here is that the initial investment only buys the rights to an association but there is still a need to exploit this further by investing additional sums. The association can then be promoted and leveraged beneficially using a variety of marketing communications elements (e.g., Ludwig \& Karabetsos, 1999; Javalgi, Traylor, Gross, \& Lampman, 1994; Meenaghan, 1991b). Examples of leveraging initiatives range from an advertising campaign launched as the sponsored event approaches, to a PR campaign that increases awareness of the sponsorship, to linking a sought-after sponsee image with an integrated marketing mix (Irwin \& Sutton, 1994; Hoek, Gendall \& Sanders, 1993; Abratt, Clayton \& Pitt, 1987). 
Sponsors and occasionally sponsees leverage to (i) achieve competitive advantage (Fahy, Farrelly \& Quester, 2004), (ii) generate revenue (Flynn, 1993), and (iii) impact consumer-oriented objectives, such as increasing brand awareness, brand image, and purchase intentions (Meenaghan, 2001; Lardinoit \& Quester, 2001; Quester \& Thompson, 1999; Ludwig \& Karabetsos, 1999; Cunningham \& Taylor; 1995; Gardiner \& Shuman, 1988; Meenaghan, 1991a; Ukman, 1995).

The literature recommends spending at least the same amount as the sponsorship investment itself, and ideally more, in leveraging (Meenaghan, 2001; Quester \& Thompson, 2001), with authors suggesting that the sums required for successful leveraging may be up to five times the initial expenditure (Seguin, Teed \& O'Reilly, 2005; Shanklin \& Kuzma, 1992; Witcher, Craigen, Culligan \& Harvey, 1991; Abratt \& Grobler, 1989; Eisenhart, 1988). For example, a number of the sponsors of Euro $1996^{8}$ spent in excess of a 3:1 ratio on leveraging their sponsorships (Lardinoit \& Quester, 2001). In practice, however, the amount spent on leveraging varies greatly. For example, in a study of Canadian corporate sponsors, Thwaites, Aguilar-Manjarrez and Kidd (1998) found that only 63 percent of the sponsors studied leveraged their investment. Thus, $37 \%$ did not invest any resources beyond the initial sponsorship fee.

\subsubsection{Sponsorship and Exclusivity}

The concept of exclusivity refers to a sponsor being given the right to be the only sponsor of a given event in their business category (e.g. automobile, airline, etc.). The onus often lies with the sponsee to protect the exclusivity of its sponsors from ambush

\footnotetext{
${ }^{8}$ Euro 1996 refers to the 1996 European Football Championships. The event is held every four years and is one of the largest events in Europe, if not the world.
} 
(Crow \& Hoek, 2003; McCarthy \& Lyberger, 2001). Exclusivity is often given credit for creating the high level of interest in sponsoring the Olympic Movement in the mid1980's (Pound, 1996). As a result of these very large sponsorship investments, exclusivity has become a vital aspect of sponsorship. Sponsors now demand to have their investments protected against ambush marketing, which is where organizations, typically the competitors of official sponsors, seek the benefits of official association with a megasponsee, but are unwilling to pay for such an association (Crompton, 2004b; Lyberger \& McCarthy, 2002; McCarthy \& Lyberger, 2001; Townley, Harrington \& Couchman, 1998).

In practice, exclusivity, or category exclusivity as it is now often termed, is becoming increasingly important. Studies of consumer opinion of ambush (Seguin, Lyberger, O’Reilly \& McCarthy, 2005; Shani \& Sandler, 1998) demonstrate empirically that consumers find ambush marketing to be unacceptable and are confused by it. These authors note that exclusivity is the key to success in sponsorship as sponsees must determine ways to protect the exclusive rights of sponsors, particularly in high value sponsorships (e.g. Super Bowl, Olympic Games), but with growing importance in smaller properties (Shank, 2005).

\subsubsection{Image Transfer}

An important concept in understanding how sponsorship works and differentiating sponsorship from other promotional strategies is the idea of image transfer (Walliser, 2003). Gwinner and Eaton (1999) suggest that the use of image transfer is the most effective way to leverage a sponsorship. Image transfer in the sponsorship literature 
is defined based on the fact that, in any given sponsorship, both the sponsor and the sponsee bring their own specific image values (Meenaghan \& Shipley, 1999), which in turn can be transferred to a sponsor, a sponsee or a co-sponsor (Grimes \& Meenaghan, 1998). It is important to note that this transfer takes place in the minds of the consumers who transfer, through the sponsor-sponsee association, some image value from one party to another (Gierl \& Kirchner, 1999; Giannelloni, 1993). There is literature that researches the image effects of sponsorship and provides empirical support that sponsorship contributes to the modification of certain image dimensions (Stipp \& Schiavone, 1996).

Various authors (Gwinner \& Swanson, 2003; Jagre, Watson \& Watson, 2001; Johar \& Pham, 1999; Gwinner \& Eaton, 1999; Grimes \& Meenaghan, 1998; Gwinner, 1997; Keller, 1993; McDonald, 1991) have looked specifically at the transfer of image from sponsee to sponsor. A review of this literature reveals seven key propositions concerning image transfer. First, in the case of a well-known and long-established sponsee and a less established sponsor, the chance of image transfer is less likely as consumers are more likely to relate to the well-known sponsee, and not to the association or to the sponsor. This has obvious implications in sponsor selection. Second, in the case of sport sponsees, consumers (spectators) are likely to be very focused on the event at hand suggesting that the likelihood of image transfer is reduced. Third, in the case of a sponsor promoting a low involvement product, Gwinner (1997) suggests that a sponsee with a positive brand image will be a "potent force" in building the image (brand) of the sponsor. Fourth, in the case of a sponsor and sponsee with similar images, the transfer of image and ability to leverage the association effectively is enhanced (Gwinner \& Eaton, 1999). This further supports the importance of the sponsee selection stage of a 
sponsorship relationship. Fifth, a sponsor may be able to better leverage its sponsorship if it sponsors a number of sponsees who possess consistent images (Gwinner, 1997). This demonstrates the importance of a sponsorship portfolio where the overall effectiveness of all sponsorships could be hindered by a single, inconsistent one. Sixth, the transfer of image depends on the exclusivity of the agreement between the sponsor and the sponsee. That is, the ability of the sponsor and the sponsee to reduce the frequency of ambush may lead to improved image transfer. Finally, the transfer of the image depends on the level of involvement the sponsor has with the sponsee. The more involved the sponsor becomes in the relationship with the sponsee, the stronger the perceived relationship becomes and, in turn, the greater the image transfer.

\subsubsection{Sponsee Scenarios}

We know that the demand from sponsees for sponsorship resources is significantly greater than the supply of interested sponsors (Berrett \& Slack, 2001). Only those few sponsees who are major, global properties with significant media interest and high levels of reach are in a strong business position vis-à-vis potential sponsors. These sponsees are classified here as mega-sponsees. The remainder (and vast majority) of sponsees are termed 'typical' as they struggle to achieve cash and/or in-kind resources from sponsors. When considering sponsorship for evaluation or other strategic purposes, the acknowledgment of which scenario is being dealt with is very important (Witcher, Craigen, Culligan \& Harvey, 1991).

Mega-sponsees, such as the Olympic Games, have been defined as "short-term events with long-term consequences for the cities that stage them" (Carlsen \& Taylor, 
2003, p. 19). It is widely believed that these events provide significant tourist flow to a region, in turn, providing jobs, economic impact, new urban infrastructure, and income. (Carlsen \& Taylor, 2003; Dimanche, 1996; Hughes, 1993) Further, these mega-sponsees can be characterized as news events (Getz, 2002; 1998) that are viewed positively by sponsors interested in mass-market promotions, and who, in turn, compete for official sponsor status. In practice, the mega-sponsee has many interested sponsors vying for the sponsorship rights, which leads to incredible sums of money being spent on the rights. Given the reach of a mega-sponsee, one of the most important reasons that a large sponsor seeks to enter into such a sponsorship agreement is to increase brand awareness and alter its image or that of one of its brands (Amis, 2003; Amis, Slack \& Berrett, 1999). An example is the Olympic Games and the International Olympic Committee's well known TOP program where sponsors in twelve major categories (non-alcoholic beverages, information technology, innovative products and services, health care products, film/photographics and imaging, computing equipment, life insurance/annuities, retail food services, timing/scoring/venue results services, audio/TV/video equipment, wireless communications equipment, and consumer payment systems) compete for the valuable and far-reaching official sponsorships of the Olympic Games. The value of these sponsorships is profound, as the fees for an Olympic TOP sponsorship in the 2001-2004 quadrennial averaged US\$65 million?.

Typical (smaller) sponsees, on the other hand, often lack the sophistication and reach required to attract, satisfy and maintain sponsorship (Copeland, 1991). They have also been defined by their lack of television coverage, which is known to be a very

\footnotetext{
${ }^{9}$ In addition to these fees, TOP sponsors typically invest between US $\$ 50$ million and US\$250 million towards leveraging the sponsorship.
} 
important criterion for sponsors when selecting sponsees (Witcher, Craigen, Culligan \& Harvey, 1991; Abratt, Clayton \& Pitt, 1987). Typical sponsees often carry out concurrent complementary marketing activities to make themselves more attractive to sponsors, since such activities will help create more appeal in specific targets markets where more sponsors are interested in investing, which, in turn, will increase their ability to obtain sponsorship and, in some cases, attract sponsors with whom they wish to be associated, or even encourage premium rates for such sponsorships (Gwinner \& Eaton, 1999). It is also important to note that typical sponsees are often counting on revenue from sponsorship to survive. Thus, for typical sponsees, revenue-generation takes priority over image objectives. This is particularly true for cash-starved not-for-profit and charitable foundations (Rifon, Choi, Trimble \& Li, 2004; Bendapudi, Singh \& Bendapudi, 1996).

\subsubsection{Working Definition of Sponsorship Adopted in this Dissertation}

This dissertation adopts the Cornwell and Maignan 1998 definition of sponsorship as it clearly articulates that sponsorship involves two activities: the exchange between sponsor and sponsee, and the marketing of the association that results from the exchange. Further, the Cornwell and Maignan definition (i) is based on an extensive global review of international research on sponsorship, (ii) is relatively recent and (iii) is quoted frequently in the literature (e.g. Ali, Cornwell, Nguyen, \& Coote, 2006; Felt, 2003; Ruth $\&$ Simonin, 2003). This conceptual definition is adapted in the context of the literature, as the working definition of sponsorship for this dissertation which suggests that operationally, a promotional endeavour is termed a sponsorship if the following 10 criteria are met: 
1. One party (the sponsor) invests resources in another party (the sponsee), where

a. the sponsee provides promotional value in return, and

b. the sponsor makes the investment in order to achieve image-based, brand-based and/or media-based objectives.

2. In the relationship between the sponsor and the sponsee, the sponsee is seen as providing a service to the sponsor.

3. Joint sponsor-sponsee activities are part of the sponsorship (i.e. an association exists).

4. Consumers (or members of the target market of the promotion) are exposed to three specific entities: the sponsor's brand, the sponsee's brand and the sponsor-sponsee association.

5. Consumers (or members of the target market of the promotion) are presented with a partnership between the sponsor and the sponsee. The impact of the partnership on consumers is expected to last longer than the sponsorship contract itself due to the goodwill or emotional ties that consumers build over time.

6. The sponsor-sponsee association is exploited or leveraged by one or both parties.

7. The transfer of elements of the sponsee's image to the sponsor is of interest to the sponsor.

8. The exclusivity of the sponsorship is of interest to the sponsor and the sponsee.

9. Congruency (fit) between the sponsor and the sponsee is important to both parties.

10. The primary objectives of the sponsor are marketing based (i.e. non-philanthropic). In many sponsorships, a number of other stakeholders and intermediaries are involved in the relationship between the sponsor and the sponsee. These stakeholders may include other sponsors, suppliers, supporting organizations, property management 
groups and player agents. All of these influence the relationship and need to be considered in any related research. Table 1 below provides examples of parties who may be involved in different sponsorship arrangements.

\section{Table 1: Sponsorship Arrangements}

\begin{tabular}{|l|l|}
\hline Scenario & Example \\
\hline Sponsor-Sponsee & Local bike store sponsors a local athlete \\
\hline Sponsor-Agent-Sponsee & $\begin{array}{l}\text { Coke engages a sport marketing firm to use } \\
\text { sponsorship to achieve a promotional goal }\end{array}$ \\
\hline Sponsor-Agent-Mega Sponsee & $\begin{array}{l}\text { The Super-Bowl hires a sponsorship consultant } \\
\text { to maximize their revenues from sponsorship }\end{array}$ \\
\hline Sponsor-Agent-Agent-Sponsee & $\begin{array}{l}\text { Both sponsor and sponsee have engaged agents } \\
\text { on their behalf }\end{array}$ \\
\hline Sponsor-Agent-Agent-Mega Sponsee & $\begin{array}{l}\text { Both sponsor and sponsee have engaged agents } \\
\text { on their behalf; and the sponsor is a major } \\
\text { property like the Olympic Games }\end{array}$ \\
\hline
\end{tabular}

\subsubsection{The Process of Establishing a Sponsorship}

After crafting the working definition of sponsorship, the next step is to understand the process of developing or establishing a sponsorship. The literature suggests that there are several common stages in the process of establishing sponsorship arrangements (Hoek \& Gendall, 2002; Cornwell \& Maignan, 1998). Attracting sponsorships is the act of convincing an interested sponsor to enter into some sort of exchange transaction with the sponsee (O'Hagan \& Harvey, 2000). This may often take the form of a trial relationship or an in-kind sponsorship arrangement. Once a sponsor has agreed to enter a sponsorship arrangement/contract with a given sponsee - in other words, they have been successfully attracted, the sponsee enters into the stage of attempting to satisfy the sponsor (O'Hagan \& Harvey, 2000). This stage is known to the practitioner as servicing or activating and involves making sure all of the tenets of the sponsorship contract are 
met, and that all of the sponsor's expectations are met, if not, exceeded. This would include such things as meeting the contractual agreements in terms of the amount and location of signage and television commercial slots, and the visibility or presence of the sponsor at press conferences. The final phase of sustaining a long-term sponsorship partnership is the maintenance phase. This involves negotiating with the sponsor to carry on the sponsorship arrangement in the future; striving to build a healthy long-term relationship, dedicating sponsee staff to servicing the sponsorship, demonstrating the sponsee's appeal over its competition, and undertaking the joint planning of copromotional opportunities (O’Hagan \& Harvey, 2000).

From the point of view of a sponsor, both selecting and leveraging a sponsorship requires specific tactics. In this respect, sponsors must carefully evaluate their promotional options and, if sponsorship is selected as part of that portfolio, consider which type of sponsee (industry, league, event, etc.) offers the greatest return. The selection of the sponsee has become an important aspect of sponsorship (Walliser, 2003; Thwaites \& Carruthers, 1998). Once a partnership is contracted, the sponsor must then plan to fully leverage the partnership to maximize the return on their investment. Seguin, Teed and O'Reilly (2005) note a number of leveraging activities including (i) media relations programs to enhance publicity around the sponsorship, (ii) television coverage to promote the sponsorship, (iii) cross-promotions to build relationships with suppliers and partners, (iv) public appearances by high-profile athletes or entertainment stars at retail outlets or company functions, (v) related charitable ventures to associate a positive social or community benefit with the sponsorship, and (vi) hospitality activities for key partners, clients and suppliers. 


\subsection{Sponsorship Industry ${ }^{10}$ Growth and Key Industry Segments}

The use of sponsorship as a promotional tool has grown steadily over the past 25 years (Meenaghan, 1998). Grimes and Meenaghan (1998) argue that this growth is a result of four main factors: (i) the cluttered marketplace, (ii) the onset of government restrictions on tobacco and alcohol advertising, (iii) the increased popularity and commercialism of sports and arts, and (iv) the increasing trend towards globalization, where corporations are attracted to sponsees whose reach transcends borders and cultures. Global investment has progressed from approximately US\$500 million in 1982 (Kuzma \& Shanklin, 1994), to US $\$ 3$ billion in 1989 (Boyle \& Haynes, 2000), to US\$11 billion in 1996 (Boyle \& Haynes, 2000), to US\$19.5 billion (Boyle \& Haynes, 2000) in 1999, to US\$24.4 billion in 2002 (Kolah, $2003^{11}$ ), to US\$28 billion in 2004 (IEG, 2004), and to an estimated US\$30.5 billion in 2006 (IEG, 2006). In terms of its contribution to promotional spending, sponsorship has increased in importance from $2.5 \%$ of all promotional expenditures in 1987 to an estimated 5.8\% in 2001 (IEG, 2000), with Andref and Nys (2002) suggesting that sponsorship will grow to represent $8.5 \%$ of all advertising expenditures by 2010 .

Sponsorship for the 2012 Olympic Games in London, England is reported to be priced at around $\$ 50$ million British pounds for a 6-year deal leading up to 2012 (Sport Business News, 2006). The Royal Canadian Mint was announced as a second tier sponsor of the 2010 Olympic Games in Vancouver with a \$15 million (Canadian)

\footnotetext{
${ }^{10}$ For a summary of important industry trends affecting sponsorship, please go to Appendix L.

${ }^{11}$ Kolah (2003) also noted that globally (i) 145 sponsorships had a value of US $\$ 10,000,000$ or greater, (ii) the 50 largest sponsorships averaged 6.7 years in length, and (iii) soccer is the most common sponsee as well as the sponsee that receives the most sponsorship dollars (US\$1.44 billion annually).
} 
commitment (VANOC, 2006). Further, VANOC recently announced that it has already raised $\$ 565$ million in sponsorship, including $\$ 200$ million from Bell Canada and $\$ 110$ million from RBC Financial Group, for the 2010 Winter Olympic Games, with a final sponsorship goal of $\$ 700$ million, or enough to pay for half of the Games' operating budget (Ogilvie, 2006). Table 2 below details how sponsorship is growing on all comers of the globe.

Table 2: Global Sponsorship Values (Source: IEG, 2003)

\begin{tabular}{|l|c|c|}
\hline Territory & $\begin{array}{c}\text { Sponsorship values in } \\
\text { 2003 (US\$ billions) }\end{array}$ & $\begin{array}{c}\text { Percentage growth (over } \\
\text { 2002) }\end{array}$ \\
\hline North America & $\$ 10.5$ & $9.1 \%$ \\
\hline Central and South America & $\$ 2.2$ & $4.8 \%$ \\
\hline Europe & $\$ 7.4$ & $4.2 \%$ \\
\hline Pacific Rim & $\$ 4.7$ & $9.3 \%$ \\
\hline Other & $\$ 1.4$ & $7.6 \%$ \\
\hline
\end{tabular}

Sponsorship is clearly a significant global industry and, like any such industry, it is varied and segmented. In a study of 1353 international sponsorship deals in $2002,80 \%$ were sport sponsorship, $10 \%$ were broadcast sponsorships, $7 \%$ included arts and culture sponsorship, and $3 \%$ involved the sponsorship of charities or cause-related events and activities (Kolah, 2003). As these figures illustrate, sponsorship has traditionally been used most extensively in the sport sector (Copeland, Frisby \& McCarville, 1996;

Thwaites, 1995), and approximately 65-80\% (IEG, 2006; Kolah, 2003) of its use and spending on sponsorship is still in that context. In fact, $94 \%$ of all rights fees invested in sponsorship were invested in sport sponsees (Kolah, 2003). Other areas of sponsorship

\footnotetext{
${ }^{12}$ There is very little to no official published data on total sponsorship spending in Canada. The only known sources are a dated study by Thwaites, Aguilar-Manjarrez and Kidd (1998) which estimated that approximately CAD\$375 million was spent on sponsorship in Canada in 1997, and a recent estimate of CAD\$750 million put forth in an industry publication (Issues in Sponsorship, 2003).
} 
application including the arts, the environment, universities, and social functions - all of which are also very important - has been much smaller than in sport (Kolah, 2003; Quester \& Thompson, 2001; Witcher, Craigen, Culligan \& Harvey, 1991). However, a number of researchers have forecasted that the gap between sport sponsorship and arts sponsorship will close over time as sport sponsees' prices escalate and sport sponsorship opportunities saturate (Quester \& Thompson, 2001; Meerabeau, Gillet, Kennedy, Adeoba, Byasss \& Tabi, 1991).

Although it continues to lag behind sport in its share of the sponsorship market, the industry known as 'the arts' is beginning to receive more attention in the literature, and receives a significant amount of investment from sponsors each year. In $2002,7 \%$ of all sponsorship deals representing $2 \%$ of global sponsorship investment were in the arts (Kolah, 2003). Although much of the process is the same for an arts sponsorship as it is for a sport sponsorship, the literature does identify a number of differences (Wolton, 1988). First, as opposed to sponsors of sport who work out of their marketing departments, sponsors of arts are typically based in their public relations departments (Quester \& Thompson, 2001). Second, arts sponsors typically seek a very specific target audience that can be reached only by events, while sport sponsorship typically relies heavily on the media to reach mass market audiences (Sparks, 1997; Marshall \& Cook, 1992; Abratt \& Grobler, 1989). Finally, the literature demonstrates that arts sponsors typically seek to pursue image rather than sales-related objectives from the association (Quester \& Thompson, 2001).

Another area that has received attention in the literature is sponsorship involving celebrities. This is where the celebrity is a sponsee and the sponsor seeks to transfer the 
celebrity's image to that of their product (McCracken, 1989). This has obvious similarities to both sport sponsorship and arts sponsorship (i.e., high-profile athletes and artists as sponsees). A celebrity is defined in a variety of ways, but it typically refers to an individual who may be a sport star, movie star or politician whose name is well known and whose image is well understood by some market (see Ferrand \& Pages, 1996). Kahle and Homer (1985) show that the more closely related the images of the celebrity and the sponsor, the greater the effectiveness of the sponsorship. This finding is very similar to what happens when consumers perceive a congruent fit between a sponsor and a high profile sport or art sponsee (McDaniel, 1999). In all cases, it is well established that consumers respond better to congruent sponsor-sponsee relationships (Cornwell, Roy \& Steinard, 2001; Gwinner \& Eaton, 1999; Cornwell, 1995).

\subsection{Sponsorship and Marketing Theory}

There is consensus in contemporary literature that sponsorship fits as an element of promotion strategy (Shannon, 1996; Cunningham \& Taylor, 1996). However, there remains considerable lack of agreement as to whether it fits as a distinct element of the promotional mix or as a sub-tactic of advertising. While some authors consider sponsorship as part of advertising (see Cornwall \& Maignan, 1998); others position it as different from advertising and as a promotional strategy unique in its application and benefits (e.g., Amis, Slack \& Berrett, 1999; Meenaghan, 1998; 1991b; Cornwell, 1995; Hastings, 1984). For example, Thwaites (1995), Amis, Slack and Berrett (1994), Furlong (1994), Meenaghan (1994), and Sleight (1989) argue that sponsorship fits quite naturally alongside advertising, public relations, sales promotion, and personal selling as an 
element of the marketing communications mix because its basic function lies in achieving communications objectives. Others view sponsorship as part of sales promotion (Bennett, Lamm \& Fry, 1988), as a specific consumer-oriented sales promotion (Belch \& Belch, 2001), as a television-based sport promotion technique (Cannon \& Riordan, 1994), and as a public relations or publicity activity (Kotler, 1997; Lancaster \& Massingham, 1993; Zikmund \& d'Amico, 1998).

Although debate continues (e.g., Grewal \& Pechmann, 1998), sponsorship is now widely believed to be different than advertising (Meenaghan, 2001; Tripodi, 2001). Bloxam (1998) outlines three key differences between sponsorship and advertising, which are detailed in Table 3 below.

Table 3: Sponsorship's Distinction from Advertising (Bloxam, 1998)

\begin{tabular}{|l|l|l|}
\hline Distinction & Meaning & Example \\
\hline $\begin{array}{l}\text { Sponsors } \\
\text { viewed as 'part } \\
\text { of the } \\
\text { program' }\end{array}$ & $\begin{array}{l}\text { Due to the association effect, } \\
\text { consumers perceive a sponsor as } \\
\text { more involved with the sponsee } \\
\text { than an advertiser who lacks the } \\
\text { association. }\end{array}$ & $\begin{array}{l}\text { The Nike Run TO event in } \\
\text { Toronto (sponsor) versus a Nike } \\
\text { TV commercial (advertising) } \\
\text { during CBC Sportsweekend }\end{array}$ \\
\hline $\begin{array}{l}\text { Advertising \& } \\
\text { Sponsorship } \\
\text { function } \\
\text { differently }\end{array}$ & $\begin{array}{l}\text { The process by which the } \\
\text { communication takes place differs. } \\
\text { In sponsorship, the message is } \\
\text { coded, delivered and decoded in } \\
\text { collaboration with the sponsee } \\
\text { while in advertising the process } \\
\text { occurs independently. }\end{array}$ & $\begin{array}{l}\text { Leading up to and during the } \\
\text { Olympic Games, the IOC and its } \\
\text { TOP Sponsors work together on } \\
\text { all promotions, while Ford, } \\
\text { purchasing an advertisement in } \\
\text { the Globe and Mail, develops the } \\
\text { promotion on its own. }\end{array}$ \\
\hline $\begin{array}{l}\text { Sponsorship is } \\
\text { widely } \\
\text { believed to } \\
\text { benefit a wider } \\
\text { audience }\end{array}$ & $\begin{array}{l}\text { Consumers often believe that } \\
\text { supporting a sponsor has greater } \\
\text { benefit than supporting an } \\
\text { advertiser as the perception is that } \\
\text { the sponsee will benefit. This is } \\
\text { particularly important in the } \\
\text { sponsorship of causes (e.g., } \\
\text { amateur sport, charity, etc.). }\end{array}$ & $\begin{array}{l}\text { The CIBC Run for the Cure is a } \\
\text { strong example of this distinction } \\
\text { as consumers are exposed to } \\
\text { CIBC investing resources to } \\
\text { directly support the Run for the } \\
\text { Cure. }\end{array}$ \\
\hline
\end{tabular}


What differentiates sponsorship from advertising is the association between the two parties (sponsor and sponsee) which enhances the relationship beyond a basic cash purchase of promotional value (advertising). Often, in sport, charity or art sponsorships, an emotional connection is key to this enhancement (Shank 2005; Meenaghan, 2001; 1999). Lyberger and McCarthy (2002) and Javalgi, Traylor, Gross and Lampman (1994) note that sponsorship differs from advertising in that the medium and created messaging are not as tightly controlled by the sponsor as they would be by an advertiser. Meenaghan (1991b) suggests that 'goodwill' is the main differentiating factor between advertising and sponsorship, since much higher levels of goodwill are created by consumers (often fans in the sport setting) as a result of a sponsor's involvement with an event (Meenaghan, 1991b). Parker (1991) empirically supports this distinction by finding that consumers who were subject to both sponsorship and advertising programs had a more positive attitude toward sponsors than toward advertisers (Parker, 1991). In this regard, the point of difference is that communications to consumers created by sponsorship are non-verbal and non-argued in nature (Derbaix \& Pham, 1991) implying that the process of encouraging consumer change and action via sponsorship occurs peripherally (Petty \& Cacioppo, 1986).

An additional but very important difference between sponsorship and advertising lies in how each works to persuade customers. Advertising exploits the construct of emotion and sponsorship seeks to 'connect' with the emotion inherent in sport sponsee or the arts sponsee or the charity sponsee (Meenaghan, 2001). Other authors describe sponsorship as fundamentally different from advertising since it persuades consumers indirectly (Crimmins \& Horn, 1996). This is based on the association that exists and the 
fact that consumers are influenced by the sponsee, the association and the sponsor, not just the sponsor. If a firm is seen to be supportive of a sponsee (team, charity, event, athlete, etc.), the sponsor's expectation is that the consumer - who is interested to some extent in the sponsee - will view the sponsor positively provided that there is a good fit between the image of the sponsor, the sponsee, and the association. Kover (2001) differentiates sponsorship by describing how it offers an 'interaction' with consumers as opposed to advertising which only 'talks' to them. This, in theory, allows sponsorship to create a bond with consumers via the values they both share by association with the sponsee of interest (Kover, 2001). For example, Coke's sponsorship of the Olympic Games allows for the transfer of attributes from the sponsee's image (Olympic Games: performance, international, etc.) to the sponsor's product's image via the promotion of the association amongst the two.

A brief analysis of the objectives sought by advertising and sponsorship provides a good view of the similarities and differences between the two promotional tools. Consistent with advertising, sponsorship may, in some cases, be employed to enhance public awareness of a sponsor or to improve or change a previously established image (Cornwell, Roy \& Steinard, 2001). Another similarity to advertising is that sponsorship may seek to increase sales or increase media exposure (Cornwell, Roy \& Steinard, 2001). Conversely, Meenaghan and Shipley (1999) argue that a sponsorship can achieve more diverse objectives than an advertisement, including the increased awareness towards altering the image of a brand or the enhanced ability to improve business relationships with customers. Cornwell, Roy and Steinard (2001) point out that there are two additional objectives that demonstrate sponsorship's difference from advertising: (a) achieving 
corporate hospitality and (b) advancing the personal agendas and interests of senior executives, both of which are enabled by the fact that a sponsorship can be leveraged and, thus, more readily allows for associated events and activities. Hoek, Gendall, Jeffcoat and Orsman (1997) supported this distinction empirically by examining consumers' responses to sponsorship and advertising and finding that, although neither had a significant impact on behaviours (intent to purchase), that attitudes were more positively reinforced by sponsorship.

Sponsorship as a source of competitive advantage for organizations is well developed in the literature (Fahy, Farrelly \& Quester, 2004; Amis, Slack \& Berrett, 1999; Hamel \& Prahalad, 1994). The literature on competitive advantage shows that firms must differentiate themselves from competitors on some asset or process and, to be sustainable, this capability or competency gap must be enduring (Bharadwaj, Varadarajan \& Fahy, 1993). Any advantage gained, of course, is not enduring or sustained if it can be easily imitated or otherwise replicated (Peteraf, 1993; Grant, 1991). Specifically then, how does sponsorship enable sustained competitive advantage? The literature suggests that a sponsorship should yield a unique outcome which fits with the image that the sponsor is trying to convey (Amis, Slack \& Berrett, 1997; Ferrand \& Pages, 1996). An example of a successful sponsor-sponsee relationship, such as Budweiser's sponsorship of the National Football League (NFL) where the sponsor (Budweiser) has built an enduring and positive association with the NFL (sponsee), its fans and the sport of football, illustrates how a sponsor can develop its sponsorship into a sustained competitive advantage (Amis, Pant \& Slack, 1997). 
In summary, the literature supports sponsorship as an independent element of promotion strategy, distinct from advertising.

\subsection{Summary: Sponsorship}

This chapter has presented an analysis of the literature on sponsorship, which makes a number of important contributions to this dissertation. First, definitions of sponsorship were reviewed and a working definition crafted. Second, sponsorship's distinction from advertising was presented and supported. Third, the use of sponsorship as a promotional tool was shown to be growing and expanding. Fourth, the key concepts of sponsorship (e.g., involvement, leveraging, exclusivity, and mega-sponsor) were described. Finally, the sponsor-sponsee relationship was presented to provide the basis for the work on evaluation in subsequent chapters. 


\subsection{SPONSORSHIP EVALUATION}

The purpose of the following chapter is to review the current state of sponsorship evaluation, both in practice and in the literature. This review includes literature on evaluation in general, performance measurement, objectives, sponsorship evaluation, and sponsorship implementation, as well as content related to the tactics, methods and general practice of sponsorship evaluation. This will provide the essential information and knowledge required to address the major dissertation objective of developing a sponsorship evaluation process model. The first draft of the model was constructed based largely on the sponsorship evaluation literature.

\subsection{Introducing Sponsorship Evaluation}

It has long been understood that the most difficult task in sponsorship is being able to observe tangible results that are attributed to the sponsorship program (Harvey, 2001; Bowey, 1998; Copeland, Frisby \& McCarville, 1996; Cornwell, 1995; Meenaghan, 1983). The literature often discusses evaluation and the need to evaluate sponsorship relationships yet many researchers have reported that few sponsors evaluate their investments in sponsorship to any significant extent (e.g., McDaniel \& Kinney, 1998; Farrelly, Quester \& Burton, 1997; Marshall \& Cook, 1992). In fact, Gardiner and Shumman (1988) report that over 50\% of sponsors do not evaluate their sponsorships. Berrett and Slack (1995) found that most Canadian companies under study had no clear idea of the benefits they received from sponsorship and that most evaluations were relatively informal and fairly infrequent. Further, those who do evaluate often use procedures, such as media impressions, TV ratings and print coverage (Marshall \& Cook, 
1992). For the most part, academic researchers who have written about sponsorship evaluation focus on the use of measurement techniques from advertising (Olkkonen, 2001; Meenaghan, 2001), as opposed to the development and adoption of sponsorshipspecific measurement (Farrelly, Quester \& Burton, 1997; Abratt \& Grobler, 1989). Although such approaches may provide evidence of impact, they are deficient in their ability to assess all aspects of a sponsorship. Supporting this point, Brooks (1994) notes that the fundamental problem in sponsorship evaluation lies in demonstrating that it worked better, relatively, than more traditional methods of promotion (e.g., advertising or sales promotion).

A major aspect of the sponsorship evaluation challenge stems from the many objectives that sponsors seek with sponsorship programs (Cornwell \& Maignan, 1998; Berrett \& Slack, 1995; Berrett, 1993). In fact, a review of literature reveals that 61 distinct objectives have been identified by various authors. This list can be found in Appendix A, where the range of objectives is considerable; each requiring unique evaluation methods.

\subsubsection{The Attribution Issue}

A fundamental challenge in all evaluations is the issue of attribution. Within the attribution issue, two general concerns are always present: (i) issues around measuring intent, and (ii) consideration of the effect of externalities on the dependent variable. The attribution issue and these two concerns are relevant to sponsorship evaluation.

In sponsorship evaluation research, like much consumer-based research, the reliability and validity of a respondent to self-analyze their 'intent' to behave (e.g., 
purchase, act, etc.) is questionable as 'intent' may not be the normal way of thinking for individuals (Schwarz, 1999), making any such questions difficult to answer. Considerable research explores the underlying question: 'what is the intent to purchase question capturing?' For example, (i) a respondent may construct an answer as opposed to providing a response based on a decision (intent) that they have already made ( $a$ 'false positive') or (ii) respondents who do not like to be manipulated might respond 'no' to an intent based question, even though their purchase patterns are in fact influenced by a given sponsorship (a 'false negative'); (Schwarz, 1999; Sia, Lord, Blessum, Ratcliff, \& Lepper, 1997; Feldman \& Lynch, 1988). When answering questions, respondents may refer to the most accessible answer in their memory which infers that respondents may be providing an overall opinion of all sponsors of a given event as opposed to the specific sponsor of interest (Feldman \& Lynch, 1988). The issue here is not the formation of questions around the intent to purchase but may be related to the influence of 'category exemplars' that are 'top of mind' for respondents when they are asked a question related to intent to purchase. A category exemplar here refers to the answer that comes to mind immediately (e.g. Olympic Sponsor $=$ Coke; Super Bowl Sponsor $=$ Budweiser $)$ and what effect that has on the respondents' ability to answer correctly (Sia, Lord, Blessum, Ratcliff \& Leppter, 1997). As Schwarz (1999) points out, 'social desirability' may also have an impact. Respondents may answer positively because it appears to be the appropriate thing to do or they may answer negatively because they do not want to be tricked by a promotional tactic. This is often handled by assuring respondent anonymity and communicating clearly that no entity benefits financially from the research.

Identifying whether there are factors other than the sponsorship that affect the 
variable of interest (the dependent variable) (e.g. sales, awareness, employee morale, etc.) is a major concern in all consumer-based research including sponsorship evaluation. For sponsorship evaluation researchers, the concern refers specifically to the ability of the research to attribute the effect of the sponsorship (as opposed to other messaging) on opinions of the sponsor and/or the sponsee held by the target groups and on its effect to drive the purchase of that sponsor's products (i.e. intent to purchase). For example, Irwin, Lachowetz, Cornwell and Clark's (2003) finding that courier company Federal Express' sponsorship of the 2000 St. Jude Classic golf tournament positively influenced spectators' affinity for St. Jude's Children's Research Hospital (the charity benefiting from the event) has to be questioned in light of other external factors which might have contributed to the result (e.g., other St. Jude's Children's hospital promotions, the percentage of spectators who were parents, etc.). Typically, this issue is handled by asking respondents multiple questions about the many potential influencers and then determining which are most impactful.

\subsubsection{Demand for Improved Sponsorship Evaluation}

The noted expressions of the difficulty or even 'impossibility' (Berrett, 1993) of sponsorship evaluation, however, are not well received in practice. In recent years, the calls from organizations (both sponsors and sponsees alike) for a viable tool for measuring sponsorship effectiveness have increased (Mullin, Hardy \& Sutton, 2000; Milne \& McDonald, 1999). The original idea for this dissertation was generated from practitioner interest expressed by the $\mathrm{CEO}$ of a medium-sized Canadian sport marketing agency directly to the author (Mark Harrison, personal communication, October 27, 
2002). As described earlier in this document, organizations are increasing their spending on sponsorships globally. As spending increases, interest in evaluating sponsorships also increases among both sponsors and sponsees.

Pope and Voges (1994) are believed to be the first researchers to note that sponsors should begin to make use of evaluation techniques to assess the return on their sponsorship investments. Following that recommendation, a limited number of methods to evaluate sponsorship were developed, mostly by practitioners. In practice, these methods include counting 'footsteps' (i.e., number of people who came to your store as a result of sponsorship), measuring 'impressions' or 'eyeballs' (i.e., the number of people who likely saw your sponsorship and were made aware of it), and gauging changes in sales figures. A few evaluation models also exist in the literature. Cornwell, Pruitt \& Clark (2005), Cornwell (1995), Pope and Voges (1994), and Irwin and Asimakopoulos (1992) all proposed sponsorship evaluation models to assist sponsors with the evaluation of their sponsorship programs in relation to the measurement of specific sponsorship objectives. These models do not include return on investment analysis or the measurement of sponsor recall in consumers, which limits their value to practitioners. Although these efforts contribute to the process of moving sponsorship knowledge forward, to date they do not represent sufficient approaches for dealing effectively with sponsorship evaluation.

Clearly, there is high demand for improved sponsorship evaluation in the literature and in practitioner circles. This high demand justifies this research and sets the stage for the deeper analysis of the evaluation, performance measurement and sponsorship evaluation literature, which follows in the remainder of this chapter. These 
sections provide the knowledge foundation for the dissertation. Notably, the brief reviews of evaluation theory and performance measurement provide guidance and key concepts for the process model that exist outside of the sponsorship evaluation literature, while the review of sponsorship evaluation literature provides the underlying necessary knowledge for the construction of that model.

\subsection{Evaluation}

The act of assessing the effectiveness of an activity is known as evaluation. Evaluation can be formal and documented or informal and undocumented. Formal evaluation refers to assessment exercises which are planned, documented and analyzed (e.g. a survey of voters post-election to determine the effectiveness of political campaigns) while informal evaluation refers to everyday assessments that are not documented (e.g. how does my hair look today?). This dissertation is interested in formal evaluation. It is important to note that formal evaluation can lead to both positive (e.g. improved customer or employee satisfaction) and negative (e.g. delaying or avoiding decisions) results (Newburn, 2001).

Redfern (1998) traces the history of formal evaluation back to the $5^{\text {th }}$ century BC, when Socrates used evaluative questioning in pedagogy; known as the Socratic Method of Discourse. Formal evaluation has evolved into what Scriven (1998) describes as two types of evaluation: formative and summative. Formative evaluation is defined as a means of improving "an intervention of service with feedback" (Newburn, 2001, p. 6). This involves querying some group (e.g., consumers, employees, etc.) on some intervention (e.g., marketing program, employee benefit plan, etc.) to evaluate that 
interaction. Summative evaluation, conversely, measures the impact and effectiveness of programs or initiatives (Newburn, 2001). Examples would include the assessment of a course instructor, a government policy, or a sponsorship. At its basic level, formal evaluation is abstract with wide-ranging application. At its most complex levels, it is viewed as a human cognitive process occurring both consciously and unconsciously in decision making (Kodish, 2003). Examples of evaluation include athletic events, customer satisfaction surveys, employee performance evaluations, medical examinations, and standard educational evaluation. This dissertation research is focused on developing a process model for the summative evaluation of sponsorship.

Formal evaluation practice is widespread in its application in areas of academia, government, and business ${ }^{13}$. In marketing, the evaluation of consumers on a variety of measures (e.g., satisfaction, intent to purchase, brand awareness, post-purchase opinion, etc.) is carried out in a variety of ways (e.g., customer surveys, comment cards, online surveys, etc.), which impact an organization's marketing mix (Meredith, 1993). In terms of its execution, there are generally three important factors required for successful formal evaluation: (i) clearly articulated baseline measures (to measure effectiveness against), (ii) clear, measurable objectives, and (iii) support from key stakeholders on the evaluation (i.e., 'buy-in'); (Crane, Kerin, Hartley, Berkowitz \& Rudelius, 2006).

\subsection{Performance Measurement}

Performance measurement is an established way of evaluating that prescribes methods to assess the short-term outputs and long-term impacts of programs, processes and activities. The purpose of introducing it in this dissertation is that it provides context,

\footnotetext{
${ }^{13}$ See Appendix_Footnote for a short summary of the widespread application of evaluation.
} 
concepts and an alternative view on evaluation. A number of the tenets of performance evaluation are applicable to the evaluation of sponsorship and are incorporated in the development of the process model. The specific benefits that performance measurement provides to this dissertation are outlined in this sub-section.

The performance measurement literature provides important direction to enable useful evaluation, as well as for implementing effective measurement practices. Heslop and Fadaie's (2002) ' 3 Bs of impact assessment' are particularly useful in this regard. Their work on measuring the performance of technology transfer programs reveals that successful impact assessment requires (i) the buy-in of key stakeholders to the measurement model and approaches being used, (ii) believability in both the procedures to be followed and the outcomes that will be generated, and (iii) the existence of buyers or users of the results who will ensure good application as well as the dissemination and promotion of the results (Heslop \& Fadaie, 2002). The emphasis on efficient process is evident in performance measurement as demonstrated by Heslop and Fadaie's (2002, p. 223) rationale for the 3Bs:

Since program assessments of any kind require considerable resources and the outcomes can be expected to affect future planning and resource flows, there is value in getting the process right. In many ways, poor assessments can be more detrimental than no assessment at all. Considerably more effort needs to be directed to determining which methods and means yield useable results...One overarching determination of the worth of an assessment is the extent to which managers and decision makers at all levels and among all stakeholders both within and outside the organization find the process outcomes useful and useable. Use of the results will only occur if managers feel they are part of the process, have significant input, believe the results are credible, accurate and representative, and decisions based on the outcomes will be better decisions.

In terms of the process of performance measurement itself, models such as costbenefit analysis typically guide the determination of targets, indicators, measures and 
data collection procedures. Figure 1 below is Heslop and Fadaie's (2002) representation of how two well-known models (Teather \& Montague and Montague) of performance measurement can be depicted. The figure provides an example of a typical performance measurement approach.

Figure 1: Models for Performance Measurement (Heslop \& Fadaie, 2002)

\begin{tabular}{|c|c|c|c|c|c|}
\hline Inputs $\Rightarrow$ & Activities \& & Outputs & & Outcomes $\Rightarrow$ & Impacts $\Rightarrow$ \\
\hline \multicolumn{3}{|c|}{ Resources } & Reach & \multicolumn{2}{|c|}{ Results } \\
\hline $\begin{array}{l}\text { Examples: } \\
\text { number of } \\
\text { researchers } \\
\text { employed, } \\
\text { size of } \\
\text { budgets }\end{array}$ & $\begin{array}{l}\text { Examples: } \\
\text { number of } \\
\text { projects }\end{array}$ & $\begin{array}{l}\text { Examples: } \\
\text { number of } \\
\text { partnership } \\
\text { agreements, } \\
\text { intellectual } \\
\text { property } \\
\text { agreements }\end{array}$ & $\begin{array}{l}\text { Examples: } \\
\text { Clients, } \\
\text { users, co- } \\
\text { deliverers, } \\
\text { beneficiaries }\end{array}$ & $\begin{array}{l}\text { Initial } \\
\text { effects } \\
\text { usually firm- } \\
\text { based e.g. } \\
\text { client } \\
\text { satisfaction, } \\
\text { new } \\
\text { products, } \\
\text { increased } \\
\text { revenue, } \\
\text { improved } \\
\text { productivity }\end{array}$ & $\begin{array}{l}\text { Related to the } \\
\text { mission of } \\
\text { program e.g. } \\
\text { wealth } \\
\text { creation, } \\
\text { industry } \\
\text { sector } \\
\text { development, } \\
\text { environment, } \\
\text { health, } \\
\text { safety, } \\
\text { sovereignty }\end{array}$ \\
\hline
\end{tabular}

This review yielded five (5) specific benefits of performance measurement to this dissertation. First, the importance of time in the measurement of results is emphasized and noted by the identification of both short-term outcomes and long-term impacts. Second, the concept of reach is an important contribution to sponsorship evaluation, where consideration of which groups will be reached may allow for improved evaluation as a typical objective is likely to have multiple targets suggesting that multiple measurements (one per target) are required. Third, the importance of resources in performance measurement is a key concept that can be transferred to sponsorship evaluation where leveraging and evaluation are both, in and of themselves, resource- 
intensive undertakings. Fourth, the importance of including non-economic measurements in sponsorship evaluation is underlined, as the many objectives in sponsorship require approaches outside of economic measurement which only capture a small part of the overall value (Heslop \& Fadaie, 2002). Finally, while evaluations are often overly broad, lengthy in their implementation and costly both in terms of human and financial resources (Melkers \& Cozzens, 1997), performance measurement activities are more results-oriented and can be a major input to good performance reviews (Heslop \& Fadaie, 2002). Therefore, since the focus on many processes, specific activities and outcomes leads to more efficient and effective evaluation (Heslop \& Fadaie, 2002; Bozeman \& Papadakis, 1995) the performance measurement approach is readily adopted.

\subsection{Sponsorship Evaluation}

As noted previously, an objective of this chapter is to review the sponsorship evaluation literature and provide the baseline information necessary for the construction of a new process model. In order to accomplish this purpose, this section presents the challenges of sponsorship evaluation identified in the literature, the development of this literature, the identification of practical applications of sponsorship evaluation, and the role of evaluation in implementing a sponsorship.

\subsubsection{The Challenges of Sponsorship Evaluation}

Walliser's (2003) in-depth review of the literature on sponsorship identifies three specific challenges that researchers are faced with. First, Walliser $(2003$, p. 88$)$ points out that "overall, little is known about the conditions which lead to successful and durable 
image transfer from the activity supported to the sponsor". Here, Walliser is referring to the obstacle of limited knowledge of the image transfer process, which reinforces the need to better understand the complexities of the sponsor-sponsee relationship vis-à-vis image transfer. Second, the literature argues that "objectives other than awareness and image also need to be addressed. It is more than surprising that the impact of sponsorship on employee motivation has not received more attention" (Walliser, 2003, p. 90), thereby noting the challenge of expanding sponsorship evaluation theory and practice beyond awareness and image. Other researchers (e.g., Harvey, 2001) have similarly noted that sponsorship evaluation is an area requiring more attention from researchers. In this regard, Meenaghan (2001) and Olkkonen (2001) both suggest that this is needed as prior research typically involved (i) non-complex tests of recall and recognition and/or (ii) the use of advertising measurement tools to measure sponsorship. This further emphasizes the lack of theory in sponsorship evaluation and the challenge researchers are faced with to move away from advertising-based evaluation approaches. The third challenge faced by sponsorship evaluation researchers is to overcome the methodological deficiencies that currently limit sponsorship evaluation, as summarized by Walliser (2003, p. 93):

On the methodological side, sample quality and size can still be improved considerably...extending research [beyond student samples] to other age and professional groups would be beneficial to sponsorship research. Furthermore, a more frequent use of longitudinal designs would make it easier to study how sponsor awareness may be maintained and under what conditions image transfer takes place.

Clearly, more sophisticated metrics are required that are directly related to the objectives of interest in the sponsor-sponsee relationship of interest. 


\subsubsection{The Sponsorship Evaluation Literature}

The literature on sponsorship evaluation involves articles evaluating how sponsorship affects awareness, image and purchase intention (Walliser, 2003). The sophistication and form of sponsorship measurement has changed somewhat in recent years, with emphasis moving from recall and recognition (Lascu, Giese, Toolan, Guehring \& Mercer, 1995) to understanding how the sponsor's brand and/or products are perceived by the customer (Scherer \& Sam, 2005). The vast majority of the literature adopts tracking (recall and recognition measures) techniques to examine consumer changes among targeted customers (Moore, Pickett \& Groove, 1999; Easton \& Mackie, 1998; Walliser, 1994). Walliser (2003, p. 92) describes the overall output of these studies:

There is considerable evidence that recall increases as a function of duration of exposure to sponsors, previous brand awareness of sponsors, message length and design, socio-demographic variables of the spectators, such as age and spectator involvement with, and interest in, the activity sponsored. With regards to the integration of sponsorship and other communication tools, an increase of awareness scores is observed when sponsorship is used in conjunction with broadcast sponsorship...or classical advertising.

Other research suggests that time is an important consideration in sponsorship evaluation since it has been demonstrated that brand recall levels increase slightly prior to and during a sponsored event, then fall back to prior levels following the event (Walliser \& Nanopoulos, 2000; Cornwell, Maignan \& Irwin, 1997; Quester, 1997a; 1997b).

Studies on image, purchase intention and location dependency make up the remaining (but much smaller) three areas of sponsorship evaluation research. The majority of the studies on image (e.g., Meenaghan \& Shipley, 1999; Grimes \& Meenaghan, 1998; Giannelloni, 1993) show that sponsorship contributes to image 
transfer. Research in the area of purchase intention is limited in the sponsorship evaluation literature; however several surveys have shown that sponsorship can impact intent to purchase (Cornwell, Pruitt \& van Ness, 2001; Daneshvary \& Schwer, 2000). Research in the area of location dependency is rare in sponsorship evaluation; however a group of studies (Westerbeek \& Smith, 2002; Westerbeek, 2000; Westerbeek \& Shilbury, 1999) have evaluated the importance of the geographical location of the venue or facility where the sponsored property is held.

The early literature on sponsorship evaluation described the published work as war stories (i.e., unsophisticated evaluation) focused on macro-level issues (Sandler \& Shani, 1993). Pope (1998) reported on this time period noting that most of the work in sponsorship was descriptive or prescriptive in nature with little attention paid to measuring consumer opinion. Some examples include (i) Stotlar (1993) mentioning that Visa demonstrated market share gains following its sponsorship of the 1998 Olympic Games, (ii) Jeannet and Hennessey (1992) reporting that sales of their tennis racquets increased $1000 \%$ following their sponsorship of athlete Boris Becker in 1985, and (iii) Volvo measuring a 6:1 ROI on its sport sponsorship programs (Irwin \& Asimakopoulos, 1992).

The period that followed (1993-2004) was marked by many calls for more sophisticated evaluation and evaluation techniques in sponsorship (e.g. Pope \& Voges, 1994). Walliser's (2003) in-depth review of the literature on sponsorship reports on 83 published studies related to the measurement of sponsorship impact and noted that $65 \%$ of those studies were published after 1996. Importantly, Walliser (2003) also noted that the majority of these studies did not provide actual metrics and, for those few who did, 
most adopted basic tracking techniques or experiments to measure awareness or image constructs, with few exploring purchase intention. In this period, a number of researchers reviewed the evaluation practices of practitioners. For example, Ludwig and Karabetsos (1999) reviewed the practices implemented by the sponsors of the 1996 Olympic Games. They found, via questionnaire, that ten out of eleven Olympic sponsors indicated that benchmarks (pre and post-Olympic measurements) were used to evaluate outcomes of their respective sponsorships and that hospitality opportunity, sales, media coverage and image were the most important evaluation criteria (Ludwig \& Karabetsos, 1999).

\subsubsection{Sponsorship Evaluation Practice}

The contemporary literature on sponsorship evaluation documents a variety of evaluation practices. These practices include tracking changes in the sponsor's stock price (if publicly traded) before, during and after the sponsorship relationship (Cornwell, Pruitt \& Clark, 2005; Cornwell, Roy \& Steinard, 2001), quantitative assessment of news clippings, exposure and attitude measures (Cornwell, Roy \& Steinard, 2001), media exposure measures such as ratings, impressions and footsteps (Meenaghan, 2001), and profiling management practice (i.e., tracking management's effectiveness in implementing the sponsorship); (Meenaghan, 2001). These studies demonstrate the attention on sponsorship evaluation, the varied objectives which sponsorship can seek and the fact that researchers are seeking new evaluation metrics.

In general, the promotional benefits of sponsorship are classified as either tangible or intangible (Ludwig \& Karabestos, 1999). Tangible benefits are measured through a number of protocols; including consumer surveys, advertising impressions, televised 
signage impressions, ticket sales and impressions from on-site signage. The evaluation of intangible benefits employs such measures as the level of audience loyalty, category exclusivity by consumer response and awareness levels of specific brands, owned trademarks and patented logos.

Crompton (2004a) supports that the ideal measure by which to evaluate sponsorships is sales (traffic, leads or sales figures), followed by intent to purchase which he deems 'useful' and finally media equivalency and awareness/recall studies which he defines as 'common but flawed'. A review of the literature on models, methods or frameworks of sponsorship evaluation demonstrates that the literature does not follow Crompton's prescription (see Table 4).

Table 4: Models, Methods and Frameworks of Sponsorship Evaluation

\begin{tabular}{|l|l|l|}
\hline Model & Description & Metrics \\
\hline $\begin{array}{l}\text { Cornwell, } \\
\text { Pruitt, \& Clark }\end{array}$ & $\begin{array}{l}\text { Event study of the effect of } \\
\text { sponsorship of major North } \\
\text { American professional } \\
\text { sport properties on } \\
\text { sponsors' stock valuations. }\end{array}$ & $\begin{array}{l}\text { Changes in sponsors' stock market prices (using } \\
\text { the Scholes-Williams model) tested around } \\
\text { sponsorship announcements with five major } \\
\text { sponsees (NBA, MLB, NHL, NFL and MLB). A } \\
\text { 51-day trading window (25 trading days prior and } \\
\text { 25 days following the sponsorship announcement). }\end{array}$ \\
\hline $\begin{array}{l}\text { Cornwell, \& } \\
\text { Coote (2005) }\end{array}$ & $\begin{array}{l}\text { Purchase Intention in } \\
\text { Individuals }\end{array}$ & $\begin{array}{l}\text { Questionnaires to participants (mostly sponsors) at } \\
\text { a special luncheon supporting breast cancer and } \\
\text { sponsored by 70 organizations. }\end{array}$ \\
\hline $\begin{array}{l}\text { Grohs, Wagner, Vsetecka } \\
(2004)\end{array}$ & $\begin{array}{l}\text { Empirical study to identify } \\
\text { obstacles to awareness and } \\
\text { image transfer in sport } \\
\text { sponsorship. }\end{array}$ & $\begin{array}{l}\text { Mass market consumer surveys pre- and post-event } \\
\text { (2001 Alpine Ski World Championships in } \\
\text { Austria). Questions asked, and metrics analyzed, } \\
\text { about sponsor awareness (percentages), brand } \\
\text { prominence (Chi Square tests), event-sponsor fit } \\
\text { (Chi Square tests), event involvement (odds ratio), } \\
\text { exposure (multinomial logistic regression), and } \\
\text { sponsor \& event images (regression model). }\end{array}$ \\
\hline $\begin{array}{l}\text { Crompton } \\
\text { (2004a) }\end{array}$ & $\begin{array}{l}\text { Assessment of Evaluation } \\
\text { in the Literature }\end{array}$ & $\begin{array}{l}\text { No new metrics provided as work was a review of } \\
\text { literature and an articulation of the current state of } \\
\text { sponsorship evaluation. }\end{array}$ \\
\hline
\end{tabular}




\begin{tabular}{|c|c|c|}
\hline $\begin{array}{l}\text { Pitts \& Slattery } \\
\text { (2004) }\end{array}$ & $\begin{array}{l}\text { Examining the effects of } \\
\text { time on sponsorship } \\
\text { awareness. }\end{array}$ & $\begin{array}{l}\text { Season ticket holders of a U.S. university football } \\
\text { team were queried using a selective sampling } \\
\text { technique (every } 22 \text { name on list) with the survey } \\
\text { sent by mail. Descriptive statistics and a z-test } \\
\text { were adopted to analyze the data; measuring the } \\
\text { effects of time (before, during and after) on the } \\
\text { effectiveness of a sponsorship on awareness. }\end{array}$ \\
\hline $\begin{array}{l}\text { Fahy, Farrelly \& } \\
\text { Quester (2004) }\end{array}$ & $\begin{array}{l}\text { Model of Competitive } \\
\text { Advantage Through } \\
\text { Sponsorship. }\end{array}$ & $\begin{array}{l}\text { Study involved a review of literature and no new } \\
\text { metrics were developed. }\end{array}$ \\
\hline $\begin{array}{l}\text { Gwinner, \& } \\
\text { Swanson (2003) }\end{array}$ & $\begin{array}{l}\text { Modeling Fan } \\
\text { Identification }\end{array}$ & $\begin{array}{l}\text { Surveys of spectators at an NCAA Division } 1 \\
\text { conference game on measures about the } \\
\text { antecedents and outcomes of sponsor recognition, } \\
\text { sponsor attitudes, sponsor patronage and } \\
\text { satisfaction with the sponsor. }\end{array}$ \\
\hline $\begin{array}{l}\text { Lachowetz, } \\
\text { McDonald, } \\
\text { Sutton \& } \\
\text { Hedrick (2003) }\end{array}$ & $\begin{array}{l}\text { Professional Sport (NBA) } \\
\text { and Corporate Sales } \\
\text { Activities and Sponsor } \\
\text { Retention }\end{array}$ & $\begin{array}{l}\text { Surveyed corporate sales managers of NBA } \\
\text { franchises with a } 40 \text {-item phone survey to identify } \\
\text { tactics to build loyal corporate ticket-buyers and } \\
\text { sponsors. }\end{array}$ \\
\hline $\begin{array}{l}\text { Irwin, } \\
\text { Lachowetz, } \\
\text { Cornwell, \& } \\
\text { Clark (2003) }\end{array}$ & $\begin{array}{l}\text { Sponsorship Evaluation in } \\
\text { Cause-Related Sport } \\
\text { Sponsorships }\end{array}$ & $\begin{array}{l}\text { A survey instrument of demographic variables and } \\
\text { questions designed to measure respondent beliefs, } \\
\text { attitudes and behavioural intent was designed and } \\
\text { distributed during a major golf tournament with a } \\
\text { cause-related sponsor. Various analyses were } \\
\text { carried out included descriptive stats, ANOVAs, } \\
\text { and others to explore the sponsorship's influence } \\
\text { on the beliefs, attitudes and behavioural intent of } \\
\text { the sample. }\end{array}$ \\
\hline $\begin{array}{l}\text { Jalleh, } \\
\text { Donovan, } \\
\text { Giles-Corti, \& } \\
\text { Holman (2002) }\end{array}$ & $\begin{array}{l}\text { Sponsorship Impact on } \\
\text { Brand Awareness and } \\
\text { Attitudes, based on a } \\
\text { hierarchical } \\
\text { communication model that } \\
\text { outlines steps from } \\
\text { exposure to success } \\
\end{array}$ & $\begin{array}{l}\text { Two health and four commercial sponsorships } \\
\text { were evaluated on brand awareness and brand } \\
\text { attitude. Two independent samples (one/measure) } \\
\text { were taken at each event pre- and post-. Two } \\
\text { questionnaires (one/measure) were administered to } \\
\text { event spectators. Basic comparative statistics were } \\
\text { then used to compare pre- and post-. }\end{array}$ \\
\hline $\begin{array}{l}\text { Meenaghan } \\
(2002)\end{array}$ & $\begin{array}{l}\text { Sponsorship Development } \\
\text { into Partnership }\end{array}$ & $\begin{array}{l}\text { In-depth case analysis of the Guinness-Hurling } \\
\text { Championships sponsorship relationship, including } \\
\text { some quantitative analysis to measure influence on } \\
\text { partnership development. }\end{array}$ \\
\hline Madrigal (2001) & $\begin{array}{l}\text { Social Identity Effects on } \\
\text { Belief-Attitude-Intentions } \\
\text { Relationship. }\end{array}$ & $\begin{array}{l}\text { A random digit dialing methodology (i.e., random } \\
\text { telephone dialing in a large area: Ohio) enabled a } \\
\text { large sample who completed a phone questionnaire } \\
\text { focused on the respondents' identification with the } \\
\text { local sport franchise of interest and how that } \\
\text { impacts their intent to purchase sponsors' } \\
\text { products. }\end{array}$ \\
\hline
\end{tabular}




\begin{tabular}{|c|c|c|}
\hline $\begin{array}{l}\text { Miyazaki, \& } \\
\text { Morgan }(2001)\end{array}$ & $\begin{array}{l}\text { Assessing market value } \\
\text { from Olympic sponsorship } \\
\text { ('the valuation dilemma') }\end{array}$ & $\begin{array}{l}\text { The effects of sponsorship announcements on firm } \\
\text { value are measured using event study analysis } \\
\text { (from finance). Results showed the event } \\
\text { sponsorship provides value. }\end{array}$ \\
\hline $\begin{array}{l}\text { Webb, \& Carter } \\
\text { (2001) }\end{array}$ & $\begin{array}{l}\text { Sponsorship activities in } \\
\text { small business sector. }\end{array}$ & $\begin{array}{l}\text { Questionnaire mailed to SMEs and analyzed } \\
\text { measuring the extent of sponsorship. No metrics. }\end{array}$ \\
\hline $\begin{array}{l}\text { Cornwell, Roy, } \\
\text { \& Steinard } \\
(2001) \\
\end{array}$ & $\begin{array}{l}\text { Managers' Perceptions of } \\
\text { Sponsorship Impact }\end{array}$ & $\begin{array}{l}\text { Managers of firms who use sponsorship responded } \\
\text { to 4-page questionnaires one-year apart on } \\
\text { sponsorship's role in brand-building over time. }\end{array}$ \\
\hline $\begin{array}{l}\text { Speed, \& } \\
\text { Thompson } \\
(2000)\end{array}$ & $\begin{array}{l}\text { A classical conditioning } \\
\text { framework to measure } \\
\text { consumer response to sport } \\
\text { sponsorship }\end{array}$ & $\begin{array}{l}\text { The dependent variable - sponsorship response- } \\
\text { was based on respondents' interest in the sponsor, } \\
\text { their opinion of the sponsor and their use of the } \\
\text { sponsor's products. Six independent variables } \\
\text { were measured: sponsor-event fit, personal liking } \\
\text { for the event, attitude toward the sponsor, ubiquity } \\
\text { of the sponsor, sincerity of the sponsor, and } \\
\text { perceived status of the sponsored event. }\end{array}$ \\
\hline $\begin{array}{l}\text { Nicholls, } \\
\text { Roslow, \& } \\
\text { Dublish (1999) }\end{array}$ & $\begin{array}{l}\text { Brand recall and brand } \\
\text { preference study at } \\
\text { sponsored tournaments } \\
\text { (golf) }\end{array}$ & $\begin{array}{l}\text { On-site surveys (intercept technique) with } \\
\text { questions to independent samples on brand recall } \\
\text { and brand preference. Brand recall measured by } \\
\text { asking "name the first brand which comes to } \\
\text { mind" and brand preference from "which of the } \\
\text { following brands do you prefer". Correlations. }\end{array}$ \\
\hline $\begin{array}{l}\text { Ludwig, \& } \\
\text { Karabetsos } \\
(1999)\end{array}$ & $\begin{array}{l}\text { Identification of important } \\
\text { items to evaluation for } \\
\text { event sponsorship } \\
\text { effectiveness }\end{array}$ & $\begin{array}{l}\text { Hospitality opportunity, sales, media coverage, } \\
\text { image and public perception, attitude towards ads, } \\
\text { distributors, market share, and sponsor awareness. } \\
\text { Empirical analysis of the } 1996 \text { Olympics included. }\end{array}$ \\
\hline $\begin{array}{l}\text { McDaniel } \\
\text { (1999) }\end{array}$ & $\begin{array}{l}\text { Match-Up Effects from } \\
\text { Customer Schemas in } \\
\text { Sport Sponsorship } \\
\text { Advertising }\end{array}$ & $\begin{array}{l}\text { Survey research measuring consumer reaction to } \\
\text { three events (Olympics, Super Bowl, Professional } \\
\text { Bowling) in two print media sources Sports } \\
\text { Illustrated, Spin). An experiment with } 3 \times 2 \times 2 \\
\text { factorial design is adopted with } 3 \text { variations of a } \\
\text { print ad, } 2 \text { magazine covers and gender used. } \\
\text { Analysis of variance is used to analyze results. }\end{array}$ \\
\hline $\begin{array}{l}\text { Gwinner, \& } \\
\text { Eaton (1999) }\end{array}$ & $\begin{array}{l}\text { Image Transfer from Event } \\
\text { Sponsorship }\end{array}$ & $\begin{array}{l}\text { A between-groups experiment was conducted on a } \\
\text { number of pre-test identified event-sponsor } \\
\text { alternative pairings on both objective based and } \\
\text { holistic image (mental imagery) transfer measures. } \\
\text { MANOVA analysis is used to ascertain results. }\end{array}$ \\
\hline $\begin{array}{l}\text { Johar \& Pham } \\
\text { (1999) }\end{array}$ & $\begin{array}{l}\text { Understanding Sponsor } \\
\text { Identification }\end{array}$ & $\begin{array}{l}\text { Two experiments that (i) explore prominence bias } \\
\text { in sponsor identification and (ii) examine the } \\
\text { relative magnitude of reliance on prominence and } \\
\text { relatedness when both are applicable to } \\
\text { sponsorship identification. Both were } 2 \times 2 \text { design } \\
\text { and data were collected from subjects following } \\
\text { exposure to press releases. }\end{array}$ \\
\hline
\end{tabular}




\begin{tabular}{|c|c|c|}
\hline Pope (1998) & $\begin{array}{l}\text { Consumption Values, } \\
\text { Sponsorship Awareness, } \\
\text { Brand/Product Use }\end{array}$ & $\begin{array}{l}\text { A three step methodology of (i) focus groups about } \\
\text { products/brands to establish value parameters, (ii) } \\
\text { questionnaire administration to test the values } \\
\text { against the brands and products, and (iii) factor } \\
\text { analysis of data and discriminant analysis between } \\
\text { factors. }\end{array}$ \\
\hline $\begin{array}{l}\text { Quester, \& } \\
\text { Farrelly (1998) }\end{array}$ & $\begin{array}{l}\text { A Model of Brand } \\
\text { Association and Decay } \\
\text { Effects of Sponsorship }\end{array}$ & $\begin{array}{l}\text { Mass market sampling during and one week } \\
\text { following the Australian Formula One Grand Prix } \\
\text { to assess recall over time (association and decay). } \\
\text { Both aided and unaided recall questions were } \\
\text { included. }\end{array}$ \\
\hline $\begin{array}{l}\text { Society of } \\
\text { British } \\
\text { Advertisers } \\
\text { (ISBA, 1998) }\end{array}$ & $\begin{array}{l}\text { Model of general } \\
\text { communication } \\
\text { effectiveness with the } \\
\text { following measurable: } \\
\text { sponsorship reach \& } \\
\text { demographics, awareness } \\
\& \text { attitude, media coverage, } \\
\text { reach \& quality, } \\
\text { merchandise, sales, staff } \\
\text { attitudes }\end{array}$ & $\begin{array}{l}\text { No metrics provided. A theoretical piece that } \\
\text { drafted a model based on the literature. }\end{array}$ \\
\hline $\begin{array}{l}\text { McCarville, } \\
\text { Flood, \& Froats } \\
\text { (1998) }\end{array}$ & $\begin{array}{l}\text { Effectiveness of Nonprofit } \\
\text { event sponsorship }\end{array}$ & $\begin{array}{l}\text { Using a hypothetical scenario, } 5 \text { focus groups were } \\
\text { carried out with the promotional methods being } \\
\text { altered slightly for each group. Results were coded } \\
\text { and analyzed using ANOVAs to assess } \\
\text { effectiveness. }\end{array}$ \\
\hline $\begin{array}{l}\text { Pope, \& Vogues } \\
\text { (1997) }\end{array}$ & $\begin{array}{l}\text { Television recall and } \\
\text { recognition of stadium } \\
\text { sponsorship placements in } \\
\text { Australian Rugby matches. }\end{array}$ & $\begin{array}{l}\text { Survey of recall and recognition about stadium } \\
\text { signage viewed on television. }\end{array}$ \\
\hline $\begin{array}{l}\text { Kinney, \& } \\
\text { McDaniel } \\
\text { (1996); Arani } \\
\text { (1992); } \\
\text { Meenaghan } \\
\text { (1991a; 1991b) }\end{array}$ & $\begin{array}{l}\text { Various studies have } \\
\text { identified sponsorship } \\
\text { evaluation practices, } \\
\text { although no specific model } \\
\text { was provided. These } \\
\text { practices are listed here. }\end{array}$ & $\begin{array}{l}\text { - Column centimeters in print/online press } \\
\text { - Product trial opportunities achieved (i.e., \#'s) } \\
\text { - Cost-benefit analysis between sponsorship and } \\
\text { other promotional tactics } \\
\text { - Demographics of readers, viewers or listeners } \\
\text { (segments, profiles, stats) } \\
\text { - Effect on community relations } \\
\text { - Merchandising and/or hospitality success } \\
\text { (revenue, visits, etc.) } \\
\text { - Media reach (impressions, ratings, etc.), } \\
\text { including cost/1000 of audience reached } \\
\text { - TV exposure time (time X ad rates ( } 30 \text { sec.) } \\
\text { - Radio exposure time (time X ad rates ( } 30 \text { sec.) } \\
\text { - Cross impacts between sponsorship and any of } \\
\text { sales, sales promotion, public relations, } \\
\text { advertising, and direct selling }\end{array}$ \\
\hline
\end{tabular}




\begin{tabular}{|c|c|c|}
\hline & & $\begin{array}{l}\text { - Attendance (spectators) } \\
\text { - Staff, consumer or spectator surveys } \\
\text { - Attitudinal surveys toward the sponsor(s) pre- } \\
\text { and post-event } \\
\text { - Staff incentives/rewards } \\
\text { - Post-event publicity (how long it continues) } \\
\text { - Longitudinal studies of product awareness, } \\
\text { - sponsor image } \\
\text { - Sponsor's name recall } \\
\text { - Return on Investment } \\
\text { - Increased business (i.e., new clients) }\end{array}$ \\
\hline $\begin{array}{l}\text { Stipp, and } \\
\text { Schiavone } \\
\text { (1996) }\end{array}$ & $\begin{array}{l}\text { Study of the relationship } \\
\text { between sponsorship } \\
\text { characteristics and } \\
\text { consumers' perceptions. } \\
\text { Stipp and Schiavone did so } \\
\text { at the } 1992 \text { Olympic } \\
\text { Games. } \\
\text { *Note, the critique of this } \\
\text { type of study is its overly } \\
\text { short-term focus } \\
\text { (Roajaretnam, 1994) which } \\
\text { ignores longer-term } \\
\text { outcomes of sponsorship. }\end{array}$ & $\begin{array}{l}\text { Consumer (attitudinal) surveys on a wide variety } \\
\text { of sponsorship scenarios stemming from the } 1992 \\
\text { Olympic Games. Measurement tool was a } \\
\text { questionnaire administered immediately following } \\
\text { exposure to the Games. Questions were attitude } \\
\text { based (towards the sponsor) and most used Likert } \\
\text { Scales. }\end{array}$ \\
\hline $\begin{array}{l}\text { Shilbury, \& } \\
\text { Berriman } \\
\text { (1996) }\end{array}$ & $\begin{array}{l}\text { Sponsor and advertiser } \\
\text { recall and recognition of an } \\
\text { Australian football club }\end{array}$ & $\begin{array}{l}\text { Questionnaires to spectators on awareness } \\
\text { measures. Analysis with descriptive statistics. }\end{array}$ \\
\hline $\begin{array}{l}\text { Slack, \& Bentz } \\
\text { (1996) }\end{array}$ & $\begin{array}{l}\text { Small businesses in sport } \\
\text { sponsorship }\end{array}$ & $\begin{array}{l}\text { Interviews with small business owners focusing on } \\
\text { rationale to sponsor and identifying sponsorship } \\
\text { objectives. }\end{array}$ \\
\hline $\begin{array}{l}\text { Cornwell } \\
\text { (1995) }\end{array}$ & $\begin{array}{l}\text { Market measures of } \\
\text { evaluation }\end{array}$ & $\begin{array}{l}\text { Suggest a focus on: } \\
\text { (i) increase in market share } \\
\text { (ii) increase in sales } \\
\text { No empirical evidence or modeling was included. }\end{array}$ \\
\hline $\begin{array}{l}\text { 'Astous, \& } \\
\text { Bitz (1995) }\end{array}$ & $\begin{array}{l}\text { Assessment of the impact } \\
\text { of four components of } \\
\text { sponsorship on consumers. } \\
\text { The four components are: } \\
\text { nature of the sponsorship } \\
\text { (philanthropic versus } \\
\text { commercial), origin of the } \\
\text { sponsorship (pre-existing } \\
\text { sponsee or one created by } \\
\text { the sponsor), frequency } \\
\text { (continued or one-off), and } \\
\text { the sponsor-sponsee fit. }\end{array}$ & $\begin{array}{l}\text { A } 2 \times 2 \times 2 \times 2 \text { binary design where respondents were } \\
\text { provided with fictitious sponsorship scenarios (one } \\
\text { for each cell in the factorial design) following pre- } \\
\text { testing. Open ended responses measuring nature, } \\
\text { origin, frequency and fit were queried, coded and } \\
\text { analyzed using analysis of variance techniques. }\end{array}$ \\
\hline
\end{tabular}




\begin{tabular}{|c|c|c|}
\hline $\begin{array}{l}\text { Rajaretnam } \\
\text { (1994) }\end{array}$ & $\begin{array}{l}\text { The effect of a sponsorship } \\
\text { on awareness, corporate } \\
\text { image, and brand } \\
\text { preference in an Indian } \\
\text { organization. }\end{array}$ & $\begin{array}{l}\text { Case study with limited quantitative analysis, no } \\
\text { sales, no purchase behaviour and no long term } \\
\text { analysis. }\end{array}$ \\
\hline $\begin{array}{l}\text { Javalgi, Traylor, } \\
\text { Gross, \& } \\
\text { Lampman } \\
\text { (1994) }\end{array}$ & $\begin{array}{l}\text { The effect of sponsorship } \\
\text { on consumers' attitudes } \\
\text { towards an organizations } \\
\text { and its image. }\end{array}$ & $\begin{array}{l}\text { Attitudinal telephone surveys of sponsors and their } \\
\text { image, based on } 6 \text { interviews with sponsors from } 6 \\
\text { large Fortune } 500 \text { companies. Questions were } \\
\text { recall (aided) and recall (unaided). A MANOVA } \\
\text { analyzed awareness responses between the } 6 \\
\text { companies. }\end{array}$ \\
\hline $\begin{array}{l}\text { Cuneen, \& } \\
\text { Hannan (1993); } \\
\text { Stotlar, \& } \\
\text { Johnson (1989) }\end{array}$ & $\begin{array}{l}\text { Recognition, recall and } \\
\text { awareness in stadium } \\
\text { advertising. Cuneen and } \\
\text { Hannan (1993) re-tested } \\
\text { the original method. }\end{array}$ & $\begin{array}{l}\text { Onsite surveys on recognition, recall and } \\
\text { awareness yielding \% of each age bracket of } \\
\text { spectators who noted an ad, remembered a } \\
\text { promotion, etc. }\end{array}$ \\
\hline $\begin{array}{l}\text { Marshall, \& } \\
\text { Cook (1992); } \\
\text { Parker (1991); } \\
\text { Abratt, \& } \\
\text { Grobler (1989) }\end{array}$ & $\begin{array}{l}\text { Media Audits, including } \\
\text { Abratt and Grobler's } \\
\text { framework for sponsorship } \\
\text { evaluation based on a } \\
\text { sample of } 28 \text { sponsors in } \\
\text { South Africa in } 1988 \text {. } \\
\text { *Note that many authors } \\
\text { (e.g., Sleight, 1989; } \\
\text { Crimmins \& Horn, 1996) } \\
\text { are highly critical of this } \\
\text { technique as they are not } \\
\text { objective-driven and focus } \\
\text { on publicity as opposed to } \\
\text { evaluating a sponsorship. }\end{array}$ & $\begin{array}{l}\text { Television screening of advertisements (i.e., the } \\
\text { use of media surveys to determine if ad was seen } \\
\text { and for how long, then a monetary value is } \\
\text { attached based on maximum advertising rates). }\end{array}$ \\
\hline $\begin{array}{l}\text { Meenaghan } \\
(1991 \mathrm{a} ; 1991 \mathrm{~b})\end{array}$ & $\begin{array}{l}\text { Sponsor Effectiveness } \\
\text { Categories: media } \\
\text { exposure, levels of } \\
\text { sponsorship awareness } \\
\text { (spectators), sales, } \\
\text { spectator feedback, and } \\
\text { cost-benefit analysis. }\end{array}$ & $\begin{array}{l}\text { A literature review provided for the identification } \\
\text { of sponsor effectiveness categories. No empirical } \\
\text { analysis was undertaken. }\end{array}$ \\
\hline
\end{tabular}


Table 4 revealed three important contributions to sponsorship evaluation. First, the studies suggest five areas of sponsorship evaluation; namely (i) recognition, recall and awareness; (ii) image and attitude; (iii) brand, service or product effects; (iv) media audits; and (v) behavioural measures. Second, the studies highlight the extensive range of objectives and metrics available. Finally, as is evident from the studies listed in Table 4 and supported by other published reviews of sponsorship literature (Walliser, 2003), the vast majority of models focus on awareness which Pope (1998) points out is a serious failure, since most of a sponsorship's objectives are found in further steps of the consumer response continuum (i.e., from awareness to interest to test to conviction to purchase). Others (e.g., Hoek, Gendall \& Sanders, 1993) point out that this focus on awareness is understandable given that it is (i) simple and inexpensive to measure, (ii) the first step in achieving benefit from a sponsorship, (iii) easy to conduct from a methodological point of view, and (iv) regarded as a strong measure of advertising effectiveness and is, as such, easily adapted to sponsorship. Recognizing this, Hoek (1998) notes that evaluation of sponsorship needs to evolve to explore the awarenessbehaviour relationship, as awareness measures provide only limited insight into the effectiveness of a sponsorship, as the construct of 'sponsorship effectiveness', in the context of this analysis, is complex.

It is also important to look beyond the academic literature when reviewing practice. In this regard, a cursory review of websites related to a number of sponsorships provides some insights into sponsorship evaluation practice. This process was found to be difficult, as those entities who do evaluate do not publicly share their findings or their research protocols. For example, global airline manufacturer Boeing has established six 
general criteria which they use to benchmark their performance on sponsorship relationships. Although full details are not published at www.boeing.com, a general picture of what they seek from a sponsorship is provided on the website. However, no specific information is provided on evaluation (Boeing, 2005). The review of websites also identified a variety of promotional tactics related to a sponsorship which are measurable. These are outlined in Table 5 below.

\section{Table 5: Measurable Promotional Tactics}

\begin{tabular}{|l|l|}
\hline Tactic & Example \\
\hline Sponsor name as official team name & Anaheim Mighty Ducks \\
\hline Official sponsee poster & Movie poster \\
\hline Website title and web link & www.google.ca on event messaging \\
\hline Sponsor/Sponsee signage at track & End zone signage at CFL Game \\
\hline Front Cover of Event Program & $\begin{array}{l}\text { Product Placement (Mats Sundin drinking Pepsi } \\
\text { on front of Toronto Maple Leafs' program) }\end{array}$ \\
\hline Related publications (e.g., newsletter) & $\begin{array}{l}\text { Sony's magazine about CFL football (but really } \\
\text { promoting their products) }\end{array}$ \\
\hline $\begin{array}{l}\text { Sponsor logo on equipment and/or } \\
\text { team uniform }\end{array}$ & Tiger Woods with Nike clothing \\
\hline Mailing lists (use of) & $\begin{array}{l}\text { Endurosport (Ontario bicycle store) sponsors the } \\
\text { Ontario Association of Triathletes to access } \\
\text { their mailing lists }\end{array}$ \\
\hline $\begin{array}{l}\text { Onsite product sampling } \\
\text { slogans in advertising, packing and } \\
\text { promotions }\end{array}$ & $\begin{array}{l}\text { Power bar samples distributed at a Powerbar- } \\
\text { sponsored running event. }\end{array}$ \\
\hline Prestige of sponsee & $\begin{array}{l}\text { FINA awarded Montreal with the 2005 World } \\
\text { Aquatic Championships allowing the local } \\
\text { organizing committee to use the FINA logo on } \\
\text { all messaging }\end{array}$ \\
\hline $\begin{array}{l}\text { Awareness and association with } \\
\text { sponsee }\end{array}$ & A Super Bowl sponsor \\
\hline $\begin{array}{l}\text { Category exclusivity (no other product } \\
\text { or service in same category allowed to } \\
\text { sponsor the sponsee) }\end{array}$ & $\begin{array}{l}\text { Consumer opinion of association including } \\
\text { image transfer and awareness }\end{array}$ \\
\hline $\begin{array}{l}\text { Top Olympic sponsorship in a given category } \\
\text { (e.g., John Hancock in financial management) } \\
\text { means no similar firm can have sponsorship } \\
\text { status in the Olympic movement }\end{array}$ \\
\hline Tevel of audience interest/loyalty & $\begin{array}{l}\text { Television ratings } \\
\text { co-branding program }\end{array}$ \\
\hline $\begin{array}{l}\text { Cross-promotional benefits with } \\
\text { sponsor }\end{array}$ & \\
\hline
\end{tabular}




\begin{tabular}{|l|l|}
\hline Limited degree of sponsor clutter & $\begin{array}{l}\text { Guaranteed exclusivity and number of sponsor } \\
\text { categories by the sponsee. }\end{array}$ \\
\hline Non-ambushabilty of sponsee & $\begin{array}{l}\text { Guaranteed exclusivity and number of sponsor } \\
\text { categories by the sponsee. }\end{array}$ \\
\hline Networking Opportunities & $\begin{array}{l}\text { Associated hospitality events and VIP invite } \\
\text { list(s) }\end{array}$ \\
\hline News worthiness & Publicity achieved \\
\hline
\end{tabular}

Each of these tactics is, in turn, measurable using the various available metrics such as attitude measures (pre-post), media ratings, sales results, image transfer, employee motivation, and hospitality effectiveness.

\subsubsection{Implementing Sponsorship and the Role of Evaluation}

McAllister (2002) has developed a model of successful sponsorship implementation (from the point of view of the sponsor). McAllister's best practice model (see Figure 2 below) outlines six distinct steps in the process of implementing a successful sponsorship. Issues related to sponsorship evaluation are included in various stages of this model. The process begins with the identification of objectives for the sponsor, the sponsee and the sponsorship relationship (association). The sponsor's objectives are considered to have the most influence on subsequent evaluation. Following the development of objectives, market research is used to measure key attributes (presponsorship measurement). In the third and fourth stages of this model, promotional tactics are selected and the sponsorship is implemented. In stage five, post-sponsorship measurement provides data to compare against the pre-sponsorship measurement. Finally, the results are assessed in order to ascertain success and changes are made to the plan as required. McAllister's model (see Figure 2 below) provides an important contribution to the literature in that it presents a process by which to approach 
sponsorship evaluation. It recognizes the importance of both pre and post sponsorship measurement. Because it specifies key steps in a process of evaluation, this dissertation adopts the model as a way of organizing and reporting on the literature on sponsorship evaluation. In the following section, each step of the model is presented with accompanying briefs on related sponsorship evaluation literature.

Figure 2: Steps to Successful Implementation of a Sponsorship (adapted from McAllister, $\underline{\text { 2002) }}$

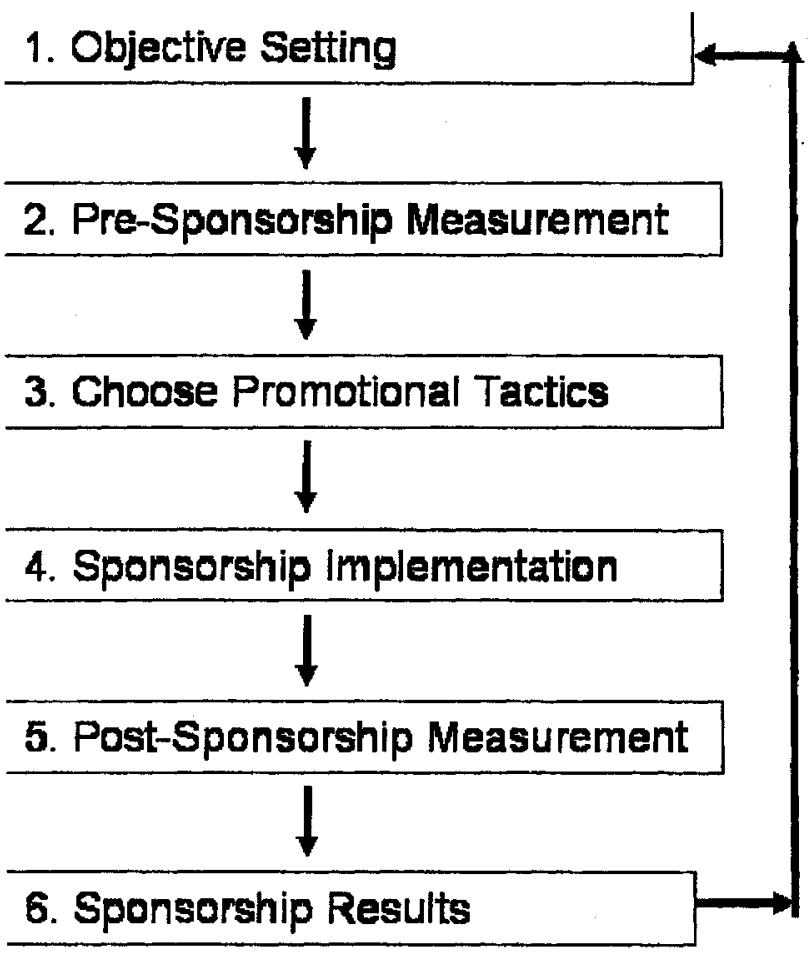

\subsubsection{Objective Setting}

An objective is a goal or a particular outcome that is sought. Objectives play a vital role in evaluating a sponsorship as they determine what will actually be measured and evaluated. The majority of authors writing on sponsorship evaluation have 
emphasized the importance of objectives in the sponsorship evaluation process (Cornwell, Pruitt \& Clark, 2005; Grohs, Wagner \& Vsetecka, 2004; Jalleh, Donovan, Giles-Corti \& Holman, 2002; Meenaghan, 2002; Dean, 1999; Cornwell \& Maignan, 1998; McDaniel \& Kinney, 1998; Gwinner, 1997; Marshall \& Cook, 1992; Crowley, 1991; Meerabeau, Gillet, Kennedy, Adeoba, Byasss \& Tabi, 1991; Armstrong, 1988; Gardiner \& Shuman, 1988; Wolton, 1988). Thus, objectives must be developed and managed carefully (Hoek, 1998). Most writers suggest that sales objectives are not a high priority amongst sponsorship managers (e.g., Crompton, 2004a; Walliser, 2003; Cornwell \& Maignan, 1998; Grimes \& Meenaghan, 1998; Hoek, 1998; Gwinner, 1997; Lee, Sandler \& Shani, 1997; Thwaites, 1995; Crowley, 1991). The most common methodological approach in the literature has been to ask sponsors to rank the importance of a set of sponsorship objectives via surveys or interviews (Mount \& Niro, 1995; Kuzma, Shanklin \& McCally, 1993; Marshall \& Cook, 1992; Otker, 1988). Thwaites, Aguilar-Manjarrez and Kidd (1998) studied practices in the management of sponsorship and assessed the extent to which selected Canadian organizations adopted the prescriptions for effective sponsorship identified in the literature. They found that 82 percent of companies set specific objectives while 69 percent sought to formulate objectives in a quantifiable manner.

Considerable empirical work exists in the literature on sponsorship objectives. This research has demonstrated that a necessary first step in sponsorship evaluation is the specification of clear objectives (Cornwell, Pruitt \& Clark, 2005; Crompton, 2004a; Abratt \& Gobbler, 1992). Research also shows that a wide range of objectives are being pursued by sponsors, sponsees and intermediaries (e.g., Polonsky \& Speed, 2001). 
Further, the literature reveals that techniques borrowed from the evaluation of advertising are most commonly used since consumer attitudes are more easily measured than links to long-term sales (Nicholls, Roslow \& Dublish, 1999; Stipp \& Schiavone, 1996). Cornwell's (1995) work on the development of sponsorship-linked marketing discusses two main measurement methods: (i) increase in market share and (ii) increase in sales. She notes that such measures may be flawed in evaluating sponsorship due to their roots in the evaluation of advertising whereby an assessment of the association via image transfer is not included. This research demonstrates that effective evaluation is often not done.

The literature on objectives specifically related to sponsorship evaluation provides two important contributions to this dissertation. First, a considerable amount of research has examined what objectives sponsors are seeking through sponsorship. The most common objectives are awareness improvement, image enhancement, relationship building through hospitality, and increased sales (Howard \& Crompton, 1995; Berrett, 1993). Second, sponsors are seeking a considerable range of objectives through sponsorship ranging from television exposure (Scott \& Suchard, 1992; Meenaghan, 1991b; Witcher, Craigen, Culligan \& Harvey, 1991) to reputation (Mason, 1999) to direct access to participants (Berrett \& Slack, 2001) to increased sales (Shank, 2005; 2002). A complete list of objectives identified in the literature is attached as Appendix A. This list of objectives can be grouped into eight summary areas, as presented below in Table 6: 
Table 6: Summary Groupings of Sponsorship Objectives

\begin{tabular}{|r|l|l|}
\hline$\#$ & Grouping & Component Objectives from Appendix $A$ \\
\hline 1 & $\begin{array}{l}\text { Efficiency of sponsorship versus } \\
\text { advertising (i.e., impact/cost ratio). }\end{array}$ & $2,6,17,34,61$ \\
\hline 2 & $\begin{array}{l}\text { Flexibility of promotional strategy both in } \\
\text { its effects and in the objectives it can meet. }\end{array}$ & $\begin{array}{l}4,7,9,13,20,22,26,38,41,42,43,50, \\
54\end{array}$ \\
\hline 3 & $\begin{array}{l}\text { Builder of brand equity, including } \\
\text { positioning sponsor as a good corporate } \\
\text { citizen. }\end{array}$ & $\begin{array}{l}3,8,12,24,36,39,44,45,46,47,52, \\
58,59\end{array}$ \\
\hline 4 & $\begin{array}{l}\text { Direct contact with key decision-makers } \\
\text { via hospitality, positive corporate } \\
\text { citizenship and other leveraging tactics. }\end{array}$ & $14,16,19,27,29,30,53,56$ \\
\hline 5 & $\begin{array}{l}\text { Ability to overcome market clutter and } \\
\text { achieve media exposure. }\end{array}$ & $\begin{array}{l}5,10,11,15,18,21,23,35,40,48,55, \\
60\end{array}$ \\
\hline 6 & $\begin{array}{l}\text { Positive impact on employees (motivation } \\
\text { and attraction of future staff). }\end{array}$ & $14,16,19,25,28$ \\
\hline 7 & Ability to enter new, international markets. & $7,24,32,33,49,51,57$ \\
\hline 8 & Management interest & 31,37 \\
\hline
\end{tabular}

Sponsorship evaluation literature also shows that benefits that are unrelated to the original objectives of either the sponsor or the sponsee are often measured and considered (Crompton, 2004a; Nicholls, Roslow \& Dublish, 1999; Stipp \& Schiavone, 1996). For example, if a sponsee provides the sponsor with a bevy of impressions and media coverage data when the sponsor's original objective was solely to build B2B (industrial) clients through a sponsorship, the sponsee is not effectively evaluating the objective of interest. This is a common practice in sponsorship evaluation. Advantages of this practice include reduced costs and reduced work on evaluation, while the disadvantages of this practice include a failure to evaluate the objectives of interest and over-stating the benefits of the sponsorship.

In summary, the literature reveals that a wide range of objectives are common in sponsorship and that a researcher working in sponsorship evaluation would have to measure the objectives relevant to each sponsorship when conducting evaluation research on that sponsorship. 


\subsubsection{Pre-Sponsorship Measurement}

The second step in McAllister's model involves the assessment of the sponsor's target market and the perceptions of that target market on a number of potential image attributes of potential sponsees (e.g., their image, their brand, etc.) in order to determine if the given sponsee's image is consistent with the sponsor's desired organizational image/brand or product image/brand. McAllister (2002) recommends significant investigation on the part of sponsors (and sponsees in the case of the mega-sponsee) in assessing a roster of potential partners for developing a sponsorship relationship. The literature advises taking a proactive stance in seeking out and selecting the appropriate partner(s) whose image(s) fit(s) with the promotional objectives that the sponsor/megasponsee is trying to achieve (Gwinner \& Eaton, 1999). Achieving such a 'fit' enables both sponsor and sponsee to leverage the association effectively to meet their own specific objectives.

For sponsorship evaluation specifically, the importance in this step is three-fold. First, the researcher needs to make sure that the sponsorship is worthy of evaluation. That is, does the cost-benefit analysis make sense (i.e. is the benefit provided by the evaluation greater than the resources required to undertake the evaluation (time, financial and human))? Second, a researcher must identify all the objectives of the sponsor(s), sponsee and intermediaries and verify that they are possible to evaluate. Finally, a well-planned pre-test can provide (i) learning for future data collection and (ii) useful baseline measurements. 


\subsubsection{Choose Promotional Tactics}

Following pre-measurement, the promotional tactics are chosen by the sponsor. In McAllister's (2002) model, this involves the selection of a sponsee. It is important to note that, in the case of the mega-sponsee, it is the sponsee who has the greater power and selects the sponsor.

Sponsee selection is the 'sponsorship decision-making process' for the typical sponsor-sponsee relationship, where the sponsor is selecting from a group of interested sponsees (e.g., Aguilar-Manjarrez, Thwaites \& Maule, 1997; Cousens \& Slack, 1996; Thwaites, Aguilar-Manjarrez \& Kidd, 1995). The literature suggests that there are several considerations in this decision-making process including assessing the 'fit' or the complimentary ability of the sponsor and the sponsee to achieve their objectives (Seguin, Teed \& O'Reilly, 2005; Cornwell \& Maignan, 1998), having 'common geographic scope' which refers to shared markets of interest (McCook, Turco \& Riley, 1997), protecting against ambushers/guaranteeing exclusivity (Arthur, Scott, Woods \& Booker, 1998; Lee, Sandler \& Shani, 1997), consideration of attendees of sponsee events (Brooks, 1994), access to television coverage (Bennett, 1999), and access to naming rights (McCarthy \& Irwin, 2000; 19.98).

With respect to sponsorship evaluation, two important points are revealed during the selection of promotional tactics. First, the researcher must assess the importance of the situation (typical versus mega-sponsee) and know where the specific sponsorship falls. It is clear that the nature of the relationship is significantly different in each situation. Second, it is vitally important for the researcher to understand how the decision 
is being made in order to conduct an effective evaluation. In this regard, the evaluator needs to be very aware of the objectives sought by all parties involved in the sponsorship.

\subsubsection{Sponsorship Implementation}

Following the selection of the sponsee (or sponsor in the case of the megasponsee), the sponsorship is implemented. Practitioners commonly refer to this step as 'activation'. This involves 'actioning' the sponsor-sponsee contract. The implementation of a sponsorship is a well articulated process with developed literature existing on various promotional techniques (signage, endorsements, etc.), leveraging the association and the media, and in various areas of sponsorship management including consumer reactions to sponsorship, sponsorship objectives, sponsorship budgets, organizational structure and individual needs addressed by sponsorship (e.g., Crompton, 2004b; Kover, 2001; Lardinoit \& Quester, 2001; Lyberger \& McCarthy, 2001; Meenaghan, 2001; Farrelly, Quester \& Burton 1997; Anne \& Cheron, 1991; Parker, 1991).

In terms of its benefit to sponsorship evaluation, this literature demonstrates that the evaluation researcher needs to be involved in the sponsorship prior to activation in order to enable effective data collection throughout the sponsorship implementation since it is an iterative process. A number of researchers seek to provide practitioners with guidance for their sponsorships in general. For example, Seguin, Teed and O'Reilly (2005) adopted an in-depth, multi-case study approach to identify the Top 10 Sponsorship Best Practices. 
Table 7: Top 10 Sponsorship Best Practices (Seguin. Teed \& O'Reilly, 2005)

\begin{tabular}{|c|l|}
\hline$\#$ & \multicolumn{1}{|c|}{ Best Practice } \\
\hline 1 & $\begin{array}{l}\text { A significant investment in human and financial resources in leveraging (3:1 to } \\
\text { sponsorship value) the investment in the sponsorship }\end{array}$ \\
\hline 2 & Clearly defined objectives (both the sponsor and sponsee) \\
\hline 3 & Integration with the sponsor's overall marketing mix \\
\hline 4 & A consideration of customer interests (drives sales, build brand, etc.) \\
\hline 5 & The need for strong long-term relationships \\
\hline 6 & The requirement of on-going television coverage on a major network \\
\hline 7 & A good fit between the sponsor's objectives and the sponsee's product(s) \\
\hline 8 & The incorporation of branding as a sponsorship objective \\
\hline 9 & Hospitality as a prominent leveraging technique \\
\hline 10 & Cross-promotion with associate sponsors \\
\hline
\end{tabular}

The best practices outlined in Table 7 are guides only and do not provide practitioners with specific direction on implementing or evaluating their objectives. The final step in Arthur, Scott, Woods and Booker's (1998) process model for the effective implementation and management of sport sponsorship programs supports this point. Here, Arthur, Scott, Woods and Booker (1998, p. 55) note that "sponsorship can be evaluated via a number of methods...[and that] sponsorship organizations should always evaluate their properties and discard those that do not measure up to pre-set objectives". This further underlines the need for the evaluation researcher to be involved during the implementation stage of the sponsorship.

\subsubsection{Post-Sponsorship Measurement and Sponsorship Results}

The final two steps of McAllister's model represent the stages of sponsorship activation that are most relevant to sponsorship evaluation. Here, it is important to acknowledge the various challenges to sponsorship measurement that must be overcome. The literature has revealed eight such challenges to measurement and evaluation. 
First, as noted earlier in this chapter, considerable literature argues that clear behavioural objectives must be established upfront in order for sponsorship to be effectively evaluated (Sandler \& Shani, 1993; Abratt \& Gobbler, 1992; Marshall \& Cook, 1992; Meenaghan, 1991b). The objectives of both the sponsor and the sponsee must be determined by the researcher. A well-articulated and complete sponsorship contract is essential (Newburn, 2001; Bergen, Dutta, \& Walker, 1992; Eisenhardt, 1989). The term 'complete' refers to the formal inclusion of as many of the sponsor's and the sponsee's objectives as possible, as it is the implied, understood or informal objectives that are most difficult to evaluate since the details are unclear, if not unknown.

Second, previous research has noted that a sponsor who typically invests in sponsorship as part of an overall promotion strategy has an established promotional mix prior to launching a sponsorship (Thwaites, Aguilar-Manjarrez \& Kidd, 1998; Quester, Burton \& Farrelly, 1998). This implies that organizations who adopt sponsorship are often doing so as part of a broader marketing strategy that includes integrated promotional tactics (e.g., advertising, public relations, sales promotion, etc.) and the leveraging of those tactics. Promotional activity concurrent to or in combination with sponsorship may cloud or bias evaluation of the sponsorship either from current or carryon effects (Thwaites, Aguilar-Manjarrez \& Kidd, 1998).

Third, pre-existing views of the sponsor, the sponsee and the sponsorship by target markets may influence the evaluation process. In this regard, the literature points to consumers and their awareness levels and opinions of the sponsor and the sponsee, as well as their attitudes towards and intent to purchase sponsors' products (Jalleh, Donovan, Giles-Corti \& Holman, 2002). In addition to a given consumer's attitude 
towards the sponsor or sponsee, Stipp and Schiavone (1996) point to two additional factors that decide if a sponsorship is effective or not in reaching a given consumer: how the consumer perceives the quality of the leveraging activities incorporated by the sponsor and the overall visibility of the sponsorship program. The measurement of these factors is very challenging if the objectives being evaluated are broader than sales and sales promotions (Hoek, 1998).

Fourth, each sponsorship objective may be linked to a different set of preferred outcomes (e.g., financial, sales, consumers views, branding, etc.) which may or may not correspond with the measurement tools used in empirical research (Mack, 1999). In general, difficulty arises for one of three reasons: (i) measurement tools are applied erroneously, (ii) no evaluation occurs, or (iii) inappropriate measurement tools are applied. These challenges point to the need to expand and disseminate the tools available for evaluating based on objectives, not based simply on available methodology. Clearly, the misapplication of measurement tools (e.g., adopting metrics from advertising research (recall and recognition) to evaluate sponsorship (Crompton, 2004a)), the snubbing of evaluation and the failure to ground metrics in the objectives of interest are important challenges facing sponsorship evaluation (Pope \& Voges, 1994).

Fifth, in practice, some sponsorship managers have little interest in evaluating their sponsorship investments; they adopt sponsorship programs to meet their own personal needs and objectives (i.e., sponsoring a sport or an art in which they, or their CEO, have a personal interest); (see Seguin, Teed \& O'Reilly, 2005). Berrett and Slack (1995) note that the existence of stated objectives and the existence of many unstated objectives, such as personal interest, make the measurement process considerably more 
challenging. In situations such as these where the sponsorship contract is incomplete, or the true rationale for its existence is hidden, evaluation will be flawed, particularly if sponsors wish to keep their true objectives private.

A sixth challenge involves the consideration (if applicable) of the effect of sponsee success (e.g., a winning sponsored team or a victorious sponsored track runner) relative to an unsuccessful sponsee (e.g., a poor theatrical performance or technical difficulties at a concert). Although some research in the area suggests that there is considerable effect from success (Cornwell, Pruitt \& van Ness, 2001) on the overall ability of a sponsorship to achieve its objectives, the ability to define and measure success remains a significant challenge in sponsorship evaluation.

Seventh, sponsorship evaluation in practice is often carried out using evaluation tools from advertising which may not consider the association component of sponsorship and, thus, does not address its full benefits. The adoption of advertising evaluation methodologies to evaluate sponsorship is commonly cited in the literature (Crompton, 2004a; Sparks, 1997; Cornwell, 1995; Vavra, 1995; Brooks, 1994; Parker, 1991; Meenaghan, 1983). Stipp and Schiavone (1996) argue that the development of sponsorship-specific evaluation tools is needed to overcome such challenges.

Finally, specific metrics to measure awareness, interest and attitude are lacking in the literature on sponsorship (Wilson, 1997). It is likely that metrics are in place in practice, but they are proprietary in nature and not shared publicly. In this regard, Quester and Farrelly (1998) have pointed out that sponsors should be measuring the awareness that consumers have of their organization and its products and that of their competition. This is important as market share (Quester \& Farrelly, 1998) and prominent brands (Johar 
\& Pham, 1999) can influence the effectiveness of a sponsorship relative to the competition. Further, evaluation literature outside of sponsorship (e.g., Greene \& McClintock, 1991) has developed similar metrics that could be adapted.

\subsection{Summary: Sponsorship Evaluation}

The review via McAllister's model provides direction around the evaluation of sponsorship. First, it is necessary to fully identify and understand the objectives sought by all relevant parties in a sponsorship. Ideally, the researcher would (i) have a reliable framework with which to organize the evaluation and (ii) be involved early enough in the sponsorship process to support the development of clear, measurable objectives. Second, a researcher is directed to collect baseline measurements pre-sponsorship to determine if the cost-benefit analysis justifies spending resources on the evaluation of the sponsorship. Third, the distinction between the typical sponsee and mega-sponsee scenarios was again supported. The researcher needs to know which scenario they are working in and be involved throughout the process. Finally, the many measurement challenges around evaluation were described with a number of recommendations provided to the researcher, including (i) the need for a complete sponsorship contract, (ii) access to marketing plans for all organizations involved in the sponsorship, and (iii) tactics related to the attribution issue.

Overall, the literature on sponsorship evaluation strongly supports the need for improved tools and models for the sophisticated evaluation of sponsorship. A variety of writers point to a number of these challenges, including (i) a lack of understanding of the sponsor-sponsee relationship, (ii) the lack of consideration, specification and use of 
objectives in the evaluation process, (iii) the limited development of appropriate metrics, (iv) the limited understanding of the barriers to, fears about, benefits of, and timing of sponsorship evaluation, and (v) the difficulty of measuring accurately in the context of larger marketing mixes. Despite the identification of these challenges, little is provided in terms of how to evaluate sponsorships effectively. Ideally, a sophisticated process for conducting sponsorship evaluation would be proposed and tested. However, to date, the author found limited evidence of such a process. Even the literature that claims to provide such a framework really does not do so. For example, although the process model published by Arthur, Scott, Woods and Booker (2001) lists ten practices to adopt for successful sponsorship management; it is not a step-by-step process model by which to evaluate a sponsorship effectively. 


\subsection{THEORETICAL FRAMEWORK}

This chapter builds on the literature reviewed in the previous chapters with the purpose of providing a clear theoretical foundation from which to view and evaluate sponsorship. A number of business-based theoretical perspectives by which to view sponsorship relationships are considered and Agency Theory is selected as the theoretical framework to guide this dissertation. The rationale for this choice is presented, followed by a review of Agency Theory and its utility as an appropriate theoretical framework on which to base the research. This includes reviewing (i) the scope of Agency Theory, (ii) its key concepts, branches and assumptions, (iii) the contract as its unit of analysis, and (iv) crafting the first draft of the process model for sponsorship evaluation.

\subsection{Selecting and introducing Agency Theory}

A number of schools of thought have been developing to explain and explore business relationships including relationship marketing, agency theory, partnership theory, and strategic alliance theory. Each provides a different perspective on different types of relationships. Relationship marketing is about improving relationships between organizations and their customers by "building solid, long-term relationships with customers [that] require a concentrated effort on the part of all employees and management to get to know what satisfies the customer and what the customer values" (Barnes, 2001). A strategic alliance, or interorganizational governance structure (Thorelli, 1986), focuses on relationships between two groups where the two groups become the same entity with common objectives and an accompanying enhanced competitive advantage (Ireland \& Hitt, 1999; Borys \& Jemison, 1989). Partnership theory focuses on 
situations where two or more entities support each other and work collaboratively towards common outcomes but do not merge into one entity to do so (Rees \& Gardiner, 2003). Deemed “important yet controversial ${ }^{14 "}$ " (Eisenhardt, 1989, p. 57), Agency Theory views a business relationship as a principal-agent relationship, where one group (i.e., the principal) relies on another group (i.e., the agent) to carry out some endeavour on behalf of the principal (Bahli \& Rivard, 2003; Bergen, Dutta, \& Walker, 1992; Eisenhardt, 1989).

Agency Theory has received considerable attention in many literatures, including accounting, economics (where it began), finance, marketing, political science, organizational behaviour and sociology (Eisenhardt, 1989), as a means to explain the relationships involved in cooperative effort between a principal and an agent of that principal in pursuit of a common business outcome. Eisenhardt (1989) points out that an agency relationship assumes that each party in the relationship has their own motive since their goals are not congruent. This infers that in any agency relationship, although it involves the agent working on behalf of the principal towards a common objective (as determined by the principal), both groups have their own 'bottom line' rationale (which may or may not be profit) for being involved in the relationship. It should also not be assumed that the principal benefits more than the agent, as this is not always the case (Sappington, 1991; Ross, 1973).

During its 'glory years' of the early 1980's, Agency Theory was hailed by many as a powerful lens through which to view organizations (e.g., Jensen, 1983). It was thought that it would provide the solution to many of the challenges facing principals.

\footnotetext{
14 This dichotomy proposed by Eisenhardt (1989) stems from the duality of Agency Theory's effective (i.e. important) yet impersonal (i.e. controversial) view on business relationships.
} 
Conversely, other theorists (e.g., Perrow, 1986) viewed Agency Theory as degrading to those involved and overly simplistic in its application. These authors argue that the principal-agent view of a relationship is limited in its ability and potentially threatening for the agent (i.e., the use of an agency approach could potentially lead to the exploitation of workers).

\subsubsection{The scope of Agency Theory}

Ross (1973, p. 134) claimed that "examples of Agency Theory are universal", indicating the broadest of scopes. Others have been very critical of the broad range, stating that Agency Theory looks only at stock prices (Hirsch \& Friedman, 1986) or that it fails to truly address any problems of interest (Perrow, 1986). Historically, the value of Agency Theory has been most evident in the economics literature (e.g., Sappington, 1991; Harris \& Raviv, 1979; Ross, 1973) while it was originally believed to be less valuable to organizational scholars (Eisenhardt, 1989). Recently, however, organizational researchers have applied Agency Theory to such relationships as consultants and clients (Basu \& Lederer, 2004), ERP implementation consultants and client organizations (Basu \& Lederer, 2004), IT outsourcers and suppliers (Bahli \& Rivard, 2003), international retailers and franchisees (Doherty \& Quinn, 1999), advertising agencies and their clients (Waller, 2004), shareholders and managers in general (Eisenhardt, 1989) and information policy in agency relationships (Jacobides \& Croson, 2001). Today, research grounded in Agency Theory continues to be found in the marketing literature and that of political science, finance, sociology, accounting, organizational behaviour, information 
technology, economics, and engineering, demonstrating the ongoing relevance of the theory.

Examples of relationships where an agency perspective would be appropriate are many and include most relationships between an organization and a facilitating agency (Bergen, Dutta, \& Walker, 1992). A facilitating agency can include such entities as sponsors, advertising agencies, research suppliers, publication warehouses and marketing agencies that act as specialists and implement some marketing objective on behalf of the principal. Facilitating agencies are remunerated by the principal in return for the work they provide. The form of payment is often fee-for-service or commission, but in the case of sponsorship could involve either a cash payment or the provision of in-kind product. It is important to note that an agency relationship may be more complex (i.e., involve more than 2 parties) than principal-agent. An example (see Table 8) would be the relationship between the owner of an NFL franchise and her star quarterback, where a number of other parties (i.e., player agent, General Manager of franchise, lawyers, coach, player's family) are also directly and indirectly involved in the relationship.

Table 8: Agency Relationship Example: NFL Franchise and Star Quarterback

\begin{tabular}{|l|l|l|}
\hline Party & Agency Theory Role & Description \\
\hline Star Quarterback & Agent & $\begin{array}{l}\text { Asked to complete a role on behalf of the } \\
\text { owner. }\end{array}$ \\
\hline Player's Family & Intermediary (Agent) & Influences player actions. \\
\hline Player's Agent & Intermediary (Agent) & $\begin{array}{l}\text { Acts on behalf of player in negotiations with } \\
\text { principal (owner). }\end{array}$ \\
\hline Player's Doctor & Intermediary (Agent) & Influences player actions. \\
\hline Player's Lawyer & Intermediary (Agent) & $\begin{array}{l}\text { Acts on behalf of player and advises player } \\
\text { in negotiations with principal (owner) }\end{array}$ \\
\hline Owner & Principal & $\begin{array}{l}\text { Entity seeking to achieve objective of on- } \\
\text { field success by engaging star quarterback } \\
\text { (agent). }\end{array}$ \\
\hline
\end{tabular}




\begin{tabular}{|l|l|l|}
\hline General Manager & $\begin{array}{l}\text { Intermediary } \\
\text { (Principal) }\end{array}$ & $\begin{array}{l}\text { Acts on behalf of owner in negotiations with } \\
\text { player (agent). }\end{array}$ \\
\hline Team Lawyer & $\begin{array}{l}\text { Intermediary } \\
\text { (Principal) }\end{array}$ & $\begin{array}{l}\text { Acts on behalf of owner and advises owner } \\
\text { in negotiations with agent (player). }\end{array}$ \\
\hline Coach & $\begin{array}{l}\text { Intermediary } \\
\text { (Principal) }\end{array}$ & Influencer on player and owner. \\
\hline Teammates & $\begin{array}{l}\text { Intermediary } \\
\text { (Principal) }\end{array}$ & Influencer on player and owner. \\
\hline
\end{tabular}

\subsubsection{An overview of Agency Theory}

Eisenhardt (1989) provides a good summary of Agency Theory in the following table adapted from her management-based review and assessment of the theory. Selected elements from this overview are further developed in chapter 4.2.

Table 9: Agency Theory Overview (adapted from Eisenhardt, 1989)

\begin{tabular}{|c|c|c|}
\hline * & Point & Description \\
\hline$\overline{K e y}$ Idea & $\begin{array}{l}\text { Principal-agent relationships should } \\
\text { reflect efficient organization of } \\
\text { information and risk-bearing costs. }\end{array}$ & $\begin{array}{l}\text { The principal strives to achieve the most efficient } \\
\text { level of monitoring to ensure compliance by the } \\
\text { agent with the sought objectives. }\end{array}$ \\
\hline $\begin{array}{l}\text { Unit of } \\
\text { analysis }\end{array}$ & Contract between principal and agent. & $\begin{array}{l}\text { The formal (written) and informal (understood) } \\
\text { agreement between the parties. }\end{array}$ \\
\hline $\begin{array}{l}\text { Human } \\
\text { assumptions }\end{array}$ & $\begin{array}{l}\text { - Self interest } \\
\text { - Bounded rationality } \\
\text { - Risk aversion }\end{array}$ & $\begin{array}{l}\text { Each party will act with their own interests in } \\
\text { mind, tending to avoid risk } \\
\text { - Within the boundaries of the contract, the } \\
\text { sponsee with act in a rational manner }\end{array}$ \\
\hline $\begin{array}{l}\text { Organizational } \\
\text { assumptions }\end{array}$ & $\begin{array}{l}\text { Partial goal conflict \& information } \\
\text { asymmetry between the principal } \\
\text { and the agent } \\
\text { - Effectiveness criterion: efficiency }\end{array}$ & $\begin{array}{l}\text { - Principal and agent have differing objectives } \\
\text { - Principal evaluates agent on their efficiency } \\
\text { - It is unlikely that the principal shares full } \\
\text { information with the agent }\end{array}$ \\
\hline $\begin{array}{l}\text { Information } \\
\text { assumptions }\end{array}$ & $\begin{array}{l}\text { Information as a purchasable } \\
\text { commodity }\end{array}$ & $\begin{array}{l}\text { Knowledge and information are key to the } \\
\text { relationship and may be sought externally }\end{array}$ \\
\hline $\begin{array}{l}\text { Contracting } \\
\text { problems }\end{array}$ & $\begin{array}{l}\text { - Agency (moral hazard }{ }^{15} \text { and } \\
\text { adverse selection }{ }^{16} \text { ) } \\
\text { - Risk sharing }\end{array}$ & $\begin{array}{l}\text { - Agency selection is typically a difficult and } \\
\text { biased task } \\
\text { - Finding a risk-sharing agent is difficult }\end{array}$ \\
\hline
\end{tabular}

\footnotetext{
${ }^{15}$ Moral hazard (Eisenhardt, 1989) refers to the condition where the principal cannot ascertain if the agent accurately represents their ability to do the work for which they are being paid.

${ }^{16}$ Adverse selection (Eisenhardt, 1989) refers to the condition where the principal cannot be sure if the agent has put forth maximal effort in pursuing the work of interest.
} 


\begin{tabular}{|l|l|l|}
\hline $\begin{array}{l}\text { Problem } \\
\text { domain }\end{array}$ & $\begin{array}{l}\text { Relationship in which the principal } \\
\text { and agent have partly differing goals } \\
\text { and risk preferences (e.g., } \\
\text { compensation, regulation, leadership, } \\
\text { impression management, whistle- } \\
\text { blowing, vertical integration, transfer } \\
\text { pricing) }\end{array}$ & $\begin{array}{l}\text { This problem domain holds for the vast majority } \\
\text { of principal-agent relationships as, typically, goals } \\
\text { and risk preferences differ considerably }\end{array}$ \\
\hline
\end{tabular}

\subsection{Key concepts in Agency Theory}

Agency Theory is complex and widely applicable. This sub-section introduces and describes some of the key aspects of Agency Theory in Table 9 that provide important descriptive background on the theory or that are relevant to this dissertation.

\subsubsection{The contract as unit of analysis}

The use of a contract and analyses of such contracts have become the units of analysis of Agency Theory, which has led the theory to focus on developing more efficient principal-agent contracts, whether they be behaviour-oriented (e.g. management philosophy) or outcome-oriented (e.g. profit) (Bergen, Dutta, \& Walker, 1992). Contracts take on many forms and contain various aspects, from written to verbal, formal to informal, and implicit to explicit. It is particularly important to note that items not expressly written in a formal contract may be part of the understanding between a principal and an agent.

\subsubsection{Assumptions in Agency Theory}

There are a number of assumptions in Agency Theory that must be fully understood before applying it to a given context. These assumptions fall into three categories: human assumptions, organizational assumptions and information 
assumptions. The human assumptions include self interest, bounded rationality, and risk aversion. In simple terms, Agency Theory assumes that individuals behave to benefit their own interests while respecting most rules and avoiding unnecessary risk. The organizational assumptions include goal conflict among participants, efficiency as the effectiveness criterion, and information asymmetry between principal and agent. Here, the organization is assumed to balance the interests of its members, seek to be as efficient as possible, and to accept the fact that the principals (typically the shareholders) know less than the agent (typically management). Finally, the information assumption is that information is a purchasable commodity.

The three categories of assumptions include seven key assumptions underlying Agency Theory. A summary of each of these seven assumptions in each of the contemporary organizational perspectives is presented below in Table 10.

Table 10: Comparison of Agency Theory Assumptions and Organizational Perspectives

\begin{tabular}{|l|c|c|c|c|c|}
\hline \multirow{2}{*}{ Assumption } & \multicolumn{5}{|c|}{ Organizational Perspective } \\
\cline { 2 - 6 } & Political & Contingency & Organizational Control & Transaction Cost & Agency \\
\hline Self-interest & $\mathrm{X}$ & & & $\mathrm{X}$ & $\mathrm{X}$ \\
\hline Goal conflict & $\mathrm{X}$ & & & $\mathrm{X}$ & $\mathrm{X}$ \\
\hline $\begin{array}{l}\text { Bounded } \\
\text { rationality }\end{array}$ & & $\mathrm{X}$ & $\mathrm{X}$ & $\mathrm{X}$ & $\mathrm{X}$ \\
\hline $\begin{array}{l}\text { Information } \\
\text { Asymmetry }\end{array}$ & & $\mathrm{X}$ & & $\mathrm{X}$ & $\mathrm{X}$ \\
\hline $\begin{array}{l}\text { Preeminence of } \\
\text { efficiency }\end{array}$ & & $\mathrm{X}$ & $\mathrm{X}$ & $\mathrm{X}$ \\
\hline Risk aversion & & & & & $\mathrm{X}$ \\
\hline $\begin{array}{l}\text { Information as a } \\
\text { commodity }\end{array}$ & & & & & $\mathrm{X}$ \\
\hline
\end{tabular}

** Taken taken directly from Eisenhardt, 1989 **

As noted in Table 10, Agency Theory involves all seven of the assumptions, while the other organizational perspectives do not. 


\subsubsection{Monitoring in Agency Theory}

Agency Theory typically examines, from the principal's point of view, the tradeoff between the cost of monitoring the agent and the attainment of the principal's objectives where the contract between the two groups is the unit of analysis. It is a well established tenet of Agency Theory that the principal cannot monitor the actions of the agent perfectly or without costs (Sappington, 1991), where the costs refer to resolving conflicts between principals and their agents and aligning the interests of the two groups (Jacobides \& Croson, 2001). This brings forth such issues as 'power' and 'trust', as both variables impact how much autonomy the principal gives to the agent and how much cost is incurred by the principal when such autonomy is not granted. It must also be recognized that this issue can swing the other way, where the agent may not trust the principal and must incur costs in monitoring the principal (e.g., making sure they are reimbursed, ensuring that their own brand is respected, etc.). In both cases, it is the combination of the principal's trust of the agent and the sharing of risk by the agent that leads to potential costs on both sides (Eisenhardt, 1989). It is important to note that the dimension of time, either the length of the relationship or the stage of its development, should also be considered when adopting an Agency Theory approach (Morgan \& Hunt, 1994). Typically, however, the literature focuses on the principal's monitoring costs as opposed to power, time and trust (Ross, 1973).

\subsubsection{Agency Theory in economics, marketing and management}

Agency Theory was born in public sector economics as a way by which to view the 'problem' that governments face in controlling the behaviour of their employees to 
insure that they act in the best interests of society and not themselves (e.g., Harris \& Raviv, 1979). This form of a principal-agent relationship was the beginning of the development of this theory and focused very much on the incentives required to deal with the agency problem (Sappington, 1991; Harris \& Raviv, 1979; Alchian \& Demsetz, 1972). These early writings presumed that the objectives of the relationship were defined by the principal and implemented by the agent, where the agent possesses more information than the principal (i.e., asymmetric information) and, as such, the principal is required to spend resources monitoring the agent to insure compliance. In addition, the fact that random external events (e.g., unforeseen economic, environmental, political, competitive and social changes) could influence the relationship was an important aspect of early Agency Theory (Harris \& Raviv, 1979).

From a management perspective, Eisenhardt (1989, p. 58) describes Agency Theory as "directed at the ubiquitous agency relationship, in which one party (the principal) delegates work to another (the agent), who performs that work". Recently, Agency Theory has been applied in the management literature with a number of useful applications identified such as the Board-CEO and Sales Director-Sales Person relationships. For example, Bahli and Rivard (2001) use Agency Theory as one of the theoretical foundations of their work on outsourcing in IT. Of particular note is the authors' use of Agency Theory to develop risk scenarios around IT sourcing principalagent relationships. Measurement problems are also identified by Bahli \& Rivard (2003) as a risk factor that can lead to disputes and potential litigation. This point is particularly relevant to sponsorship evaluation where measurement has limited use in theory and practice. Whether it evolves to litigation or not, a breakdown in a principal-agent 
relationship always has consequences: services debasement and/or cost escalation.

Service debasement refers to a reduction in the amount or quality of service performed by the agent, while cost escalation implies a rise in cost to the principal. Each can occur at any point in the relationship and both are closely related and one can lead to the other (Bahli \& Rivard, 2003).

The move of the most widely-accepted definition of marketing from its focus on the concept of the exchange (Arrow, 1985; Bagozzi, 1974) to a relationship-based definition (American Marketing Association ${ }^{17}$, 2004) is a demonstration of the growing importance of relationships in marketing theory (e.g., Barnes, 2001) and further validates the appropriateness of an Agency Theory perspective on marketing concepts, including sponsorship evaluation. Aijo (1996) reviewed the theoretical development of relationships in management and in marketing and proposed that it represented a paradigm shift in the field, driven by technology improvements that enable closer firmcustomer relationships. Gummesson (2004, p. 136), who defines relationship marketing as "marketing based on interaction within networks of relationships", tells of how relationship marketing evolved into one-to-one marketing and then to customer relationship marketing (CRM), the name by which it is often described today. Gummesson's work demonstrates the evolution of relationship marketing, as it theoretically develops the concepts of B2B (business-to-business) relationship marketing as distinct from B2C (business-to-customer) relationship marketing and introduces ROR (return on relationship). ROR is a marketing metric to measure the "long-term net

\footnotetext{
${ }^{17}$ For reference, the American Marketing Association's new definition is "marketing is an organizational function and a set of processes for creating, communicating and delivering value to customers and for managing customer relationships in ways that benefit the organization and its stakeholders" (American Marketing Association, 2004).
} 
financial outcome caused by the establishment and maintenance of an organization's network of relationships" (Gummesson, 2004, p. 141). Numerous other authors have also written about relationship marketing, including Rowley (2004) who develops relationship marketing and knowledge management as complementary paradigms and Gronroos (2004) who proposes the process by which relationship marketing occurs. Bergen, Dutta and Walker (1992) add that the majority of all marketing transactions occur via "facilitating agencies" contracted by the principal or the agent on some kind of remuneration basis and point out that the ultimate consumer can also be viewed as being in a principal-agent relationship, as explained below:

A given individual can shift from the role of principal to that of an agent across different contexts. For instance, a purchasing agent acts primarily as an agent whose job is to represent the needs and interests of others in the firm when buying goods and services from outside suppliers.

However, when seeking information from a given supplier on which to base a purchase decision, the purchasing agent acts like a principal and the supplier's salesperson is the agent. Thus, relationships are context specific, and agency models should be used to examine the relationship that is specific within a single context. (Bergen, Dutta, \& Walker, 1992, p. 26)

This differs from the view of economists who are primarily interested in the incentives needed to control the agency problem while marketers are focused on the exchange that takes place between the two parties in a given relationship, and how to insure that the objectives of both parties are met in an efficient manner.

The fact that the closely related theory of transaction cost economics has a significant track record of use in the marketing literature strongly supports the application of Agency Theory to marketing issues. Both transaction cost analysis and Agency Theory "examine efficiency aspects of how firms organize functional relationships" (Bergen, Dutta, \& Walker, 1992, p. 29) and are deemed to be complementary as both study 
contracts and involve relationships where both parties act in self-interest (Williamson, 1988; Anderson \& Oliver, 1987).

Bergen, Dutta and Walker (1992) identified three major areas where Agency Theory has been applied in marketing: (i) sales force management, (ii) distribution channel coordination and control, and (iii) promotion (Bergen, Dutta, \& Walker, 1992). Research pertaining to the relationship between a sales manager and a sales person (e.g., John, Weiss, \& Weitz, 1987) has typically centered on the determination of the most efficient and effective sales compensation plan to enhance sales. Previous studies on channel coordination and control (e.g., Moorthy, 1987) have been built on the idea that a distribution channel is a set of principal-agency relationships and related research areas (i.e., pricing mechanisms, franchising agreements, incentives, etc.). Promotion-based research using Agency Theory (e.g., Nelson, 1974) has focused mainly on the organization-consumer relationship and the signals of product quality from producers to consumers. In this relationship, the consumer is considered an agent as the organization (principal) seeks to inspire behaviour in consumers that expresses product quality to other potential consumers (e.g., positive word of mouth, observable product usage, etc.).

In summary, a management (Eisenhardt, 1989) or marketing (Bergen, Dutta, \& Walker, 1992) view of Agency Theory moves beyond the consideration of the principal's interest in the formal contract to include a broader understanding of a contract (i.e., both formal and informal) and to consider the objectives of the agent as equal in importance. 


\subsubsection{Information and Agency Theory}

The concept that information is a commodity that has a cost and can be purchased is unique to organizational research and implies that organizations can invest in information systems ${ }^{18}$ as a method of controlling agent opportunism (Eisenhardt, 1989). The concept of executive compensation is a good example of this contribution. While significant literature has called for increased executive compensation based on performance (Bebchuk \& Fried, 2003), an Agency Theory perspective would say that executive performance is contingent on a number of factors including information systems, ability to motivate employees, skills, experience, etc. For example, in the case of information systems, an agency theorist would argue that improved information systems would decrease managerial opportunism (also known as 'shirking') and, in turn, result in a decrease in performance-based pay.

\subsubsection{Risk preference and the variables in Agency Theory}

The uncertainty of the external environment on the risk aversion of either the principal or the agent is important in Agency Theory (Eisenhardt, 1989). Risk, in this case, is "viewed in terms of risk/reward trade-off, not just in terms of inability to plan" (Eisenhardt, 1989, p. 62) inferring that the contract between principal and agent is influenced both by uncertainty and the willingness of both parties to accept risk. As a point of clarification, a new venture considering the 'make or buy' decision illustrates the

\footnotetext{
${ }^{18}$ Information systems can be formal and informal and include such things as budgeting, managerial supervision, boards of directors, and databases. Of note, Eisenhardt (1989) identifies boards of directors as particularly relevant in organizational studies as they may be used as a formal information system to monitor executives on behalf of shareholders. As boards become more involved, opportunities for management 'shirking' are decreased and rewards take the form of behaviour-based results (i.e. strategic action) over outcomes.
} 
risk contribution. In this situation, the firm has limited resources and the likelihood of failure (uncertainty) is high, which means that management would likely be risk-averse, leading them to a 'buy' selection (i.e., transfer the risk to the supplier); (Eisenhardt, 1989).

Figure 3 below describes the variables at play in a principal-agent relationship. Of particular note is the focus on an efficient contract moderated by the environment. In most cases of principal-agent relationships and contracts, efficiency is defined and determined from the principal's point of view. This is because the principal is assumed to be the dominant party in the relationship where it is their desired outcomes that are considered as opposed to the objectives of the agent (Bergen, Dutta, \& Walker, 1992). Although the development of Agency Theory has centered on formal contracts, it has been applied to social contracts as well (Bergen, Dutta, \& Walker, 1992) indicating that the informal aspects of any contract must also be considered. This is very important in business research as hand shakes, mutual understandings ('my word') and informal contracts are often the relationship guiding mechanism of choice. Due to the realities of day-to-day business and legal costs, even formal contracts rarely include all details and fully elaborate all roles and responsibilities. 
Figure 3: Framework of Agency Theory Variables (adapted from Bergen, Dutta, \&

Walker, 1992)

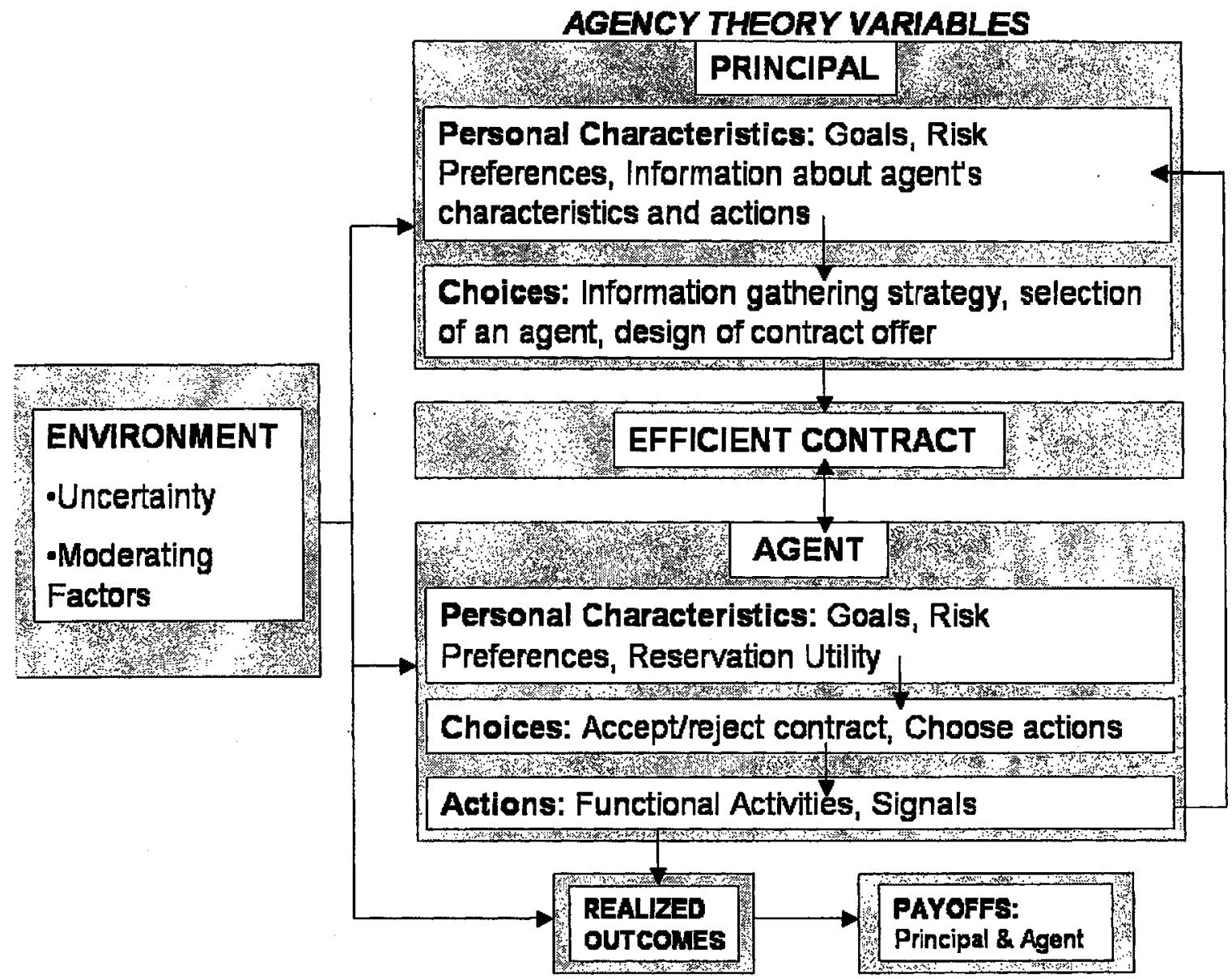

Figure 3 demonstrates that both the principal and the agent have some level of risk

preference which impacts the contract. Risk preference refers to the group's preference for adventure rather than security (Arrow, 1985). Thus, an entity is risk averse when they prefer security over adventure while an entity that prefers adventure over security is not risk averse. Should an entity be indifferent, they are dubbed risk neutral. It is when the two parties have differing levels of risk preference that problems often occur in the principal-agent relationship. 


\subsubsection{Incentives and self-interest in Agency Theory}

Perrow (1986) proposes that the introduction of Agency Theory to organizational thinking had a role in re-establishing the concepts of incentives and self-interest in related research. Perrow's view infers that organizational life - like most forms of life - is based on self-interest (Eisenhardt, 1989). Although both incentives and self-interest, like Agency Theory itself, come from economics, Perrow (1986) reminds us of the complexity of relationships, in particular intra-organizational and inter-organizational ones implying that Agency Theory plays a key role in keeping business research centered on theory and topic, as opposed to topic only which some have argued is a problem in business research (e.g., Barney, 1991; Barzel, 1982). For Agency Theory specifically, this infers that the self-interest of both principal and agent, as well as the incentives necessary to engage both, are important considerations.

\subsubsection{The two branches of Agency Theory}

Two camps have developed in the literature related to Agency Theory: positivist Agency Theory and principal-agent research. Positivist researchers focus on "identifying situations in which the principal and agent are likely to have conflicting goals and then describing the governance mechanisms that limit the agent's self-serving behaviour" (Eisenhardt, 1989, p. 66), while principal-agent researchers focus on the application of Agency Theory towards the efficient and effective functioning of principal-agent relationships (Harris \& Raviv, 1978). 


\subsubsection{Principal-agent research}

The principal-agent research stream (e.g., Eisenhardt, 1989; Jensen, 1983)

involves applying the theory of the principal-agent relationship to specific examples of

that relationship (e.g., lawyer-client, buyer-supplier, and employer-employee) with its

focus being the determination of the optimal contract (behaviour-based vs. outcome-

based) between the principal and the agent, where incongruent goals and an agent who is

more risk averse ${ }^{19}$ than the principal are assumed. The literature refers to this situation as

the simple model (Eisenhardt, 1989), for which nine cases have been identified.

\section{Table 11: Cases of the Simple Model of Principal-Agent Research}

\begin{tabular}{|l|l|l|l|}
\hline$\#$ & Case & Description & Outcome \\
\hline 1 & $\begin{array}{l}\text { Complete } \\
\text { information }\end{array}$ & $\begin{array}{l}\text { The principal knows fully } \\
\text { what behaviour the agent } \\
\text { has carried out. }\end{array}$ & $\begin{array}{l}\text { Behaviour-based contract is most efficient, as there is } \\
\text { no need to transfer risk to the agent. }\end{array}$ \\
\hline 2 & $\begin{array}{l}\text { Incomplete } \\
\text { information/ } \\
\text { unobservable } \\
\text { behaviour - } \\
\text { agent } \\
\text { shirking }\end{array}$ & $\begin{array}{l}\text { Depending on self-interest } \\
\text { of agent, they may not } \\
\text { have behaved as desired } \\
\text { by the principal. }\end{array}$ & $\begin{array}{l}\text { Principal invests in information systems in order to } \\
\text { monitor agent's behaviour (e.g., budget systems, report } \\
\text { procedures) and revert to complete information case. } \\
\text { OR } \\
\text { Principal selects an outcome-based contract to motivate } \\
\text { behaviour based on performance outcomes that align } \\
\text { the agent's goals with those of the principal. Risk (or } \\
\text { 'outcome uncertainty') is transferred to the agent and } \\
\text { arises as outcomes are not a perfect measure of } \\
\text { behaviour, especially considering the possibility of } \\
\text { external influencers (e.g., competitor action). Outcome } \\
\text { based contracts are attractive when outcome uncertainty } \\
\text { is low and cost of shifting risk to agent are low. Thus, } \\
\text { as outcome uncertainty increases, so does risk and so } \\
\text { does cost to principal. }\end{array}$ \\
\hline 3 & $\begin{array}{l}\text { Incomplete } \\
\text { information / } \\
\text { unobservable } \\
\text { behaviour- }\end{array}$ & $\begin{array}{l}\text { Agent may have claimed } \\
\text { to have certain } \\
\text { skills/abilities when hired, } \\
\text { however they do not }\end{array}$ & $\begin{array}{l}\text { Principal invests in information systems in order to } \\
\text { monitor agent's behaviour (e.g., budget systems, report } \\
\text { procedures) and revert to complete information case. } \\
\text { OR }\end{array}$ \\
\hline
\end{tabular}

\footnotetext{
${ }^{19}$ Stemming from economic theory, the rationale behind the risk aversion assumption is that, typically, an employee (agent) is less able to diversify their employment than an employer (principal) is able to diversify their investments.

${ }^{20}$ Shirking is also referred to as 'moral hazard' (e.g. Eisenhardt, 1989) in the literature and refers to the risk of the agent not exerting the agreed-to effort.
} 


\begin{tabular}{|c|c|c|c|}
\hline & $\begin{array}{l}\text { adverse } \\
\text { selection }^{21}\end{array}$ & possess such skills. & $\begin{array}{l}\text { Principal selects an outcome-based contract to motivate } \\
\text { behaviour based on performance outcomes that align } \\
\text { the agent's goals with those of the principal. Risk (or } \\
\text { 'outcome uncertainty') is transferred to the agent and } \\
\text { arises as outcomes are not a perfect measure of } \\
\text { behaviour, especially considering the possibility of } \\
\text { external influencers (e.g., competitor action). Outcome } \\
\text { based contracts are attractive when outcome uncertainty } \\
\text { is low and cost of shifting risk to agent are low. Thus, } \\
\text { as outcome uncertainty increases, so does risk and so } \\
\text { does cost to principal. }\end{array}$ \\
\hline 4 & $\begin{array}{l}\text { Simple model } \\
\text { without } \\
\text { assumption of } \\
\text { a risk-averse } \\
\text { agent }\end{array}$ & $\begin{array}{l}\text { Situations where agent } \\
\text { becomes less risk averse } \\
\text { (powerful agent, resource- } \\
\text { rich agent, agent with } \\
\text { numerous principals to } \\
\text { choose from) }\end{array}$ & $\begin{array}{l}\text { Given the decreased risk aversion of the agent, the } \\
\text { principal is in a position to use an outcome-based } \\
\text { contract to pass risk to the agent at a reduced cost. This } \\
\text { makes the option of an outcome-based contract very } \\
\text { attractive. }\end{array}$ \\
\hline 5 & $\begin{array}{l}\text { Simple model } \\
\text { with risk } \\
\text { averse } \\
\text { principal }\end{array}$ & $\begin{array}{l}\text { Situations where principal } \\
\text { becomes more risk averse } \\
\text { (limited resources, } \\
\text { financial pressure, etc.) }\end{array}$ & $\begin{array}{l}\text { Given the increased risk aversion of the principal, the } \\
\text { principal may choose to use an outcome-based contract } \\
\text { to pass risk to the agent at a reduced cost (as compared } \\
\text { to keeping the risk themselves). This makes the option } \\
\text { of an outcome-based contract very attractive. }\end{array}$ \\
\hline 6 & $\begin{array}{l}\text { Simple model } \\
\text { with goal } \\
\text { congruency }\end{array}$ & $\begin{array}{l}\text { Situations where goal } \\
\text { conflict between the } \\
\text { principal and the agent is } \\
\text { reduced/eliminated }\end{array}$ & $\begin{array}{l}\text { As goals are congruent, agent will behave as principal } \\
\text { would like. Thus, there is no need for monitoring. } \\
\text { Assuming agent remains risk-averse, a behaviour based } \\
\text { contract is recommended (with risk-sharing). }\end{array}$ \\
\hline 7 & $\begin{array}{l}\text { Simple model } \\
\text { with } \\
\text { programmable } \\
\text { agent } \\
\text { behaviour }\end{array}$ & $\begin{array}{l}\text { Programmability is } \\
\text { defined as "the degree to } \\
\text { which appropriate } \\
\text { behaviour by the agent can } \\
\text { be specified in advance" } \\
\text { (Eisenhardt, 1985) }\end{array}$ & $\begin{array}{l}\text { If the task(s) asked of the agent are programmable in } \\
\text { nature, they are easier to measure making behaviour- } \\
\text { based contracts the ideal selection in such cases. In } \\
\text { cases where tasks are highly programmable, we revert } \\
\text { to the complete information case. }\end{array}$ \\
\hline 8 & $\begin{array}{l}\text { Simple model } \\
\text { with un- } \\
\text { measurable } \\
\text { outcome(s) }\end{array}$ & $\begin{array}{l}\text { The simple model } \\
\text { assumes, outcomes that are } \\
\text { easily measurable, } \\
\text { however this if often not } \\
\text { the case. }\end{array}$ & $\begin{array}{l}\text { When outcomes are very difficult to measure (long time } \\
\text { to complete, require team effort or yield outcomes that } \\
\text { are unclear), outcome-based contracts become less } \\
\text { attractive and behaviour-based contracts are favoured. }\end{array}$ \\
\hline 9 & $\begin{array}{l}\text { Simple model } \\
\text { and long-term } \\
\text { relationships }\end{array}$ & $\begin{array}{l}\text { The concept of time is } \\
\text { important in relationships } \\
\text { and, as time passes, } \\
\text { information asymmetry } \\
\text { decreases and a } \\
\text { relationship strengthens. }\end{array}$ & $\begin{array}{l}\text { The longer a contract (relationship) goes on, the more } \\
\text { likely contracts are to be behaviour-based and the less } \\
\text { likely they are to be outcome-based. }\end{array}$ \\
\hline
\end{tabular}

As is evident in Table 11, principal-agent research involves a trade-off, from the principal's point of view, between the cost of monitoring the agent's behaviour and the cost of monitoring outcomes and transferring risk to the agent (Eisenhardt, 1989). This

\footnotetext{
${ }^{21}$ Adverse selection or 'misrepresentation of skills' occurs most often when the principal is unable to verify the existence of those skills in the recruitment process, typically due to an inability to understand said expertise.
} 
challenge manifests itself in two classes of problems facing principals; pre-contractual problems and post-contractual issues (Bergen, Dutta, \& Walker, 1992; Arrow, 1985).

\subsection{Pre-contractual problems in principal-agent research}

Pre-contractual problems exist at a number of levels for the principal, including finding an agent with the required characteristics, determining the specific goals they would like to gain from the relationship, and developing the strategies required to achieve those goals. These issues are all mediated by the risk preferences of the principal and take place prior to the offering of a contract.

Pre-contractual problems are addressed with the Hidden Information Agency Theory model (Bergen, Dutta, \& Walker, 1992). Under the assumption that the principal knows precisely what he or she wants accomplished and what characteristics they require in an agent, this model focuses on overcoming the fact that a principal does not possess full information concerning an agent and whether the agent actually possesses the knowledge and ability to perform what is expected. This leads directly to the recruitment and selection of agents. Bergen, Dutta and Walker (1992)'s review of literature provides three strategies that principals can adopt in this regard: (i) screening, (ii) examining signals from potential agents, and (iii) providing opportunities for agent self-selection. Screening potential agents involves a trade-off between costs incurred and information gathered. If the principal decides screening is worth the expense, they may adopt such tactics as interviews, reference checks, testing, or re-hiring agents from previous projects. In making the decision around whether to screen or not, the principal must balance the costs of screening with the risk of making an error in hiring and the related financial 
losses. The consideration of the effectiveness of screening tools for the traits sought is also important. It is important to point out that it is possible for situations to arise where both the screening costs and the learning by experience (i.e., not screening) costs are high. In these cases, both the principal and the agent may experience losses and other strategies should be considered. Agents may signal to principals that they possess some of the desired characteristics (e.g., additional training, certain skills). The principal can also provide the agent with opportunities for self-selection (Bergen, Dutta, \& Walker, 1992), which builds to the 'examining signals from agents' option. In such a case, the principal is not just a passive receiver of signals but a provider of self-selection options to the agents (e.g., willingness to follow a necessary training program) which could help the principal better locate an appropriate agent.

\subsection{Post-contractual problems in principal-agent research}

Following an agreement on the contract, post-contractual issues may also challenge the principal. The major issues here are around monitoring the agent's behaviour and determining what evaluations and reward-structures should be put in place to insure that the agent's behaviour mimics the principal's objectives. Post-contractual issues are typically addressed with the Hidden Action Agency Theory model (Bergen, Dutta, \& Walker, 1992; Picard, 1987). Such models are based on three important assumptions. First, both the principal and the agent are assumed to be motivated by selfinterest, typically focused on the maximization of profits. Bergen, Dutta and Walker (1992, p. 3) also point out that "the theory can also accommodate relationships in which one or both parties pursue broader social goals". This may be particularly relevant to 
marketing, where the parties may be involved in social marketing, green marketing or not-for-profit marketing. Second, it is assumed that principals normally function with incomplete information about the characteristics of the agent, while the agent functions with complete information about the principal. This was described earlier as 'information asymmetry'. Third, it is assumed that environmental factors (e.g., competition, the political environment, economic conditions, environment, and changes in technology) have some bearing on outcomes, which means that writing a 'perfect' contract is impossible and that both the principal and the agent incur risk.

Hidden action models have typically viewed the principal as risk neutral and the agent as risk averse (Bergen, Dutta, \& Walker, 1992), given that the agent is typically relying on the relationship for income purposes while the principal has many other options they could select. However, others (Harris \& Raviv, 1979; Picard, 1987) have considered that the agent may not always be more risk averse than the principal. Given these assumptions and the risk preferences of both parties, the literature provides strategies for the principal focused on avoiding shirking behaviour by the agent. Bergen, Dutta and Walker $(1992$, p. 3) provide the rationale to why shirking is an issue:

In the basic hidden action model, the agent attempts to maximize his or her own utility by choosing the best action available. Given the incompatible goals and risk preferences of the two parties, though, actions the principal would like the agent to perform are often relatively costly for the agent to undertake (i.e., they require more time, effort, or other resources from the agent). Hence, the agent may try to 'shirk' on such actions.

As such, Hidden Action Agency Theory provides the principal with two basic strategic thrusts by which to limit the chance that an agent might shirk on their post-contract behaviours. These are behaviour-based contracts (including monitoring systems) and 
outcome-based contracts (Bergen, Dutta, \& Walker, 1992). The contrast between the two has received attention in the literature. For example, Anderson and Oliver (1987) and Basu, Rajiv, Srinivasan and Staelin (1985) assess various sales force compensation systems (i.e., outcome-based versus behaviour-based) and provide recommendations for when to use each to maximize sales force control.

Behaviour-based contracts include such things as reporting, field observation and narrow span of control in an attempt to monitor agent behaviour and insure compliance (Bergen, Dutta, \& Walker, 1992). There are challenges with behaviour-based contracts as they are very costly to implement and cannot fully eliminate information asymmetry. On the other hand, outcome-based contracts where the agent is evaluated and rewarded based on performance measures (e.g., sales volume) seek to achieve both parties' goals based on the ideas of 'reservation utility' ${ }^{22}$ and 'individual rationality' ${ }^{23}$. The consideration of the bottom line ('payoffs') is important to both parties in developing the outcome focus of the contract, with the fact that the resulting payoffs must be relatively equal for both groups or problems will result (i.e. shirking by the agent or ending of the relationship by the principal). This is known in the literature as incentive compatibility. The challenge for the principal with outcome-based contracts is that they shift risk from themselves to the agent which, should the agent be risk averse, could be costly for the principal. Bergen, Dutta and Walker provide an example of this situation of shifting risk: Suppose, for example, that deteriorating economic circumstances make it impossible for a firm to realize its expected sales volume in the current year. A salesperson on straight salary would be unaffected, at least in the

\footnotetext{
${ }^{22}$ 'Reservation utility' involves comparison of the benefits to the agent of the current relationship as compared to the best alternative opportunity outside the current relationship (Bergen, Dutta, \& Walker, 1992).

${ }^{23}$ 'Individual rationality' refers to the fact that the contract must be interesting enough that the agent will undertake it (Bergen, Dutta, \& Walker, 1992).
} 
short term, but a salesperson on straight commission would bear some of the consequences in the form of lower income. Thus, a risk-averse agent would find the potential for earning $\$ 100$ in commissions less valuable than $\$ 100$ in salary. A risk-neutral firm [as is assumed], then, might be tempted to compensate the salesperson entirely with salary and absorb the risk. After all, the firm could pay less than $\$ 100$ in salary, leaving the salesperson perceiving himself [or herself] to be as well off as he [or she] was with a higher commission, and achieve higher expected profit. Unfortunately, the salesperson would then have less incentive to put forth substantial sales effort. In other words, a commission structure may be necessary to make it incentive compatible for the salesperson to expend the level of effort desire by the firm. (Bergen, Dutta, \& Walker, 1992, p. 10)

In summary, the key to a successful Hidden Action Agency Model is efficiently balancing the trade-off between the potential costs of shifting risk to the agent with the risk of the agent shirking their behaviours.

\subsubsection{The Positivist Branch of Agency Theory}

In general, positivist researchers are concerned with governance mechanisms which solve the agency problem (i.e., limit the agent's self-serving behaviour) and focus on the solutions that enable them to do so, given the incongruent goals of the principal and the agent (Eisenhardt, 1989; Jensen, 1983). Positivist theory tries to explain why contracts develop the way they do based on two common propositions (Jensen, 1983; Eisenhardt, 1989).

Table 12: Two Propositions of Positivist Theory (adapted from Eisenhardt, 1989)

\begin{tabular}{|l|l|l|}
\hline Basic Meaning & Theoretical Merit & Eisenhardt (1989) Proposition \\
\hline $\begin{array}{l}\text {...that outcome-based contracts } \\
\text { are effective in curbing agent } \\
\text { opportunism (Eisenhardt, 1989) }\end{array}$ & $\begin{array}{l}\text { Based on premise that contracts } \\
\text { work to align goals of the agent and } \\
\text { the principal since rewards for both } \\
\text { are then dependent upon the same } \\
\text { action, reducing conflicts of self- } \\
\text { interest. }\end{array}$ & $\begin{array}{l}\text { "When the contract between the } \\
\text { principal and agent is outcome } \\
\text { based, the agent is more likely to } \\
\text { behave in the interests of the } \\
\text { principal" }\end{array}$ \\
\hline
\end{tabular}


...that the implementation of information systems will also work to reduce agent shirking (Jensen, 1983)
Information systems inform the principal about agent behaviour, thus reducing shirking by the agent.
"When the principal has information to verify agent behaviour, the agent is more likely to behave in the interests of the principal"

As demonstrated by Table 12, positivist theory offers a more sophisticated view of an organization than traditional economic theory (Jensen, 1983).

In terms of its application, however, the positivist branch of Agency Theory has been concerned mostly with intra-organizational relationships (i.e., owners and management in large corporations) and in designing efficient governance mechanisms for these principal-agent relationships. Although it has a narrower focus and is considerably less formal and mathematical in its application (Eisenhardt, 1989), the positivist branch is somewhat similar to the post-contractual Hidden Action models of Agency Theory (Bergen, Dutta, \& Walker, 1992). A point of difference is that the positivist branch adopts the assumption that agents are risk neutral (as opposed to risk averse); (Bergen, Dutta, \& Walker, 1992; Williamson, 1988).

Empirically, literature in the positivist branch typically explores design structures that induce managers to act in the interests of shareholders, often supporting the notion of incentive plans motivating executives to generate shareholder wealth. Fama (1980) looks at the information effects of efficient capital and labor markets as mechanisms to control managerial opportunism. Fama and Jensen (1983) focus on boards of directors as information systems, describe how they function in large organizations, describe how they act to control management behaviour, and propose methods by which shareholders can use boards of directors to monitor the opportunism of top management and, in turn, reduce shirking. Jensen (1983) identified practices which could be better handled through 
increased board of director functioning, such as golden parachutes ${ }^{24}$ and corporate raiding ${ }^{25}$. Jensen and Meckling (1976), in their review of corporate ownership as an example of a principal-agent relationship, highlight how stock-options for management work to align management and ownership goals. In fact, they argue that firm ownership by management decreases management opportunism (Jensen \& Meckling, 1976).

\subsubsection{Comparison of Principal-Agency Research and Positivist Theory}

The complementary nature, similarities and differences of the two streams of Agency Theory are clear in the literature. The following table summarizes.

Table 13: Principal-Agency Research versus Positivist Theory

\begin{tabular}{|l|l|}
\hline Similarities & $\begin{array}{l}\text { - Both view the contract as the unit of analysis } \\
\text { - The positivist branch is similar to the post-contract or Hidden Action } \\
\text { models of principal-agent research (Bergen, Dutta, \& Walker, 1992) }\end{array}$ \\
\hline Differences & $\begin{array}{l}\text { - To date, there is more research/empirical studies in principal-agent } \\
\text { research } \\
\text { - Principal-agent research is more abstract (Eisenhardt, 1989) } \\
\text { - Principal-agent research is more mathematical (Eisenhardt, 1989) } \\
\text { - The majority of critics of Agency Theory target principal-agent } \\
\text { research in their criticisms (Perrow, 1986) } \\
\text { - Positivist theory focuses almost exclusively on the shareholder- } \\
\text { executive relationship in large, multi-national organizations } \\
\text { - Principal-agent research has a broader focus and more generalizeable } \\
\text { theoretical implications (Eisenhardt, 1989) } \\
\text { - From a research point of view, principal-agent research "includes } \\
\text { many more testable implications" (Eisenhardt, 1989) }\end{array}$ \\
\hline Complementary & $\begin{array}{l}\text { The two streams complement each other as follows: positivist theory } \\
\text { specifies various contract alternatives, while principal-agent theory } \\
\text { follows and determines the most efficient contract based on the human, } \\
\text { organizational and information assumptions in Agency Theory. }\end{array}$ \\
\hline
\end{tabular}

\footnotetext{
${ }^{24} \mathrm{~A}$ golden parachute refers a generous severance package of cash and stock options paid to executives following a dismissal, a merger or downsizing.

${ }^{25}$ Corporate raiding occurs to when a company unethically overtakes another by hiring away employees, stealing information and making side-deals.
} 


\subsection{Theory development: Agency Theory and sponsorship}

This section argues that Agency Theory is appropriate for sponsorship evaluation. Bergen, Dutta and Walker (1992) suggest that Agency Theory is most productive in analyzing four particular marketing situations:

1. where substantial goal conflict between a principal and its agents exists,

2. where there is sufficient environmental uncertainty to trigger the risk-sharing implications of Agency Theory,

3. where significant information asymmetries exist, and/or

4. where there is difficulty in evaluating performance.

Sponsorship meets all four of these criteria. First, sponsors and sponsees often have very different goals, which could cause conflict around how the resulting association is promoted. Second, given the cluttered marketplace and highly competitive environment, environmental uncertainty is very common in sponsorship. Third, the vast majority of sponsorship relationships fall under the typical sponsee scenario where the sponsor holds the balance of power and where information asymmetry exists. Fourth, sponsorship evaluation has been confirmed to be a difficult task. This is evident for all sponsees; particularly in the case of the mega-sponsee, where attributing success is very difficult. 


\subsubsection{Agency Theory, mega-sponsees and typical sponsees}

The two sponsee scenarios are presented in the following table from an Agency Theory perspective to outline the differences between a mega-sponsee and a typical sponsee from an Agency Theory perspective.

Table 14: Scenarios of the Sponsor-Sponsee Relationship

\begin{tabular}{|l|l|l|l|l|l|}
\hline $\begin{array}{l}\text { Case of Sponsor- } \\
\text { Sponsee } \\
\text { Relationship }\end{array}$ & Power & $\begin{array}{l}\text { Proportion of } \\
\text { Sponsorships }\end{array}$ & $\begin{array}{l}\text { Monitoring \& } \\
\text { Leveraging }\end{array}$ & $\begin{array}{l}\text { Driving } \\
\text { objectives }\end{array}$ & $\begin{array}{l}\text { Analogy to } \\
\text { Common Agents }\end{array}$ \\
\hline Mega-Sponsee & Sponsee & Very rare & Both & Both & CEO \\
\hline Typical Sponsee & Sponsor & Majority & Sponsor & Sponsor & $\begin{array}{l}\text { Average } \\
\text { employee }\end{array}$ \\
\hline
\end{tabular}

\subsubsection{Agency Theory, the sponsorship contract, and the sponsor-sponsee relationship}

Agency Theory focuses attention on the sponsorship contract as the unit of analysis when evaluating a sponsor-sponsee relationship. Most sponsorship contracts include both explicit (formal) and implicit (informal) parts with the explicit aspects being those that are included in the contract while implicit aspects are understood but are not written. Agency Theory requires researcher knowledge of all aspects of the sponsorship contract both explicit and implicit, including both sponsor and sponsee objectives. Methodologically, all contracted and implicit expectations of a sponsorship contract can be articulated from both the sponsor's and the sponsee's points of view. Of course, full access to data and decision-makers is required. Further, in most sponsorships, the promotional impact of the association and the risk attitudes of the sponsor and the sponsee must be considered. This is often accomplished by understanding the valuetransfer from sponsee-to-sponsor and sponsor-to-sponsee. Figure 4 was developed to 
reflect these points and provide a schematic of the principal-agent version of the sponsorsponsee relationship.

Figure 4: The Sponsorship Relationship

\section{Sponsorship Relationship}
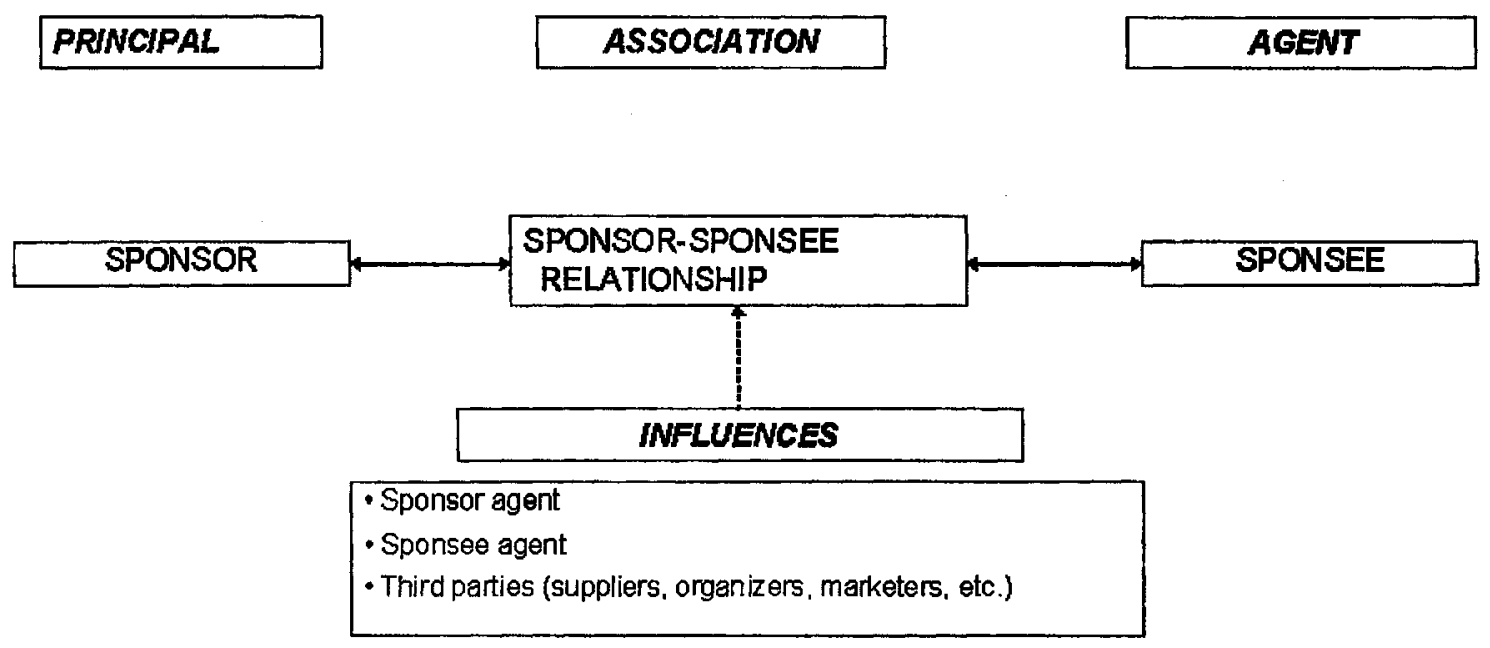

As noted in Figure 4, the targets of a sponsorship's messaging are exposed to three promotional entities: the sponsor (principal), the sponsee (agent), and the sponsorsponsee relationship (association). An additional key point (outlined in Table 15 below) is that a sponsor-sponsee relationship can take on a number of forms in terms of involved stakeholders.

Table 15: Basic Typology of Sponsors, Sponsees and Intermediaries

\begin{tabular}{|l|l|}
\hline Scenario & Example \\
\hline Sponsor-Sponsee & Local Bike Store sponsors Local Athlete \\
\hline Sponsor-Agent-Sponsee & $\begin{array}{l}\text { Coke engages a Sport Marketing Firm to use } \\
\text { Sponsorship to achieve some promotional goal }\end{array}$ \\
\hline $\begin{array}{l}\text { Sponsor-Agent-Mega } \\
\text { Sponsee }\end{array}$ & $\begin{array}{l}\text { The Super-Bowl hires a Sponsorship Consultant to } \\
\text { maximize their revenues from sponsorship }\end{array}$ \\
\hline
\end{tabular}




\begin{tabular}{|l|l|}
\hline $\begin{array}{l}\text { Sponsor-Agent-Agent- } \\
\text { Sponsee }\end{array}$ & $\begin{array}{l}\text { Both sponsor and sponsee have engaged agents on their } \\
\text { behalf }\end{array}$ \\
\hline $\begin{array}{l}\text { Sponsor-Agent-Agent-Mega } \\
\text { Sponsee }\end{array}$ & $\begin{array}{l}\text { Both sponsor and sponsee have engaged agents on their } \\
\text { behalf; and the sponsor is a major property like the } \\
\text { Olympic Games }\end{array}$ \\
\hline
\end{tabular}

\subsubsection{Agency Theory phases in sponsorship}

Agency Theory also reveals that two series of issues (pre-contract and postcontract) arise in any principal-agent situation (Eisenhardt, 1989). In the case of the sponsor-sponsee relationship, then, the theory requires focus on both the pre-sponsorship contract negotiations (from the perspectives of each the sponsor and the sponsee) and the implementation of the sponsorship post-contract. Table 16 below outlines the pre- and post-contract sponsorship phases for both sponsor and sponsee, revealing three distinct phases.

Table 16: Agency Theory Phases in Sponsorship

\begin{tabular}{|l|l|l|l|}
\hline$\#$ & Phase & Agency Theory Model & Description \\
\hline 1 & $\begin{array}{l}\text { Pre-Contract } \\
\text { (Sponsor) }\end{array}$ & Sponsee Selection & $\begin{array}{l}\text { Investor has decided to include sponsorship in } \\
\text { marketing mix }\end{array}$ \\
\hline 2 & $\begin{array}{l}\text { Pre-Contract } \\
\text { (Sponsee) }\end{array}$ & Sponsor Attainment & $\begin{array}{l}\text { Sponsee has objectives to fulfill for which the } \\
\text { interested sponsor is a good fit }\end{array}$ \\
\hline 3 & $\begin{array}{l}\text { Post-Contract } \\
\text { (Sponsor \& } \\
\text { Sponsee) }\end{array}$ & Sponsorship Activation & $\begin{array}{l}\text { Contract is in place, sponsor (or mega-sponsee in } \\
\text { scenario with powerful sponsee) implements and } \\
\text { leverages the sponsorship to maximize return }\end{array}$ \\
\hline
\end{tabular}

\subsubsection{Agency Theory, risk and sponsorship}

Much Agency Theory literature (Bebchuk \& Fried, 2003; Bergen, Dutta, \& Walker, 1992; Sappington, 1991) views the principal as risk neutral and the agent as risk averse. The agent is typically risk averse because they rely on the relationship for resource generation while the principal typically has many other alternative courses of 
action to generate resources. Applied to the 'typical' sponsor-sponsee relationship, the sponsee is believed to be risk averse and the sponsor risk neutral, since the sponsee relies on the sponsor for revenue while the sponsor has many alternate options (i.e., competing sponsees) to achieve their promotional objectives. Conversely, when applied to the 'mega' sponsor-sponsee relationship, the sponsor is believed to be risk averse and the sponsee risk neutral, since the sponsor relies on the mega-sponsee for the unique promotional value it provides while the sponsee has numerous alternative sources (i.e., competing sponsors) for revenue generation.

\subsubsection{Agency Theory, imperfect surveillance and sponsorship}

Agency Theory focuses attention on outcomes and end-goals, although they may be enduring and continue for long periods of time (Sappington, 1991). In this regard, external influencers (e.g., power, trust, time) must be considered in any agency relationship where full surveillance of the agent by the principal is not possible. This is necessary in sponsorship as imperfect surveillance is common in the sponsor-sponsee relationship. For example, Berrett and Slack (1999) show that the sponsorship activities of rival companies are influential to a sponsor's selection of a sponsee, implying that some organization's are taking a 'copy-cat' approach to sponsorship. They, and others, further argue that the sponsor must seek to foster a relationship to help prevent other sponsors from either taking the association for themselves in the future (i.e., outbid) or ambushing the sponsorship (Crompton, 2004b; Berrett \& Slack, 1999; Shani and Sandler, $1998 ; 1993 ; 1989)$. 


\subsubsection{A model of Agency Theory in sponsorship}

Figure 5 below represents the theoretical development of the Agency Theory situation (from Eisenhardt, 1989) adapted to the sponsorship relationship.

Figure 5: Agency Theory adapted to the Sponsorship Relationship (Eisenhardt, 1989 (adapted))

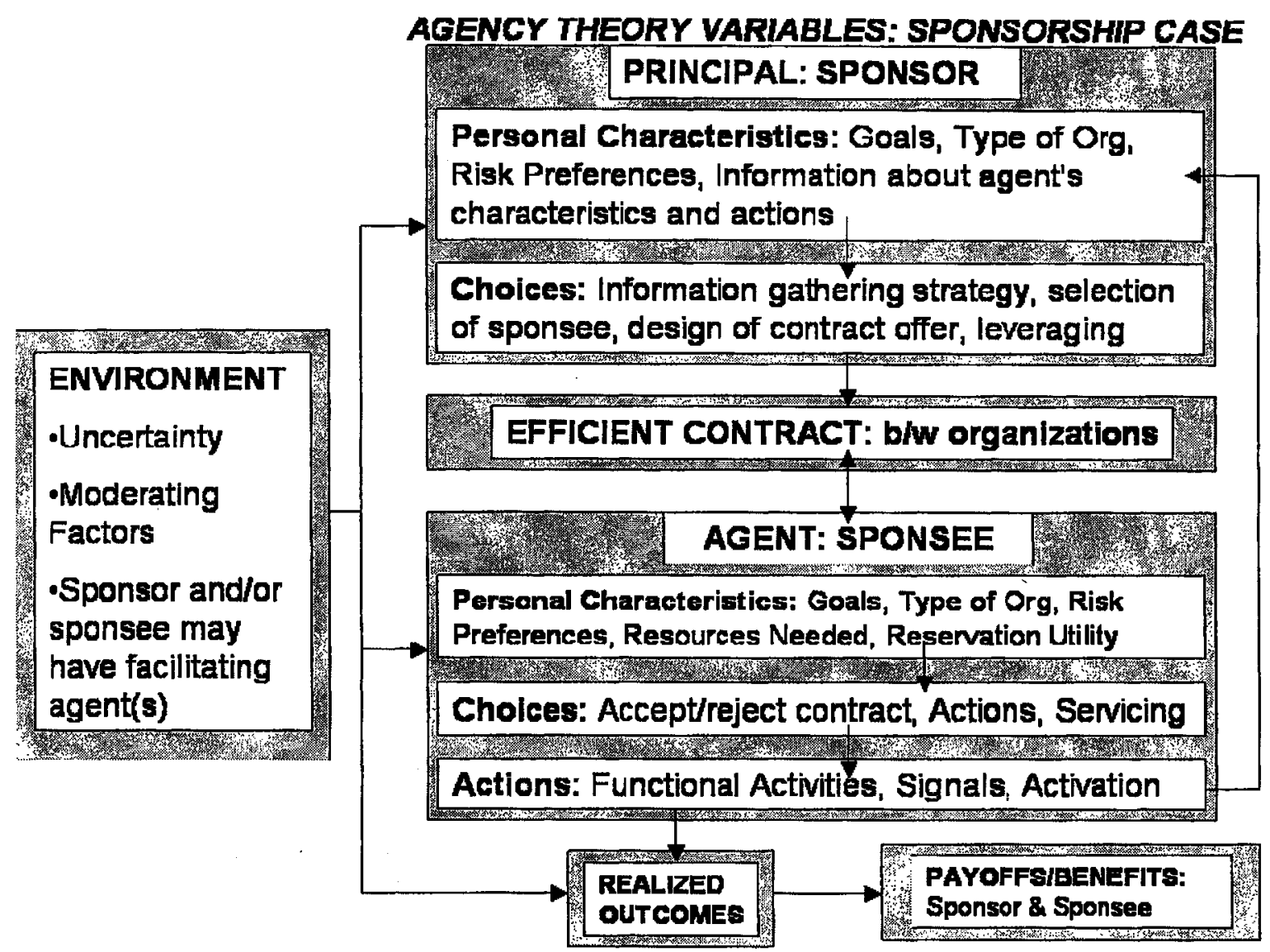

As described in the previous sections, Figure 5 is built around the focus of an efficient ${ }^{26}$ contract (both explicit and implicit) that both parties, with their own characteristics, choices and actions, seek in the context of the very uncertain sponsorship environment. As Agency Theory's unit of analysis, an efficient contract between the sponsor and

\footnotetext{
${ }^{26}$ An 'efficient' contract in Agency Theory refers to one which allows for both the principal and the agent to achieve their respective objectives in the most facilitated way possible.
} 
sponsee determines the nature of the relationship. The development of the contract (both explicit and implicit) is a blend of (i) the interests (personal characteristics) and strategic decisions (choices) of the sponsor, (ii) the interests (personal characteristics), needs (actions) and strategic decisions (choices) of the sponsee, and (iii) the realities of the environment. Following the sponsorship, its outcomes (i.e. achievement of objectives) are assessed, the benefits to each party determined and the contract is renewed, altered or deleted.

\subsubsection{Sponsorship evaluation and Agency Theory}

Agency Theory provides a lens by which to evaluate a sponsor's investment in a sponsee and the resulting relationship's ability to achieve both the sponsor's and the sponsee's specific promotional objectives. Here, Agency Theory can respond to a need in sponsorship evaluation by providing the theoretical framework that both academics and practitioners seek that will enable the viable measurement of sponsorship effectiveness. An Agency Theory approach to sponsorship evaluation infers a principal-agent relationship. In terms of measurement, Agency Theory would view the sponsor as the principal and the sponsee as the agent, with the sponsorship contract as the unit of analysis. Once the contract is signed, a 'principal as sponsor' situation results and the principal assumes the role of ensuring the sponsee meets its contractual commitments. The sponsorship contract refers to both the tenets of the formal written contract and the understood but unwritten aspects of the relationship; namely the informal contract. Examples of informal contracts include (i) the understanding that the sponsee will act in 
the best interests of the sponsor and (ii) that logos of competitors of the sponsor will not be seen on participants' clothing.

Agency Theory focuses an evaluation on the objectives of the sponsor and the sponsee, as well as any relevant intermediaries. The theory requires the evaluator to examine the sponsorship contract(s) for evidence of the objectives of all parties. It also requires that the evaluator learn about the objectives of all parties that may come into play that are not listed in any formal contracts.

\subsubsection{Draft Process model of Sponsorship Evaluation}

A draft process model for sponsorship evaluation is presented below as Figure 6. It is important to note that the proposed model is a tool which outlines a process to follow in evaluating any given sponsorship. The purpose of the model is to guide researchers and practitioners through the evaluation process in a manner which respects the sponsorship relationship and its uniqueness. It is intended to be applicable to evaluating a wide range of sponsees; be they sport, art, culture, charity, public, private or corporate.

The proposed process model is based on Agency Theory in its construction and the specifics of sponsorship evaluation and performance measurement in its detail. As dictated by Agency Theory, the unit of analysis is the contract. The fact that the process model is rooted in the objectives (implicit and explicit) of both the sponsor(s) and sponsee(s) and does not include other un-related outcomes or impacts follows an Agency Theory perspective. The consideration of resources and activities committed by the sponsor as principal is a reflection of Agency Theory's focus on monitoring the costs of the principal towards eliminating shirking by the agent (sponsee). The operational 
definition of a sponsorship, which determines if a promotional endeavour is a sponsorship or not, is built into the model and includes the criterion that the sponsorsponsee relationship must be a principal-agent relationship. As well, the importance of external influences and the link to the market are both drawn from Agency Theory. Finally, and most importantly, Step 1 (Setting the Stage) uses an Agency Theory lens to build the relationship, determine if it is a sponsorship and set the basis for an efficient and effective evaluation.

The process model is comprised of seven steps. The steps are 'set the stage', 'collect data', 'articulate objectives', 'establish metrics', 'determine metrics for resources and reach', 'collect and analyze data', and 'generate and interpret outcomes and impacts'. As noted in Figure 6, the model also considers the effects of the specific sponsor-sponsee relationship, the market and other uncontrollable external influences during the evaluation process.

The first step is a pre-cursor to the evaluation which sets the stage for an efficient and effective evaluation. First, the sponsorship is selected or offered for evaluation. It is then assessed against the working definition, the key entities (sponsor, sponsee, intermediaries) are identified and the objectives and metrics are forecasted. All of these steps are undertaken to make sure that the evaluation can be effective. If so, the evaluation would continue. If not, the evaluation would stop. If it is appropriate to continue, the research then works to build a relationship with the sponsor, the sponsee and, if necessary, the intermediaries, Upon completion, a decision is made (Go/No-Go) whether to go ahead with the evaluation or not. 
In the second step, 'collect data', the researcher accesses four key sources of data (the sponsorship contract, sponsor input, sponsee input and, if applicable, intermediary input) to enable the evaluation. The types of data gathered here would typically include the specific objectives of the sponsorship, the role of the sponsorship in the overall marketing plan of the sponsor or the sponsee, image transfer goals of the association, etc.

The third step focuses on reviewing the data gathered in Step 1 and articulating, summarizing and listing all objectives for the sponsorship. This step is known as 'articulate objectives' and likely includes two sets of objectives: (i) those that are explicitly stated and (ii) those that are implicitly understood but perhaps not articulated in the contract. Of specific note here is the link to the performance measurement concept of 'reach' which refers to the consideration of all the markets reached by each objective. An objective with multiple publics would end up with multiple metrics measuring all of those publics.

Upon completion of the third step, the 'establish metrics' stage (Step 4) takes place. This involves the assignment of a specific metric or metrics (either from the literature, past practice or newly developed) for each objective identified in Step 3. Each metric, whether adopted from past use or newly developed, is then customized to the sponsorship relationship being evaluated and a research design is planned for each. For example, this implies that if 17 objectives are identified in the 'articulation of objectives' step, then at least 17 metrics must be developed. Metrics are not included unless they relate specifically to an identified objective.

The fifth step, 'determine metrics for resources and shirking', stems from the performance management and Agency Theory literatures and involves an assessment of 
two specific resource-based items for the sponsor and potentially for the sponsee: inputs and activities, as well as a consideration of outputs unrelated to the objectives identified in Step 3 which may indicate sponsee shirking. With respect to inputs and activities, this refers to determining, respectively, the ways by which to measure the resources committed (financial, in-kind and human) and the leveraging activities undertaken. Specific to the resulting outputs which are unrelated to the identified objectives, the Agency Theory concept of shirking is measurable by the resources committed by the sponsee to outputs not sought by the sponsorship.

Step 6, the 'collect and analyze data' stage is next. This involves the implementation of each of the metrics identified in Step 3 and Step 5, including both data collection and analysis of that data. The researcher gathers evaluation data, and analyzes that data for each of the metrics. Research might include a survey of consumers, attendees at an event, or employees of a sponsor.

This leads to the final step 'generate and interpret outcomes and impacts' where the results of the analysis are considered cumulatively and presented for each metric with an overall assessment of effectiveness. Effectiveness, based on performance measurement models, is articulated as outcomes (what happened) and impacts (what does it mean for the markets concerned). Further, these benefits are contextualized against the costs to achieve them.

The draft process model (version D1) follows on the next page. 
Figure 6: Draft Process model of Sponsorship Evaluation: Process model DI

\section{Process Model: Sponsorship Evaluation}

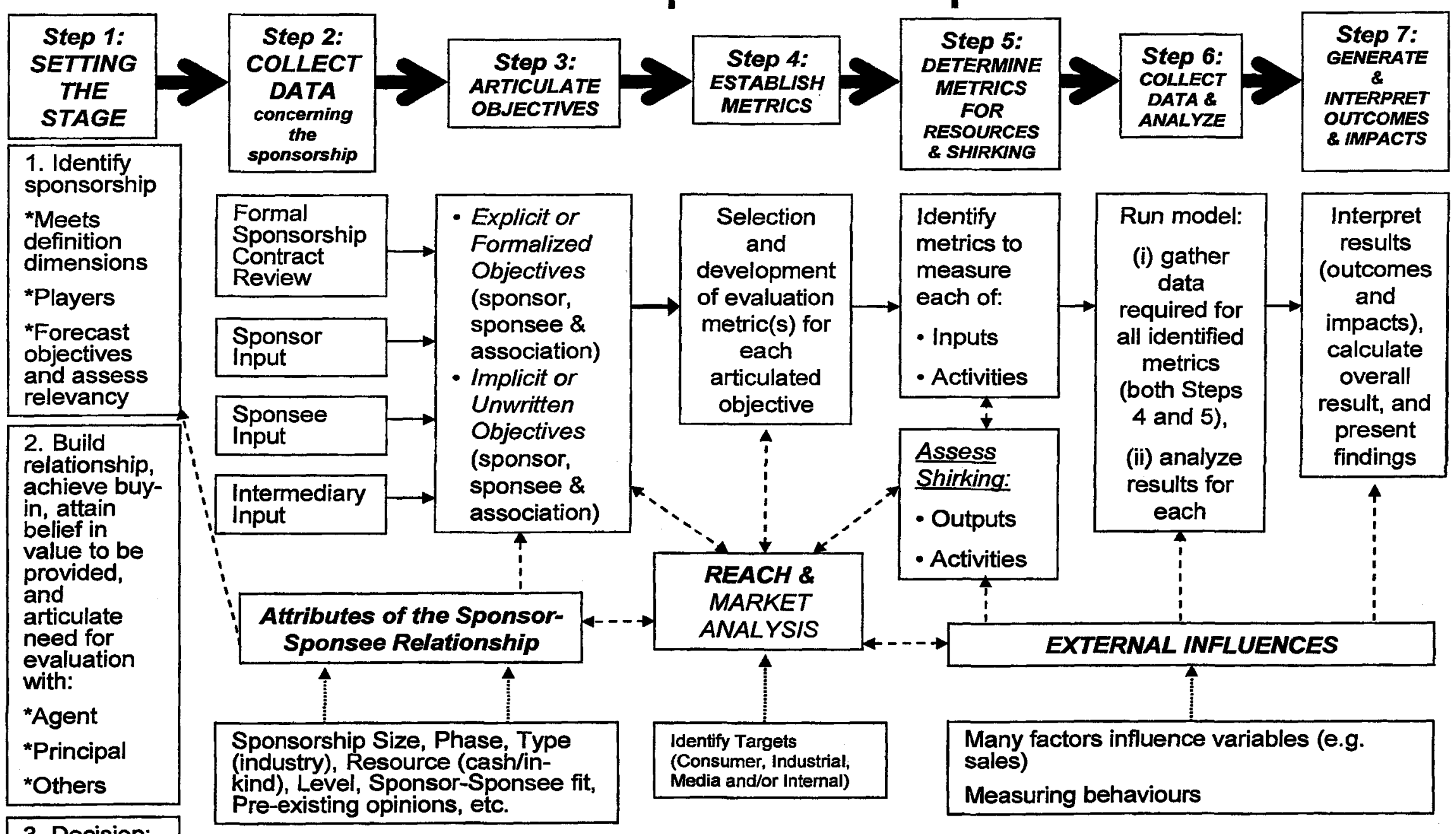




\subsection{Chapter Summary}

This chapter develops the theoretical framework for this dissertation. First, it selects Agency Theory from a number of theories on business relationships as the theoretical framework for this research. An overview of Agency Theory is then presented, along with discussions on its scope, its assumptions, its unit of analysis (the contract), its important aspects (monitoring, information, risk preference, self-interest and incentives), and its two branches (principal agent and positivist research). The scope of Agency Theory is particularly important to this dissertation as it is shown to accommodate sponsorship and the evaluation of sponsorship. The review of the Agency Theory literature supported this position strongly and outlined the four major tenets of Agency Theory that have influenced its development significantly. First, Agency Theory involves ensuring that the agent acts in the interests of the principal (Bahli \& Rivard, 2003). Second, it assumes that each party (principal and agent) in the relationship has its own profit motive since their goals are not congruent (Eisenhardt, 1989). Third, agency theorists are always aware that the principal-agent relationship may be influenced by two factors; (i) the case of asymmetric information between principal and agent, and (ii) the possibility of random external factors or events (Bergen, Dutta, \& Walker, 1992). Finally, it is known that the principal cannot monitor the actions of the agent perfectly or without costs (Sappington, 1991).

The chapter then focused on the theoretical development of Agency Theory and sponsorship. This process involved developing many of the key concepts of Agency Theory in the context of the sponsor-sponsee relationship, including articulating an agency perspective on (i) the sponsorship contract, (ii) the two sponsee scenarios (typical 
and mega), (iii) risk, (iv) time, and (v) imperfect surveillance. The theory development is captured by the adapted model of Agency Theory in sponsorship presented in section 4.3.6. Most importantly, the theory development continues with sponsorship evaluation and Agency Theory. This work clearly demonstrates how an Agency Theory approach to sponsorship evaluation will be beneficial to theory and practice by establishing a draft process model for sponsorship evaluation. 


\subsection{METHODOLOGY}

This chapter outlines the methodology followed to address the main objective and four sub-objectives of this dissertation. A two-phase methodology was implemented. Phase I involved qualitative study in the form of expert interviews while Phase II built on the results of Phase I with two in-depth sponsorship evaluation case studies.

For Phase I, a qualitative study was adopted since an in-depth, yet exploratory, understanding of evaluation in sponsorship was required. A number of alternative qualitative and quantitative methodologies were considered. Expert interviews were selected over alternate qualitative methods (i.e., observation, ethnography and focus groups) as they offer the best opportunity to fully understand a topic with limited empirical-based literature within a dynamic marketplace because they (i) provide detailed, in-depth data and (ii) are based on the views of experts in the area (Yin, 2003; Patton, 1980). Expert interviews were selected over alternative quantitative methods (i.e., surveys) as they (i) provide a smaller yet more appropriate sample of experts, and (ii) yield in-depth data that is more suited to the issue given the current lack of clarity on sponsorship evaluation in the literature and in practice (Yin, 2003).

Phase II involves sponsorship evaluation case studies. "A case study is an empirical inquiry that investigates a contemporary phenomenon within its real-life context" (Yin, 1994). Case study based research has been shown to be an effective method by which to develop theory (see Eisenhardt, 1989b), particularly in industrial (B2B) marketing (Woodside \& Wilson, 2003). Notably, sponsorship is often a B2B marketing activity where a case study method allows for "deep understanding of the 
actors, interactions, sentiments, and behaviors occurring for a specific process" (Woodside \& Wilson, 2003, p. 497).

\subsection{Phase I: Qualitative Interviews with Experts in Sponsorship}

In Phase I of the research, 14 interviews were conducted with experts in sponsorship. The adoption of the expert interview as a research methodology has precedence in the literature as past research has used the method to make key findings in applied marketing (O'Reilly \& Madill, 2007; Chalip \& Leyns, 2002; Lachowetz \& Irwin, 2002; Strauss \& Friege, 1999) and sponsorship research (e.g. Jalleh, Donovan, GilesCorti \& Holman, 2002; Hoek, Gendall, Jeffcoat \& Orsman, 1997). The expert interviews were implemented to respond to the four sub-objectives and major objective of this dissertation. The four sub-objectives involved improving knowledge of key aspects of sponsorship evaluation. First, improved understanding of the sponsor-sponsee relationship was sought with implications for image transfer, leveraging, exclusivity, sponsee selection, sponsor attainment and activation. Second, an improved understanding of current practices in sponsorship evaluation was undertaken to help identify metrics ${ }^{27}$ currently being used. Third, a deeper understanding of the sponsor-sponsee relationship was sought through the articulation of the barriers to evaluation, the fears around evaluation, and the benefits that evaluation provides. Fourth, a deeper understanding of the timing of evaluation was sought to shed light on metric identification, and the implementation or activation of sponsorship. Based on these results, the process model was refined (the major objective).

\footnotetext{
${ }^{27}$ The term 'metric' is used in this dissertation to refer to any method of assessing the effectiveness of a sponsorship to achieve a given objective.
} 
Fourteen (14) Canadian experts were selected based on (i) their level of expertise in sponsorship ${ }^{28}$, (ii) their willingness to participate, and (iii) an assessment of the roster of suggested interviewees, as developed by the researcher. The 14 interviewees were selected from an original roster of $30^{29}$ that was put together based on (i) each individual's experiences, (ii) the representation of sponsors, sponsees and intermediaries, (iii) logistics, and (iv) referrals from industry contacts. Each of the selected experts was contacted in order to set up interview appointments, and then interviewed by the doctoral researcher between March 27 and May 5, 2006. The relevant expertise of each expert was researched pre-interview (secondary data analysis) and verified during the interview. Questions were scripted in order to access with as much depth as possible the experts' knowledge of sponsorship, sponsorship evaluation and the sponsor-sponsee relationship. The format involved the posing of a scripted question followed by an opportunity for open discussion. The interview protocol is appended (Appendix B).

All 14 interviews were conducted face-to-face in various locations across Canada (Calgary, Edmonton, Mississauga, Ottawa, St. Catherines, Toronto, Vancouver) in English (13) or French (1). The interviews took between 25 and 80 minutes. On a number of occasions, follow-up discussion about the draft process model continued postinterview over lunch. Each interview was audio recorded, transcribed and analyzed. Each of the first four objectives of Phase I was addressed by the scripted questions and feedback on the process model was achieved at the end of the interviews. In many cases, the interviewee requested the model by email and provided additional feedback by email

\footnotetext{
${ }^{28}$ The known level of expertise of clients resulted from experiences of the doctoral researcher, the supervisor of this dissertation, or on the recommendation of an industry contact or another expert interviewee.

${ }^{29}$ Note that the selection of 14 of 30 is not reflective of non-response bias but is simply a function of resources (time, travel budgets, etc.). In fact, only one potential interviewee declined the offer.
} 
and/or phone in the weeks following the interviews. Detailed information on the expert respondents, their experience and roles in the sponsorship industry is provided in section 6.1 .

\subsection{Phase II: Sponsorship Evaluation Case Studies}

Phase II of the research involved implementing the process model to evaluate two sponsorship case studies. The use of case studies often involves multiple research methods within the case itself (Yin, 2003: Patton, 1980) and has recently been adopted to build theory in social marketing (O'Reilly \& Madill, 2007) and technology in marketing (O'Reilly \& Rahinel, 2006). Here, the implementation of the process model was designed specifically (i) to assess the practical effectiveness of the process model, (ii) to allow the

researcher to determine whether the process model could be implemented in practice, (iii) to learn about its strengths and weaknesses, (iv) to learn about the key issues, challenges and benefits associated with its implementation and (v) to build researcher knowledge in order to refine the model. The sponsorship evaluation case studies carried out in this dissertation were:

i) The ATB Bank sponsorship of the Edmonton Grand Prix

ii) The 2005 Kanatek Expedition to Mount Everest

In understanding the new process model, it is important for researchers to recognize the difficulty in identifying and selecting sponsorship evaluation case studies. In fact, the ability to find sponsorships is based on (i) the researcher's network or (ii) the researcher's ability to speak to industry conferences about sponsorship evaluation. Further, the researcher must be able to convince sponsors and sponsees of the value of the evaluation. 
It is only then that serious discussions about an evaluation may take place. For this dissertation, the doctoral researcher has strong ties to industry and speaks regularly at conferences. This allowed for the identification of four potential sponsorships ${ }^{30}$ for evaluation; two of which are included in this evaluation. The two not included (International Hotel Groups - Canadian Football League and Calgary Stampede - CocaCola) did not proceed past Step 1 of the Process Model.

The ATB and Kanatek sponsorship evaluation case studies developed in very different ways as outlined in sections 6.2 .1 and 6.2.2, respectively. Both, however, had a number of key points in common that allowed for an evaluation: (i) each includes sponsors and sponsees with sophisticated objectives; (ii) in both cases, access to good data existed; (iii) in both cases, an interested and cooperative industry partner existed; and (iv) each sponsor met all ten dimensions of the operational definition of sponsorship (see section 2.1.3) as outlined in Table 17 below.

\section{Table 17: Proposed Cases \& Dimensions of Operational Definition of Sponsorship}

\begin{tabular}{|l|c|c|}
\hline Dimensions of Operational Definition & Kanatek & $\boldsymbol{A T B}$ \\
\hline $\begin{array}{l}\text { One party (the sponsor) invests resources in another party (the sponsee), where: } \\
\text { a. the sponsee provides promotional value in return, and } \\
\text { b. the sponsor makes the investment in order to achieve image-based, brand-based } \\
\text { and/or media-based objectives. }\end{array}$ & $\mathrm{X}$ & $\mathrm{X}$ \\
\hline $\begin{array}{l}\text { The relationship between the sponsor and the sponsee is a principal-agent } \\
\text { relationship, where the sponsee provides a service to the sponsor. }\end{array}$ & $\mathrm{X}$ & $\mathrm{X}$ \\
\hline Joint sponsor-sponsee activities are part of the sponsorship. & $\mathrm{X}$ & $\mathrm{X}$ \\
\hline $\begin{array}{l}\text { Consumers (or members of the target market of the promotion) are exposed to } \\
\text { three specific entities: the sponsor's brand, the sponsee's brand and the sponsor- } \\
\text { sponsee association. }\end{array}$ & $\mathrm{X}$ & $\mathrm{X}$ \\
\hline $\begin{array}{l}\text { Consumers (or members of the target market of the promotion) consider the } \\
\text { sponsor of a given sponsee to be a partner of that sponsee, and this consideration } \\
\text { lasts longer than the sponsorship due to the goodwill or emotional ties that } \\
\text { consumers build over time. }\end{array}$ & $\mathrm{X}$ & $\mathrm{X}$ \\
\hline The sponsor-sponsee association is exploited or leveraged by one or both parties. & $\mathrm{X}$ & $\mathrm{X}$ \\
\hline
\end{tabular}

\footnotetext{
${ }^{30}$ Potential sponsorship here refers to those that went beyond noting that the sponsorship exists and includes those where the researcher and partner(s) began seriously exploring an evaluation.
} 


\begin{tabular}{|l|c|c|}
\hline $\begin{array}{l}\text { The transfer of elements of the sponsee's image to the sponsor is of interest to the } \\
\text { sponsor. }\end{array}$ & $\mathrm{X}$ & $\mathrm{X}$ \\
\hline The exclusivity of the sponsorship is of interest to the sponsor. & $\mathrm{X}$ & $\mathrm{X}$ \\
\hline Congruency (fit) between the sponsor and the sponsee is important to both parties. & $\mathrm{X}$ & $\mathrm{X}$ \\
\hline $\begin{array}{l}\text { Philanthropy is not the primary objective of the sponsor (i.e. the investor has non- } \\
\text { philanthropic expectations from the sponsorship). }\end{array}$ & $\mathrm{X}$ & $\mathrm{X}$ \\
\hline
\end{tabular}

Methodologically, each of the sponsorship evaluation case studies followed the 7 steps of the process model presented in section 4.3.7.1. Given the nature of the process model, the implementation leads to results that are unique to the sponsorship and that includes metrics developed specifically for the objectives identified in that specific sponsorship. The resulting methods for each objective included both qualitative (interviews) and quantitative (surveys) procedures conducted in time and resource limited environments which did not allow for pre-tests and did require short questionnaires. The complete methodological details and accompanying results are presented jointly for each of the sponsorship evaluation case studies (see sections 6.2.1 and 6.2.2). It is also important to note the timing around the sponsorship case studies as the outcomes and impacts of sponsorship could be measured over many years. For this research, outcomes and impacts were measured up to October $30^{\text {th }}, 2006$.

It is also important to recognize the challenge that exists in presenting multiplemethod case studies of a high level of complexity. Two methods of presentation were attempted, with the second being adopted. First, the dissertation was written in the traditional fashion with a complete methodology followed by presentation of results and analysis in a subsequent section. This resulted in a document with considerable repetition, added length and confusion due to repetition. This was deemed ineffective. Second, these chapters were re-written to include a brief methodology section followed by a chapter that included methods, results and analysis together. This philosophy was adopted from 
Woodside and Wilson (2003) as an integrative way of presenting a case study that allows for better understanding of the learning provided by each case study. The approach is further supported by Stake (1995) whose text titled The Art of Case Study Research provides examples of presented case study research in a fashion similar to that adopted here and focuses on his concept of the unique case as an "integrated system" (p. 2). He further supports the approach taken for this dissertation by noting that a "case study is the study of the particularity and complexity of a single case, coming to understand its activity within important circumstances" (Stake, 1995, p. ix) and that "a 20 - page case is likely to run 50 if the researcher doesn't 'ruthlessly winnow and sift'" (Stake, 1995, p. 121).

Following the completion of each sponsorship evaluation case study, the process model was refined based on what was learned about the practical effectiveness, usability, strengths, weaknesses, challenges and benefits of the process model.

\subsubsection{Articulation of Objectives, Metrics and Methods}

A methodological step in the case studies is the process of identifying, defining and operationalizing the measurement of each objective (or shirking behaviour). For each case, an extensive process is undertaken to identify all objectives sought through the sponsorship by sponsor(s), sponsee and intermediaries. Upon completion of this process, each objective is evaluated individually. The objectives that seek to reach more than one target market deserve special attention. In these cases, the objective is further evaluated individually for each target market that it hopes to reach. For example, if an objective for a sponsor was to increase employee satisfaction with the marketing efforts of the 
company in three employee groups (management, sales and IT), then three evaluations would be administered.

Once each objective has been identified, a number of possible metrics and methods are considered for each, where a metric is defined as 'a way of measuring a given objective' and a method is then described as 'the research method selected to carry out the metric (sampling plan, analysis plan, statistics, research method, etc.)'. These metrics are found in the literature or are developed based on metrics in the literature specific to the given objective. Metrics were chosen based on their applicability to the objective, the resources required to implement the metrics and the data available to the researcher. Once a metric is selected, the method is selected or designed for that metric. Figure 7 below outlines this process.

\section{Figure 7: Defining Metrics and Methods}

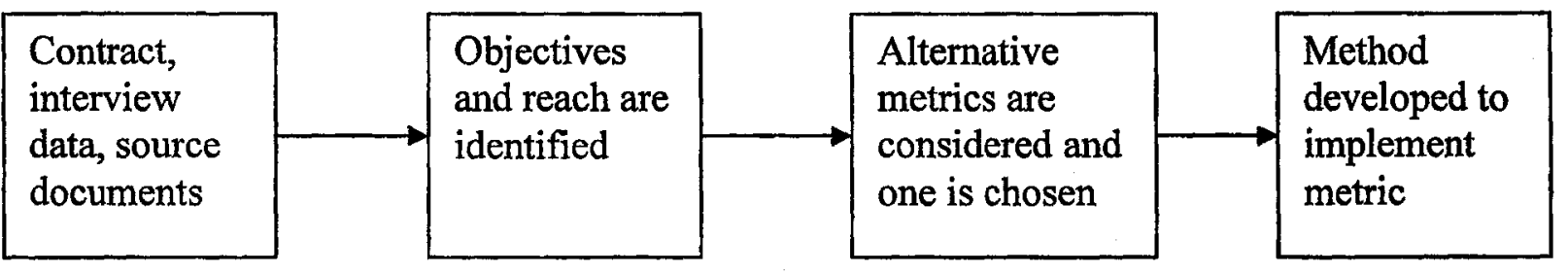

An example of the application of the four steps of Figure 7 is drawn from a study (O'Reilly, Nadeau, Seguin and Harrison, 2006) of in-stadium sponsorships at the 2004 Grey Cup, the championship game of the Canadian Football League (CFL). First, a review of marketing materials and the sponsorship contract was carried out, followed by interviews with key marketing contacts. Second, a number of objectives were identified. One sponsor, a large manufacturer of consumer products, had its sponsorship of the 
National Hockey League cancelled due to a league-wide strike and decided to re-allocate those resources to other major Canadian sport properties, including the CFL. The objective was to build awareness of two specific products. In return for the promotional opportunities offered by the CFL, this sponsor committed $\$ 390,000$ in return for sponsorship rights. One of the in-stadium tactics implemented was two broadcast vignettes (one per product) on the Jumbotron. Third, the evaluation was planned by considering a variety of metrics. Options included (i) post-event interviews with marketing staff, (ii) tracking sales data following the Grey Cup, (iii) random, in-stadium questionnaires immediately following the vignettes, (iv) pre- and post-event recall surveys around the stadium, and (v) post-event mass market studies. A combination of options iii and iv was chosen for a number of reasons including granted access to the stadium, resources available, ability to measure immediate impact of the vignettes, access to data, ability to achieve ethics approval and overall cost. Fourth, the specific method was developed to implement the metric, which included having 8 researchers in randomly selected stadium sections with clipboards, short surveys (one-page) and stadium access passes so that the researchers were at the ready to exploit the small window of opportunity in the minute(s) following the diffusion of each of the vignettes. The same group of researchers also collected data pre-game and post-game with an additional set of surveys. The questions included on all three surveys were designed to assess the effectiveness of the vignettes in achieving awareness of the two products. 


\subsection{Summary of methodology}

Phase I involved qualitative interviews with sponsorship experts, followed by Phase II which was comprised of two sponsorship evaluation case studies. The process model was adapted after the expert interviews were completed, then again following the two sponsorship evaluation case studies. Table 18 below summarizes the methodology:

Table 18: Research Plan (Phase 1 and Phase 2) for Dissertation Objectives

\begin{tabular}{|c|c|c|c|}
\hline \# & Dissertation Objectives & Method & Sample \\
\hline 1 & $\begin{array}{l}\text { i) Improve Understanding of the Sponsor- } \\
\text { Sponsee Relationship }\end{array}$ & \multirow[t]{5}{*}{$\begin{array}{l}\text { Expert } \\
\text { Interviews }\end{array}$} & \multirow[t]{5}{*}{\begin{tabular}{|l|} 
Fourteen (14) \\
sponsorship experts
\end{tabular}} \\
\hline & $\begin{array}{l}\text { ii) Improve Understanding of Current } \\
\text { Practices in Sponsorship Evaluation }\end{array}$ & & \\
\hline & $\begin{array}{l}\text { iii) Articulate Barriers to Evaluation, Fears } \\
\text { around Evaluation and Benefits of Evaluation }\end{array}$ & & \\
\hline & $\begin{array}{l}\text { iv) Improve Understanding of the Timing of } \\
\text { Evaluation }\end{array}$ & & \\
\hline & v) Revision of Process Model & & \\
\hline \multirow[t]{2}{*}{2} & $\begin{array}{l}\text { i) Conduct Case Study Sponsorship } \\
\text { Evaluations }\end{array}$ & \multirow{2}{*}{$\begin{array}{l}\text { Implementation } \\
\text { of the Process } \\
\text { Model with } \\
\text { Industry } \\
\text { Partners } \\
\end{array}$} & \multirow{2}{*}{$\begin{array}{l}\text { Case 1: Kanatek } \\
\text { Mount Everest } \\
\text { Expedition } \\
\text { Case 2:ATB - } \\
\text { Edmonton Grand Prix }\end{array}$} \\
\hline & ii) Refinement of Process Model & & \\
\hline
\end{tabular}

A potential disadvantage of the research methods selected for the dissertation is that the combination of expert interviews and in-depth case studies, although rich in detail, may be limited in its 'generalizability' to broader instances of sponsorship. In order to mitigate this potential weakness, 14 experts from a variety of industries, experiences and positions (sponsor, sponsee, intermediary) were selected and a case study from each sponsee scenario (one typical, one mega) was selected. 


\subsection{RESULTS AND ANALYSIS}

This chapter presents the results and analysis for Phase I and Phase II. The first sub-section reports on the results and analyses of the Phase I expert interviews ending with an updated draft of the process model. The second sub-section is divided in two parts, one for each of the sponsorship evaluation case studies. Given the step-by-step, iterative nature of the process model, results and analysis for each of the sponsorship evaluation case studies are presented concurrently to the methodological developments of each process model. A final process model refinement is presented following the two sponsorship evaluation case studies.

\subsection{Phase I: Expert Interviews}

The expert interviews were structured in six sections. First, interviewees were asked to verify their expertise, to provide background information on sponsorship practice in their experience, and to comment on issues in sponsorship. The remaining sections of the interviews corresponded to the four dissertation sub-objectives plus an opportunity to provide feedback on the process model (the major dissertation objective). The results and analyses of these interviews are summarized and presented using the same structure.

\subsubsection{Background on Interviewees}

Table 19 below summarizes the roster of interviewees and outlines their involvement and expertise with sponsorship evaluation. The overall goal of the selection of these expert interviewees was to include experts representing the points of view of the 
various roles involved in sponsorship including sponsors, sponsees and intermediaries.

The identification of each expert interviewee is kept confidential and for the remainder of the dissertation, each interviewee is referred to based on their primary role in the sponsorship relationship (sponsor, sponsee or intermediary) as follows:

- Four Intermediaries (Int_1, Int_2, Int_3, Int_4)

- Four Sponsees (SSee_1, SSee_2, SSee_3, SSee_4)

- Six Sponsors (SSor_1, SSor_2, SSor_3, SSor_4, SSor_5, SSor_6)

Although the intermediaries are all agents who work for agencies, we refer to them as intermediaries to avoid confusion with the Agency Theory terminology and the 'sponsee as agent analogy' which is fundamental to this research.

Table 19: Roster and Expertise of Interviewees

\begin{tabular}{|c|c|c|c|c|}
\hline $\begin{array}{l}\text { Title \& } \\
\text { Role }\end{array}$ & Current Position & $\begin{array}{l}\text { Years } \\
\text { Exp. }\end{array}$ & $\begin{array}{l}\text { \# of spon } \\
\text { last } 2 \text { yrs. }\end{array}$ & Expertise and Background \\
\hline Int_1 & $\begin{array}{l}\text { President of Sport } \\
\text { Marketing Agency }\end{array}$ & 18.5 & 40 & $\begin{array}{l}\text { - Founder and president of successful agency } \\
\text { - Experience with over } 100 \text { sponsorships } \\
\text { - Organizes and presents at conferences globally }\end{array}$ \\
\hline Int_2 & $\begin{array}{l}\text { CEO, Marketing } \\
\text { Consulting Group }\end{array}$ & $25+$ & 100 & $\begin{array}{l}\text { - Founder and CEO of successful agency } \\
\text { - Worked on over } 1000 \text { sponsorships } \\
\text { - Extensive experience, including own proprietary } \\
\text { model, on sponsorship evaluation } \\
\text { - Gives workshops and lectures on sponsorship }\end{array}$ \\
\hline Int_3 & $\begin{array}{l}\text { Director of } \\
\text { Corporate } \\
\text { Alliances, Event } \\
\text { Marketing Agency }\end{array}$ & 4 & 14 & $\begin{array}{l}\text { - Former elite athlete, successful raising sponsorship } \\
\$ \$ \$ ' s \\
\text { - Extensive experience in event management and } \\
\text { event communications, including sponsorship sales }\end{array}$ \\
\hline Int 4 & $\begin{array}{l}\text { Director, Social } \\
\text { Marketing } \\
\text { Consulting Centre }\end{array}$ & 30 & 30 & $\begin{array}{l}\text { - Part-time Professor, Carleton University } \\
\text { - Former Senior Executive at Health Canada } \\
\text { overseeing all marketing initiatives } \\
\text { - Involved in over } 1000 \text { sponsorships } \\
\text { - International Guest Speaker, Workshops/Lectures }\end{array}$ \\
\hline SSee 1 & $\begin{array}{l}\text { Executive Director } \\
\text { Revenue } \\
\text { Generation, Brand } \\
\text { Management and } \\
\text { Communications, } \\
\text { Canadian Olympic } \\
\text { Committee }\end{array}$ & 26 & 17 & $\begin{array}{l}\text { - Worked on "100's and 100's" of sponsorships } \\
\text { - Former senior executive at IMG: Toronto and New } \\
\text { York } \\
\text { - Chef de Mission, } 2004 \text { Canada Olympic Team } \\
\text { - Current and Past Board Member of COC, Aquatics } \\
\text { Federation of Canada, Water Polo Canada }\end{array}$ \\
\hline
\end{tabular}




\begin{tabular}{|c|c|c|c|c|}
\hline SSee_2 & $\begin{array}{l}\text { Senior Director of } \\
\text { Partnerships, } \\
\text { Canadian Football } \\
\text { League }\end{array}$ & 15 & 25 & $\begin{array}{l}\text { - Important position with large sport league } \\
\text { - Formerly with the } \mathrm{WWE}^{31} \text { in senior marketing } \\
\text { position } \\
\text { - Vast experience in sponsorships of various types }\end{array}$ \\
\hline SSee_3 & $\begin{array}{l}\text { Senior Vice- } \\
\text { President, } \\
\text { Operations and } \\
\text { Marketing, Hockey } \\
\text { Canada }\end{array}$ & 15 & 28 & $\begin{array}{l}\text { - Senior position with one of Canada's largest } \\
\text { National Sport Organization in terms of sponsorship } \\
\text { - Previous work with Provincial Sport Association in } \\
\text { New Brunswick }\end{array}$ \\
\hline SSee_4 & $\begin{array}{l}\text { Marketing } \\
\text { Manager \& Project } \\
\text { Manager on Events }\end{array}$ & 11 & 4 & $\begin{array}{l}\text { - Project Manager and Marketing Manager for many } \\
\text { sponsorships, many of which are/were events that } \\
\text { they created } \\
\text { - Worked on over } 40 \text { sponsorships }\end{array}$ \\
\hline SSor_1 & $\begin{array}{l}\text { Director of Media } \\
\text { and Strategic } \\
\text { Sponsorship, } \\
\text { Molson } \\
\end{array}$ & 17 & 25 & $\begin{array}{l}\text { - } 10 \text { years with Molson Breweries following } 7 \mathrm{in} \\
\text { media } \\
\text { - Over } 250 \text { sponsorships worked on } \\
\text { - Own model for sponsorship evaluation }\end{array}$ \\
\hline SSor_2 & $\begin{array}{l}\text { Sponsorship } \\
\text { Consultant, Nike }\end{array}$ & 10 & 8 & $\begin{array}{l}\text { - Has worked on over } 100 \text { sponsorships with Nike } \\
\text { - Published author on sponsorship } \\
\text { - Vast work with athlete sponsorships } \\
\text { - Chair, Olympic Marketing Research Centre }\end{array}$ \\
\hline SSor_3 & $\begin{array}{l}\text { Manager of } \\
\text { Corporate } \\
\text { Sponsorship and } \\
\text { Field Marketing at } \\
\text { Purolator Courier. } \\
\end{array}$ & 6 & 25 & $\begin{array}{l}\text { - Former Manager of Marketing Properties at } \\
\text { Basketball Canada } \\
\text { - Worked on over } 100 \text { sponsorships } \\
\text { - Strong understanding of both B2B and B2C } \\
\text { sponsorship, particularly B2B } \\
\end{array}$ \\
\hline SSor_4 & $\begin{array}{l}\text { Brands Marketing } \\
\text { Manager, Inter- } \\
\text { Continental Hotels }\end{array}$ & 14 & 3 & $\begin{array}{l}\text { - In charge of all Canadian Marketing for ICH, } \\
\text { including Holiday Inn } \\
\text { - Has managed the implementation of over } 100 \\
\text { sponsorships }\end{array}$ \\
\hline SSor_5 & \begin{tabular}{|l|} 
President of \\
Kanatek \\
Technologies \\
\end{tabular} & 20 & 15 & $\begin{array}{l}\text { - Worked on } 75 \text { sponsorships } \\
\text { - Sponsor of a variety of events, both } 3 \text { party and } \\
\text { own-events - highly strategic focus }\end{array}$ \\
\hline SSor_6 & \begin{tabular}{|l|} 
Manager \\
Marketing, ATB \\
Investor Services
\end{tabular} & 10 & 7 & $\begin{array}{l}\text { - Considerable experience in all areas of sponsorship } \\
\text { (from sponsor side) from investment to decision to } \\
\text { activation to leveraging to evaluation } \\
\text { - In charge of activation and evaluation for Edmonton } \\
\text { Grand Prix and Calgary Stampede sponsorships }\end{array}$ \\
\hline
\end{tabular}

As Table 19 demonstrates, the goal of including sponsors, sponsees and intermediaries in the roster of interviewees was met. Each interviewee (i) currently occupies a senior position in the sponsorship industry, (ii) has an average of 15.8 years (Median: 15) of work experience in sponsorship, and (iii) has worked on 25.4 sponsorships (Median: 21) over the past two years. All were asked if they were experts in the field of sponsorship

${ }^{31}$ WWE is World Wrestling Entertainment 
and all but one expert self-identified as an expert, with modesty expressed in many cases (considering their high levels of expertise). These experts have worked on a wide range of different sizes and types of sponsorships including international mega-sponsees like the Olympic Games or the Grey Cup and a variety of typical-sponsees such as the Nike Toronto 10km run and Clear \& Clean Basketball Skills Days ${ }^{32}$.

Interviewees were also asked about the nature of their specific work on sponsorships. The wording of the question was: "In working on a sponsorship, both during negotiations to sign a contract and during the implementation of the contract itself, what kinds of things are you typically involved in?" The information provided by the sponsees reveals that all have been involved in most aspects of the sponsorship process ranging from the first stages of planning to sales through to contract negotiation, activation and evaluation. Some provided very detailed descriptions while others were more general in their responses. One expert provided a detailed description of the sponsorship process which provides valuable insight:

It would start with a presentation where our focus is making that sales pitch or presentation to show that we are the right property and in doing that, we attempt to do the research and understand what the sport strategy and more specifically what the hockey strategy is of the partner and we spin that back to them in such a way as to show that we are an attractive resource for them and present that in a format to their key marketing representative. We [then] attempt to structure the sales presentation to the level of the person you are pitching it to. You may have someone who is intricately involved both in negotiating and signing the deal and also executing the deal so the attention to detail in that presentation is critical or you may be presenting to a high level marketing representative who wants to know the high level components. So, that is more of the verbal approach to how you are making the pitch. Through the negotiation process it is clearly critical to document any modifications, any adjustments, [and] any side agreements to insure that expectations are managed. And then, once the agreement is in place, then the real work begins to make sure that you can deliver on what the expectations are against the

\footnotetext{
${ }^{32}$ Clear and Clean Basketball Skills Days are events run in Ontario high schools targeted at high school females and promoting basketball skills and healthy skin.
} 
opportunities that you promised. At [the organization], we have a document called our seasonal plans which includes everything from quarterly meetings to weekly telephone calls to regular conference calls to the delivery of say goods \& services...tickets, banners, promotional materials, processes for the singing off of activation, sign off on point of sale or point of purchase materials...reporting against the objectives, regularly through the year but then in a formal way at the end of the year. Documenting details and critical dates on the submission of advertisements for event programs, those types of technical components. And, then once through the agreement, conducting a detailed assessment on the ROI. (SSee_3)

All interviewees have worked in most aspects of sponsorship, with particular emphasis on the areas related to their position, function or organization. Differences between the work of sponsors, sponsees and intermediaries is also clear with the work of sponsors emphasizing sponsorship renewal, activation and contract negotiations; the work of sponsees involving the monitoring of the sponsor and intermediaries, as well as resource allocation; and that of intermediaries typically including work to keep both sponsor(s) and sponsee(s) happy.

Interestingly, one sponsee expert added that part of his work recently involved engaging a $3^{\text {rd }}$ party to evaluate sponsorships up for renewal: "we conducted an independent assessment with IEG on what the value of the sponsor offering was" (SSee_3). He further added that the main reason for obtaining the $3^{\text {rd }}$ party review was "to develop a good negotiation support document [an evaluation study] to be able to say 'a bona fide agency who you do some work with also believes that this offering is worth what we're asking for'...it is more about what their [IEG - the firm doing the evaluation] reputation is than the report they send back" (SSee_3). 


\subsubsection{Background Sponsorship Information}

At the onset of the interviews, the interviewees were asked a series of questions around three topics related to the sponsorship literature: (i) the definition of sponsorship, (ii) sponsorship's effectiveness vis-à-vis the other promotional strategies, and (iii) sponsorship's distinction from advertising. The posing of these questions had two purposes; to delve deeper into issues yet to be resolved in the literature and to set the stage for the more important questions that followed. Full results and analysis are not reported here although a few summary points directly related to the objectives of this dissertation are noted. First, the responses of the interviewees supported all 10 tenets of the working definition of sponsorship crafted for this dissertation. Second, when asked for their general opinion on the overall effectiveness of sponsorship, responses were unanimously very positive. Third, interviewees were asked if sponsorship is different from advertising with 13 of the 14 experts agreeing clearly that they are distinct and the final expert being undecided.

\subsubsection{Understanding the sponsor-sponsee relationship}

A major section of the interviews sought to improve understanding of the sponsor-sponsee relationship and asked interviewees 10 questions on related issues that were identified in the review of literature. The questions posed ranged from how sponsorship relationships are typically started to how they are typically terminated. These results are summarized in the subsections that follow. 


\subsubsection{How sponsorships begin and end}

In order to learn more about how sponsorship relationships are created, interviewees were asked to describe how a recent sponsorship was initiated and how, in their experience, they are normally terminated. The resulting responses show a varied landscape of how sponsorships are initiated and how they are terminated, where sponsors, sponsees and intermediaries all expressed that they typically started sponsorship relationships themselves. It appears that each group believes that they play the most important role in creating sponsorships.

Three of the four intermediaries suggested that sponsorship relationships typically begin with them working on behalf of a sponsor who has identified specific marketing objectives that they wish to achieve. As stated by Int_2: "we start off with what we are trying to achieve for our client [sponsor] and we take a look at what it is that we need to achieve through a sponsorship component and identify properties [sponsees] who provide for that", while Int_1 said that "we recommended a relationship [sponsee] to the client [sponsor]."

All four sponsees indicated that they typically begin sponsorships based on the need for resources (typical sponsees) or for the pursuit of specific global marketing objectives (mega-sponsees). SSee_1 provided an example of the most recent IOC Top Sponsor:

It was started because for years this major global corporation was looking for a platform that they could leverage in multiple countries and then when Beijing [China] was named the 2008 host city and China is their single largest growing market. And, their research said that the Olympic Games were incredibly well known in China and very popular and so they decided that this gave them a platform to - one - grow their business in China which was their number 1 corporate objective but - two - give all regions a common platform to deal with. (SSee_1) 
Although this story is an interesting mega-sponsee example, SSee_1 admitted that this was not normal practice for typical sponsees. In his experience of how mega-sponsee relationships are initiated, he noted the following.

There is a myriad of ways that they happen from the CEO likes to golf so he wants to invest in golf, to the people who own the sponsorship rights out flogging them on the street with no understanding of what the corporate needs are of the people they are flogging them to - to corporations that clearly know what their goals and objectives are and identify a need within those objectives that a sponsorship program can help deliver against.... [basically] various levels of sophistication. (SSee_1)

Thus, for typical sponsees, the impetus for beginning sponsorship relationships is to gain access to additional resources. In drawing on his long experience as a sponsee at Health Canada, Int_4 recalled that they decided to embark on sponsorship "based on a policy initiative or strategy based on our marketing plan with clear measurable objectives and then [we] went out and sought sponsors who tied into our plan." Int_4 also indicated that "other times, it does come from the sponsor who wants to work with us and approaches us"; although in this case he noted that "if somebody [sponsee] comes to you, it is always a problem as it is very rare that it is a good fit". He further noted that in the case of sponsors approaching the sponsee:

Sometimes sponsors will come and pitch you on why you should put antismoking messages on their products or their events with not a thought if it meets the needs of Health Canada and/or its target groups. Sometimes the political arm gets involved and Health Canada may be forced to do something that doesn't fit with the plan and is not the best fit for the message or product or service. This is rare but it does happen. Sometimes people also get 'starry-eyes'... and they just want to be part of some property for the wrong reasons so this leads to potential sponsors going after properties that are not really a good fit or a smart business choice. (Int 4) 
Sponsors reported on a variety of reasons for entering into a sponsorship relationship. Experts reported that there was very little overlap between and among the six sponsors. The reasons cited by sponsors included (i) as a means to work with industry partners (e.g., "We always go out to our partners, nobody other than that" (SSor_4)), (ii) to replace a previously ended sponsorship, (iii) to develop a sponsorship from an existing relationship with a sponsee (e.g., "It started as initiated dialogue between the sponsor and the President of the sponsee" (SSor_1); "I think that the key for many of them today is based on relationships" (SSor_2)), (iv) as an enabler of highly targeted marketing action (e.g., "It isn't just mainstream advertising, it is a very targeted event" (SSor_1)), (v) via a sponsee request (e.g., "Ninety percent of the time, we're being approached by properties...to gauge our interest level and we go from there" (SSor_3)), and (vi) through the strategic pursuit of "best-fit" (SSor_3) with the sponsee as a partner.

Responses from all experts (sponsors, sponsees and intermediaries) reveal two general ways by which a sponsor-sponsee relationship can end. Table 20 lists these by frequency of mention in all interviews.

Table 20: Sponsorship Relationships: Methods of Termination

\begin{tabular}{|l|c|}
\hline \multicolumn{1}{|c|}{ Sponsorship Relationship Ending } & Mentions \\
\hline $\begin{array}{l}\text { Contract ends and is not renewed (a variety of reasons put forth } \\
\text { including dissatisfaction, conflict, change in strategy, financial issues, } \\
\text { failed negotiations on price, poor results, key contact leaves or is } \\
\text { replaced, a better offer comes along, and sponsor fatigue) }\end{array}$ & 22 \\
\hline $\begin{array}{l}\text { Contract terminated (a variety of reasons provided including, sponsee } \\
\text { failure to deliver on contractual obligations, conflict, dissatisfaction, } \\
\text { and poor activation by the sponsor) }\end{array}$ & 9 \\
\hline
\end{tabular}

**Note: Interviewees often provided more than one mention

As noted in Table 20, it is clear that the vast majority of sponsorships (22 of the 31 mentions) end at the end of the contract or over a failure to renew the contract (price, 
strategy, etc.). One of the experts recounts a good anecdote that demonstrates how tenuous these relationships can be:

I think the last one I'll tell you is that we have had a couple of situations, one in particular when I first started that they were sold...a telecommunications company was sold an opportunity to be title to one of our development programs...and, we were clear with them through the sales process that they were buying the right to be title sponsor and have promotional rights in and around that and their marketing staff thought that they had the right to adjust, manipulate, maneuver, change the title and the delivery methods of the program and we spent the better part of 15 months realizing that we weren't meant for each other and we agreed to shake hands and walk away. So, you know, we also operate with the philosophy that - even with our top sponsors who pay us a pretty substantial amount of money, you know well into the 6 figures nearing 7 figures on an annual basis - if it is not right, let's have the conversation and see if it is not best to just shake hands and walk away. (SSee_3)

\subsubsection{Frequency of Sponsor-Sponsee Communication}

An important aspect of any sponsorship relationship is the amount of effort and time that the parties involved in the relationship spend communicating. All experts were asked about the frequency of contact in the relationship. The responses of the 14 experts are summarized in the histogram (Figure 8) below. 
Figure 8: Frequency of Sponsor-Sponsee Contact

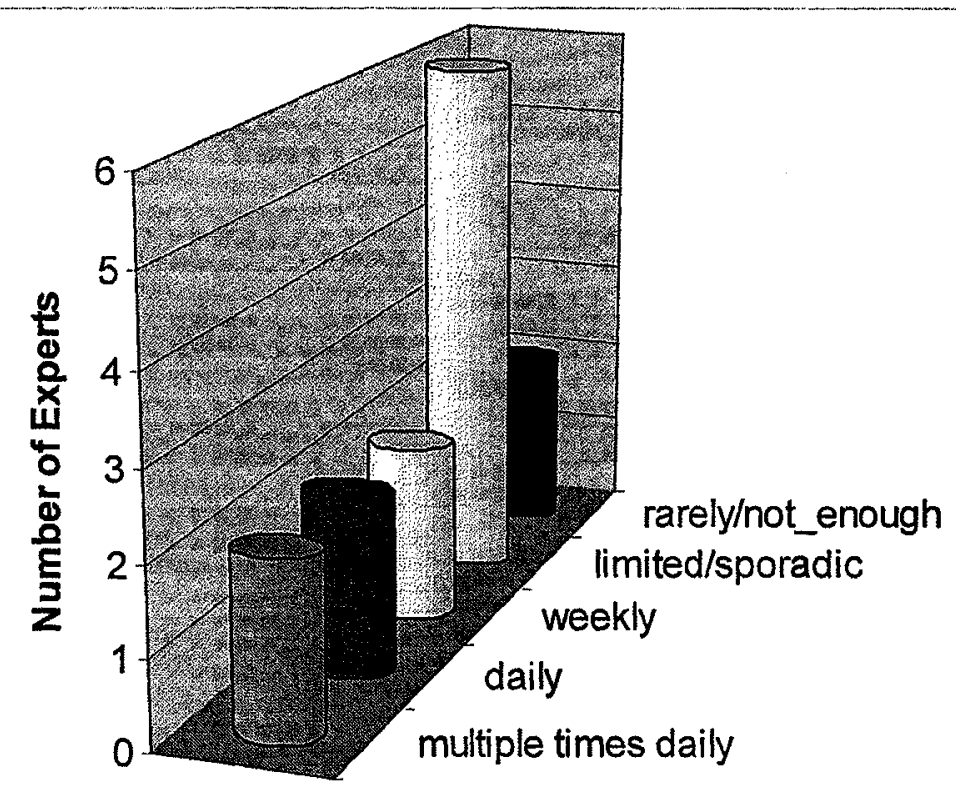

Figure 8 reports that 'limited/sporadic' is the most common response of experts.

However, a wide variety of responses reveals that variation in communication exists as expert responses range from "unfortunately not enough" (Int_2) to "it becomes more intensive the closer it gets to the event" (Int_3) to "I probably talk to my properties more than I talk to my wife during the day" (SSor_3).

Within this variation, the key theme that more communication is needed in sponsorship emerges. Int_2 puts forth a strong argument in this regard with support, tactics and examples:

What happens when you sign a contract...you sign it and there are a whole bunch of deliverables and the person who is signing the sponsorship is usually involved in a million other things that they are trying to do, then you get closer to the event and the sponsor at that point wants some attention and the person who sold the sponsorship is trying to wrestle or deal with 50 people like that sponsor so they don't get the attention that they want. So, I think that that is one of the huge areas where there is a concern because if you don't work with them all the way through it, the odds of it being successful are a lot less and so I think that people tend to sign the deal and then, you know, move on and 
then when there is an issue, they deal with it because they are dealing with so many other crises and such. But, you know, what we tend to do is, for example, is when we sign a sponsorship deal with somebody it sort of depends whether it is short term or long term or whatever. So, for example, I was involved with raising about $\$ 5$ million for school-net grass-roots program which was a national initiative to get people to encourage teachers to use online technologies in the classroom. And, we went out and got anywhere from 60 thousand to a million dollar sponsorships with companies like Microsoft and AOL and Cisco Systems and Imperial Oil and $\mathrm{CN}$ and all these companies and the agreement was over a 3 year period so what we did was that we built in a quarterly reporting mechanism to provide people with updates so that they were always getting updates. We gave them an annual report that said here is the reach and here is what we accomplished over the last year so we built reporting mechanisms right into that. The other thing that we do...is we'll give them a list of key deliverables and deadlines that are required on their part so that when the sign the agreement, the next thing that they get from this thing is a letter saying thanks a lot now here is your list of what is due and when it is due by. (Int_2)

SSee 3 agrees and adopts some alternate strategies to encourage communication:

We structure a process on any major project...we have an account manager assigned to every sponsor who is the point of contact and the goto person for that sponsor. We try to divvy up those responsibilities and that contact is happening on a regular basis, at least on a week-to-week basis but, in some cases because of the need and the desire for a little bit of hand holding, it could be on a daily basis. Formally, that group comes together on a monthly basis via conference call starting about 6 months out from the event...so that gives you a bit of a framework of how things were initiated and managed through the process.

\subsubsection{Agency Theory in sponsorship}

Throughout the interviews, a number of questions were asked around key components of Agency Theory (e.g. the contract, monitoring, etc.) and if they fit with sponsorship. These results are summarized in the following sub-sections. 


\subsection{Formal Sponsorship Contract}

The contract is the unit of analysis in Agency Theory. Thus, a question was asked to assess the relative occurrence of formal contracts in sponsorship. All 14 of the experts reported that, today, contracts - either a formal legal contract or a simpler letter of understanding (Int_2) - are involved in all sponsorships.

\subsection{Evidence of Sponsee Monitoring}

In looking at the sponsor-sponsee relationship as an instance of a principal-agent relationship, we would expect to see evidence of the sponsor monitoring the activities of the sponsee to control for shirking behaviour. The question posed was "does the sponsor monitor the sponsee in any way?" with further explanation required if requested by the interviewee or determined to be necessary by the interviewer. Results indicate that "increased attention is being paid to monitoring" (SSee_1), and that the monitoring of sponsees is common in sponsorship as all six of the sponsors, three of four sponsees, and three of the four intermediaries reported that sponsors monitor sponsees to some level. The sponsee and intermediary who reported to the contrary were strong in their claims. For example, Int_1 indicated that "sponsors often don't monitor".

This line of questioning also revealed that the monitoring that is taking place is often of limited sophistication and scope. SSee_2 clarifies that "many factors will result in how often the sponsor will follow-up with the sponsee" and SSee_3 notes that "we monitor each other" reminding us that monitoring and shirking are two-way constructs. 
SSor_l has taken this a step further and now has "a recent contract with a clause in there that sort of holds them [sponsee] to ensuring that they comply with the contract".

\subsection{Sponsee Compliance}

Interviewees were asked to respond on what sponsors do (or can do) to encourage sponsee compliance to the items agreed to in a sponsorship contract. In Agency Theory terms, what can the sponsor do vis-à-vis timing to monitor the sponsee to reduce shirking? The importance of sponsee compliance in sponsorship renewal was noted:

A huge part of servicing sponsors and the whole sponsorship process is having people renew sponsorships. The worse kind of sponsorship you can have is a oneoff, one-year opportunity because you can't really generate true results in a one year opportunity and so, you know, we do what we can to try to make them happy since if they like you the odds are that they'll forgive you on something too. (Int_2)

In total, the interviews suggested 12 different strategies that a sponsor could employ to encourage compliance. These responses were then grouped by common theme into 4 general recommendations to sponsors: (i) ensure the development of a clear, strong and binding contract that includes deadlines and termination clauses for deliverables $(5$ mentions), (ii) monitor the sponsee regularly with sponsee-provided weekly reports and daily communication (5 mentions), (iii) adopt project management practices (2 mentions), and (iv) engage outside sponsorship expertise where necessary (1 mention). 


\subsubsection{Sponsor and sponsee objectives}

Each of the experts was asked to provide their 'top 3' lists of sponsor and sponsee objectives. Table 21 provides a summary of the top sponsor objectives provided by the experts and Table 22 provides a summary of the top sponsee objectives. ${ }^{33}$

\section{Table 21: Top Sponsor Objectives}

\begin{tabular}{|l|c|}
\hline \multicolumn{1}{|c|}{ Objective } & Mentions \\
\hline To increase prospects/sales/return on investment (ROI) & 9 \\
\hline $\begin{array}{l}\text { To obtain improved visibility/awareness/exposure (TV, media, } \\
\text { web, on-site, etc.) }\end{array}$ & 7 \\
\hline $\begin{array}{l}\text { To gain affiliation with 'something sexy' or 'prestigious' } \\
\text { brands or trademarks (e.g. co-branding) }\end{array}$ & 6 \\
\hline $\begin{array}{l}\text { To create an impact or an experience (audience and } \\
\text { stakeholders) (e.g. link of product to sporting event) }\end{array}$ & 5 \\
\hline To work with an honest and upfront business partner & 4 \\
\hline To access a specific target market/target new customers & 3 \\
\hline To obtain 'category exclusivity' & 1 \\
\hline To open specific access points to leverage/build programs on & 1 \\
\hline To achieve community support & 1 \\
\hline Hospitality-related (e.g., opportunities for key stakeholders) & 1 \\
\hline Access to first right to provide services & 1 \\
\hline
\end{tabular}

Table 21 demonstrates the importance of the objectives related to ROI, exposure, association and impact.

Table 22 provides a summary of the sponsee objectives communicated.

\footnotetext{
${ }^{33}$ Note that not all experts provided a maximum of three objectives for each question
} 


\section{Table 22: Top Sponsee Objectives}

\begin{tabular}{|l|c|}
\hline \multicolumn{1}{|c|}{ Objective } & Mentions \\
\hline To generate revenue (cash) to deliver programs & 12 \\
\hline To associate with a credible sponsor/brand & 6 \\
\hline To build solid, professional long-term relationships & 5 \\
\hline To access in-kind services & 4 \\
\hline To build brand awareness/exposure & 4 \\
\hline To access referrals to new sponsors/new industry contacts & 2 \\
\hline To leverage their own sport property & 2 \\
\hline To create opportunities for hospitality & 1 \\
\hline To deliver good ROI to sponsor & 1 \\
\hline To achieve 'shared experience' for customers & 1 \\
\hline
\end{tabular}

Table 22 expresses that resource generation (cash and in-kind) is the most common sponsee objective, however the association with credible sponsors/brands and awareness are also important; as are developing solid relationships.

\subsubsection{Frequency of intermediary involvement}

Intermediaries in the sponsorship relationship work with both sponsors and sponsees. In large, complex sponsorships, there may be a half-dozen or more intermediaries involved. Expert interviewees were asked how often intermediaries are involved in sponsorship relationships. Figure 9 below outlines the findings and shows that involvement of intermediaries differs greatly from rarely to often. 
Figure 9: Histogram of frequency of intermediary involvement

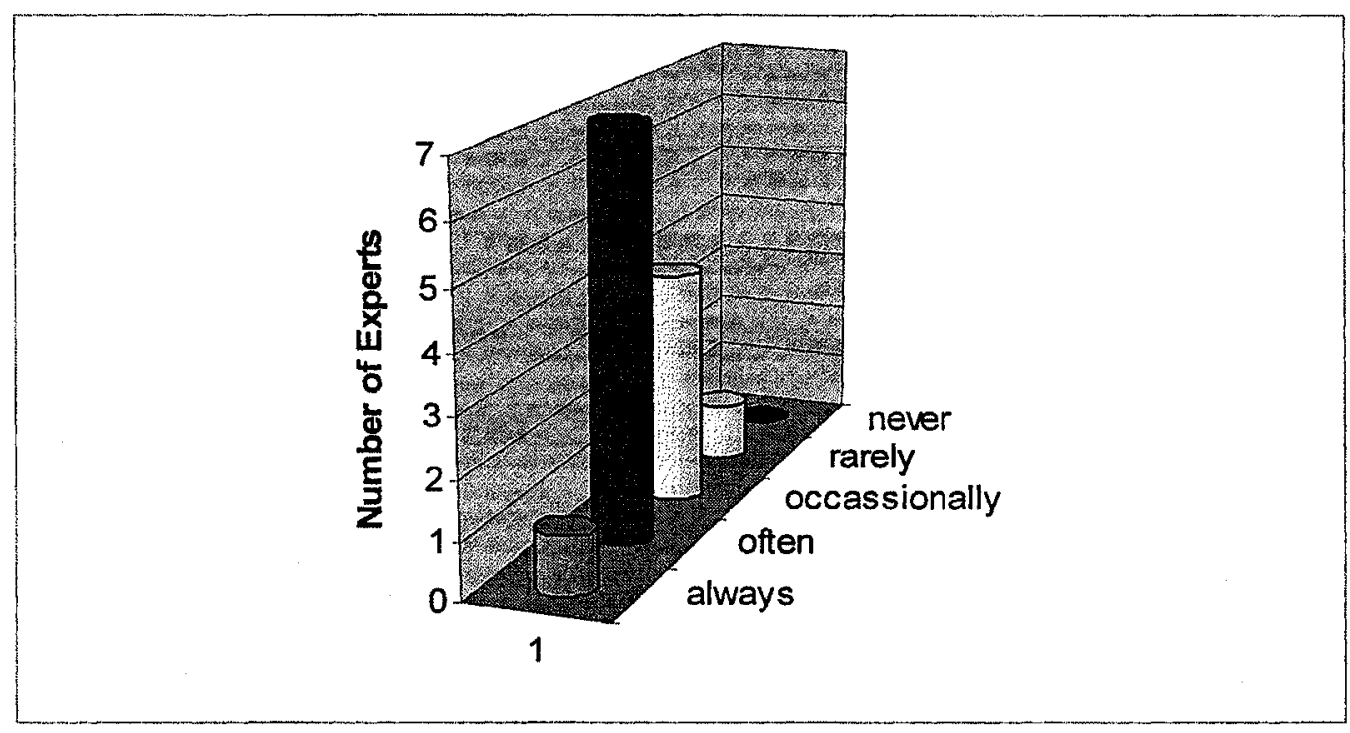

Overall, Figure 9 indicates that intermediaries are involved in sponsorship 'often' ( 7 of 13 experts) or 'occasionally' ( 4 of 13). No expert indicated that intermediaries are never involved although one indicated that they are always involved. The experts also pointed to the impact of both size and type of sponsorship as influencers on frequency of intermediaries as both sport sponsorships (Int_2) and large sponsorships (SSee_4; SSor_2) were felt to be more likely to include intermediaries. A few experts also pointed out that there is often more than 1 intermediary involved with any given sponsorship (SSee_3). Intermediaries are also common when a certain expertise can not be found inhouse (SSee_4; SSor_1).

\subsubsection{The importance of exclusivity}

Interviewees were asked to comment on the importance of exclusivity; specifically when and how important it is. Although seven of the experts indicated that exclusivity is critically important, results here are quite interesting and, at times, 
contradictory. One expert clarified that "exclusivity by product category is important [but] exclusivity for the event itself is not" (Int_2) underlining the importance of categories and their boundaries in exclusivity, which is often complicated as "some companies now compete in many markets with many product/brand offerings making product category exclusivity even more difficult" (Int_2). SSee_1 provides a good example of this:

Well, here's a good example, in the Olympic world, McDonalds has a slew of [sponsorship] rights for everything from serving ice cream to french-fries to you-name-it [fast food ...]. Where if you go down to the Air Canada Centre, you see ads for Mr. Sub, Tim Horton's, Pizza Pizza, and McDonalds. And, now, if you ask each of those companies if they were competitive with each other they'd say absolutely but it is 'he who has the gold rules' right and at MLSE [Maple Leaf Sport and Entertainment - owner's of Air Canada Centre] they can set the rules and say well no you're burger and you're pizza and you're donut and do you want in or not?

Another important theme is that exclusivity is only typically offered in large, for-profitbased sponsorships and is not practiced in small sponsorships (SSor_4; SSor_5). One expert (Int_3) noted that "the only time exclusivity isn't offered is where it is a low-dollar amount...unless you commit $\$ 50,000$ or so, there's no exclusivity guaranteed." The distinction between sponsors where exclusivity is common and a licensee ${ }^{34}$ where exclusivity is rare was also highlighted by SSee_3 who explained that his organization has " 16 sponsors or corporate partners and about 55 licensees and our licensees don't necessarily have exclusivity but all of our sponsors in some way have a form of exclusivity." An additional and related theme brought forward is the role of 'clutter' in sponsorship and the need to avoid "logo-soup and being 1 of 50 sponsors of a property [where] you can get lost" (SSor_3) and where "as sponsors, nobody wins in that situation

\footnotetext{
${ }^{34} \mathrm{~A}$ licensee is a term used to describe an organization that has purchased the rights ('license') to a given property from the property owner and is allowed to use that property in its business activities.
} 
because nobody is getting...their pound of flesh out of the agreement...nobody wins" (SSor_1).

Contradicting these views is SSee_1 who brings forth the NASCAR model as it allows exclusivity as competing sponsors are visible on cars, stadiums and television broadcasts. He states: "I personally prefer the NASCAR model but that is because I'd rather be able to sell more!" (SSee_1). SSee_2 also points out that exclusivity is not always important, particularly when "a brand can't afford to buy exclusivity and they'll be willing to bet that they'll get it". Further, he indicates that

...it is a bit superficial though because they know and the property knows that it is pretty rare to go out and get somebody else to come on board in that category if a competitor is already there. You'd think that, yes, they'd want to be there to compete with that competitor but they'll say no that they'd rather find their own property that they can own. So, yes, in a couple of cases, we won't have exclusivity language written in [the contract]. (SSee_2)

Similarly, SSee_4 points out that she had not encountered problems around exclusivity since they organize all of their events and sponsorships with partners who they know and work with regularly.

\subsubsection{The Importance of leveraging}

Experts were asked for their opinions on the role of leveraging in sponsorship in an attempt to further understand the sponsorship relationship. Eleven of the experts expressed views that were very consistent in suggesting that leveraging is very important. Typical comments included "leveraging is important 100\% of the time" (SSor_6) and "I'd say that $50 \%$ of sponsors are really committed to and looking for ways to leverage it, which is not enough in my mind" (SSee_2). One expert noted that "if you don't leverage, 
you are wasting the investment [since] sponsorship is the purchase of some asset that needs, in turn, to be leveraged. It is not an end-promotion in and of itself" (Int_4). Two additional key points were expressed. First, one expert identified a marketing strategy where no leveraging takes place: "I mean there is only one reason to buy a sponsorship and not leverage it and that is if you want to freeze out your competitors and that is a strategic buy just to keep them out of it" (SSee1). Second, it was widely noted (five experts) that leveraging is unique to the sponsorship and the ratio and tactics should be determined based on the sponsorship.

\subsubsection{Understanding current practice in sponsorship evaluation}

The next series of questions was posed in order to develop increased awareness and a better understanding of sponsorship evaluation practices.

\subsubsection{Sponsorship evaluation experience}

All interviewees were asked to describe their own experience with sponsorship evaluation. Results showed that all the experts have significant experience in sponsorship evaluation, including four (SSor_1, SSor_3, Int_3, SSee_2) who have developed their own models to do so. In terms of the intermediaries, all four sell evaluation as a service to clients. Of note is that seven of the experts are rarely involved in the data collection, analysis or application of evaluations, they (likely due to their senior positions) normally only read the summary reports, particularly in the case where a $3^{\text {rd }}$ party is engaged to do the evaluation. 


\subsubsection{Frequency of Sponsorship Evaluation}

Each respondent was asked to put a percentage to their estimation of how frequently sponsorships are actually evaluated in practice. Twelve of the 14 experts provided estimates of the frequency of evaluation in sponsorship, as summarized in Table 23 below.

\section{Table 23: Estimates of the Frequency of Sponsorship Evaluation}

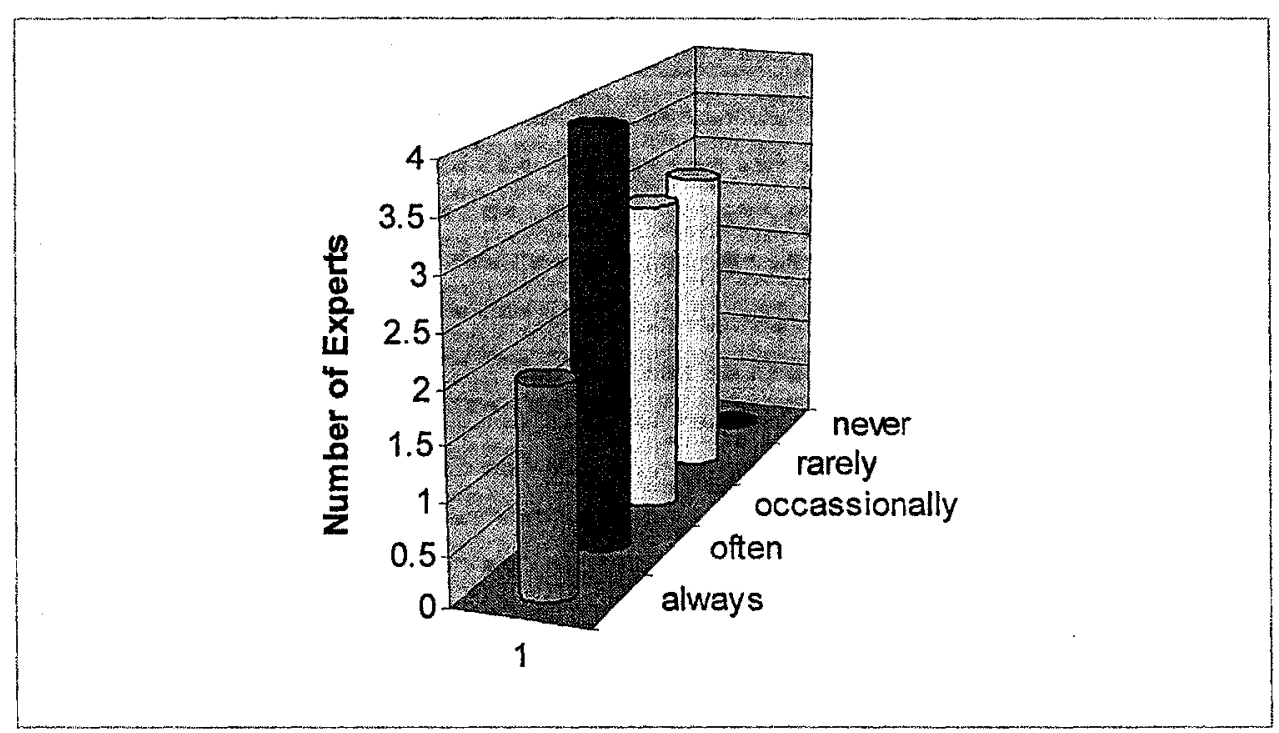

The results provided in Table 23 show vast differences in experiences as to how often sponsorships are actually evaluated. Deeper evaluation shows that interviewees have varying views and experiences on three aspects: formal/informal, internal/external and techniques. First, confusion clearly exists over what is formal evaluation versus what less formal (or informal). Some experts do not distinguish formal from informal (e.g., "I would say $65-70 \%$ [are evaluated]" (Int_1)) which others do (e.g., "Formally one-third and informally two-thirds [are evaluated]" (SSor_4)). Second, two of the experts evaluate all of their own sponsorships which alters their views on frequency (e.g., "we've always 
done our own assessments and evaluations" (SSee_3)). Third, five of the experts make reference to the level of sophistication of techniques used to evaluate, critiquing their validity: "they are very unsophisticated" (SSee_2), "In a sophisticated manner, very few are evaluated" (SSor_5), "some have no strategic evaluation tools attached" (SSor_2). Although one of the experts comments that evaluation "is now more scientific than anecdotal" (SSee_1), a general theme is that evaluation is infrequent and unsophisticated. One expert suggests that this may be due to the fact that sponsorships "are typically priced by instinct and by adding together some elements that they think they can put a price on but guessing the rest" (Int_2).

\subsubsection{Identification of sponsorship evaluation practices}

In an effort to identify any new or previously undetected methods for sponsorship evaluation, the interviewees were asked to list all the sponsorship evaluation practices of which they are aware, including those of their competitors. Although only one of the 14 experts knew of the practices of their competition, a number of practices were identified from the experiences of all 14 experts. These are grouped by theme in the table below.

\section{Table 24: Sponsorship Evaluation - Themes Observed in Current Practices}

\begin{tabular}{|l|c|}
\hline Sponsorship - Themes Observed in Current Practice & Mentions \\
\hline $\begin{array}{l}\text { Sales (measured by average turn, sales force interviews, hits or calls) and/or Purchase } \\
\text { Intent (via web survey or focus groups) }\end{array}$ & 7 \\
\hline $\begin{array}{l}\text { Media measurements (internal communication between sponsor \& sponsee, reach, PR } \\
\text { value, awareness, scorecard, ratings, exposure time, CPMs, etc.) }\end{array}$ & 6 \\
\hline Attendee/Customer/Employee interviews about exclusivity (at events or post-event) & 5 \\
\hline $\begin{array}{l}\text { The measurement of both tangible and intangible value, including the effectiveness of } \\
\text { the sponsor/sponsee association and tenets of the contract }\end{array}$ & 3 \\
\hline Assessment of financial statements/expenses (including ROI, opportunity costs) & 3 \\
\hline Measures of clutter and ambush effectiveness (by mass market questionnaires) & 2 \\
\hline Branding (equity, awareness, etc.) & 1 \\
\hline
\end{tabular}


Table 24 provides a summary of the groupings of the expert-identified evaluation practices. In agreement with the literature, the most common practice suggested by the experts is to measure sales or intent to purchase, followed by media measurements and consumer surveys to study the effectiveness of exclusivity as a concept.

It was noted previously that four of the respondents had developed their own models of evaluation. One respondent, Int_2, provided a full and detailed report of his model for sponsorship evaluation. His model fully supports the mandate of this dissertation and is described in detail in Appendix M.

\subsubsection{Mega-sponsee evaluation practice}

A question was asked to assess whether or not the experts viewed mega-sponsees differently from typical sponsorships in terms of how they evaluate sponsorship. Results suggest that the majority of experts (ten of 14) believe that sponsorships involving megasponsees and those involving typical sponsees are evaluated differently due to the resources involved. One expert summarizes that "it is a matter of the resources that you are able to put against the measurement techniques [for the evaluation]" (SSee_1). Another expert (Int_3) said "the bigger the money involved, the deeper the evaluation goes". Three other experts further provide support: SSor_5 notes that "with megasponsees, they are likely more sophisticated in their evaluation processes as there are higher stakes and they don't rely on volunteers". SSee_4 reiterates that "size has a considerable impact", and Int_4 says that "of course the mega ones have to as they are spending a great deal of money". 
Interestingly, Int_1 expresses an opposite view: "the larger the property [sponsee] the less true measurement that's provided." SSee_3, SSor_6 and SSor_4 indicated that they have no evidence that anything is done differently in evaluating mega and typical sponsee sponsorships. Three other experts (SSor_1, SSee_3 and SSor_3) answered the question very differently as they attempted to rationalize the situation based on their experiences. For example, SSee_3 said, "I don't know. I really don't know." While SSor_1 shared:

I would say - it is a very good question - because when you think of the kinds of dollars that are paid to get rights for the NFL for example, they are astronomical, they make absolutely no sense to me. You know, when you start hearing that people are spending hundreds of millions of dollars to get sponsorship rights for the NFL, I don't get it and I'm not sure how they got to a number like that or how they could possibly present somebody with a number that says 'and this sponsorship is a paltry number of $\$ 350$ million'... that doesn't make any sense to me. But I think that those mega-sponsorships, and you think about the Bells of the world in terms of how much they paid for the Olympic rights, that makes no sense to me. They might have their own analysis to say that the back-end of this rights and of using the technology on sight and so on and so forth, is going to pay dividends that we projected to be whatever because we're trying to get a foothold into the western market but otherwise I would say that a lot of times the sponsorships that I see outside of those ones, perhaps call it the 2 level sponsorship like a hockey team not a mega one, tend to be a little bit more based on reality but not totally based on reality. Because - and I'll finish this just so you understand exactly what I'm trying to say - sometimes a team could say that a sign is worth whatever. A great example to give you is the Calgary Flames right now. They could basically take our suite that we have as part of our deal and put it up for auction, you know...so the number doesn't mean anything anymore, it is what the market will bear.

SSor_ 3 noted that he thinks "in general, that the industry does a really poor job of evaluation" and spoke more about the lack of effective evaluation in sponsorship and the fact that this issue must be addressed before various aspects of evaluation can be compared and contrasted. 


\subsubsection{Forecasting the Future of Sponsorship Evaluation Practice}

The final question related to current practice in sponsorship evaluation asked the experts to forecast the future of sponsorship evaluation and provide their views on where it is headed. Again, expert opinions were consistent with all 14 interviewees supporting the view that sponsorship evaluation must improve and develop in terms of its theory, its practice, and its tools. A few of the many relevant expert statements are presented here. The lack of evaluation was supported by six of the experts with one (Int_2) claiming that "currently 26 per cent don't spend a nickel on evaluation and another 30 per cent of sponsors spend less than one per cent of their total sponsorship funds on evaluation". Some of the experts (three) focused on the benefits of evaluation. SSee_1 notes that "the more evaluations that people do, the better job they can do of weeding out [weak...] properties. And, the more crappy properties that are weeded out, the more legitimate and popular sponsorship will become". See_2 proposed that "agencies that specialize or position themselves as specialists in not just brokering sponsorship but in evaluating sponsorship will be well-positioned to succeed". The most important contribution from this line of questioning is that all of the experts emphasized the need for better tools in evaluation, especially given the growth of sponsorship. For example, SSee_4 suggested that "better developed tools and tactics" are needed. Int_4, SSor_1, SSor4, and SSor_6 all called for a more quantitative/ROI-based approach focused on sales generation. The experts stressed a need for an enhanced link between sponsorship and sales/ROI. 


\subsubsection{Barriers, Fears and Benefits of Evaluation}

A set of nine questions were asked to probe the advantages, limitations and barriers to effective sponsorship evaluation. The goal was to identify items that a wellplanned process model would emphasize (benefits) or seek to overcome (barriers and fears).

\subsubsection{Belief in sponsorship evaluation}

As a starting point for this line of questioning, interviewees were asked if they believed that sponsorship could be evaluated effectively. All 14 expert interviewees indicated that they believed that sponsorship could be evaluated effectively; with 12 of 14 responding with an outright yes and 2 of the 14 putting conditions on their yes. SSee_2 responded "yes, I do as long as the metrics are mutually agreed to at the beginning of the process" and SSor_2 answered "I think it can be but I also think there is an incredible amount of wiggle room for misinterpretation." Thus, overall the results point strongly to the fact that this group of experts strongly believes in sponsorship evaluation and that it can be done well. SSor_1, however, points out a very important challenge (i.e., attribution) facing sponsorship evaluation by reminding us that "we are always going to have grey areas in a sponsorship that are going to be difficult to put values to."

\subsubsection{Senior management motivations for sponsorship evaluation}

The reasons that motivate senior managers to evaluate sponsorships were a point of contention in the sponsorship evaluation literature that was equally expressed by the expert interviewees. Four of the experts noted that, sometimes, senior managers choose to 
sponsor properties because they are personally involved in the property (e.g., "[they] sponsor golf because they play golf." (Int__ 4)). All fourteen experts pointed to increasing instances of sponsorship being a business decision, while the level of emphasis varied between respondents.

The trend of sponsorship turning increasingly into a business decision is of central importance to this dissertation. SSee_2 noted that senior management "has to... [demonstrate] that [sponsorship is] a worthwhile investment that would validate their decisions". Others noted varying motivations for evaluating sponsorship within a business-based approach. SSee_4 noted that senior management often commission evaluations in order to convince a partner to be involved in future events. SSor_1 indicated that, in some industries, competition is on the rise and margins are getting tighter, motivating senior management to evaluate in order to justify the spending of "dollars that you would otherwise spend on other areas, so you'd better be sure that what you are sponsoring isn't just a CEO prerogative of 'hey my wife likes figure skating so lets sponsor that', it...generates ROI". SSor_2 summarizes a variety of reasons why senior management decides to evaluate a sponsorship:

I think that they need to be increasingly accountable to the dotted line budgets that are attached to these sponsorships, to the marketing communications budgets. And, I think today in the business culture that is more open for responsibility, they need to demonstrate that these corporate partners, particular the big money ones, the partnership meet the end goals and objectives of what they are trying to accomplish.

But most of the experts (10) support that the main motivation of a sponsorship evaluation is to verify/measure ROI or "to determine ROI, value of the investment" (SSor_4) or "to determine if the return on their investment was worth it" (SSor_6). SSor_3 summarizes: 
To me, it is just them being responsible as senior managers and understanding what the return is on the investment that they are making. I think marketing has always been seen as an expense which it is and thus there has always been this difficultly linking it to revenue growth. So think that again as sponsorship grows and becomes more important to companies across the globe and plays a bigger role in their overall marketing efforts and takes a bigger chunk of their marketing budgets, with that increased spending senior management are going to have to justify, whether it be to their senior management or to the shareholders, what the return is on the investment.

Motivations to not evaluate were also expressed from a business point of view. For example, SSor 2 noted that fatigue in the form of "de-motivated people" postsponsorship (where evaluations usually take place) often leads to the cancelling of evaluations.

\subsubsection{Resource allocation and sponsorship evaluation}

Interviewees were asked if they thought sponsorship evaluations had an effect on future funding decisions and resource allocations by sponsors and sponsees. As expected, experts reported that a positive evaluation affects future funding and/or resource allocation decisions.

The expert interviewees unanimously supported the notion that future decisions would be affected by either a positive or a negative evaluation. But they were emphatic that a negative evaluation would likely have a more significant impact than a positive evaluation, since "generally with a bad experience, you are less likely to want to repeat" (SSee_1) "with a greater pre-disposition for termination" (SSee_3). SSee_2 summarized:

On the negative side, sponsorship is very fickle by nature; it is not a commodity like media. There are a lot of emotional, a lot of experiential elements to it that if it didn't work or if it didn't drive sales or it didn't return or give a good ROI, well then $100 \%$ it would be still an easy decision to say let's spend our money elsewhere. 
With respect to the impact of a positive evaluation, experts were strong in their support including Int_4 who emphatically reported: "absolutely...you have the results...you can go back next year" and SSor_3 who explained that "if you show that your investment has been paid off and that it has been a valuable property, it gives you ammunition and leverage to go back and do that deal again but it also provides for investigating new opportunities with other properties".

\subsubsection{Barriers to effective sponsorship evaluation}

When building towards a process model for the evaluation of sponsorship, it is important to identify the key barriers that affect one's ability to effectively evaluate a sponsorship. Once these barriers are known, the model can be developed to overcome or mitigate their effects. The 14 experts provided a total of 31 barriers during the interviews. Their responses were reviewed and grouped by theme in Table 25 below.

\section{Table 25: Barriers to Effective Sponsorship Evaluation}

\begin{tabular}{|l|c|l|}
\hline \multicolumn{1}{|c|}{ Barrier } & Mentions & \multicolumn{1}{|c|}{ Explanation } \\
\hline $\begin{array}{l}\text { A lack of communication } \\
\text { between sponsor and sponsee }\end{array}$ & 9 & $\begin{array}{l}\text { Weak preparation, poor planning and limited resources leads } \\
\text { to a lack of information sharing between sponsor, sponsee \& } \\
\text { intermediary }\end{array}$ \\
\hline $\begin{array}{l}\text { Lack of effective and } \\
\text { consistent evaluation tools }\end{array}$ & 8 & $\begin{array}{l}\text { Although many have their own proprietary methods, there } \\
\text { exist few options, no agreed upon metrics (including for ROI } \\
\text { and brand/image effects) and no cohesive, recognized model }\end{array}$ \\
\hline $\begin{array}{l}\text { Lack of energy, support and } \\
\text { resources to complete post- } \\
\text { event evaluation }\end{array}$ & 8 & $\begin{array}{l}\text { After hard work to make an event happen, not much left to get } \\
\text { geared up for a full evaluation, including those who fear the } \\
\text { effects of a poor evaluation }\end{array}$ \\
\hline $\begin{array}{l}\text { Poorly conceived strategy and } \\
\text { implementation plan for the } \\
\text { evaluation }\end{array}$ & 5 & $\begin{array}{l}\text { A common barrier identified is that evaluation is often an } \\
\text { after-thought which means it is not properly planned and } \\
\text { implemented, leading to poor and 'untrusted' results }\end{array}$ \\
\hline $\begin{array}{l}\text { Philanthropic activity still } \\
\text { being carried out under the } \\
\text { banner of sponsorship }\end{array}$ & 1 & $\begin{array}{l}\text { pretending donations are sponsorships hurts both future } \\
\text { sponsorship and future philanthropy }\end{array}$ \\
\hline
\end{tabular}


As noted in Table 25, there are four barriers (by theme) that received considerable mention from the experts. These four empirical findings support the literature on sponsorship evaluation and the hypothesis of this dissertation that emphasizes the importance of a functioning sponsor-sponsee relationship, the need for consistent and effective tools of evaluation, and the need to increase support and strategic planning in sponsorship evaluation.

\subsubsection{Identification of fears about sponsorship evaluation}

Fears that exist around sponsorship evaluation may affect one's ability to effectively evaluate a sponsorship. Once these fears are discovered, the process model can be developed to overcome or mitigate their effects. During the interviews, the interviewees identified a total of 18 fears about sponsorship evaluation. These were analyzed, grouped and presented in Table 26 below.

\section{Table 26: List: Fears about Sponsorship Evaluation}

\begin{tabular}{|l|c|l|}
\hline \multicolumn{1}{|c|}{ Fear } & Mentions & \multicolumn{1}{c|}{ Expert Provided Support } \\
\hline $\begin{array}{l}\text { Fear of negative results or } \\
\text { failed event (sponsors fear lost } \\
\text { investment/ sponsees fear not } \\
\text { getting renewed / fear of 3rd } \\
\text { party evaluation) }\end{array}$ & 14 & $\begin{array}{l}\text { What will happen? What if we don't achieve our objectives? } \\
\text { What will my boss say? Could we lose key contacts or } \\
\text { damage key relationships? What if we run out of time or } \\
\text { resources? What if other priorities come up? }\end{array}$ \\
\hline $\begin{array}{l}\text { Fear that investment was not } \\
\text { leveraged or properly } \\
\text { leveraged }\end{array}$ & 2 & $\begin{array}{l}\text { For whatever reason (lazy, financial, etc.) we didn't leverage } \\
\text { like we should have... what if senior management finds out? }\end{array}$ \\
\hline $\begin{array}{l}\text { Fear that reason will be } \\
\text { uncovered }\end{array}$ & 1 & $\begin{array}{l}\text { Senior management fear that it will be discovered that they } \\
\text { invested because of personal interest or connection }\end{array}$ \\
\hline $\begin{array}{l}\text { Sponsee fear of asking/using } \\
\text { more money for evaluation }\end{array}$ & 1 & $\begin{array}{l}\text { We've already spent a lot of dollars and time, will people } \\
\text { object to more? }\end{array}$ \\
\hline
\end{tabular}

Table 26 demonstrates a strong consistency amongst the experts that a fear of negative results is a major problem in sponsorship evaluation. Additionally three minor themes 
were identified that may also be related to the major theme, as fears about leveraging, revealing the true reason for a sponsorship and asking for resources for an evaluation could all be generated by a fear of negative results or a fear of those who fear negative results.

\subsubsection{Benefits of Evaluation}

Given the expectation that evaluation results - positive or negative - would impact future funding decisions and that various barriers and fears would impede sponsorship evaluation, interviewees were asked to share some of the benefits of a welldone evaluation so that the benefits could be used to help make the case to sponsors and sponsees to evaluate properly. The interviewees mentioned 22 benefits, which were analyzed and grouped by theme. This process generated two major themes around the benefits of evaluation. First, experts pointed to the fact that a well-done sponsorship evaluation provides direction and justification (mitigated risk) for future business decisions (12 mentions). Second, the interviewees stressed the benefit that a well-done sponsorship evaluation provides specific measured results on the objectives of interest to all parties involved (including shared objectives) including both ROI and media benefits (10 mentions).

\subsubsection{Frequency of Dually-Supported (Sponsor and Sponsee) Evaluation}

The final question in this part of the interview simply asked experts to estimate how often sponsorship evaluation occurs with both the sponsor and the sponsee fully supportive of the evaluation. Given the position that this is an ideal scenario, the 
frequency of this occurrence was deemed important to the research. Reporting provided by the expert interviewees was varied and inconclusive: three experts opted out of answering the question, five noted that such situations are very rare, four noted that it is common or increasing in frequency ("I think it is more common than it used to be (SSee_1)), and 2 (SSee_2; Int_1) suggested it is something that sponsees would like but are not privy to.

\subsubsection{Understanding the Timing of Evaluation}

The final series of interview questions focused on developing an understanding around the timing of evaluation. The results of these questions were reviewed and analyzed to provide background on timing. When asked at what point evaluation is typically first discussed, the experts were divided in their opinions: six indicated 'precontract', five said 'during-contract', and three noted 'post-contract'. Deeper analysis provides interesting results. Of the six experts who indicated that evaluation was first mentioned pre-contract during negotiations, four were sponsors and two were intermediaries, but notably, none were sponsees. Of the five experts who said that evaluation was mentioned during the contract, three were sponsees and two sponsors; perhaps implying that evaluation in these cases was driven by a senior management request for an ROI. The three experts who recalled that evaluation is typically mentioned post-contract are all involved principally with non-profit and minor properties, so perhaps this is their reality due to resource issues. One of the interviewees (SSee_3) provided a detailed response that summarizes these issues and demonstrates the importance of evaluation. 
When I first started [this job] there was a mixture of ROI relationships and there were buddy to buddy or colleague relationships. So, through that first 4 years, we kind of lived through the ups and downs of that and we conducted a major process of renewal in 2001/2002 season...and attempted to shift everything more to ROI deliverables. Then we talked at that time knowing that the possibility of the Olympics coming to Vancouver and our concern was sponsorship...36 to $38 \%$ of our gross revenue and we thought that we needed to protect ourselves and position ourselves properly leading up to 2010 but also more importantly protect post 2010 . So, knowing that you need a product to sell, we spent some time managing...kind of collecting and building our inventory of events...so we gathered that, put that all in place and we had that package ready to go pre the July 2003 or 2004 announcement regarding 2010 ...we then went through a process where we evaluated our sales agency at the time and decided it was best to bring it in house and contracted a new sponsorship sales employee dedicated to us and also dedicated to selling inventory around our major events so we're not re-inventing the wheel. Then the last piece of the puzzle was OK how do we find out what all of this is worth...how do we put in place some reasonable approach to evaluate this and see what it is worth. So, evaluation is kind-of the last piece of that puzzle.

The experts (13 out of 14) believe strongly that evaluation can happen post-hoc but they caution - on a number of levels - that it can only work if planned properly, in an unbiased fashion, with access to reliable and valid data as noted by SSee_2: "it is just a matter of having access to deliverables and research, such as ratings or visibility scores".

\subsubsection{Updated Sponsorship Evaluation Process Model}

Expert interviewees were asked to review the first draft (D1) of the Process Model. The protocol involved allowing the interviewee as much time as they would like to review the model followed by the interviewer taking three to five minutes to explain the model and its terminology. This then led, typically, to discussion around the model and identification of areas where it could potentially be improved. The level of this discussion varied widely by interviewee, ranging from no discussion (one expert) to 
animated feedback that lasted 30 minutes and carried over into lunch (five experts). Three of the experts asked for the model to be sent by email and then provided additional feedback in the weeks following their interviews.

Results revealed unanimous agreement amongst the 14 interviewees that the model is needed and appropriate to sponsorship evaluation. SSee_1 commented that: "I think it is actually really good...these are things that I know but I haven't seen it laid out like that" while SSor_4 said "it is complex but looks good to me". SSee_3 supported the model as well: "I think that we follow many of those steps. I don't think that there is anything there I would look at and go 'oh jeez we do something differently" (SSee_3). SSee_4 said "I have nothing to add...looks comprehensive to me". A very positive sign was that five of the experts offered one of their sponsorships to test the model. In general, the experts also like the concept of reach (SSee_3; SSee_2; SSee_4) and the fact that the model was conservative and realistic in nature (Int_1; SSor_1; SSor_6).

A number of suggestions (18) were proposed to improve the process model. In this regard, two sources of suggestions were obtained: (i) those explicitly provided in the final question of the expert interviews, as well as (ii) those refinements gleaned from the analysis of the expert interviews. Each suggestion was reviewed in detail and carefully considered. A list of the suggested alterations, the rationales for consideration and the adoption statuses follows in Table 27: 
Table 27: Process Model Refinements

\begin{tabular}{|c|c|c|}
\hline Proposed Change & Rationale given by Expert & Adoption Status \\
\hline $\begin{array}{l}\text { Length of implementation } \\
\text { clarified }\end{array}$ & $\begin{array}{l}\text { If done properly, model could require } 3 \text { years with } \\
\text { significant data required (Int } 2 ; \text { SSee } 2 \text { ) }\end{array}$ & No change. Implicit in the model. \\
\hline $\begin{array}{l}\text { Objectives (Step 3) need to also } \\
\text { be considered in Step } 1 \text { (i.e. a } \\
\text { forecast) }\end{array}$ & $\begin{array}{l}\text { Avoid embarking on evaluation if objectives are not } \\
\text { known to avoid inefficiency as you shouldn't do a } \\
\text { sponsorship unless you know objectives up front } \\
\text { (SSee 1; Int 4) }\end{array}$ & $\begin{array}{l}\text { Built into Step 1, Setting the Stage } \\
\text { as a sub-point under item } 1 .\end{array}$ \\
\hline $\begin{array}{l}\text { Where is the mega-sponsee versus } \\
\text { typical sponsee stuff we talked so } \\
\text { much about? }\end{array}$ & $\begin{array}{l}\text { If it is so important why isn't the distinction very clear } \\
\text { in the model? (SSee_1) }\end{array}$ & $\begin{array}{l}\text { Built into Step 1, part 1- } \\
\text { determination of scenario }\end{array}$ \\
\hline $\begin{array}{l}\text { Be clear that philanthropy or } \\
\text { donation is not sponsorship }\end{array}$ & $\begin{array}{l}\text { Since you are not acquiring someone else's equity they } \\
\text { should not be included (SSee 1; SSor 3) }\end{array}$ & Wording clarified in Step 1 \\
\hline $\begin{array}{l}\text { Enhance importance of upfront } \\
\text { determination of sponsorship or } \\
\text { not }\end{array}$ & $\begin{array}{l}\text { The working definition is good... want to make sure } \\
\text { that only those that meet the definition go forward } \\
\text { (SSee 2) }\end{array}$ & Wording clarified in Step 1 \\
\hline $\begin{array}{l}\text { Ideally, model needs to be set up } \\
\text { to be used by both sides }\end{array}$ & Sponsor and sponsee use (SSee_2) & No change. Implicit in the model. \\
\hline $\begin{array}{l}\text { Include upfront cost/benefit } \\
\text { analysis before going forward }\end{array}$ & $\begin{array}{l}\text { "we want to know that although there is this exchange } \\
\text { of cash for return of services, at the end of the day if it } \\
\text { doesn't make us money, if it doesn"t deliver something } \\
\text { to the bottom line or if it doesn't help us deliver a } \\
\text { program better, then that is not our business. There has } \\
\text { to be a net to the bottom line" (SSee 3) }\end{array}$ & $\begin{array}{l}\text { New step added to Step 1: called the } \\
\text { "Cost/Benefit Pre-Test" }\end{array}$ \\
\hline $\begin{array}{l}\text { The inclusion of industry } \\
\text { specificity (i.e. industry-based } \\
\text { impacts) }\end{array}$ & $\begin{array}{l}\text { "The biggest gap that exists is that you cannot build or } \\
\text { apply a model that would apply to every industry or } \\
\text { every company" (SSor_1) }\end{array}$ & $\begin{array}{l}\text { 'Industry effects' added to Step } 2 / 3 \\
\text { box that influences attributes of } \\
\text { relationship }\end{array}$ \\
\hline $\begin{array}{l}\text { Include a more holistic } \\
\text { perspective on sponsorship }\end{array}$ & $\begin{array}{l}\text { Regarding sponsorship from a relationship marketing } \\
\text { framework is new in the literature (SSor_2) }\end{array}$ & No change. Implicit in the model. \\
\hline
\end{tabular}




\begin{tabular}{|l|l|l|}
\hline Include 'major event' impact & $\begin{array}{l}\text { "If something happened that changed the flow of the } \\
\text { partnership. Let's say something major so an athlete } \\
\text { drops out of an event. For example, Mats Sundin leaves } \\
\text { the Leafs and a sponsor had their program built around } \\
\text { them. Do you feel that this contingency factor, this } \\
\text { feedback loop is included in the model?" (SSor 2) }\end{array}$ & $\begin{array}{l}\text { "Unplanned events" impact added to } \\
\text { shirking box (Step 5) }\end{array}$ \\
\hline $\begin{array}{l}\text { Consideration of co-sponsorship } \\
\text { effects }\end{array}$ & $\begin{array}{l}\text { "There is usually more than one sponsor who all have } \\
\text { different goals and you have to know that going } \\
\text { in...move it up to beginning" (Int 4) }\end{array}$ & $\begin{array}{l}\text { "Co-sponsoring effects (activities of } \\
\text { other sponsors)" added to external } \\
\text { influences box (Step 6/7) }\end{array}$ \\
\hline $\begin{array}{l}\text { Consider augmenting } \\
\text { consideration of 'shirking' effect }\end{array}$ & $\begin{array}{l}\text { I don't think it has every really been measured } \\
\text { (SSor_3) }\end{array}$ & $\begin{array}{l}\text { (-) added to shirking box (Step 5) to } \\
\text { demonstrate that it will be subtracted } \\
\text { from results }\end{array}$ \\
\hline $\begin{array}{l}\text { Include rigourous data collection } \\
\text { which includes face-to-face time } \\
\text { with key decisions makers }\end{array}$ & $\begin{array}{l}\text { Necessary to understand clearly the objectives and } \\
\text { motivations of those involved, which then enables } \\
\text { improved evaluation (SSor 3) }\end{array}$ & $\begin{array}{l}\text { 'Talk to Key Players' box added to } \\
\text { Step 4 (Establish Metrics) }\end{array}$ \\
\hline $\begin{array}{l}\text { The role of economic impact } \\
\text { needs to be further considered }\end{array}$ & $\begin{array}{l}\text { Would consideration of these models help? (SSor_3) } \\
\text { Flexible implementation is a } \\
\text { necessary aspect of the model }\end{array}$ & $\begin{array}{l}\text { Nothing added but concept of direct, } \\
\text { indirect and intangible impacts may } \\
\text { be used to report results }\end{array}$ \\
\hline $\begin{array}{l}\text { 6...everybody's business objectives are different...I } \\
\text { think that there has to be some sort of flexibility or } \\
\text { something that allows you to tailor the model to your } \\
\text { business that will make sense for your world...it would } \\
\text { be great if an adaptable, flexible model that was easy to } \\
\text { implement could be developed and shared" (SSor_1) }\end{array}$ & $\begin{array}{l}\text { The process model designed with } \\
\text { flexibility in mind so it can be } \\
\text { customized for each sponsorship } \\
\text { evaluation }\end{array}$ \\
\hline
\end{tabular}

As outlined in Table 27 above, a number of changes were made to the model to improve its functional usefulness. Based on these

changes, the updated model follows: 


\section{Process Model: Sponsorship Evaluation}

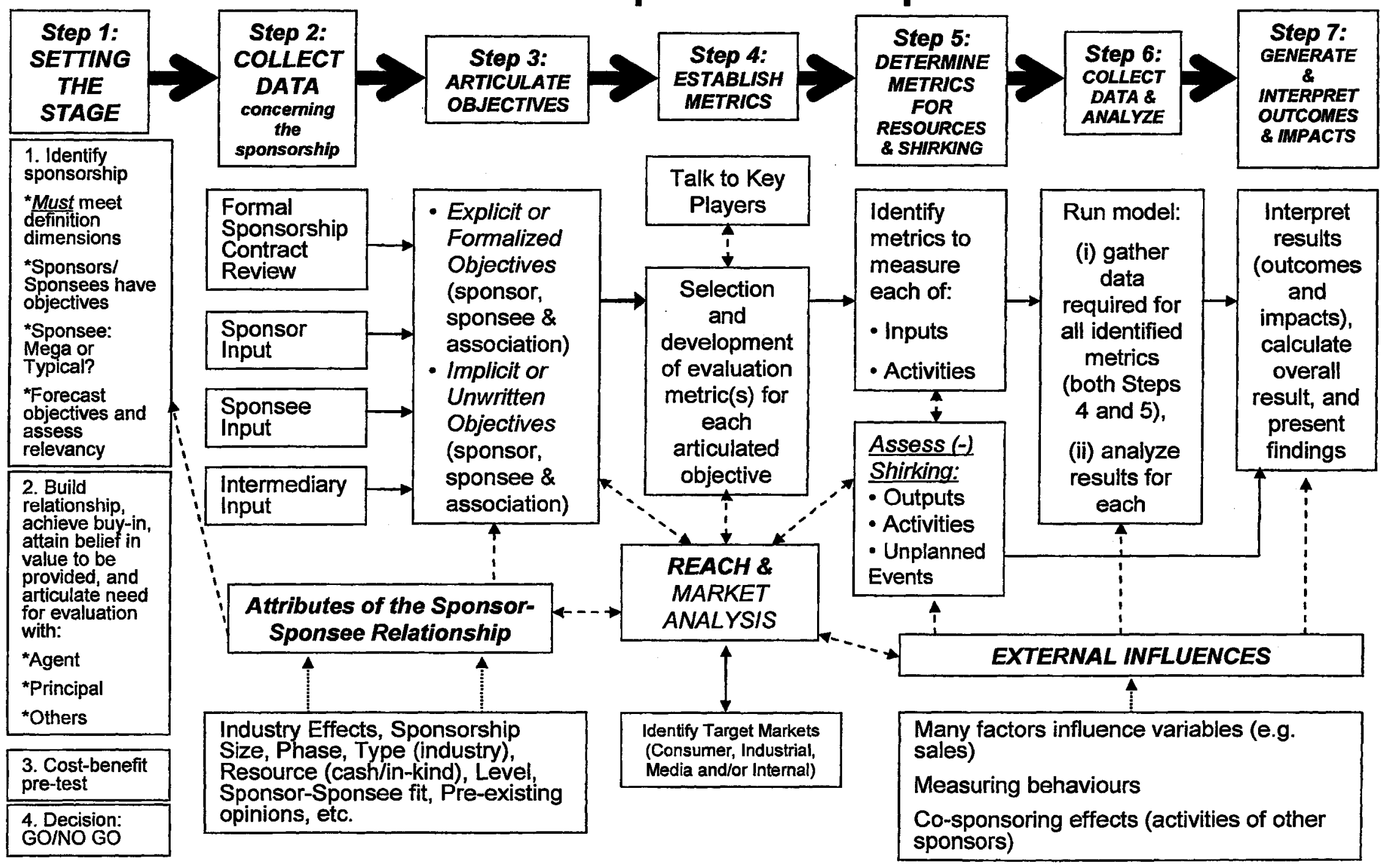




\subsection{Results Phase 2: Sponsorship Evaluation Case Studies}

Each of the two sponsorship evaluation case studies is presented in this section separately. For each evaluation, the research approach involves implementing the steps of Process Model D2. Results and analysis are presented for each of the case studies per the steps taken and the data gathered at each step, with methodological considerations provided where necessary, including an introductory background analysis on how each case study was conceived. For each case, the steps and sub-steps are presented in the same order as they appear in Process Model D2. As noted in Chapter 5 (methodology), methods, results and analysis are presented together to best articulate the implementation of the process model.

\subsubsection{Sponsorship evaluation 1: ATB Financial - Edmonton Grand Prix Sponsorship}

On November 26,2005 , the author presented an early version of this process model at the Canadian Sponsorship Forum in Vancouver, British Columbia. Following the presentation, he was approached by Kelly Rudan, the Marketing Manager of ATB Investor Services - a key division of a large Alberta-based financial services institution and a discussion ensued regarding the model and sponsorship evaluation. The discussion carried over into further phone and email communication leading to the proposed idea of using the model to evaluate ATB's forthcoming (at the time) sponsorship of the Edmonton Grand Prix car race, one of the largest events in the province. 


\subsubsection{Step 1: setting the stage}

The following four sub-sections follow the four sub-sections of Step 1 of the process model.

\subsection{Identify sponsorship}

This sub-section introduces the key players in the sponsorship. Alberta Treasury Branches (ATB Financial) has assets of $\$ 17.6$ billion making it one of Alberta's largest full-service financial institutions. Its competitors include the 'Big 5' Canadian banks (CIBC, RBC, Scotiabank, TD Bank, and Bank of Montreal), Credit Unions and the Canadian Western Bank (Rudan, 2006a). Headquartered in Edmonton, ATB serves over

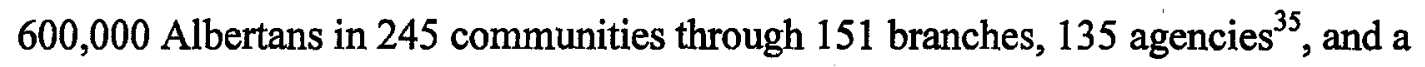
Customer Contact Centre in Calgary. ATB has approximately 3,500 employees who work in the head office, the call centers, the processing centers and the branches. ATB also reaches its customers via Automated Banking Machines (ABMs), Internet and Telephone. The bank offers a wide range of wealth management products and services through its ATB Investor Services division. ATB, formerly a government entity, is managed by a Board of Directors which is appointed by the Lieutenant Governor of Alberta. ATB has been performing very well in recent years. In fact, since 1997, the bank has reported a profit in every quarter and its market share has grown significantly. The results of ATB Financial's year-end March 31, 2006 report underline the bank's strong position with net income of $\$ 198.7$ million, assets of $\$ 17.6$ billion, total deposits of $\$ 15.9$ billion, loans amounting to $\$ 14.8$ billion, and equity of $\$ 1.35$ billion. ATB also holds a number of important memberships and maintains partnerships with key

\footnotetext{
${ }^{35}$ Agencies refer to partner financial institutions such as a local credit union
} 
organizations, including Canadian Payments Association, Interac Association, MasterCard Canada, and Canadian Bankers Association. ATB is organized in four divisions including ATB MasterCard. The other divisions are Investor Services, Business Financial Services and Customer Financial Services.

ATB's market share has been growing; however industry study results demonstrate some uncertainty as to how much. One study (see Table 28 below) shows ATB Financial as ranking $3^{\text {rd }}$ in Alberta with $13 \%$ of the market of Albertan Financial Institutions.

Table 28: Financial Institution Market Share, Alberta, 2002 and 2005

\begin{tabular}{|l|c|c|}
\hline Financial Institution & Market Share (2005) & Market Share (2002) \\
\hline RBC Financial & $21 \%$ & $20 \%$ \\
\hline TD Canada Trust & $17 \%$ & $18 \%$ \\
\hline ATB Financial & $13 \%$ & $8 \%$ \\
\hline CIBC & $12 \%$ & $14 \%$ \\
\hline Any Credit Union & $11 \%$ & $12 \%$ \\
\hline Scotiabank & $10 \%$ & $6 \%$ \\
\hline Bank of Montreal & $9 \%$ & $14 \%$ \\
\hline President's Choice & $4 \%$ & $1 \%$ \\
\hline HSBC & $1 \%$ & $0 \%$ \\
\hline ING Direct & $0 \%$ & $0 \%$ \\
\hline National Bank & $0 \%$ & $0 \%$ \\
\hline
\end{tabular}

Source: Market Share in Alberta (Main Institution, Primary Users), Third Party Agency Report

However, based on a different study that shows ATB Financial with an $8.7 \%$ market share, Figure 11 below shows ATB Financial trailing the Big 5 Canadian banks in Alberta. 


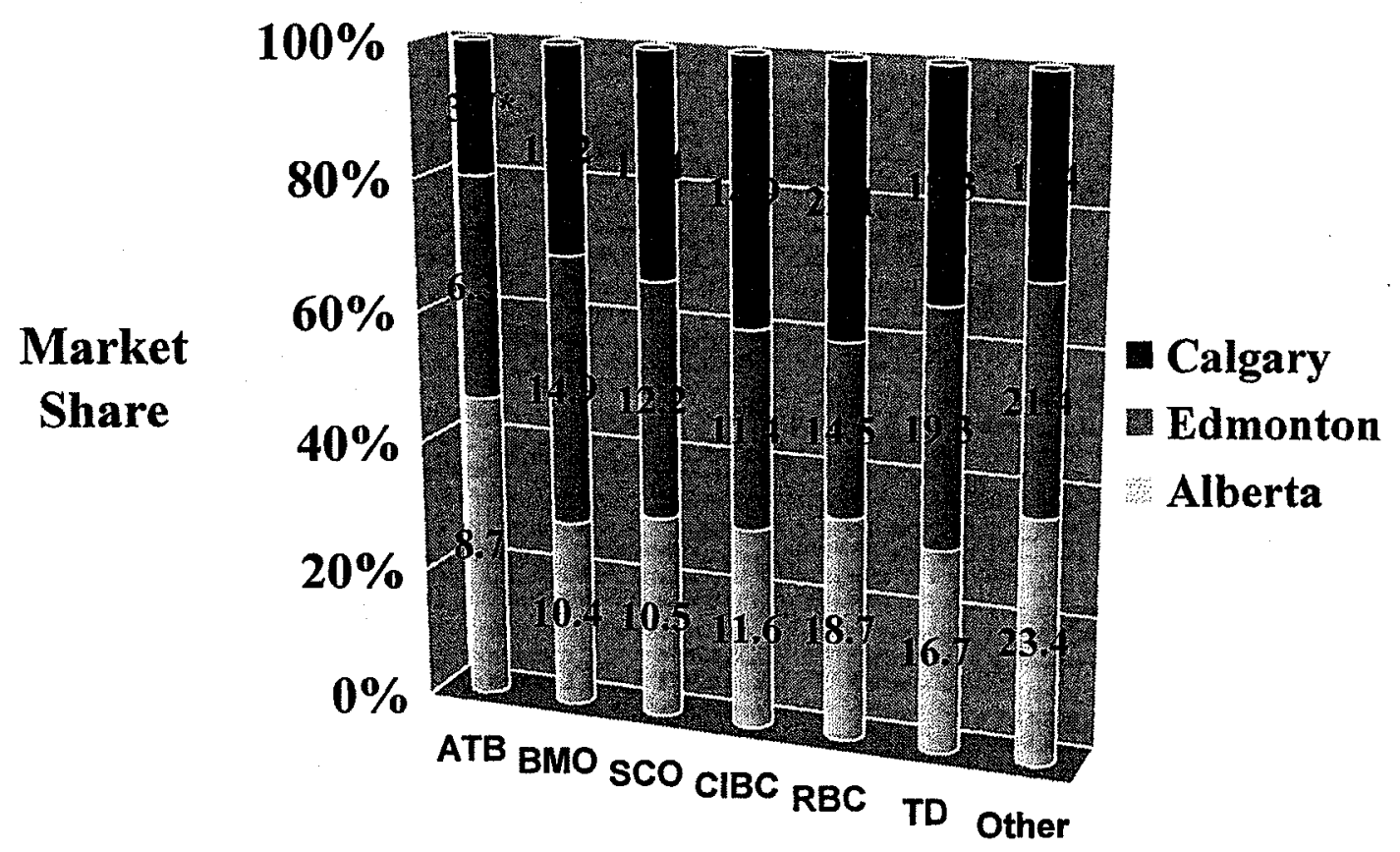

The 2006 Edmonton Grand Prix (EGP) was the $2^{\text {nd }}$ running of a major automobile race in the city. It was scheduled for July $21^{\text {st }}$ to $23^{\text {rd }}, 2006$ in Edmonton, Alberta. It was held at the City Centre Airport on a temporary $3.15 \mathrm{~km}$ course. The event was part of the Champ Car World Series and was officially titled the '2006 West Edmonton Mall Grand Prix, presented by The Brick'. The title sponsors of the 2006 Champ Car World Series were Ford and Bridgestone, which hold promotional rights at all series' events. The EGP itself had 25 sponsors including ATB, as outlined in Table 29 below:

\section{Table 29: 2006 EGP Sponsors}

\begin{tabular}{|l|l|}
\hline Type of Sponsor & Sponsor \\
\hline Title Sponsor & West Edmonton Mall \\
\hline Presenting Sponsor & The Brick \\
\hline Platinum Sponsors (5) & $\begin{array}{l}\text { EPCOR, Konica Minolta, Ford, Travel Alberta, Edmonton } \\
\text { Tourism }\end{array}$ \\
\hline Television Promotional Partner & Global Edmonton \\
\hline
\end{tabular}




\begin{tabular}{|l|l|}
\hline Newspaper Promotional Partner & Edmonton Journal \\
\hline Radio Broadcast Rights Holder & AM 630 CHED \\
\hline Beer Supplier & Molson Canadian \\
\hline Gold Sponsors (4) & $\begin{array}{l}\text { The Sutton Place Hotel, ATB Financial, Driving Force } \\
\text { Vehicle Sales Rentals Leasing, River Cree Resort and Casino }\end{array}$ \\
\hline Silver Sponsors (3) & Hole's Gardening, Mac's, Pepsi \\
\hline Pit Lane Club Sponsor & Capital City Savings Business Banking \\
\hline High Octane Club Sponsor & SS INC Shipper and Supplier \\
\hline Friends of the Grand Prix & $\begin{array}{l}\text { Alberta Motor Association, ATCO Frontec, Roger's } \\
\text { Wireless, Yellow Cab }\end{array}$ \\
\hline This race was made possible by & Edmonton Airports \\
\hline
\end{tabular}

**Note: the amounts of the sponsorships and criteria for each type are not public information

The three-day agenda for the EGP involved both on-track and off-track activities

providing three full days of entertainment for fans, running from 7:00am every morning until late each night. On-track activities included practice runs, qualifying rounds, various races, pace car track activities and autograph sessions. Off-track activities included 12 rock concerts (including names like Honeymoon Suite and 5440), autograph sessions, and a Miss Grand Prix pageant. The infrastructure for the event includes grandstand seating for over 50,000 people, theme parks, and a downtown race course on city streets. The Marketing Manager of ATB described it as follows: "this thing is more like a festival than a race, since there will be all sorts of activities there ranging from booths to rides to hosting venues to the race itself" (Rudan, 2006a). Ticket prices are outlined in Table 30 below:

\section{Table 30: 2006 EGP Ticket Prices}

\begin{tabular}{|l|l|}
\hline Ticket Package & Price \\
\hline Gold Package - 3-day reserved seating ('best seats at the track') & $\$ 235$ \\
\hline Silver Package - 3-day reserved seating ('close to the action') & $\$ 170$ \\
\hline Bronze Package - 3-daq reserved seating ('prime racing areas') & $\$ 105$ \\
\hline Paddock Passes (houses the Champ Cars and team transporter vehicles) & $\$ 50$ \\
\hline Pit Passes (access to pit row, where cars and teams are located) & $\$ 25$ \\
\hline
\end{tabular}

36 "This race was made possible by" is one of the official sponsorship categories. 
The decision and approval to proceed with the evaluation was officially made on February 16, 2006 following a cost-benefit pre-test and the subsequent approval by senior management at ATB. As the Process Model prescribes, a number of steps (described in the sub-sections that follow) took place prior to final approval (between November 28 , 2005 and February 10, 2006) in order to be certain that the ATB-EGP sponsorship was an appropriate candidate for evaluation.

\subsection{Pre-Sponsorship Investigation}

This subsection describes the investigation vis-à-vis the four aspects of Process Model D2 Step 1, Box 1. The purpose of this is to learn enough about the sponsorship to allow for a preliminary assessment to determine if the sponsorship is an appropriate candidate for evaluation. This pre-investigation involved numerous email and phone conversations between the author and the ATB Marketing Manager, as well as a review of the event and ATB websites. Following this review, it was observed that this sponsorship meets all the dimensions of the working definition of sponsorship (see Table 31 below for full explanation of how each tenet was met), that both sponsors and sponsees have objectives (Rudan, 2005a), that both parties would be willing to contribute to and participate in the evaluation (Rudan, 2005a) and that it meets the definition of a mega-sponsee sponsorship situation ("...the Grand Prix race itself is a huge event, worldwide TV coverage, Alberta's largest event along with the Calgary Stampede... with, in my estimation, over ten million [dollars] in sponsorship revenues" (Rudan, 2005b)). Discussions about the sponsorship also revealed that the objectives of the sponsorship were complex and extensive enough to warrant evaluation (Rudan 2005b; Rudan 2006b). 
Finally, it was noted that the evaluation process would contribute to the development of

the process model.

\section{Table 31: ATB-EGP Sponsorship and Working Definition}

\begin{tabular}{|c|c|}
\hline Dimensions of Operational Definition & How met by ATB-EGP Sponsorship \\
\hline $\begin{array}{l}\text { One party (the sponsor) invests resources in } \\
\text { another party (the sponsee), where: } \\
\text { a. the sponsee provides promotional value in } \\
\text { return, and } \\
\text { b. the sponsor makes the investment in order to } \\
\text { achieve image-based, brand-based and/or } \\
\text { media-based objectives. }\end{array}$ & $\begin{array}{l}\text { ATB Bank is investing significant resources } \\
\text { to become a sponsor of the Edmonton } \\
\text { Grand Prix automobile race where the EGP } \\
\text { is providing ATB with promotional value in } \\
\text { return for cash. ATB has image, brand, } \\
\text { media and sales objectives. }\end{array}$ \\
\hline $\begin{array}{l}\text { The relationship between the sponsor and the } \\
\text { sponsee is a principal-agent relationship, where } \\
\text { the sponsee provides a service to the sponsor. }\end{array}$ & $\begin{array}{l}\text { ATB is taking the role of principal and has } \\
\text { contracted EGP as its agent to achieve a } \\
\text { variety of marketing objectives. }\end{array}$ \\
\hline $\begin{array}{l}\text { Joint sponsor-sponsee activities are part of the } \\
\text { sponsorship. }\end{array}$ & $\begin{array}{l}\text { ATB will be working with the co-sponsor } \\
\text { (MasterCard) and EGP on a number of } \\
\text { initiatives. }\end{array}$ \\
\hline $\begin{array}{l}\text { Consumers (or members of the target market of } \\
\text { the promotion) are exposed to three specific } \\
\text { entities: the sponsor's brand, the sponsee's } \\
\text { brand and the sponsor-sponsee association. }\end{array}$ & $\begin{array}{l}\text { In addition to ATB and EGP, the } \\
\text { sponsorship involves considerable } \\
\text { promotion of the ATB-EGP association via } \\
\text { a variety of activities (e.g., website, go-kart } \\
\text { track). }\end{array}$ \\
\hline $\begin{array}{l}\text { Consumers (or members of the target market of } \\
\text { the promotion) consider the sponsor of a given } \\
\text { sponsee to be a partner of that sponsee, and this } \\
\text { consideration lasts longer than the sponsorship } \\
\text { due to the goodwill or emotional ties that } \\
\text { consumers build over time. }\end{array}$ & $\begin{array}{l}\text { EGP promotes all of its sponsors as partners } \\
\text { in bringing such a major event to the city } \\
\text { and the province. In the case of ATB, its } \\
\text { messaging includes identifying ATB as a } \\
\text { partner in Alberta. }\end{array}$ \\
\hline $\begin{array}{l}\text { The sponsor-sponsee association is exploited or } \\
\text { leveraged by one or both parties. }\end{array}$ & $\begin{array}{l}\text { Both ATB and EGP had extensive plans to } \\
\text { leverage the sponsorship. }\end{array}$ \\
\hline $\begin{array}{l}\text { The transfer of elements of the sponsee's image } \\
\text { to the sponsor is of interest to the sponsor. }\end{array}$ & $\begin{array}{l}\text { One of ATB's objectives is to re-brand } \\
\text { itself as a full-service Albertan bank } \\
\text { particularly in the cities, an element of the } \\
\text { EGP's image. }\end{array}$ \\
\hline $\begin{array}{l}\text { The exclusivity of the sponsorship is of interest } \\
\text { to the sponsor. }\end{array}$ & As per the sponsorship contract. \\
\hline $\begin{array}{l}\text { Congruency (fit) between the sponsor and the } \\
\text { sponsee is important to both parties. }\end{array}$ & $\begin{array}{l}\text { Given the mega-sponsee situation both } \\
\text { parties considered their options and } \\
\text { determined that congruency exists. Both } \\
\text { parties noted that they had alternative } \\
\text { options to consider. }\end{array}$ \\
\hline $\begin{array}{l}\text { Philanthropy is not the primary objective of the } \\
\text { sponsor (i.e. the investor has non-philanthropic } \\
\text { expectations from the sponsorship). }\end{array}$ & $\begin{array}{l}\text { ATB's decision to sponsor is a business } \\
\text { decision. }\end{array}$ \\
\hline
\end{tabular}




\subsection{Build relationships}

This sub-section reports on the status of the relationships between each organization involved with the sponsorship and the doctoral researcher. In addition to the sponsor (ATB) and the sponsee (EGP), four intermediaries were identified: (i) Stratotech who ran the Go-Kart track, (ii) ATB MasterCard, (iii) the sign-maker, and (iv) the vendor who supplied food and drink for the hospitality suite. The author then assessed that solid relationships were in place - or would be possible to develop - with the sponsor, the cosponsor, the sponsee and the related intermediaries. This was accomplished through frequent communications, 'selling' the benefits of the evaluation and meeting deadlines. A key factor in this process was the strong support and high level of interest expressed by representatives from ATB (Rudan, 2006b).

\subsection{Cost-benefit pre-test}

Following the identification of the sponsorship and the establishment of solid relationship foundations, an informal cost-benefit pre-test was carried out by the author. This involved consideration of (i) the reach of the Mega-sponsee, (ii) the estimated size of the sponsorship that was communicated (Rudan, 2005a), and (iii) the potential impact of the general objectives expressed or forecasted from the discussions to that point (Rudan, 2005b; Rudan, 2006a). The results of the pre-test indicated that considerable costs were to be incurred and that considerable benefits were anticipated, thus making the sponsorship an ideal candidate for evaluation. 


\subsection{Decision}

The fourth step was the GO/NO-GO decision which was made over a two day period of February 15, 2006 when the author proposed going ahead formally and February 16, 2006 when ATB Financial agreed to the evaluation, with final approvals of surveys and a non-disclosure agreement to be completed at a later date.

\subsubsection{Step 2: Collect data concerning the sponsorship}

Following the February 16 approval of the evaluation, data collection concerning the sponsorship (Step 2 of the Process Model) began. This process lasted for a total of 10 months. This length of time was required for four major reasons, including (i) achieving ATB internal approvals for the sharing of information including the signing of nondisclosure agreements (NDAs), (ii) awaiting completion of important documents related to the sponsorship (e.g. marketing plan), (iii) updating work due to consistently changing documentation (e.g. budgets), and (iv) the process of convincing other parties (beside ATB) of the value of the sponsorship evaluation.

\subsection{Data gathering}

The purpose of this step is to accumulate the necessary information related to the sponsorship, with the particular goal of identifying the objectives sought by the sponsorship. This process included obtaining and reviewing various documents, based on Process Model D2, which prescribes a review of the formal sponsorship contract, sponsor input, sponsee input and intermediary input. The documents accessed are presented in the following table in chronological order. 
Table 32: Secondary data sources

\begin{tabular}{|c|c|c|}
\hline Document & Source \& Date & Rationale for Retrieval \\
\hline $\begin{array}{l}\text { A preliminary version of the } \\
\text { sponsorship contract }\end{array}$ & $\begin{array}{l}\text { Received February } 28, \\
2006 \text { from ATB Financial }\end{array}$ & $\begin{array}{l}\text { Identification of } \\
\text { objectives }\end{array}$ \\
\hline $\begin{array}{l}\text { ATB's marketing plan for the } \\
\text { EGP sponsorship }\end{array}$ & \begin{tabular}{|l|} 
Received February 28, \\
2006 from ATB Financial
\end{tabular} & $\begin{array}{l}\text { Identification of } \\
\text { objectives }\end{array}$ \\
\hline $\begin{array}{l}\text { EGP marketing plan } \\
\text { (preliminary) }\end{array}$ & $\begin{array}{l}\text { Received May 10,2006 } \\
\text { from EGP }\end{array}$ & $\begin{array}{l}\text { Identification of } \\
\text { objectives }\end{array}$ \\
\hline $\begin{array}{l}2004 \text { ATB market share data } \\
\text { by branch }\end{array}$ & $\begin{array}{l}\text { Received May 12, } 2006 \\
\text { from ATB Financial }\end{array}$ & Development of Metrics \\
\hline $\begin{array}{l}\text { MasterCard preliminary budget } \\
\text { for ATB-EGP sponsorship }\end{array}$ & $\begin{array}{l}\text { Received June 14, } 2006 \\
\text { from ATB-MasterCard }\end{array}$ & $\begin{array}{l}\text { Identification of } \\
\text { objectives and } \\
\text { development of metrics }\end{array}$ \\
\hline EGP m & $\begin{array}{l}\text { Received June 14, } 2006 \\
\text { from EGP }\end{array}$ & $\begin{array}{l}\text { Identification of } \\
\text { objectives }\end{array}$ \\
\hline EGP media plan & $\begin{array}{l}\text { Received June 14, } 2006 \\
\text { from EGP }\end{array}$ & $\begin{array}{l}\text { Identification of } \\
\text { objectives and } \\
\text { development of metrics }\end{array}$ \\
\hline $\begin{array}{l}\text { Final, signed version of } \\
\text { sponsorship contract }\end{array}$ & $\begin{array}{l}\text { ed July } 30,2006 \\
\text { TB Financial }\end{array}$ & $\begin{array}{l}\text { Confirmation of } \\
\text { objectives }\end{array}$ \\
\hline $\begin{array}{l}\text { ATB sponsorship group } \\
\text { internal review }\end{array}$ & $\begin{array}{l}\text { Received July 30,2006 } \\
\text { from ATB Financial } \\
\end{array}$ & Information for evaluation \\
\hline ATB sponsorship budget EGP & $\begin{array}{l}\text { Received July 30, } 2006 \\
\text { from ATB Financial }\end{array}$ & Information for evaluation \\
\hline ATB media plan budget EGP & $\begin{array}{l}\begin{array}{l}\text { Received July } 302006 \\
\text { from EGP }\end{array} \\
\end{array}$ & Information for evaluation \\
\hline $\begin{array}{l}\text { ATB 1 } \\
\text { site A }\end{array}$ & $\begin{array}{l}\begin{array}{l}\text { Received August 1,2006 } \\
\text { from ATB Financial }\end{array} \\
\end{array}$ & Information for \\
\hline $\begin{array}{l}\text { MasterCard final budget for } \\
\text { ATB-EGP sponsorship }\end{array}$ & $\begin{array}{l}\text { Received August 14, } 2006 \\
\text { from ATB MasterCard }\end{array}$ & Information for evaluation \\
\hline ATB budget (final) & $\begin{array}{l}\text { Received August 20,2006 } \\
\text { from ATB Financial }\end{array}$ & Information for evaluation \\
\hline $\begin{array}{l}\text { ATB legal sign-off on } \\
\text { evaluation }\end{array}$ & $\begin{array}{l}\text { Received August 28, } 2006 \\
\text { from ATB Financial }\end{array}$ & Permission to continue \\
\hline $\begin{array}{l}\text { MasterCard Post-Mortem } \\
\text { Report }\end{array}$ & \begin{tabular}{|l} 
Received September 1, \\
2006 from ATB Financial \\
\end{tabular} & Information for evaluation \\
\hline $\begin{array}{l}\text { Email testimonials from ATB } \\
\text { staff and guests }\end{array}$ & \begin{tabular}{|l|} 
Received September 5, \\
2006 from ATB Financial
\end{tabular} & Information for evaluation \\
\hline $\begin{array}{l}\text { ATB Alberta market share } \\
\text { research information }\end{array}$ & $\begin{array}{l}\text { Received: October 12, } \\
2006 \text { from ATB Financial }\end{array}$ & Information for evaluation \\
\hline
\end{tabular}


The contract noted on two occasions in Table 32 is of particular interest given that is serves as the unit of analysis for this evaluation. The approved version of the contract was 16 pages in length and very detailed.

The documents noted in Table 32 were supplemented with considerable personal communication (including emails and phone calls) and interviews, notably:

1. Extensive Feedback on Questions by Kelly Rudan (received: March 27, 2006)

2. Phone Conference Interview with ATB Marketing Team (Rudan and Arychuk) (completed: March 28, 2006)

3. Extensive Feedback on Questions by Kelly Rudan (received: April 25, 2006)

4. Extensive Feedback on Questions by Kelly Rudan (received: May 10, 2006)

5. Extensive Feedback on Questions by Kelly Rudan (received: May 12, 2006)

6. Extensive Feedback on Questions by Kelly Rudan (received: June 26, 2006)

7. Extensive Feedback on Questions by Kelly Rudan (received: July 10, 2006)

8. Extensive Feedback on Questions by Kelly Rudan (received: July 11, 2006)

9. Phone Interview with Kathy Arychuk (ATB) on July 27, 2006

10. Phone Interview with Candice Sperling (MasterCard) on July 27, 2006

11. Author 3-day visit to Edmonton and ATB offices (July $30^{\text {th }}$ to Aug 1,2006), which included in-depth interviews with 2 representatives of the sponsee and 5 representatives of the sponsor.

It should also be noted that ATB did considerable due diligence on the nature of this research and the researcher to protect ATB and validate the project; particularly with two initiatives:

1. Non-Disclosure Agreement 
2. Interview with ATB's Vice-President of Marketing on August 1, 2006

Through the investigation, only one of the intermediaries was identified as having more interest in the ATB-EGP sponsorship than simply supplying services to either the sponsor or the sponsee. This was ATB MasterCard whose situation vis-à-vis the sponsorship is quite interesting. ATB's MasterCard Marketing Manager describes the relationship:

MasterCard International is sort of the governing body for MasterCard so they don't actually have a MasterCard but they own the brand. So that would be brand ownership and then we [MasterCard at ATB] are a MasterCard supplier...Let me just clarify the funding of the sponsorship a little bit. MasterCard International put in a little bit of money but we [MasterCard at ATB] put in the majority here. Because MasterCard International is always interested in branding and they do have funds set aside to help suppliers or - from their perspective - vendors. But, we put in the majority of the dollars. (Sperling, 2006)

Essentially, MasterCard is one of the products that ATB offers (Sperling, 2006; Rudan, 2006d), so ATB MasterCard and ATB Investor Services could be viewed as co-sponsors of the EGP. This was further supported by ATB's Manager of Community Relationships who indicated that "MasterCard is one of our products, our product lines and so this sponsorship was sort of a co-sponsorship" (Arychuk, 2006). Based on this, the ATB sponsorship was viewed as a co-sponsorship for the process model implementation.

\subsection{Attributes of the sponsor-sponsee relationship}

The following attributes of the sponsor-sponsee (ATB-EGP) relationship were observed as per Process Model D2:

- Sponsorship Age: This was the first year of a two-year agreement for ATB-EGP. For the EGP, it was the second year of its existence. This sponsorship took place in the 
third year of ATB's enhanced marketing efforts and planning that included sponsorship (Rudan, 2006c). Thus, it was a new sponsorship as ATB had not sponsored a car race previously.

- Sponsorship Size: In considering sponsorship fees, leveraging investments and other costs, the ATB sponsorship of the EGP exceeds $\$ 500,000$ /year, making it a mediumsized sponsorship ${ }^{37}$.

- Sponsee Type: As supported above, this is an instance of a Mega-sponsee (see section 2.1.2.5 for definitions of mega-sponsee and typical sponsee).

- Phase: the research started during the contract negotiations phase of the sponsorship, eight months prior to the event and continued until two months post-event.

- Type (industry): There are three industries of interest here:

- Financial Services and Credit Card Services: these industries are both characterized by the following trends: (i) increased competition, (ii) satisfied customers, (iii) the high-growth economy in Alberta: new people, more investment dollars, etc., (iv) baby boomer inheritances to come, (v) increased confidence in credit/bank cards, and (vi) increased investments for retirement/education/etc. (Rudan, 2006c).

- Car Races: comprised of a number of different sub-industries (Formula 1, NASCAR, Champ Car, etc.), this is a fast growing (spectator) sport in North America. Although much of its popularity is in the United States, it is gaining acceptance in Canada (Edmonton Grand Prix General Manager, 2006).

\footnotetext{
${ }^{37}$ The label of 'medium-sized' sponsorship is based on an author-created scale which views any sponsorship of under $\$ 10,000$ in value as very small; between $\$ 10,000$ and $\$ 100,000$ as small; from $\$ 100,000$ to $\$ 1,000,000$ as medium; from $\$ 1,000,000$ to $\$ 10,000,000$ as large; and greater than $\$ 10,000,000$ as very large.
} 
- Resources: The ATB sponsorship of the EGP is cash only. No in-kind contributions are included. Both the sponsor and sponsee leveraged with additional funds:

- Sponsor (ATB) - ATB (including MasterCard) invested an additional $\$ 240,289.63$ to leverage its $\$ 200,000$ sponsorship, ratio of $1.2: 1$.

- Sponsee (EGP) - invested $\$ 2.9$ million in a promotional budget (TV, internet, radio, etc.) was put in place in Alberta $(90 \%)$ and beyond. ATB had minor coverage as a gold sponsor in such promotions.

- The media collateral (materials: posters, flyers, etc.) that accompanied the sponsorship went out in branches in early June, media shortly after with primary theme: "Win tickets by visiting www.atbgrandprix.com".

- Merchandising: ATB decided against any merchandising.

- Level: ATB is a gold sponsor of the EGP (see table 29 above), meaning that ATB is an important but secondary sponsor (i.e. not title) of the EGP.

- Sponsor-Sponsee fit: Representatives from both sides confirm that they feel there is a good strategic fit between ATB and the EGP due to their shared markets.

- Pre-existing opinions: No significant pre-existing opinions of the sponsor by the sponsee and vice-versa were observed; as expected with a first-time sponsorship.

- Target Market: Research conducted by the EGP at the 2005 event provides a general description of the target market who attends the event:

- $93 \%$ attendees live in the province of Alberta

- Average age: 36

- Age range: $86 \%$ were between 18 and 54

- More than $50 \%$ had post-secondary education

- Average household income: $\$ 75,000$

- $72 \%$ male

- $67 \%$ married 


\subsubsection{Step 3: Articulate Objectives}

The purpose of this sub-section is to review the contract, interview data and source documents with the purpose of harvesting and articulating all the objectives of the sponsorship. Following a review of the contract, marketing plans, organizational strategies, sponsor input (via interview), sponsee input (via interview) and intermediary input (via interview), the articulation of objectives chart was first drafted on May 4, 2006. This chart was then sent to the marketing group at ATB (4 individuals) requesting comments. Detailed feedback concerning the sponsorship was returned from ATB on May 10, 2006 by the marketing department in the form of comments for each objective. This type of communication continued until post-event as input and documentation continued to be received until October of 2006.

The final version of the 'articulation of objectives' table is outlined below in Table 33 and includes both the formal and the implicit objectives obtained from the data collection. Specifically, objectives and their targets (reach) were obtained following review of the following (i) the sponsorship contract, (ii) marketing plans for each of sponsor, sponsee and co-sponsor, and (iii) in-depth interviews (transcripts) with the leads on the sponsorship from each of the sponsor, sponsee and co-sponsor. Note that those objectives from the contract would be the formal/explicit ones while those from the interviews would be considered informal/implicit. It is important to note that objectives are presented as they were expressed in the contract, documentation or interview transcripts. This research did not involve the researcher constructing or altering the wording of any of the objectives. 
Table 33: ATB-EGP Sponsorship: Articulation of Objectives

\begin{tabular}{|c|c|c|}
\hline Data Source & Objective for $A T B$ & Reach \\
\hline \multirow{9}{*}{$\begin{array}{l}\text { Contract (signed } \\
\text { June } 6,2006)- \\
\text { developed using the } \\
\text { April } 12,2006 \text { draft } \\
\text { and updated with } \\
\text { final version once } \\
\text { received. Objectives } \\
\text { were identified via } \\
\text { thorough review of } \\
\text { the contract. }\end{array}$} & \multirow[t]{3}{*}{ Customer Acquisition } & $\begin{array}{l}\text { Edmonton residents who are not ATB } \\
\text { customers }\end{array}$ \\
\hline & & $\begin{array}{l}\text { Calgary residents who are not ATB } \\
\text { customers }\end{array}$ \\
\hline & & $\begin{array}{l}\text { Other residents of Alberta who are not } \\
\text { ATB customers }\end{array}$ \\
\hline & "Impact" key customers and prospects & $\begin{array}{l}\text { Top } 1 \% \text { of customers (or prospects); both } \\
\text { business and personal }\end{array}$ \\
\hline & Increase awareness that ATB exists & All Albertans \\
\hline & $\begin{array}{l}\text { Increase awareness that ATB cares } \\
\text { about Alberta }\end{array}$ & All Albertans \\
\hline & $\begin{array}{l}\text { Improve brand prestige in current } \\
\text { customers }\end{array}$ & Current customers \\
\hline & $\begin{array}{l}\text { Internal marketing (increase employee } \\
\text { motivation) }\end{array}$ & All Staff \\
\hline & $\begin{array}{l}\text { Achieve competitive advantage over } \\
\text { other banks }\end{array}$ & All Albertans \\
\hline \multirow{6}{*}{$\begin{array}{l}\text { Sponsor Interviews } \\
\text { (Kelly Rudan and } \\
\text { Kathy Arychuk - } \\
\text { March 29, 2006; } \\
\text { Kelly Rudan May } \\
\text { 12, 2006; Kelly } \\
\text { Rudan, June 26, } \\
\text { 2006) }\end{array}$} & \multirow[t]{2}{*}{$\begin{array}{l}\text { Establish ATB as a major player in the } \\
\text { Alberta banking market }\end{array}$} & $\begin{array}{l}\text { Residents of Alberta who currently utilize } \\
\text { ATB banking products and services }\end{array}$ \\
\hline & & $\begin{array}{l}\text { Residents of Alberta who currently utilize } \\
\text { banking products and services of other } \\
\text { banks }\end{array}$ \\
\hline & \multirow{2}{*}{$\begin{array}{l}\text { Re-branding: continued effort to move } \\
\text { from being viewed primarily as a } \\
\text { 'small town Alberta bank' to a full- } \\
\text { service province-wide bank }\end{array}$} & $\begin{array}{l}\text { Residents of Alberta who currently utilize } \\
\text { ATB banking products and services }\end{array}$ \\
\hline & & $\begin{array}{l}\text { Residents of Alberta who currently utilize } \\
\text { banking products and services of other } \\
\text { banks }\end{array}$ \\
\hline & $\begin{array}{l}\text { Internal marketing: build employee } \\
\text { pride in ATB }\end{array}$ & All Staff \\
\hline & Assess sponsorship effectiveness & Senior Management \\
\hline Data Source & Objective for $E G P$ & Reach \\
\hline \multirow{4}{*}{$\begin{array}{l}\text { Sponsee Interview } \\
\text { (EGP Director and } \\
\text { Sponsorship } \\
\text { Consultant); both } \\
\text { August 1, 2006) } \\
\end{array}$} & Revenue Generation & Sponsors in Gold Category \\
\hline & Develop long-term partnerships & ATB \\
\hline & Build an affinity with Alberta market & All Albertans \\
\hline & Effectively service sponsors & ATB Sponsorship Management \& Staff \\
\hline Data Source & Objective for ATB MasterCard & Reach \\
\hline \multirow{2}{*}{$\begin{array}{l}\text { Intermediary (Co- } \\
\text { sponsor): ATB } \\
\text { MasterCard: } \\
\text { Documents and } \\
\text { Candice Sperling } \\
\text { Interview, July 26, } \\
2006\end{array}$} & Customer acquisition & $\begin{array}{l}\text { Attendees of EGP who did not previously } \\
\text { have an ATB MasterCard }\end{array}$ \\
\hline & Awareness of the ATB MasterCard & All Albertans \\
\hline
\end{tabular}

Table 33 lists the 21 objectives pursued by the sponsorship participants. Each 'reach' is considered a distinct objective. Of these 21 objectives, 9 were formal and 12 informal. 


\subsubsection{Step 4: Establish Metrics}

The purpose of this step is to work with the relevant players involved in the sponsorship to collaboratively develop the evaluation metrics for each objective. Table 34 below outlines the metric developed for each of the 21 objectives. Eight data collection exercises (see Table 35) were designed to acquire the data necessary for evaluating the 21 objectives. It is important to note that the selection of metrics and methods to measure each objective was based on a collaborative decision-making process between the researcher, ATB, the EGP and ATB MasterCard vis-à-vis resources available and the relative importance of the objective. 
Table 34: ATB - EGP Sponsorship: Metrics

\begin{tabular}{|c|c|c|c|c|c|}
\hline Objective & $\#$ & Reach & Metrics & Method & Rationale for Selection \\
\hline \multirow[t]{3}{*}{$\begin{array}{l}\text { Customer } \\
\text { Acquisition }\end{array}$} & 1 & $\begin{array}{l}\text { Edmonton residents who } \\
\text { are not ATB customers }\end{array}$ & $\begin{array}{l}\text { - Macro-micro approach using both } \\
\text { consumer survey data at the branch as } \\
\text { well as internal company sales data to } \\
\text { ascertain contribution of sponsorship } \\
\text { to customers acquisition }\end{array}$ & $\begin{array}{l}\text {-In-branch surveys to sample } \\
\text { (one Edmonton branch) } \\
\text {-Overall changes in customer } \\
\text { base and balances (from } \\
\text { internal ATB data) }\end{array}$ & $\begin{array}{l}\text { - Access and cooperation } \\
\text { possible } \\
\text { - Supportive branch manager } \\
\text { - One branch considered as a } \\
\text { representative sample }\end{array}$ \\
\hline & $\overline{2}$ & $\begin{array}{l}\text { Calgary residents who are } \\
\text { not ATB customers }\end{array}$ & $\begin{array}{l}\text { - Macro-micro approach using both } \\
\text { consumer survey data at the branch as } \\
\text { well as internal company sales data to } \\
\text { ascertain contribution of sponsorship } \\
\text { to customers acquisition }\end{array}$ & $\begin{array}{l}\text {-In-branch surveys to sample } \\
\text { (one Calgary branch) } \\
\text { - Overall changes in customer } \\
\text { base and balances (from } \\
\text { internal ATB data) }\end{array}$ & $\begin{array}{l}\text { - Access and cooperation } \\
\text { possible } \\
\text { - Supportive branch manager } \\
\text { - One branch considered } \\
\text { sufficient }\end{array}$ \\
\hline & 3 & $\begin{array}{l}\text { Other residents of Alberta } \\
\text { who are not ATB } \\
\text { customers }\end{array}$ & $\begin{array}{l}\text { Proxy analysis from opinions } \\
\text { expressed by micro-site visitors } \\
\text { compared to overall changes in } \\
\text { customer base and balances (non- } \\
\text { Calgary/non-Edmonton residents) }\end{array}$ & $\begin{array}{l}\text { OWww.atbgrandprix.com } \\
\text { micro-site web-based survey } \\
\text { - Overall changes in customer } \\
\text { base and balances (from } \\
\text { internal ATB data) } \\
\end{array}$ & $\begin{array}{l}\text {-Branch access outside of } \\
\text { Edmonton and Calgary not } \\
\text { readily available \& expensive } \\
\text { - Best alternative option } \\
\text { available } \\
\end{array}$ \\
\hline $\begin{array}{l}\text { "Impact" key } \\
\text { customers and } \\
\text { prospects }\end{array}$ & 4 & $\begin{array}{l}\text { Top } 1 \% \text { of customers (or } \\
\text { prospects); both business } \\
\text { and personal }\end{array}$ & $\begin{array}{l}\text { - Combination qualitative and } \\
\text { quantitative study using the hospitality } \\
\text { suite for sampling. } \\
\text {-Qualitative metric was post-event } \\
\text { interviews with suite hosts. } \\
\text {-Quantitative metric adopted survey of } \\
\text { guests to determine satisfaction with } \\
\text { suite based on internal ATB data. }\end{array}$ & $\begin{array}{l}\text { - Suite host interviews } \\
\text { - Onsite hospitality survey } \\
\text { Invitee analysis to determine } \\
\text { cost/hit } \\
\text { - Review of aggregate ATB } \\
\text { internal data for Top } 1 \%\end{array}$ & $\begin{array}{l}\text {-Best access to very specific } \\
\text { target market } \\
\text { - In-event situation } \\
\text { - Supportive Suite Hosts and } \\
\text { organizers (ATB) } \\
\text { - Low cost/high return }\end{array}$ \\
\hline $\begin{array}{l}\text { Increase } \\
\text { awareness ATB } \\
\text { exists }\end{array}$ & 5 & Albertans & $\begin{array}{l}\text { - Mass market survey of representative } \\
\text { sample }\end{array}$ & $\begin{array}{l}\text { - Mass market telephone } \\
\text { survey of Albertans }\end{array}$ & $\begin{array}{l}\text {-Representative sample } \\
\text { - Sufficient sample size } \\
\text {-Expensive but resources } \\
\text { available through ATB } \\
\end{array}$ \\
\hline $\begin{array}{l}\text { Increase } \\
\text { awareness that } \\
\text { ATB cares }\end{array}$ & 6 & Albertans & $\begin{array}{l}\text { - Mass market survey of representative } \\
\text { sample }\end{array}$ & $\begin{array}{l}\text { - Mass market telephone } \\
\text { survey of Albertans }\end{array}$ & $\begin{array}{l}\text { - Representative sample } \\
\text { - Sufficient sample size } \\
\text { - Expensive but resources } \\
\text { available through ATB } \\
\end{array}$ \\
\hline
\end{tabular}




\begin{tabular}{|c|c|c|c|c|c|}
\hline $\begin{array}{l}\text { Improve brand } \\
\text { prestige in } \\
\text { current } \\
\text { customers }\end{array}$ & 7 & Current customers & $\begin{array}{l}\text { - Branch surveys of representative } \\
\text { sample of ATB customers }\end{array}$ & $\begin{array}{l}\text {-Branch surveys in one } \\
\text { Edmonton and one Calgary } \\
\text { branch }\end{array}$ & $\begin{array}{l}\text { - Access and cooperation } \\
\text { possible } \\
\text { - Supportive branch manager } \\
\text { - Two branches considered } \\
\text { sufficient }\end{array}$ \\
\hline $\begin{array}{l}\text { Internal } \\
\text { marketing } \\
\text { (motivation) }\end{array}$ & 8 & Staff & $\begin{array}{l}\text { - Survey staff on satisfaction with the } \\
\text { sponsorship including an analysis of } \\
\text { employee ticket program }\end{array}$ & $\begin{array}{l}\text { - Jan } 2006 \text { ATB-wide } \\
\text { satisfaction survey } \\
\text {-Employee interviews } \\
\text { - Analysis of employee ticket } \\
\text { program }\end{array}$ & $\begin{array}{l}\text {-Ideal metric (employee } \\
\text { survey post-event) cancelled } \\
\text { by ATB senior admin } \\
\text { - Best alternative available }\end{array}$ \\
\hline $\begin{array}{l}\text { Achieve } \\
\text { competitive } \\
\text { advantage }\end{array}$ & 9 & Albertans & $\begin{array}{l}\text { - Mass market survey of representative } \\
\text { sample }\end{array}$ & $\begin{array}{l}\text { - Mass market telephone } \\
\text { survey of Albertans }\end{array}$ & $\begin{array}{l}\text { - Representative sample } \\
\text { - Sufficient sample size } \\
\text {-Expensive but resources } \\
\text { available through ATB }\end{array}$ \\
\hline \multirow[t]{2}{*}{$\begin{array}{l}\text { Establish ATB } \\
\text { as a major } \\
\text { player in the } \\
\text { Alberta banking } \\
\text { market }\end{array}$} & 10 & $\begin{array}{l}\text { Residents of Alberta who } \\
\text { currently utilize ATB } \\
\text { banking products and } \\
\text { services }\end{array}$ & $\begin{array}{l}\text {-Branch surveys of representative } \\
\text { sample of ATB customers }\end{array}$ & $\begin{array}{l}\text { - Branch surveys in one } \\
\text { Edmonton and one Calgary } \\
\text { branch } \\
\text { - Microsite survey }\end{array}$ & $\begin{array}{l}\text {-Access and cooperation } \\
\text { possible } \\
\text { - Supportive branch manager } \\
\text { - Two branches considered } \\
\text { sufficient } \\
\end{array}$ \\
\hline & 11 & $\begin{array}{l}\text { Residents of Alberta who } \\
\text { currently utilize banking } \\
\text { products and services of } \\
\text { other banks }\end{array}$ & $\begin{array}{l}\text { - Mass market survey of representative } \\
\text { sample }\end{array}$ & $\begin{array}{l}\text {-Mass market telephone } \\
\text { survey of Albertans }\end{array}$ & $\begin{array}{l}\text { - Representative sample } \\
\text { - Sufficient sample size } \\
\text {-Expensive but resources } \\
\text { available through ATB }\end{array}$ \\
\hline \multirow{2}{*}{$\begin{array}{l}\text { Re-branding: } \\
\text { continued effort } \\
\text { to move from } \\
\text { being viewed } \\
\text { primarily as a } \\
\text { 'small town } \\
\text { Alberta bank' to } \\
\text { a full-service } \\
\text { provide-wide } \\
\text { bank }\end{array}$} & 12 & $\begin{array}{l}\text { Residents of Alberta who } \\
\text { currently utilize ATB } \\
\text { banking products and } \\
\text { services }\end{array}$ & $\begin{array}{l}\text { - Branch surveys of representative } \\
\text { sample of ATB customers }\end{array}$ & $\begin{array}{l}\text { - Branch surveys in one } \\
\text { Edmonton and one Calgary } \\
\text { branch } \\
\text { - Microsite survey }\end{array}$ & $\begin{array}{l}\text {-Access and cooperation } \\
\text { possible } \\
\text {-Supportive branch manager } \\
\text { - Two branches considered } \\
\text { sufficient }\end{array}$ \\
\hline & 13 & $\begin{array}{l}\text { Residents of Alberta who } \\
\text { currently utilize banking } \\
\text { products and services of } \\
\text { other banks }\end{array}$ & $\begin{array}{l}\text { - Mass market survey of representative } \\
\text { sample }\end{array}$ & $\begin{array}{l}\text {-Mass market telephone } \\
\text { survey of Albertans }\end{array}$ & $\begin{array}{l}\text { - Representative sample } \\
\text { - Sufficient sample size } \\
\text {-Expensive but resources } \\
\text { available through ATB }\end{array}$ \\
\hline $\begin{array}{l}\text { Build employee } \\
\text { pride in ATB }\end{array}$ & 14 & Staff & $\begin{array}{l}\text {-Survey staff on pride including an } \\
\text { analysis of employee ticket program }\end{array}$ & $\begin{array}{l}\text {-Employee interviews } \\
\text {-Analysis of employee ticket } \\
\text { program }\end{array}$ & $\begin{array}{l}\text {-Ideal metric (employee } \\
\text { survey post-event) cancelled } \\
\text { by ATB senior admin } \\
\text { - Best alternative available }\end{array}$ \\
\hline
\end{tabular}




\begin{tabular}{|c|c|c|c|c|c|}
\hline $\begin{array}{l}\text { Assess } \\
\text { sponsorship } \\
\text { effectiveness }\end{array}$ & 15 & Senior Management & - This sponsorship evaluation & $\begin{array}{l}\text { - Sponsor, Sponsee, Co- } \\
\text { sponsor interviews } \\
\text { - Overall results of study }\end{array}$ & -Reason for this research \\
\hline $\begin{array}{l}\text { Revenue } \\
\text { Generation }\end{array}$ & 16 & $\begin{array}{l}\text { Sponsors in Gold } \\
\text { Category }\end{array}$ & $\begin{array}{l}\text { - Amounts per category determined } \\
\text { based on budget needs }\end{array}$ & $\begin{array}{l}\text { Assessment versus } \\
\text { objective achieved ( } \$ 410,000 \\
\text { for 2-years) (Edmonton } \\
\text { Grand Prix General Manager, } \\
2006 \text { ) } \\
\end{array}$ & $\begin{array}{l}\text {-Access to financial } \\
\text { information available } \\
\text { - Support from } \\
\text { sponsor/sponsee }\end{array}$ \\
\hline $\begin{array}{l}\text { Develop long- } \\
\text { term } \\
\text { partnerships }\end{array}$ & 17 & ATB & $\begin{array}{l}\text { - In-depth qualitative study sampling } \\
\text { representatives from partner of interest }\end{array}$ & $\begin{array}{l}\text { Post-event interviews with } \\
\text { sponsor and sponsee } \\
\text { representatives }\end{array}$ & $\begin{array}{l}\text { - Most appropriate way to } \\
\text { evaluate difficult issue to } \\
\text { measure } \\
\text { - Access to both sponsor and } \\
\text { sponsee key stakeholders } \\
\text { possible }\end{array}$ \\
\hline $\begin{array}{l}\text { Build an affinity } \\
\text { with Alberta } \\
\text { market (through } \\
\text { ATB } \\
\text { association) }\end{array}$ & 18 & Albertans & $\begin{array}{l}\text { - Mass market survey of representative } \\
\text { sample }\end{array}$ & $\begin{array}{l}\text { - Mass market telephone } \\
\text { survey of Albertans }\end{array}$ & $\begin{array}{l}\text { - Representative sample } \\
\text { - Sufficient sample size } \\
\text {-Expensive but resources } \\
\text { available through ATB }\end{array}$ \\
\hline $\begin{array}{l}\text { Effectively } \\
\text { service sponsors }\end{array}$ & 19 & $\begin{array}{l}\text { ATB Sponsorship } \\
\text { Management \& Staff }\end{array}$ & $\begin{array}{l}\text { - In-depth qualitative study sampling } \\
\text { representatives from partner of interest }\end{array}$ & $\begin{array}{l}\text { Post-event interviews with } \\
\text { sponsor and sponsee } \\
\text { representatives }\end{array}$ & $\begin{array}{l}\text { - Most appropriate way to } \\
\text { evaluate touchy issue } \\
\text {-Access to both sponsor and } \\
\text { sponsee key stakeholders } \\
\text { possible }\end{array}$ \\
\hline $\begin{array}{l}\text { Customer } \\
\text { acquisition }\end{array}$ & 20 & $\begin{array}{l}\text { Attendees of EGP who } \\
\text { did not previously have an } \\
\text { ATB MasterCard }\end{array}$ & $\begin{array}{l}\text { - Assessment of effectiveness of } \\
\text { related customer recruitment }\end{array}$ & $\begin{array}{l}\text { Results of on-site } \\
\text { recruitment efforts }\end{array}$ & $\begin{array}{l}\text { - Most appropriate way to } \\
\text { measure customer acquisition } \\
\text { is through sales data }\end{array}$ \\
\hline $\begin{array}{l}\text { Awareness of } \\
\text { the ATB } \\
\text { MasterCard }\end{array}$ & 21 & $\begin{array}{l}\text { ATB Customers and } \\
\text { Prospects }\end{array}$ & $\begin{array}{l}\text { - Branch surveys of representative } \\
\text { sample of ATB customers }\end{array}$ & $\begin{array}{l}- \text { Branch surveys in one } \\
\text { Edmonton and one Calgary } \\
\text { branch } \\
\text {-Microsite survey }\end{array}$ & $\begin{array}{l}\text {-Access and cooperation } \\
\text { possible } \\
\text { - Supportive branch manager } \\
\text { - Two branches considered } \\
\text { sufficient }\end{array}$ \\
\hline
\end{tabular}


Table 34 above summarizes the metrics and methods for each of the 21 objectives. By omitting those metrics which can be obtained with a single communication from the sponsor, the sponsee or an intermediary (e.g. the results (\# of sign-ups) of ATB MasterCard's onsite recruitment or attendance figures), the methods outlined in Table 34 above can be merged into 8 main data collection exercises, some of which were designed to gather data to assess more than one objective. These are outlined in Table 35 below and described in more detail in Section 6.2.1.6 where a short section is devoted to each data collection exercise.

\section{Table 35: Data Collection Details}

\begin{tabular}{|c|c|c|}
\hline Protocol & Description & Steps in Methodology \\
\hline $\begin{array}{l}\text { Web } \\
\text { Survey }\end{array}$ & $\begin{array}{l}\text { Online survey on } \\
\text { micro-site - live } \\
\text { until one week prior } \\
\text { to event }\end{array}$ & $\begin{array}{l}\text { - Survey was part of online contest launched with ATB micro-site } \\
\text { (www.atbgrandprix.com) } \\
\text { - Researcher allowed to contribute questions to the survey } \\
\text { - Alberta-wide promotional campaign to drive ATB customers and } \\
\text { interested parties to the site }\end{array}$ \\
\hline $\begin{array}{l}\text { Internal } \\
\text { Customer } \\
\text { Activity } \\
\text { Data }\end{array}$ & $\begin{array}{l}\text { Report for two } \\
\text { branches only for } \\
\text { months of June, } \\
\text { July, and August of } \\
2006\end{array}$ & $\begin{array}{l}\text { - ATB to provide for each of the two branches: } \\
\text { - Number of customers (Business Financial Services (BFS), } \\
\text { Personal Financial Services (PFS) \& Customer Financial } \\
\text { Services (CFS)) } \\
\text { - Number of new customers (BFS, PFS, \& CFS) } \\
\text { - Average bank balance (personal \& business) } \\
\text { - ATB, through CFS division, to provide aggregate data for top 1\% } \\
\text { clients for each brand (or overall): } \\
\text { - Number of customers (personal \& business) } \\
\text { - Number of new customers (personal \& business) }\end{array}$ \\
\hline $\begin{array}{l}\text { In-Branch } \\
\text { customer } \\
\text { survey }\end{array}$ & $\begin{array}{l}\text { In-branch (two } \\
\text { branches) intercept } \\
\text { surveys to be } \\
\text { completed by two } \\
\text { UofA students } \\
\text { working (one an } \\
\text { ATB staff) with } \\
\text { ATB branch staff }\end{array}$ & $\begin{array}{l}\text { - ATB selected branches and achieved permission from senior } \\
\text { admin and branch managers } \\
\text { - Survey designed by researcher in collaboration with ATB research } \\
\text { department } \\
\text { - Survey approved by ATB research, marketing and legal } \\
\text { departments and implemented in one Edmonton and one Calgary } \\
\text { branch between August } 28 \text { and } 31,2006 \text { with incentives (bottled } \\
\text { water) }\end{array}$ \\
\hline $\begin{array}{l}\text { Hospitality } \\
\text { Survey - } \\
\text { Onsite \& } \\
\text { Suite host }\end{array}$ & $\begin{array}{l}\text { Surveys completed } \\
\text { during all } 3 \text { days of } \\
\text { hospitality suite at } \\
\text { EGP. Interviews }\end{array}$ & $\begin{array}{l}\text { - ATB obtained permission to collect surveys during event in } \\
\text { hospitality suites } \\
\text { - Suite hosts administered surveys } \\
\text { - Survey designed by researcher; approved by ATB research }\end{array}$ \\
\hline
\end{tabular}




\begin{tabular}{|c|c|c|}
\hline interviews & $\begin{array}{l}\text { with } 2 \text { of the hosts } \\
\text { and feedback from } \\
\text { other. }\end{array}$ & $\begin{array}{l}\text { department } \\
\text { - No incentives offered } \\
\text { - Interviews with three (3) Suite Hosts carried out to supplement } \\
\text { surveys }\end{array}$ \\
\hline $\begin{array}{l}\text { Mass } \\
\text { market } \\
\text { (Alberta) } \\
\text { Intercept } \\
\text { Survey } \\
\end{array}$ & $\begin{array}{l}\text { Mid-august } \\
\text { telephone } \\
\text { surveys...500 } \\
\text { province-wide }\end{array}$ & $\begin{array}{l}\text { - Researcher drafted questionnaire to accommodate all related } \\
\text { objectives in collaboration with ATB research department } \\
\text { - Approved by ATB marketing, legal and research and implemented } \\
\text { by telephone August } 2006\end{array}$ \\
\hline $\begin{array}{l}\text { ATB Staff } \\
\text { Survey \& } \\
\text { Interviews }\end{array}$ & $\begin{array}{l}\text { Use of ATB } \\
\text { company survey and } \\
\text { interviews (August) }\end{array}$ & $\begin{array}{l}\text { - Select results from the } 2006 \text { ATB internal survey were provided to } \\
\text { researcher } \\
\text { - Eight (8) post-event employee interviews completed by researcher } \\
\text { in person (3) and by phone (5) }\end{array}$ \\
\hline $\begin{array}{l}\text { Employee } \\
\text { ticket sales } \\
\text { and } \\
\text { discounts }\end{array}$ & $\begin{array}{l}\text { Assessment of } \\
\text { effectiveness of } \\
\text { program }\end{array}$ & $\begin{array}{l}\text { - Results of ticket sales program were provided to the researcher by } \\
\text { ATB }\end{array}$ \\
\hline $\begin{array}{l}\text { Post-Event } \\
\text { Interviews }\end{array}$ & $\begin{array}{l}\text { In-person (3) and } \\
\text { telephone (5) } \\
\text { interviews to assess } \\
\text { various objectives }\end{array}$ & $\begin{array}{l}\text { - Eight post-event interviews completed by researcher with: } \\
\text { 1. General Manager, EGP } \\
\text { 2. Sponsorship Consultant, EGP } \\
\text { 3. Marketing Manager, MasterCard, ATB } \\
\text { 4. Marketing Manager, Investor Services, ATB } \\
\text { 5. Marketing Manager, Financial Services, ATB } \\
\text { 6. 6-8 ATB Employees } \\
\text { 7. ATB Employee dedicated to sponsorship } \\
\text { 8. 2-3 Hospitality Suite Hosts, ATB }\end{array}$ \\
\hline
\end{tabular}

\subsubsection{Step 5: Determine Metrics for Resources and Shirking}

The purpose of this section is two-fold. First, it seeks to identify the resources (inputs and activities) put in place by the sponsor, sponsee and co-sponsor to achieve their desired objectives. Second, it identifies the behaviours and activities taking place which detract from the effectiveness of the sponsorship (i.e., that undermine the 21 identified objectives). These are known as shirking behaviours. This section then develops metrics and methods to assess each of these shirking behaviours. 


\subsection{Resources and Activities}

The sponsorship fees paid by ATB Financial and ATB MasterCard for the 2006 Gold sponsorship of the EGP totaled $\$ 200,000$ ( $\$ 115,000$ ATB Financial and $\$ 85,000$ ATB MasterCard). Note that $\$ 45,000$ of the ATB MasterCard portion was paid by MasterCard International). For the 2007 sponsorship, the contract stipulates an increase in this fee to $\$ 210,000$ ( $\$ 120,750$ ATB Financial and $\$ 89,250$ ATB MasterCard). As noted previously, in 2006 , the $\$ 200,000$ fee was leveraged by a 1.75 to 1 ratio as described in the summary expense budget (see Table 36 below).

ATB committed the $\$ 410,000$ to be a two-year gold level sponsor of the EGP. The package included exclusivity as official financial institution, category exclusivity in Alberta Zone, Tuner Show, and Alberta National Resources Show, a race car appearance at an ATB branch, rights to the grand prix logo/name, and an advertising/signage package. ATB leveraging activities included a variety of activities including a microwebsite (www.atbgrandprix.com), online contest with prize packages, branch promotions, sponsorship of the Go-Kart track, a client hosting program, an employee discounted ticket program, a road show, ATB race week activities, a merchandising plan, a communications/media plan, and the participation of ATB associates as event volunteers. A number of these activities required additional resources, including the hospitality suite which was designed for 75 guests ( 3 days of 25 each) and included a variety of hosting related activities including the daily visit of a high profile race car driver, gift-bags, and the full serviced of a suite host/hostess.

The EGP also committed resources to the sponsorship in the form of a dedicated staff person to work with ATB (shared with all sponsors), tickets, paddock passes, the 
hospitality suite, signage, volunteer opportunities, the overall management of a major international event, a $\$ 2.9$ million promotional campaign (TV, radio, print), website management, e-marketing, and print materials (brochures, posters, mail-outs, souvenir programs, tickets, etc.).

MasterCard, as an important co-sponsor, provided $\$ 80,000 /$ year of the sponsorship fee and received category exclusivity in credit cards, onsite signage, four onsite booths for customer sign-up, and tickets (a single all-access pass and 40 gold level passes). MasterCard also committed resources including hiring $3^{\text {rd }}$ party sales teams to work the booths, signage and uniforms.

A budget break-down of the ATB Financial and ATB MasterCard fees and expenses reveals a considerable difference in their investment in leveraging (ratios ${ }^{38}$ of 1.75:1 for ATB Financial and 0.46:1 for ATB MasterCard). Full budget details follow as Table 36.

Table 36: ATB Financial/ATB MasterCard Sponsorship Budget Expenses

\begin{tabular}{|r|c|}
\hline \multicolumn{1}{|c|}{ ITEM } & AMOUNT \\
\hline Sponsorship Fees & \\
\hline ATB-Financial & $\$ 115,000.00$ \\
\hline MasterCard & $\$ 85,000.00$ \\
\hline MasterCard Activation & \\
\hline On-Site Signage & $\$ 19,900$ \\
\hline 3 Party Sales Teams & $\$ 8,567$ \\
\hline Signage for MasterCard tents & $\$ 1,772$ \\
\hline Additional contest expenses & $\$ 1,848$ \\
\hline Insert cost & $\$ 3,538$ \\
\hline T-Shirts for Race Week in branches & $\$ 1,951$ \\
\hline Golf shirts for workers & $\$ 1,263$ \\
\hline Signage & \\
\hline Suite signage & $\$ 175.05$ \\
\hline go-kart truss top/panels & $\$ 582.15$ \\
\hline go-kart fence & $\$ 1,857.90$ \\
\hline
\end{tabular}

\footnotetext{
${ }^{38}$ Ratios are calculated by dividing the dollar amount invested beyond the sponsorship fee by the sponsorship fee. For example, $\$ 200$ spent on a $\$ 100$ fee would be a $2: 1$ ratio.
} 


\begin{tabular}{|c|c|}
\hline onsite signage & $\$ 17,404.37$ \\
\hline Surveys & $\$ 7,000.00$ \\
\hline Media & $\$ 71,632.00$ \\
\hline \multicolumn{2}{|l|}{ Microsite } \\
\hline design and development & $\$ 36,269.00$ \\
\hline additional content work & $\$ 276.25$ \\
\hline \multicolumn{2}{|l|}{ Branch Collateral } \\
\hline Floor stickers & $\$ 4,723.18$ \\
\hline contest inserts & $\$ 950.60$ \\
\hline floor stands & $\$ 4,129.00$ \\
\hline Counter displays & $\$ 3,740.00$ \\
\hline ATB Race Week T-Shirts & $\$ 5,852.00$ \\
\hline \multicolumn{2}{|l|}{ Volunteer Program } \\
\hline polo shirts (75) & $\$ 2,775.00$ \\
\hline jackets (optional) & $\$ 0.00$ \\
\hline volunteer lunches & $\$ 651.00$ \\
\hline Water & $\$ 113.90$ \\
\hline Ticket Program & $\$ 21,167.02$ \\
\hline \multicolumn{2}{|l|}{ Suite Food/Entertainment } \\
\hline chalet upgrade & $\$ 1,874.35$ \\
\hline food/refreshments & $\$ 4,912.57$ \\
\hline ear plugs & $\$ 525.00$ \\
\hline Invitations & $\$ 198.77$ \\
\hline in site chalet food/refreshments & $\$ 2,180.47$ \\
\hline \multicolumn{2}{|l|}{ Gift packages (suite/contest) } \\
\hline Hats (75) & $\$ 900.00$ \\
\hline Pens & $\$ 399.00$ \\
\hline secondary prizes $(10 \times \$ 105)$ & $\$ 1,050.00$ \\
\hline gift bags for suite & $\$ 189.60$ \\
\hline Host Hotel & $\$ 617.48$ \\
\hline Road Show & $\$ 500.00$ \\
\hline grand prix inserts for Calgary & $\$ 179.78$ \\
\hline Race Car Driver Appearance Fee & $\$ 4,500.00$ \\
\hline \multicolumn{2}{|l|}{ Promotional Items } \\
\hline Hats & $\$ 900.00$ \\
\hline sports bags & $\$ 2,000.00$ \\
\hline Window Painting & $\$ 1,225.00$ \\
\hline TOTAL & $\$ 440,289.63$ \\
\hline
\end{tabular}

\subsection{Shirking}

The purpose of this section is to identify and then measure any shirking behaviours that may be detracting from the effectiveness of the sponsorship. The data recovered in Steps 1 and 2, taken in the context of the objectives identified in Step 3 and operationalized in Step 4, indicate that from an Agency Theory point of view, the ATBEGP Sponsor-Sponsee relationship was a good one with the agent/sponsee (EGP) acting 
mostly according to the contractual objectives of the principal/sponsor (ATB). However, analysis of the contract and interview transcripts revealed nine instances of potential shirking behaviour. These are assessed in Step 6 and outlined in Table 37 below.

Table 37: Sponsee Shirking in the ATB-EGP Sponsorship

\begin{tabular}{|c|c|c|c|}
\hline $\begin{array}{l}\text { Incident of } \\
\text { Shirking } \\
\text { (Source) }\end{array}$ & $\begin{array}{l}\text { Related Outputs, Activities \& } \\
\text { Issues }\end{array}$ & Metric for Measure & Methods \\
\hline $\begin{array}{l}\text { Sponsor Conflict } \\
\text { (Contract) }\end{array}$ & $\begin{array}{l}\text { As per sponsorship contract } \\
\text { (Clause 2.2), a pre-existing } \\
\text { agreement with Capital City } \\
\text { Savings - a direct competitor } \\
\text { of ATB - for their sponsorship } \\
\text { of the Pit Lane Club will be } \\
\text { honoured and allowed to exist } \\
\text { concurrently to ATB } \\
\text { sponsorship. }\end{array}$ & $\begin{array}{l}\text { Question a representative } \\
\text { sample of Albertans to } \\
\text { determine if confusion } \\
\text { caused by the suggested } \\
\text { shirk. }\end{array}$ & $\begin{array}{l}\text { Questions on mass } \\
\text { market survey to } \\
\text { determine the extent } \\
\text { of the confusion this } \\
\text { causes in consumers' } \\
\text { minds. }\end{array}$ \\
\hline $\begin{array}{l}\text { No On-Site } \\
\text { Product Sales } \\
\text { (Contract) } \\
\end{array}$ & $\begin{array}{l}\text { On-site ATMs were not ATB } \\
\text { ATMs. }\end{array}$ & $\begin{array}{l}\text { Forecast of on-site } \\
\text { expenditures to estimate } \\
\text { lost profit. }\end{array}$ & $\begin{array}{l}\text { Use of industry data } \\
\text { and internal data to } \\
\text { estimate effect. }\end{array}$ \\
\hline $\begin{array}{l}\text { Signage Problem } \\
\text { (Internal Review) }\end{array}$ & $\begin{array}{l}\text { Scrim fencing that was } \\
\text { promised was not ordered by } \\
\text { the sponsor, banners used } \\
\text { instead leading to lower quality } \\
\text { signage and signage that was } \\
\text { on front of fence only, not } \\
\text { back... reducing visibility. }\end{array}$ & $\begin{array}{l}\text { Combination qualitative } \\
\text { (employee interviews) } \\
\text { and quantitative (mass- } \\
\text { market consumer surveys) } \\
\text { to assess effect. }\end{array}$ & $\begin{array}{l}\text { Mass market survey } \\
\text { and post-event } \\
\text { Interviews to } \\
\text { understand situation } \\
\text { and estimate - in the } \\
\text { context of other } \\
\text { results - the impact. }\end{array}$ \\
\hline $\begin{array}{l}\text { Service } \\
\text { Efficiency } \\
\text { (Internal Review) }\end{array}$ & $\begin{array}{l}\text { Numerous incidents of } \\
\text { frustration and delays } \\
\text { expressed. }\end{array}$ & $\begin{array}{l}\text { Qualitative study } \\
\text { sampling those involved } \\
\text { in service delivery }\end{array}$ & $\begin{array}{l}\text { Post-event Interviews } \\
\text { to estimate time lost } \\
\text { and cost. }\end{array}$ \\
\hline $\begin{array}{l}\text { Celebrity Race } \\
\text { Car Driver } \\
\text { Investment } \\
\text { (Internal Review) }\end{array}$ & $\begin{array}{l}\text { A significant investment was } \\
\text { made to bring the driver in to } \\
\text { the hospitality booth on all } 3 \\
\text { days. On all three days he was } \\
\text { late and spent less time than } \\
\text { contracted. }\end{array}$ & $\begin{array}{l}\text { Qualitative study } \\
\text { sampling the staff who } \\
\text { had direct contact with } \\
\text { the driver and the chance } \\
\text { to observe the situation. }\end{array}$ & $\begin{array}{l}\text { Post-event Suite Host } \\
\text { Interviews to } \\
\text { understand situation } \\
\text { and estimate impact. }\end{array}$ \\
\hline $\begin{array}{l}\text { Go-Kart Track } \\
\text { Location } \\
\text { (Internal Review) }\end{array}$ & $\begin{array}{l}\text { Contrary to promise, the Go- } \\
\text { Kart track was located far from } \\
\text { the family zone (rides, etc.) } \\
\text { and near the beer tent and food } \\
\text { vendors. }\end{array}$ & $\begin{array}{l}\text { Combination qualitative } \\
\text { (employee interviews) } \\
\text { and quantitative (mass- } \\
\text { market consumer surveys) } \\
\text { to assess effect. }\end{array}$ & $\begin{array}{l}\text { Mass market surveys } \\
\text { and post-event } \\
\text { Interviews to } \\
\text { understand situation } \\
\text { and estimate impact. }\end{array}$ \\
\hline $\begin{array}{l}\text { PA } \\
\text { Announcements } \\
\text { (Internal Review) }\end{array}$ & $\begin{array}{l}\text { Messaging wasted as volume } \\
\text { was insufficient over the event } \\
\text { noise. }\end{array}$ & $\begin{array}{l}\text { Qualitative study } \\
\text { sampling those involved } \\
\text { onsite. }\end{array}$ & $\begin{array}{l}\text { Post-event Interviews } \\
\text { to understand } \\
\text { situation and estimate } \\
\text { impact. }\end{array}$ \\
\hline
\end{tabular}




\begin{tabular}{|l|l|l|l|}
\hline $\begin{array}{l}\text { Allocation of } \\
\text { tickets and } \\
\text { hospitality suite }\end{array}$ & $\begin{array}{l}\text { Feedback was provided that } \\
\text { there were issues and } \\
\text { perceived unfairness in this } \\
\text { process. }\end{array}$ & $\begin{array}{l}\text { Qualitative study of ATB } \\
\text { employees and review of } \\
\text { effectiveness of ticket } \\
\text { allocation program. }\end{array}$ & $\begin{array}{l}\text { Post-event interviews } \\
\text { and assessment of } \\
\text { ticket allocation }\end{array}$ \\
\hline $\begin{array}{l}\text { ATB MasterCard } \\
\text { - ATB }\end{array}$ & $\begin{array}{l}\text { Feedback revealed } \\
\text { organization issues between } \\
\text { the sponsor and co-sponsor }\end{array}$ & $\begin{array}{l}\text { Qualitative study } \\
\text { sampling those involved } \\
\text { in the relationship. }\end{array}$ & $\begin{array}{l}\text { Post-event Interviews } \\
\text { to understand } \\
\text { situation and estimate } \\
\text { impact. }\end{array}$ \\
\hline
\end{tabular}

Each of these nine items will be measured and subtracted from the overall impacts of the sponsorship.

\subsubsection{Step 6: Collect and Analyze the Data (Results)}

The objective of this step is to run the metrics and calculate results. It involves implementing all of the metrics by first gathering the necessary data and, second, analyzing the generated results.

Each of the data collection exercises was executed as planned. Given the fact that 21 objectives and 9 shirking effects were measured using 8 data collection methods, the presentation of these results and analysis is lengthy and complex. In order to present the findings in a coherent way that outlines the process undertaken, 38 short sub-sections are presented comprised of (i) the methodological details of each of the 8 data collection exercises, (ii) the data analysis for each of the 21 objectives, and (iii) the data analysis for each of the 9 potential shirking behaviours. The data gathering exercises are presented first, as the analysis of the 21 objectives and 9 shirking behaviours are based in some part on those data. A description of how each objective, data collection exercise and metric is linked is provided in the 21 sub-sections on each objective and the 9 sub-sections on each shirking behaviour. 


\subsection{Data Collection Exercises}

Data Collection Exercise \#1: Web Survey: To provide the data necessary to measure the objectives targeted at residents of Alberta related to customer acquisition, building awareness and re-branding ATB (i.e., objectives \#3, \#10, \#12, and \#21 from Table 34), it was decided to utilize a pre-event web-based survey. In developing the final survey, the researcher worked with ATB's in-house research professional, who approved the final product. Questions were designed related to objectives \#3, \#10,\#12 and \#21, as well as (i) to shed light on how individuals came to visit the site, (ii) to ascertain their opinions of ATB Financial and (iii) to understand their views about the EGP sponsorship. The web survey, consisting of 10 questions designed to evaluate opinions of the site and the sponsorship (Appendix C), was posted on the ATB-EGP micro-site (www.atbgrandprix.com) which launched on June 1, 2006. Banner advertising on www.atb.com was launched concurrently using banner rotation to promote the microsite (i.e. the EGP banner was displayed to approximately 1 out of 5 visitors to the ATB website). On June 5, banner rotation stopped (i.e. all ATB website visitors see micro-site link), in branch promotions (e.g. signage) began and media campaign launched (e.g. radio and television advertising).

Designed as a pre-event promotional site, the micro-site was live for 43 days (June $1^{\text {st }}$ to July $13^{\text {th }}$ ) closing at mid-night on July $13^{\text {th }}, 2006$. During that time, there were 28,934 total visits by 14,583 different users (unique visits) with a total of 81,915 page views. Traffic was consistent throughout the 43 days except for the days following the marketing launch (June 5 to 8,2006 ) when traffic was approximately double. As a result, 3484 valid responses were obtained from individuals who came to the site in one 
of three ways: (i) via learning about the site through collateral materials (tent cards, stand-up units) in branches in June 2006, (ii) via newspaper, print and radio advertisements in Edmonton (mainly) and Calgary in June, or (iii) via the atb.com home page banner that had a link to the micro-site (Rudan, 2006d). The demographics of the visitors show that the sample consisted of Albertan residents, $48.9 \%$ male, distributed evenly by age, of varied job backgrounds ( 21 career fields well represented), and from all geographic areas of Alberta (over 200 municipalities represented, most being from Edmonton (37.1\% of the sample) and Calgary (11.2\% of the sample). Thus, $51.7 \%$ of the respondents were from outside of Calgary and Edmonton.

Respondents were asked how they learned about the micro-website. One-third (32.3\% (1158)) came to the micro-site from the banner advertisement at www.atb.com, $13.9 \%$ (498) from newspaper ads, $13.3 \%$ (478) via an email invitation, $12.2 \%$ (438) learned of the micro-site from an in-branch poster, $10.6 \%$ (382) via word-of-mouth, $1.8 \%$ (63) through a search engine, and $1.7 \%$ (61) as a result of a radio ad. They were also asked about their perceptions of ATB's quality with over $76 \%$ of respondents indicating that they viewed ATB as very high or high quality and an additional $20 \%$ indicating average quality. Many (82\%) also noted that they knew ATB products and services very well. In terms of the EGP sponsorship itself, $53.7 \%$ of respondents believed that it is the best choice for ATB, $19.8 \%$ noted that it is a good choice while only $1.6 \%$ indicated that the event was not appropriate for an ATB sponsorship.

Interestingly, when asked if ATB's sponsorship of the Grand Prix had changed their opinion of ATB, results (see table 38 below) show some effect. Notably, 557 
respondents (15.5\%) indicated that the sponsorship significantly positively increased their opinion of ATB.

Table 38: Impact of EGP sponsorship on positive opinion of $A T B$

\section{SPIMPACT}

\begin{tabular}{|c|c|c|c|c|c|}
\hline & & Frequency & Percent & Valid Percent & $\begin{array}{c}\text { Cumulative } \\
\text { Percent }\end{array}$ \\
\hline \multirow[t]{6}{*}{ Valid } & Significantly increased & 557 & 15.5 & 16.0 & 16.0 \\
\hline & Somewhat increased & 1021 & 28.5 & 29.3 & 45.3 \\
\hline & No change & 1896 & 52.8 & 54.4 & 99.7 \\
\hline & Somewhat decreased & 8 & .2 & .2 & 99.9 \\
\hline & Significantly decreased & 2 & .1 & .1 & 100.0 \\
\hline & Total & 3484 & 97.1 & 100.0 & \\
\hline Missing & System & 104 & 2.9 & & \\
\hline Total & & 3588 & 100.0 & & \\
\hline
\end{tabular}

A question was asked to assess the potential effects of the sponsorship on behaviour (i.e., increased business measured by branch visits), where $24.2 \%$ indicate that they were very likely or likely to visit an ATB branch more in the near future due to the sponsorship, while $39 \%$ responded that they were very unlikely or unlikely to do so. This is perhaps as a result of the fact that the vast majority of respondents were already ATB Financial customers. This point is supported by the question related to switching financial institutions to ATB Financial where $84 \%$ of respondents indicated no change or that they were already ATB Financial customers. Of the remaining $16 \%$, only $0.5 \%$ indicated that the EGP sponsorship decreased their chance of switching their business to ATB Financial.

Finally, respondents were asked to describe their perception of ATB Financial in the Alberta market. Ninety-one percent responded that they felt ATB Financial is a 'major player' in the Albertan market. Most respondents (82.9\%) also knew that ATB is 
a full-service Albertan bank, however there remains some confusion about the scope of the financial institution's operations with $5.6 \%$ thinking it operates coast-to-coast, $6.8 \%$ viewing it only as a small-town Albertan bank, and a single respondent supporting that it is a BC bank expanding into Alberta. Finally, when asked if the EGP sponsorship could potentially change their opinion of ATB Financial, only 28 of the 109 who incorrectly described ATB as "a Canadian bank from coast-to-coast" and 19 of the 226 who described it as "a small town Alberta bank" (the organization's past image which they are seeking to change) noted that they would consider changing their opinion of ATB.

Data Collection Exercise \#2: ATB Internal Customer Data: Following the signing of the NDAs and considerable effort by ATB marketing personnel, ATB officials provided data (received October 24, 2006) for two Calgary and two Edmonton branches for each of the months of June, July, and August 2006 to support the measurement of objectives \#1, \#2, \#3, and \#4 (see Table 34). Branches were selected by ATB based on one urban/one suburban branch in each city. This data included (i) \# of households, (ii) \# of households lost from previous month, (iii) \# of households gained from previous month, (iv) average deposit balance of households, (v) average loan balance of households, (vi) average deposit balance of households gained from previous month, and (vii) average loan balance of households gained from previous month. The data was requested in order to calculate metrics related to customer acquisition in Edmonton and Calgary. Reports were generated by assessing internal ATB reporting systems and are summarized below in Table 39. 
Table 39: ATB Internal Customer Data, 4 Branches

\section{CALGARY BRANCH \#1}

\begin{tabular}{l|rrr}
\hline & $30-J u n-06$ & $31-J u l-06$ & 31-Aug-06 \\
\hline \# of households & 5,944 & 5,932 & 5,936 \\
\# of households lost & 52 & 51 & 63 \\
\# of households gained & 73 & 60 & 65 \\
Average deposit balance of households & $\$ 77,116.77$ & $\$ 73,607.91$ & $\$ 82,581.30$ \\
Average loan balance of households & $\$ 321,153.33$ & $\$ 334,884.08$ & $\$ 362,302.10$ \\
Average deposit balance of households gained & $\$ 31,127.55$ & $\$ 23,362.65$ & $\$ 54,009.77$ \\
Average loan balance of households gained & $\$ 495,201.75$ & $\$ 207,120.17$ & $\$ 727,538.63$
\end{tabular}

\section{CALGARY BRANCH \#2}

\begin{tabular}{l|rrr}
\hline & $30-J u n-06$ & $31-J u l-06$ & 31-Aug-06 \\
\hline \# of households & 5,973 & 5,962 & 5,983 \\
\# of households lost & 38 & 49 & 56 \\
\# of households gained & 46 & 45 & 65 \\
Average deposit balance of households & $\$ 19,077.11$ & $\$ 18,821.57$ & $\$ 19,333.13$ \\
Average loan balance of households & $\$ 42,431.74$ & $\$ 43,477.11$ & $\$ 43,268.39$ \\
Average deposit balance of households gained & $\$ 8,776.70$ & $\$ 18,688.76$ & $\$ 550.23$ \\
Average loan balance of households gained & $\$ 25,046.43$ & $\$ 79,478.36$ & $\$ 2,886.52$
\end{tabular}

\section{EDMONTON BRANCH \#1}

\begin{tabular}{l|rrr}
\hline & $30-J u n-06$ & $31-J u l-06$ & 31-Aug-06 \\
\hline \# of households & 4,679 & 4,682 & 4,656 \\
\# of households lost & 43 & 37 & 33 \\
\# of households gained & 15 & 33 & 24 \\
Average deposit balance of households & $\$ 30,414.17$ & $\$ 28,619.54$ & $\$ 32,711.37$ \\
Average loan balance of households & $\$ 48,766.81$ & $\$ 48,473.17$ & $\$ 47,477.92$ \\
Average deposit balance of households gained & $\$ 524.33$ & $\$ 9,410.52$ & $\$ 8,657.38$ \\
Average loan balance of households gained & $\$ 5,196.27$ & $\$ 33,746.55$ & $\$ 6,304.21$
\end{tabular}

\section{EDMONTON BRANCH \#2}

\# of households lost

\# of households gained

Average deposit balance of households

Average loan balance of households

Average deposit balance of households gained

Average loan balance of households gained

30-Jun-06

4,362

31-Jul-06

4,361

31-Aug-06

60

34

4,361

34

30

$\$ 29,984.75 \quad \$ 29,726.24$

$\$ 42,250.11 \quad \$ 43,789.62$

$\$ 5,123.50 \quad \$ 3,780.53$

$\$ 35,613.50 \quad \$ 85,400.37$

$\$ 43,453.74$

$\$ 12,537.83$

$\$ 3,670.97$

Further, ATB aggregate data was provided and is provided in Table 40. 
Table 40: ATB Internal Customer Data, Aggregate

\begin{tabular}{l|rrr} 
ALLATB & & & \\
\hline & $30-J u n-06$ & $31-J u l-06$ & 31-Aug-06 \\
\hline \# of households & 362,047 & 363,089 & 363,624 \\
\# of households lost & 2,742 & 2542 & 2912 \\
\# of households gained & 3,266 & 3294 & 3471 \\
Average deposit balance of households & $\$ 19,524.69$ & $\$ 19,019.69$ & $\$ 19,395.24$ \\
Average loan balance of households & $\$ 42,469.58$ & $\$ 42,940.70$ & $\$ 43,747.69$ \\
Average deposit balance of households gained & $\$ 4,897.62$ & $\$ 5,854.11$ & $\$ 6,645.49$ \\
Average loan balance of households gained & $\$ 22,862.84$ & $\$ 17,539.37$ & $\$ 32,472.03$
\end{tabular}

Data Collection Exercise \#3: In-Branch Surveys: Metrics for six of the objectives identified in Table 34 (i.e., \#1 and \#2 (customer acquisition in Edmonton and Calgary), \#7 (brand prestige in current customers), \#10 (consumer knowledge of ATB), \#12 (rebranding ATB as full service financial institution), and \#21 (awareness of ATB MasterCard) required a survey of current customers. Based on permissions, resources and access, it was decided that in-branch surveys with ATB customers at one Calgary and one Edmonton branch would be the best method. The survey (attached as Appendix D) was developed in collaboration with ATB's internal research professional and approved by ATB.

Surveys were carried out at one Calgary branch and one Edmonton branch. These branches were chosen for their respective city locations and the fact that both branch managers were supportive of the evaluation. The decision was made by ATB in consultation with the researcher. Two research assistants (University of Alberta Commerce students; one of whom had worked with ATB previously) were recruited by the researcher to collect data from the Calgary branch over a three day period (August 28-30, 2006) and over a two day period in the Edmonton branch (August 31-September $1,2006)$. The research assistants were provided training from August $23-25,2006$ by the 
author and ATB's Marketing Manager, Investor Services. Researchers set up at a table in the branch and offered customers an incentive (cold bottled water and an energy bar) to complete the survey, which took three to five minutes to self-complete. Each customer in the bank was approached to participate.

One-hundred-eleven (111) and 106 surveys were collected from the Calgary and Edmonton branches, respectively. Approximately $20 \%$ of the surveys were collected on each of Monday, Tuesday, Wednesday, Thursday and Friday distributed throughout the banking day (Morning (39.5\%), Noon-Hour (24.9\%), and Afternoon (35.6\%)).

Researchers reported that data collection was smooth and that most bank patrons completed the survey and that those who did not typically did not do so because there was already a line-up of people completing it. The support of the branch staff was noted.

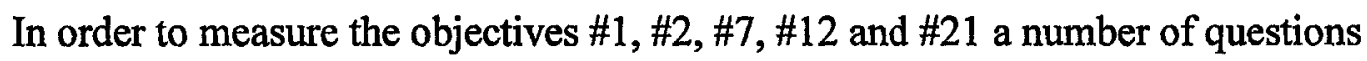
were asked. Ten (or 4.6\%) indicated that they had become ATB customers in the past two months while 22 (or 9.2\%) noted that they had increased their business with ATB over the past two months. Characteristics of the sample measured included gender $(50.6 \%$ male), age (18-24 (10.3\%), 25-34 (15.9\%), 35-44 (15.9\%), 45-54 (25.8\%), 55-64 (16.4\%), 65+ (15.4\%)), and household income (Refused/Don't Know (12.4\%), Less than \$50k (34.5\%), \$50k-\$100k (26.7\%), \$100k-\$150k (11.9\%), \$150k-\$250k (7.3\%), $\$ 250 \mathrm{k}+(6.9 \%))$. Table 41 below, provides a comparison between the Edmonton and Calgary results as some of these objectives (\#1 and \#2, particularly) are specific to each market. 
Table 41: Edmonton Versus Calgary Branch Comparison, In-branch Surveys

\begin{tabular}{|l|c|c|}
\hline Item & Edmonton ( $=111)$ & Calgary (n-106) \\
\hline ATB Customers & 94 (or 84.6\%) & 66 (or 62.2\%) \\
\hline $\begin{array}{l}\text { Likelihood of non-customers } \\
\text { becoming customers }\end{array}$ & 7 yes, 9 no, 1 don't know & 19 yes, 20 no, 1 don't know \\
\hline Current customer situation & $\begin{array}{c}41(37.0 \%) \text { bank only with ATB } \\
\text { while 54 (48.6\%) bank with ATB } \\
\text { and other FIs }\end{array}$ & $\begin{array}{c}24(22.6 \%) \text { bank only with ATB } \\
\text { while 42 (39.6\%) bank with ATB } \\
\text { and other FIs }\end{array}$ \\
\hline Banking at home branch & $30(31.9 \%)$ were at home branch & $29(43.9 \%)$ were at home branch \\
\hline New Customers (last 2 mos.) & 4 & 6 \\
\hline Increased business (2 mos.) & 11 & 11 \\
\hline $\begin{array}{l}\text { ATB Brand Prestige Relative } \\
\text { to Other Financial Institutions }\end{array}$ & $\begin{array}{c}\text { Very High: } 24(21.6 \%) \\
\text { High: } 42(37.8 \%)\end{array}$ & $\begin{array}{c}\text { Very High: } 16(15.0 \%) \\
\text { High: } 31(28.9 \%)\end{array}$ \\
\hline ATB as important FI player & Yes: $70(63.1 \%)$ & Yes: $38(35.55)$ \\
\hline
\end{tabular}

Table 41 notes some differences in the Edmonton and Calgary samples which will be assessed in the assessment of specific objectives.

Data Collection Exercise \#4: Hospitality Surveys and Suite-Host Interviews: High end customers (i.e. 'top 1\%') are an important target of this sponsorship and ATB identified objectives (\#4 and \#10) to impact these key customers and prospects. In order to assess these objectives, metrics including aggregate data, tracking of attendees, a survey, and post-event interviews with suite hosts were developed. For the survey, it was decided that a survey during the event at the hospitality suite was the best method. The survey (Appendix E) was designed in collaboration with the ATB in-house research professional who gave final approval.

During the EGP, ATB Suite Hosts were instructed to administer surveys to each of the 25 attendees of the ATB Financial hospitality suite each day. ATB obtained permission to administer the surveys and no incentive was offered. The survey was administered by a different Suite Host each day. Attendees self-completed the surveys. Following the event, each suite host was approached for an interview (question template is attached as Appendix F). The three Suite Hosts provided valuable context to the survey 
results. The question and discussion style interviews were taped and transcribed. Each was approximately 20 minutes in length. The interviewees had high knowledge of the event, sponsorship experience and previous experience working in hospitality and with ATB.

A total of 37 surveys were completed by the 75 ( 25 each day) hospitality suite attendees, of which 29 were valid and useable (response rate $=38.7 \%$ ). The main reason surveys were discarded was for incompleteness, normally when only one side was completed. Nine (9) valid surveys were completed on Friday, sixteen (16) on Saturday and four (4) on Sunday. Twenty-two (76\%) of the 29 hospitality suite attendees rated their overall Grand Prix experience as 'excellent', 6 (21\%) indicated it was 'very good' and only $1(3 \%)$ described their experience as 'fair'. Twenty-eight out of 29 (or 97\%) said they would come back next year if invited again. A series of questions asking for their level of agreement (Strongly Disagree, Disagree, Neither Agree nor Disagree, Agree, Strongly Agree) delved deeper into these opinions and results are outlined in Table 42 below.

\section{Table 42: Consumer Opinion of Impacts on ATB}

\begin{tabular}{|l|c|c|c|}
\hline Question & $\begin{array}{c}\text { Strongly Agree } \\
\text { or Agree }\end{array}$ & $\begin{array}{c}\text { Neither Agree } \\
\text { nor Disagree }\end{array}$ & $\begin{array}{c}\text { Strongly Disagree } \\
\text { or Disagree }\end{array}$ \\
\hline Will experience increase business with ATB? & $21(72 \%)$ & $6(21 \%)$ & $2(7 \%)$ \\
\hline Will experience increase opinion of ATB? & $29(100 \%)$ & 0 & 0 \\
\hline $\begin{array}{l}\text { Will experience increase ATB word of } \\
\text { mouth? }\end{array}$ & $28(97 \%)$ & $1(3 \%)$ & 0 \\
\hline $\begin{array}{l}\text { Will experience increase opinion of ATB as } \\
\text { FI? }\end{array}$ & $25(86 \%)$ & $4(14 \%)$ & 0 \\
\hline $\begin{array}{l}\text { Will experience increase desire to deal with } \\
\text { ATB? }\end{array}$ & $23(79 \%)$ & $5(17 \%)$ & $1(3 \%)$ \\
\hline
\end{tabular}


A number of additional points about the sample are important to this data collection exercise. First, 22 (76\%) of the respondents were ATB clients while $7(24 \%)$ were not. Second, 15 (52\%) respondents indicated that ATB is their primary bank while $14(28 \%)$ indicated that it is not (note that for the 14 for whom ATB is not their primary bank, 7 (24\%) do bank at ATB and 7 (24\%) do not bank at ATB at all). Third, 7 (24\%) respondents only bank at ATB while $22(76 \%)$ also use the services of other financial institutions. Fourth, within the sample of 22 who use other financial institutions, it was determined that they (a) use $1.8(+/ . .9)$ other FIs with a minimum of 1 and a maximum of 4 , and (b) they do $47.0 \%+/-38.0 \%$ of their banking with ATB; range of 0 to $95 \%$. Fifth, of those attendees who were ATB clients, they have been clients for an average of $15.8+/-15$ years with a range of 1 year to 50 years. Finally, household income was asked as a proxy for level of customer, where results showed that 21 (or 72\%) had a household income greater than $\$ 100,000,6$ (or $21 \%$ ) had a household income between $\$ 60,000$ and $\$ 100,000$ and 2 (or $7 \%$ ) had a household income under $\$ 60,000$.

The suite host interviewees described the suite as a success from both a hospitality and sponsorship point of view, and indicated that guests had a very good time while there (Suite_Host_1, 2006; Suite_Host_2,2006). With respect to the benefit to ATB's sponsorship of the EGP, the hosts pointed out that the suite was a particular success in targeting and reaching the top end clients and showing that they are valued customers (Suite_Host_1, 2006; Suite_Host_2, 2006), however "there were some invitation logistics as perhaps too many executives were there and not enough clients" (Suite_Host_2, 2006). The interviewees were also asked to describe the suite attendees 
demographically, noting that "executives were there...relationship managers, the $\mathrm{COO}^{39}$ and two other executives, the $\mathrm{COO}$ with his guest...it was a mix of couples, friends, daughter, top end customers who had money" (Suite_Host_2, 2006) and that attendees were mostly "ATB's top customers... all with guests. About 20 total, 10 groups of two, 50/50 men/women with a few kids" (Suite_Host_1, 2006).

The interviewees reported that (i) ATB signage and gift bags were well presented and distributed, (ii) that they, as hosts, took on many other roles during the day (barkeeper, ticket manager, event program distribution, gift bag assembly and distribution, and coordinating the race car driver suite visit), (iii) that attendees were very cooperative and willing to complete surveys although some never did, and (iv) that guests were treated very well (lobster and filet mignon lunch, taxi chits to get home, and classy service) (Suite_Host_1, 2006; Suite_Host_2, 2006). Finally, two specific suggestions were brought forth for improvement; (i) to invite fewer people or to rent a larger suite in order to reduce the congestion and to allow for all guests to sit down and (ii) to manage the ticket allocation to allow for more clients and fewer ATB employees and their spouses.

Data Collection Exercise \#5: Mass Market (Alberta) Surveys: In order to assess the 5 objectives related to the impact of the sponsorship on the Albertan market (i.e., increased awareness (\#5 and \#6), achievement of competitive advantage (\#9), consumer opinion of ATB (\#11), re-branding ATB as full-service FI (\#13), and the EGP's ability to build an affinity with Albertans (\#18)), 500 phone surveys (random) were completed province wide in August 2006 by a market research house (Trend Research Inc.) partner contracted by ATB. As with the previous questionnaires, the researcher developed the

${ }^{39} \mathrm{COO}$ refers to the Chief Operating Officer of ATB. 
draft, then collaborated with ATB's in-house research professional who, in turn, contributed to and approved the final version. The survey is attached at Appendix G. Data collection was done via the random calling of Alberta phone numbers until the target of 500 was reached. Initial screening questions were asked to rule out respondents under 18 years of age or employees of any financial institutions.

The demographic make-up of the sample (age and household income) was generally representative of the larger Albertan market, except for gender which was $38.4 \%$ male and $61.6 \%$ female compared to the Albertan population which is approximately 50/50 (the 2001 Census $^{40}$ reported that $1,486,590$ men and 1,488,220 women lived in Alberta). One hundred and seventy-seven respondents (35.4\%) were selected from the Metropolitan Calgary area, 162 (32.4\%) from the Metropolitan Edmonton region, 110 (22.0\%) from other Albertan cities, and 51 (10.2\%) from largely rural areas of Alberta. Sample age distribution was representative of the Albertan population (Statistics Canada, 2007) as outlined in Table 43 below.

\section{Table 43: Age of Mass Market Survey Respondents}

AGE

\begin{tabular}{|lr|r|r|r|r|}
\hline & & Frequency & Percent & Valid Percent & $\begin{array}{c}\text { Cumulative } \\
\text { Percent }\end{array}$ \\
\hline Valid & $18-24$ & 48 & 9.6 & 9.6 & 9.6 \\
& $25-34$ & 86 & 17.2 & 17.2 & 26.8 \\
& $35-44$ & 110 & 22.0 & 22.0 & 48.8 \\
& $45-54$ & 118 & 23.6 & 23.6 & 72.4 \\
& $55-64$ & 65 & 13.0 & 13.0 & 85.4 \\
$65+$ & 73 & 14.6 & 14.6 & 100.0 \\
& Total & 500 & 100.0 & 100.0 & \\
\hline
\end{tabular}

\footnotetext{
${ }^{40}$ Details on the 2001 Census can be found at www.statscan.ca
} 
Sample household income was also found to be representative of the Albertan population (Statistics Canada, 2007) and is outlined in Table 44 below.

Table 44: Household Income of Mass Market Survey Respondents

\begin{tabular}{|c|c|c|c|c|c|}
\hline \multicolumn{6}{|c|}{ INCOME } \\
\hline & & Frequency & Percent & Valid Percent & $\begin{array}{c}\text { Cumulative } \\
\text { Percent }\end{array}$ \\
\hline \multirow[t]{7}{*}{ Valid } & less than $\$ 50 \mathrm{k}$ & 127 & 25.4 & 25.4 & 25.4 \\
\hline & $\$ 50 \mathrm{~K}$ to $\$ 100 \mathrm{~K}$ & 160 & 32.0 & 32.0 & 57.4 \\
\hline & $\$ 100 K$ to $\$ 150 k$ & 78 & 15.6 & 15.6 & 73.0 \\
\hline & $\$ 150 k$ to $\$ 250 k$ & 28 & 5.6 & 5.6 & 78.6 \\
\hline & more than $\$ 250 \mathrm{~K}$ & 14 & 2.8 & 2.8 & 81.4 \\
\hline & Don't know/refused & 93 & 18.6 & 18.6 & 100.0 \\
\hline & Total & 500 & 100.0 & 100.0 & \\
\hline
\end{tabular}

The next series of questions assessed respondents' past knowledge and interest in car racing: $11.8 \%$ (or 59 individuals) had attended and $23.6 \%$ (or 118 individuals) had watched an Indy, NASCAR or CHAMPCAR race previously. Of note, 17 respondents (3.4\%) attended the 2006 EGP in person, 52 (10.4\%) watched the race on television and $48(9.6 \%)$ took in the event by radio or the internet. Respondents were then asked if they could identify (aided recall) the event title sponsor from a list of 7 options where one of the options was 'none of the above'. Table 45 below describes the responses, showing significant confusion as $39.4 \%$ indicated 'don't know' while the true title sponsor was the choice of only $21.0 \%$ of respondents. 
Table 45: Title Sponsor Recognition

TITLE_SP

\begin{tabular}{|c|c|c|c|c|c|}
\hline & & Frequency & Percent & Valid Percent & $\begin{array}{l}\text { Cumulative } \\
\text { Percent }\end{array}$ \\
\hline \multirow[t]{9}{*}{ Valid } & Edmonton Tourims & 10 & 2.0 & 2.0 & 2.0 \\
\hline & Molson & 77 & 15.4 & 15.4 & 17.4 \\
\hline & Travel Alberta & 13 & 2.6 & 2.6 & 20.0 \\
\hline & Ford & 23 & 4.6 & 4.6 & 24.6 \\
\hline & The Brick & 34 & 6.8 & 6.8 & 31.4 \\
\hline & West Edmonton Mall & 105 & 21.0 & 21.0 & 52.4 \\
\hline & None of the Above & 41 & 8.2 & 8.2 & 60.6 \\
\hline & Don't Know & 197 & 39.4 & 39.4 & 100.0 \\
\hline & Total & 500 & 100.0 & 100.0 & \\
\hline
\end{tabular}

A similar question asked the respondents to identify the official Financial Institution sponsor of the 2006 Edmonton Grand prix. Table 46 below outlines these results.

Table 46: Financial Institution Sponsor Recognition

\begin{tabular}{|l|r|r|r|r|}
\hline \multicolumn{7}{|c|}{ OFFFI_SP } \\
\hline Valid & Frequency & Percent & Valid Percent & $\begin{array}{c}\text { Cumulative } \\
\text { Percent }\end{array}$ \\
\hline ATB & 57 & 11.4 & 11.4 & 11.4 \\
Alberta Credit Unions & 71 & 14.2 & 14.2 & 25.6 \\
Capital City Savings & 5 & 1.0 & 1.0 & 26.6 \\
Bank of Alberta & 18 & 3.6 & 3.6 & 30.2 \\
None of the Above & 6 & 1.2 & 1.2 & 31.4 \\
Don't Know & 54 & 10.8 & 10.8 & 42.2 \\
Total & 289 & 57.8 & 57.8 & 100.0 \\
\hline
\end{tabular}

Once again, 'Don't Know' was the most common choice while only 71 respondents (or $14.5 \%)$ said ATB, the correct answer. Widespread awareness is clearly not evident as RBC (55 respondents or 11.0\%) and None of the Above (54 respondents of 10.8\%) received similar scores and well over half the sample (289 or $57.8 \%$ ) indicated that they didn't know. Of note, is that Capital City Savings (a direct competitor of ATB who were 
also involved with the EGP as sponsor of the Capital City Savings Pit Lane Club) were noted by 18 respondents (3.6\%).

The remainder of the survey occurred after each respondent was told that ATB was the official FI sponsor. Background questions revealed that 87 respondents $(17.4 \%)$ are currently customers of ATB and that the majority (56.8\% or 284$)$ define ATB correctly as a 'full service, province-wide Albertan financial institution'. However, a significant portion (43.2\%) of the sample still defines ATB incorrectly.

The next series of 8 questions assessed the effectiveness of the EGP sponsorship using 5-option (Strongly Agree, Agree, Neither Agree nor Disagree, Disagree, Strongly Disagree) Likert scale type questions. In order to clearly present agreement/neither/disagreement, results are collapsed into 3 groups with the agreement and disagreement options joined and presented in Table 47.

Table 47: Frequency Responses, EGP Sponsorship Effectiveness

\begin{tabular}{|l|c|c|c|}
\hline Question & $\begin{array}{c}\text { Strongly Agree } \\
\text { or Agree }\end{array}$ & $\begin{array}{c}\text { Neither Agree } \\
\text { nor Disagree }\end{array}$ & $\begin{array}{c}\text { Strongly Disagree } \\
\text { or Disagree }\end{array}$ \\
\hline $\begin{array}{l}\text { I am now more aware of the products and } \\
\text { services of ATB Financial after their } \\
\text { sponsorship of the Edmonton Grand Prix. }\end{array}$ & $82(16.4 \%)$ & $71(14.2 \%)$ & $320(64.0 \%)$ \\
\hline $\begin{array}{l}\text { After leaming that ATB Financial was } \\
\text { sponsoring the Edmonton Grand Prix, my belief } \\
\text { that they care about Albertans increased. }\end{array}$ & $217(43.4 \%)$ & $109(21.8 \%)$ & $146(29.2 \%)$ \\
\hline $\begin{array}{l}\text { In my opinion, the ATB sponsorship of the } \\
\text { Edmonton Grand Prix helps demonstrate that } \\
\text { ATB is a major player in the Alberta banking } \\
\text { market }\end{array}$ & $324(64.8 \%)$ & $61(12.2 \%)$ & $90(18.0 \%)$ \\
\hline $\begin{array}{l}\text { When I think of ATB Financial, I think of a full- } \\
\text { service, province wide financial institution. }\end{array}$ & $377(75.4 \%)$ & $40(8.0 \%)$ & $56(11.2 \%)$ \\
\hline $\begin{array}{l}\text { ATB being one of the sponsors for Edmonton } \\
\text { Grand Prix made me prouder that the event is } \\
\text { hosted in Alberta. }\end{array}$ & $244(48.8 \%)$ & $117(23.4 \%)$ & $114(22.8 \%)$ \\
\hline $\begin{array}{l}\text { The fact that ATB Financial sponsored the } \\
\text { Edmonton Grand Prix makes me more likely to } \\
\text { [open an account at ATB OR use more of } \\
\text { ATB's services]. }\end{array}$ & $69(13.8 \%)$ & $70(14.0 \%)$ & $339(67.8 \%)$ \\
\hline
\end{tabular}




\begin{tabular}{|l|c|c|c|}
\hline $\begin{array}{l}\text { When I think of ATB Financial, I think of a } \\
\text { rural Alberta financial institution. }\end{array}$ & $223(44.6 \%)$ & $44(8.8 \%)$ & $209(41.8 \%)$ \\
\hline $\begin{array}{l}\text { The fact that ATB Financial sponsored the } \\
\text { Edmonton Grand Prix while other Albertan } \\
\text { banks did not led me to view ATB as having an } \\
\text { advantage over these other banks. }\end{array}$ & $130(26.0 \%)$ & $83(16.6 \%)$ & $256(51.2 \%)$ \\
\hline
\end{tabular}

The use of these results is described in detail under the objective sub-sections that follow. However, two of the results noted in Table 47 are important to identify here. First, in response to the question 'After learning that ATB Financial was sponsoring the Edmonton Grand Prix, my belief that they care about Albertans increased', a strong positive response ( $43.4 \%$ of respondents agreed or strongly agreed) was received. Second, it is important to note that a large portion of respondents (64.6\%) agree that ATB is a major player in the Alberta banking market.

Data Collection Exercise \#6: ATB Staff Survey \& Interviews: This exercise was designed to assess internal marketing objectives of ATB (employee motivation (\#8) and employee pride (\#14) in ATB). The original data collection plan was to implement an ATB-wide employee survey (online) to determine the impact of the sponsorship on all staff. This option, however, was abandoned in August 2006 when ATB senior management and the ATB in-house research professional decided that one major employee survey a year (an employee satisfaction survey is done annually in January of each year) was enough for employees. They did not wish to overburden staff and employees with too many surveys. An alternate plan was developed that would meet the satisfaction of ATB management which included employee interviews (Appendix H) and select data from the annual employee satisfaction survey. The concept was that the opinions of a small sample of employees could be used to estimate the effects of the 
sponsorship on employee pride and satisfaction in the context of the macro-level results from the annual survey.

The data shared from the January 2006 version of annual employee survey included the following from the 3520 returned surveys (a response rate of $88 \%$ of all ATB employees as of January 2006) which showed that $64 \%$ either 'strongly agree' or 'agree' that ATB overall is a good place to work and that $91 \%$ either 'agree' or 'strongly agree' that ATB acts as a good corporate citizen. In the context of this general level of employee satisfaction that exists at ATB, seven phone interviews were conducted with ATB employees to assess the impact of the EGP sponsorship. A suggested list of potential interviewees (approximately 20 ) was suggested by ATB and a random selection of seven of these individuals was actually interviewed. In an attempt to reduce selection bias and provide generalizeable results, ATB was asked to provide a roster of potential interviewees who were representative of the organization and connected to the marketing function. The names of the interviewees are not disclosed to protect the privacy of the individuals.

The sample of interviewees represented a wide range of functions at ATB (including Director, Customer Service Representative, Financial Advisor, and Mortgage Specialist) and included representation from head office and the branches. Interviews lasted between 3 and 15 minutes. They were recorded and transcribed. All interviews were completed by phone. It should be noted that the roster of interviewees was provided by ATB and may be biased to include those known to head office who are perhaps more satisfied with ATB than the general population of employees. The possibility of bias is recognized here and Table 48 below highlights the results. 
Table 48: General Results - Post-Event Employee Interviews

\begin{tabular}{|c|c|}
\hline Metric/Concept & Results \\
\hline Number of interviews & 7 \\
\hline Number who attended event & 0 \\
\hline Gender breakdown & $4 \mathrm{~F} / 3 \mathrm{M}$ \\
\hline Years worked @ ATB & $8.2+/-4.9$ years (range: $3-18)$ \\
\hline ATB (Good place to work) & Yes $-6 / \mathrm{No}-1$ (similar to survey results) \\
\hline $\begin{array}{l}\text { ATB (Satisfied with way you } \\
\text { are treated) }\end{array}$ & Yes $-7 /$ No -0 (similar to survey results) \\
\hline $\begin{array}{l}\text { ATB (Are most employees } \\
\text { satisfied) }\end{array}$ & $\begin{array}{l}\text { Variable answers including "for the most part", "about } \\
50 / 50 " \text { ", "yes", "I think so... actually, somewhat...some } \\
\text { are not happy" }\end{array}$ \\
\hline $\begin{array}{l}\text { Performance of ATB marketing } \\
\text { group over past year }\end{array}$ & $\begin{array}{l}\text { Variable answers including: "Yes, wonderful job", } \\
\text { "Fun guys", "I tend to deal with the marketing guys on } \\
\text { the business side of the office...I'd probably give them } \\
\text { a } 5 / 10 \text { and the reason I would do that is that they are } \\
\text { very challenged in terms of the number of resources } \\
\text { they have relative to priorities and I am always on the } \\
\text { low end of priorities", "Strong performance except on } \\
\text { employee retention" }\end{array}$ \\
\hline $\begin{array}{l}\text { Identification of specific } \\
\text { activities run by the marketing } \\
\text { group }\end{array}$ & $\begin{array}{l}\text { A number of positive activities pointed out including } \\
\text { charity work, community events, sponsorship of big } \\
\text { ticket items, "the razor stuff" (i.e., new razor cell } \\
\text { phone), staff prizes and internal events }\end{array}$ \\
\hline $\begin{array}{l}\text { Did ATB-EGP sponsorship } \\
\text { contribute to your pride in } \\
\text { ATB? }\end{array}$ & $\begin{array}{l}\text { Mixed comments. Bottom line: it may have helped } \\
\text { other ATB branches in the Edmonton market but these } \\
\text { particular individuals were not impacted directly, } \\
\text { although some of their clients were. Here's a sample: } \\
\text { (i) "...our clients [6] were happy - all of them enjoyed } \\
\text { it - they were wined and dined" } \\
\text { (ii) "That is not a mickey mouse event and for us to be } \\
\text { a gold sponsor, I think that that is money well spent } \\
\text { but it is hard to quantify. But I think that it is } \\
\text { important for ATB to have its name out there." } \\
\text { (iii) "I think so big time...because they are } \\
\text { everywhere...all events." } \\
\text { (iv) "Yes, But I think more for the Edmonton market." }\end{array}$ \\
\hline $\begin{array}{l}\text { Can you allocate a percentage } \\
\text { as to how much the EGP } \\
\text { sponsorship contributed to } \\
\text { employee satisfaction/pride? }\end{array}$ & $\begin{array}{l}\text { No one gave a numeric value. However, two } \\
\text { respondents inferred a 'fairly big impact' }\end{array}$ \\
\hline
\end{tabular}




\begin{tabular}{|c|c|}
\hline $\begin{array}{l}\text { Feeling when sponsorship } \\
\text { announced? }\end{array}$ & $\begin{array}{l}\text { All seven gave positive responses, including "I was } \\
\text { proud", "I thought good for ATB", "it gets our name } \\
\text { out there", "my reaction was wow", "it was good } \\
\text { cause; I could get tickets myself". }\end{array}$ \\
\hline $\begin{array}{l}\text { Feeling around office when } \\
\text { sponsorship was announced? }\end{array}$ & $\begin{array}{l}\text { Mixed, including "I thought it was more for Edmonton } \\
\text { branches", "I think they all thought it was good...but } \\
\text { the only thing I find is that we don't get enough notice } \\
\text { to get tickets to make arrangements for people", } \\
\text { "overall feel was good but not everybody got to invite } \\
\text { clients", "I never heard anything negative" }\end{array}$ \\
\hline $\begin{array}{l}\text { Were you aware that ATB had a } \\
\text { staff discount ticket program? }\end{array}$ & Yes $-5 \mathrm{No}-2$ \\
\hline Did you take advantage? & $\begin{array}{l}\text { No one did (but two indicated they tried but were too } \\
\text { late to get tickets) }\end{array}$ \\
\hline Was it popular with employees? & $\begin{array}{l}\text { Mixed, including "I think so", "I have no idea", } \\
\text { "Many people went", "Unsure", "Didn't get feedback" }\end{array}$ \\
\hline $\begin{array}{l}\text { Post-event - do you feel it was a } \\
\text { good marketing initiative? }\end{array}$ & Yes $-7 \mathrm{No}-0$ \\
\hline Is this general consensus? & $\begin{array}{l}\text { Yes - } 6 \text { No }-1 \text { - although one said "most don't care } \\
\text { but ya" }\end{array}$ \\
\hline $\begin{array}{l}\text { Did sponsorship make you } \\
\text { proud? }\end{array}$ & $\begin{array}{l}\text { Yes - } 6 \mathrm{No}-1 \text { - including: "Absolutely", "ya, I take } \\
\text { great pride whenever I see the organization involved in } \\
\text { important events, particularly events that put the city } \\
\text { and the province. And that was a world class event, it } \\
\text { was great.", "my friends know where I work so ya" }\end{array}$ \\
\hline $\begin{array}{l}\text { Did sponsorship raise employee } \\
\text { morale around the office? }\end{array}$ & $\begin{array}{l}\text { Most responses indicated that the sponsorship had } \\
\text { little effect on raising employee morale around ATB } \\
\text { offices, including: "No", "I don't know", "I don't } \\
\text { think out in branch-land but in head office probably", } \\
\text { "Really, it didn't make much of a difference, just } \\
\text { another promotion", "Not where I work" }\end{array}$ \\
\hline
\end{tabular}

Data Collection Exercise \#7: Employee Ticket Sales and Discounts: This exercise

is a second protocol related to the internal marketing objectives of ATB (employee motivation (\#8) and employee pride (\#14) in ATB) and seeks to measure the effectiveness of the employee ticket program in this regard. In order to assess the effectiveness of this program, the results were tracked by ATB and provided to the researcher. One-hundred-fifty tickets were sold at a $20 \%$ reduction off the posted ticket price. The tickets were allocated (sold, used for prizing, given away) very quickly (three 
days following announcement) and demand was "significantly" higher than supply (Rudan, 2006c). Tickets ordered included 47 Gold, 24 Silver, and 79 Bronze. Of those, 41 Gold, 18 Silver and 33 Bronze were purchased by employees; 40 Bronze were used for prizing (internal ATB) and 6 Gold, 6 Silver and 6 Bronze were given away (destination uncertain). In addition, the EGP provided seven paddock passes to ATB, two of which were given to employees. The paddock passes were "good ground seats for all three days but not a private suite pass" (Kelly Rudan, 2006a). As noted above, several of the post-event employee interviews (see data collection exercise \#6 above) reported on how well this program worked.

Data Collection Exercise \#8: Post-Event Expert Interviews/Reports: As part of the metrics to measure objectives related to the development of long-term partnerships and sponsor servicing (\#15,\#16,\#17, and \#19), a second set of post-event interviews were completed with key 'experts' from both the sponsor and the sponsee side of the sponsorship. The expert interviewees included:

1. Lisa McKillop (in-person), Marketing and Community Relations, ATB, worked directly on sponsorship

2. Candice Sperling (by phone), Marketing Manager, MasterCard, contact for sponsorship

3. General Manager (by phone), Edmonton Grand Prix

4. Kathie Arychuk (by phone), Manager of Community Relations, ATB

5. Kelly Rudan (in-person), Marketing Manager, ATB Investor Services, lead on sponsorship

6. Jade Tan (in-person), In-House Research Professional, ATB 


\section{Sponsorship Consultant (by phone), Edmonton Grand Prix}

The interviews were carried out either in-person, on the phone or via email. Based on the responses to the questions, the interviews ranged from a short email or a 10 minute phone interview to interviews that lasted over an hour. All were recorded and transcribed. Questions were scripted for each interview based on the individual's role.

Given the unique nature of each interview, details of the results are not presented here. Results will be reported under the analysis of each objective where the relevant interview fits.

\subsection{Additional Information Gathered}

In addition to the eight protocols described above, additional information was collected as follows:

1) EGP officials provided final and official attendance figures of: Friday: 47,932 , Saturday: 59,538, Sunday: 63,921, and Total: $171,391$.

2) Calgary Urban Strategy - Rudan (2006c) reported on ATB's successful strategy to increase market share through sponsorship of the Calgary Stampede and how this strategy spawned the idea of working with the EGP in Edmonton. Tactics included official sponsorship, large displays in 4 downtown branches, a Stampede breakfast with showpiece car, hand-out cards in downtown core over lunch hours, and regular displays/promotions in suburban branches.

3) Media Buy - ATB's media buy totaled approximately $\$ 71,600$ which included the following: 
a) $\$ 27,500$ for considerable newspaper coverage (ads, publicity and contest information from June 12 to July 20, 2006) in the Edmonton Journal and a few TV spots ( 60 second driver profiles presented by ATB) plus some pre-promotion on Global Edmonton.

b) $\$ 15,600$ for newspaper coverage in the Edmonton Sun, St. Albert Gazette, St. Albert Saint CityNews, Sherwood Park News, Leduc Representative, Spruce Grove Examiner and the Stony Plain Reporter.

c) $\$ 2,700$ for online coverage at www.EdmontonJournal.com and www.EdmontonSun.com.

d) $\$ 18,000$ for extensive radio coverage on 4 major Edmonton stations (CISN, CFBR, CKNG, CFCW)

4) ATB Race Week T-Shirts - $\$ 5,852$ was spent on T-shirts for ATB staff in Edmonton and area branches to wear the week before the race.

5) Road Show - $\$ 500$ was spent to have a race car in Calgary to promote the sponsorship.

6) Alberta National Resources Show - originally part of the sponsorship, this was cancelled pre-event because "not enough companies were interested" (Rudan, 2006a).

7) "Money Can't Buy Packages" were awarded through customer contests (three on the microsite and one by MasterCard) using an enter-to-win lottery. The package included a pace car ride and a gold level ticket package. The MasterCard package was awarded via a random draw where every person who signed up for or used their MasterCard was eligible (Rudan, 2006a). 
8) In conjunction with Kelly Rudan (2006a; 2006n), a basic segmentation of ATB employees was carried out, identifying the following segments:

a) 'Frontline staff' (approx. 1000 people) - those who deal with customers or seek new business

b) 'Support staff' (approx. 1650 people) - administrative, channel administration, technical and behind-the-scenes support in branches and central offices

c) 'Finance staff' (approx. 200 people) - those who advise on financial matters, carry out complex financial transactions or manage lending programs/accounts

d) 'Branch managers' (150) people) - individuals responsible for the overall direction and operation of individual branches

e) 'Head office staff' (approx. 500 people) - functional area employees (marketing, $\mathrm{HR}$, operations, legal, etc.) who work out of head office

9) National TV spots - these were included in early versions of the sponsorship contract (pre-signing), however were removed prior to signing. About 2 weeks prior to the race, the EGP mentioned to ATB that some 'unsold' spots remained and they would run the ATB spot. However, formatting and delivery issues prevented it from ever being developed (Rudan, 2006c).

\subsection{Data Analysis: Objectives}

The following section is comprised of 21 sub-sections, one per objective, which describes the analysis of each objective and the method that was followed.

Objective 1: ATB Customer Acquisition-Edmonton Residents: The metric developed to assess Objective 1 was designed to estimate the effects of the EGP 
sponsorship on customer acquisition for ATB, where customer acquisition includes both new customers and increased business from current customers (assumed to mean transfer of business from other FIs). The metric is a three-stage approach: (i) survey data of branch customers to ascertain the contribution of the sponsorship to changes (if any) in reported customer activity, (ii) analysis of ATB internal data to track customer growth and decline monthly, and (iii) any changes in the macro level data are multiplied by the calculated attribution of the sponsorship to those changes (from survey data) in order to estimate customer acquisition (or loss) due to the sponsorship.

A sample $(n=111)$ of one Edmonton area branch is used to determine the effects of the EGP sponsorship on branch customer acquisition. Within this sample, it was determined that a smaller sub-sample of respondents $(n=4$, or $3.6 \%)$ had become ATB customers in the months of July or August, 2006 and 11 others (or 9.9\%) had increased the amount of business with ATB in the same time frame. This total sub-sample of 15 respondents was considered to measure customer acquisition. Of the four new customers, only 1 indicated that the EGP sponsorship had 'at least some' impact on the decision to join ATB. Similarly, 2 of the 11 who indicated that they had increased their business with ATB said that the EGP sponsorship had 'at least some impact' on that decision. These respondents also indicated that other factors had 'at least some' impact on their decisions to become ATB customers or increase their business with ATB. Table 49 (below) reports the frequency of these factors. 
Table 49: Impacts on Decisions to Join or Increase Business with ATB

\begin{tabular}{|c|c|}
\hline $\begin{array}{l}\text { ATB Customer Acquisition } \\
\text { (last } 2 \text { months) }\end{array}$ & Factors with 'some impact' on Decision \\
\hline 4 New Customers & $\begin{array}{l}\text { Seen or heard ATB advertising (3) } \\
\text { Wanted to switch to a local bank (3) } \\
\text { Proximity of branch to home (3) } \\
\text { Proximity of branch to work (2) } \\
\text { ATB sponsorship of the Edmonton Grand Prix (1) } \\
\text { ATB sponsorship of the Calgary stampede (0) } \\
\text { The quality of products we offer (3) } \\
\text { A specific product we offer (0) } \\
\text { A friend or family member who works at ATB (1) } \\
\text { A current sales promotion (1) } \\
\text { ATB's customer service standards (3) } \\
\text { ATB's hospitality suites at the EGP (0) } \\
\text { The ATB Visa Card (0) } \\
\text { The ATB Master Card (2) } \\
\text { Other ( } 3 \text { responses provided) }\end{array}$ \\
\hline 11 Increased Business & $\begin{array}{l}\text { Seen or heard ATB advertising (3) } \\
\text { Wanted to switch to a local bank (1) } \\
\text { Proximity of branch to home (3) } \\
\text { Proximity of branch to work (4) } \\
\text { ATB sponsorship of the Edmonton Grand Prix (2) } \\
\text { ATB sponsorship of the Calgary stampede (1) } \\
\text { The quality of products we offer (7) } \\
\text { A specific product we offer (5) } \\
\text { A friend or family member who works at ATB (1) } \\
\text { A current sales promotion (0) } \\
\text { ATB's customer service standards (8) } \\
\text { ATB's hospitality suites at the EGP (1) } \\
\text { The ATB Visa Card (0) } \\
\text { The ATB Master Card (3) } \\
\text { Other (6 responses provided) }\end{array}$ \\
\hline
\end{tabular}

The data in Table 49 demonstrates that attributing customer acquisition is difficult given the many influences expressed on consumer banking decisions. However, it may be reasonable to say that the sponsorship played some role and, if we explore the data deeper, we can estimate the level of impact that the EGP had on this decision. Respondents who joined ATB with some influence from the EGP sponsorship also 
indicated that 7 other factors affected that decision. Thus, if we assume that all factors influence equally, one could infer that one eighth of new customer activity was inspired by the EGP sponsorship. Similarly, the two respondents who increased their business with ATB with some influence from the EGP sponsorship indicated that 7 and 9 other factors, respectively, affected their decisions. Thus, one could infer that one ninth (average of one eighth and one tenth) of all customers who increased their business were inspired by the EGP sponsorship.

Examination or analysis of macro-level ATB internal data for the Edmonton branch reveals an increase of 33 and 24 customers in the months of July and August, respectively. Using the estimate calculated above, one could infer that 7 of these customers (4 in July and 3 in August) resulted from the EGP sponsorship. Given the average size of new accounts provided, it can be estimated that these customers bring $\$ 63,614.22$ in deposits and $\$ 153,898.83$ in loans to ATB in the first month as new clients. With respect to ATB customers who increased their business with ATB in the months of July and August, there is no support for any impact of the EGP sponsorship as both average deposits and average loan balances for the Edmonton branch did not show any significant increase.

In summary, the metric for Objective 1 estimates an acquisition of 7 new customers in the 2 months following the EGP sponsorship attributed to that sponsorship. It also notes no change in increased business from current customers in that 2 month period due to the sponsorship.

Objective 2: ATB Customer Acquisition - Calgary Residents: Objective 2 adopts the same metric as Objective 1 but using a Calgary branch instead. Here, a sample of one 
Calgary area branch is used to estimate customer acquisition. As with Objective 1, the metric involves a branch-level intercept survey $(n=106)$ and internal sales data for the branch. The sample assessed was comprised of those respondents ( $n=6$, or $5.6 \%)$ who had become ATB customers in the months of July or August, 2006 and those $(n=11$, or 10.4\%) who indicated that they had increased the amount of business with ATB in the same time frame. Of the six new customers, no one indicated that the EGP sponsorship had 'at least some' impact on the decision to join ATB. Similarly, no one of the 11 who indicated that they had increased their business with ATB said that the EGP sponsorship had 'at least some impact' on that decision. Thus, no effect on customer acquisition was found on the Calgary market. This finding lends credibility to the finding in Objective \#1 related to customer acquisition in Edmonton.

Objective 3: ATB Customer Acquisition-Other Alberta Residents: Given that no empirical data was collected at branches outside of Metropolitan Edmonton and Metropolitan Calgary, an alternate metric for customer acquisition was developed for the sample of Albertan residents outside of Edmonton and Calgary. Here, the metric involved taking survey data from the micro-site web survey (for non-Edmonton, non-Calgary residents only) to ascertain contribution of sponsorship to changes (if any) in customer base and activity and estimating overall customer acquisition (or loss) due to the EGP sponsorship based on any changes to the macro level (internally generated) ATB customer data. A 3-month period is considered for this metric as the web survey was implemented in early June.

Results from the micro-site survey were taken over a 43-day period prior to the EGP but provide an estimate of the sponsorship's impact on customer acquisition since 
respondents were attracted to the micro-site by promotions related to the sponsorship and asked questions about the sponsorship. Of the 1937 respondents who indicated that they were not ATB customers, 82 (4.2\%) reported that the EGP sponsorship 'significantly increased' the probability that they would switch from their current financial institution to ATB. An additional $371(19.2 \%)$ said the chances were 'somewhat increased' while the majority (1469 or $75.8 \%)$ indicated 'no change' and a very small number (15 or $0.8 \%)$ said that the chances were somewhat or significantly decreased. A related question that asked respondents who were not ATB customers of their interest in visiting an ATB branch in the near future provides supporting results. Of these 1937 respondents, 192 (9.9\%) said 'very unlikely', 554 (28.6\%) indicated 'unlikely', 799 (41.2\%) said 'maybe', 272 (14.0\%) indicated 'likely', and 120 (6.2\%) said 'very likely'.

From the internal data, it is observed that ATB saw an increase in number of customers ( +1577 customers) over the months of June, July and August 2006, with an accompanying growth in average loan balances $(\$ 1278.11)$ and deposit balances that were constant throughout the 3-month period. Although previous data was not available for comparison, a senior ATB official noted that these increases were considerably higher than typical trends in recent years (Rudan, 2006e).

If we assume that those who indicated 'significantly increases' are largely motivated to switch to ATB due to the EGP sponsorship, we can infer that 66 new customers $^{41}$ were generated in Alberta by the EGP sponsorship. We also know that $51.7 \%$ of the sample came from outside of Calgary and Edmonton (this is the geographical distribution of the overall survey population), suggesting that 34 new

\footnotetext{
${ }^{41}$ The number 66 is calculated by considering that 82 respondents of the original sample of 1937 (or $4.2 \%$ ) indicated 'strongly increases'. Considering that 1577 new customers were added, $4.2 \%$ is 66 .
} 
customers were generated outside Edmonton and Calgary. Using averages from the internal data, this would infer $\$ 197,168.50$ in first month household deposits and $\$ 825,908.25$ in first month household loans.

In summary, results for Objective 3 suggest that 34 new customers were acquired due to the sponsorship, however - given that the estimate is based on a pre-event web survey (as opposed to a direct, post-event survey of the target market), this result should be considered a weak estimate at best.

Objective 4: Impact Key ATB Customers and Prospects: The assessment of this objective involves a metric developed to calculate how the hospitality suite impacted key ATB customers and prospects. Given that ATB defines 'key' as the Top $1 \%$ of customers, the best sampling opportunity available was the ATB hospitality suite at the EGP. The metric involves the use of three sources of data: (i) surveys administered to hospitality suite guests (invite-only) over the 3-days of the EGP, (ii) post-event interviews with the suite hosts and (iii) a report, provided by ATB marketing, outlining the invitee list and hospitality suite budget. These sources are combined to make an assessment of cost per hit to impact key customers and prospects. Impact is measured as satisfaction with the hospitality experience.

The Suite Host interviewees offered their opinions that attendee satisfaction was very high with the event, the service, the food, the race car driver visit and the atmosphere provided by ATB. One host noted that "three of those that attended called me the next day and also sent thank you cards to me, it was very cool, they all had fun, it was very worthwhile" (Suite_Host_2, 2006). A relationship manager (who provided a client with tickets to the suite but was not there himself) reported: "I spoke to my client and he 
was thrilled with the event. He said that he was looked after very well and he is a huge race car fan, so it went over very well...[he also said that] the quality of the event was truly stunning" (ATB relationship manager, personal communication, August 6, 2006).

The survey of hospitality suite attendees (response rate $=39 \%$ ) supported these views with questions related to their satisfaction with the EGP experience. The majority (76\%) of attendees rated their overall EGP experience as 'excellent' and $97 \%$ said they would come back next year if invited again. More importantly, $72 \%$ said they'd increase their business with ATB and $100 \%$ reported that their experience at the EGP had improved their overall opinion of ATB. Considering those respondents defined as prospects (i.e., non-ATB clients), $71 \%$ expressed agreement that their experience could lead to an increase in the amount of business they do with ATB. These findings may be biased as surveys were administered in the midst of an enjoyable ATB activity.

ATB top clients and prospects were defined as the Top 1\% of ATB customers and a benchmark of household income greater than $\$ 100,000 /$ year was used to determine if guests were from the sought target. Results showed that $72 \%$ of attendees had a household income greater than $\$ 100,000$ while $21 \%$ between $\$ 60,000$ and $\$ 100,000$ and $7 \%$ under $\$ 60,000$. This means that there were some individuals present who did not fit the target market. ATB marketing personnel and the Suite Hosts led an assessment of the allocation of spots in hospitality. The analysis was based on the fact that 75 total guest places were available for the suite ( 25 places for each of three days). These 75 spots were taken as follows: (i) 12 by ATB executives and their guests, (ii) 10 by ATB staff (nonexecutive) and their spouses, (iii) 48 by Guests (Top Clients \& Prospects) and their spouses, and (v) 5 by no-shows (all Friday). Given that the 48 guests were comprised of 
26 clients/prospects and 22 spouses, one could infer that the hospitality suite was for 26 targets. The total cost of the suite was $\$ 37,402.73$, which included entertainment (suite upgrade, food, drinks, ear plugs, invitations, race car driver visit) and gift bags (hats, pens, cash giveaways, secondary prizing). If we divide this number by the 26 targets attending, we can estimate a cost per target of $\$ 1,432.78$. If we consider only those Guests who meet the definition of Top 1\% (i.e. household income greater than $\$ 100,000$ ), which was 21 of the 26 guests, the cost per target ratio goes to $\$ 1,781.08$.

In summary, it is clear that the suite was a success in 'impacting' key targets and top customers who were present. Noting that the number of true Top $1 \%$ customers/prospects attending could have been higher, the cost per target to reach these high-end customers is still low considering the size of the accounts and loans that these individuals have or could have with ATB. The survey also found high levels of guest satisfaction and a strong intent to increase business with ATB.

Objective 5: Increase Awareness that ATB exists: Awareness levels of the ATB in Alberta were measured using questions included in the mass market survey of 500 Albertans. In measuring the effect of the EGP sponsorship on the awareness of ATB, results from the mass market survey revealed that $16.4 \%$ (87 out of 500) of Albertans' awareness of the products and services of ATB increased following the EGP sponsorship. Of note, increases in awareness were similar across most demographic variables: (i) no gender differences between male and female ( $t=.012$ ), (ii) no difference between high and low household income $(\$ 100,000$ cut point for $t=.507)$, and (iii) no difference between Edmonton and Calgary ( $t=456$ ). There were some notable differences: (i) those under 55 years of age experienced significantly higher increases in awareness than those 55 years 
of age and older $(t=2.857, p<.005)$, (ii) those who saw the EGP on television experienced significantly higher increases in awareness than those who did not $(t=2.094, p<.05)$, and (iii) non-ATB customers experienced significantly higher increases in awareness than current ATB customers ( $\mathrm{t}=2.005, \mathrm{p}<.005)$. In summary, awareness that ATB exists increased in $16 \%$ of respondents, particularly with those respondents less than 55 years of age, those who watched the EGP on television, and non-ATB customers. A regression model $(F=4.085, p=.007)$ with the dependent variable set to awareness increase and independent variables of age, TV, and customer status, resulted in a model where age $(t=4.166, p=.006)$ is a strong predictor and television $(t=1.766, p=.078)$ is a weak predictor on increases in awareness. See the summary presented in Table 50 below.

\section{Table 50: Summary results, Objective 5 Regression Model}

\begin{tabular}{|l|l|r|r|r|}
\hline Model Summary \\
\hline Model & R & R Square & $\begin{array}{c}\text { Adjusted } \\
\text { R Square }\end{array}$ & $\begin{array}{r}\text { Std. Error of } \\
\text { the Estimate }\end{array}$ \\
\hline 1 & $.155^{2}$ & .024 & .018 & 1.749 \\
\hline
\end{tabular}

a. Predictors: (Constant), GP_TV, ATB_CUST, AGE

Objective 6: Increase Awareness that ATB Cares: Using the same metric as

Objective 5, this objective measures the effect of the EGP sponsorship on the awareness ${ }^{42}$ that ATB cares about Albertans. Results from a question on the mass market survey revealed that $43.4 \%$ (217 out of 500) of Albertans' believe that ATB cares about Albertans. Interestingly, when asked if the sponsorship of the EGP increased their belief that ATB cares, the resulting increase in awareness that ATB cares was much higher than

\footnotetext{
${ }^{42}$ Note that although 'awareness that ATB cares' was the objective that ATB sought to achieve, this measure could also be viewed as measuring respondents' 'belief' that ATB cares.
} 
the increase in awareness that ATB exists (Objective 5); in fact the difference is highly significant $(t=8.542, p<.001)$. In summary, there is strong evidence that the EGP sponsorship was effective in increasing levels of awareness that ATB cares about Albertans.

Objective 7: ATB - Improve Brand Prestige in Current Customers: ATB's objective to improve levels of brand prestige with current customers was measured using the in-branch surveys (one Calgary branch and one Edmonton branch). A series of questions sought to assess ATB's brand prestige relative to other FIs and then evaluate the impact of the EGP sponsorship on those levels. Of the 217 completed surveys, 160 respondents indicated that they were ATB customers, and as such they are the focus of this objective. When asked to rate ATB's brand prestige relative to other FIs, most (70.6\%) reported that ATB had very high (25.0\%) or high (45.6\%) brand prestige relative to other FIs while $25 \%$ rated ATB as 'average' and only $1.8 \%$ expressed that ATB brand prestige relative to other FIs was low or very low.

The sample of 160 ATB customers was then asked if their assessment of the prestige of the ATB brand had increased in the past two months. Here, $20 \%$ (32) of ATB customer respondents indicated that it had. These 32 respondents were then asked about factors (aided recall but with 15 stated factors and ability to insert others) which led to this increased opinion of ATB brand prestige in the past two months. In total, the 32 respondents identified 157 different factors. This represents an average of 4.9 mentions per respondent with 'ATB's customer service standards' being the most mentioned (29) followed by the quality of ATB products with 22 mentions. ATB's sponsorship of the EGP was mentioned 12 times (tied for the $5^{\text {th }}$ most mentioned factor), 3 more than the 
number of mentions about ATB's sponsorship of the Calgary Stampede. Thus, for those customers who noted an increase in brand prestige in the past two months, 37.5\% (12 of 32) noted that the EGP sponsorship played a role. It is important to note the role that branch location plays here, as analysis showed that Edmonton customers had a significantly higher assessment of both ATB brand prestige $(t=3.411, p<.005)$ and the increase in ATB brand prestige the past two months $(t=3.627, p<.001)$ than Calgary customers. These relationships may be due to the Edmonton location of the EGP.

Assuming an equal contribution of all 157 identified factors to the increased brand prestige, we can estimate that the EGP sponsorship provided $7.6 \%(12 / 157)$ of the rationale for the increased opinion of ATB brand prestige in those ATB consumers who indicated such. Considering the overall sample of 160 ATB customers, it could be said that the sponsorship of the EGP enabled an increase in brand equity opinion in 1 out of every 66 ATB customers ${ }^{43}$. If we consider the differences between Calgary (Mean response $=1.10$ ) and Edmonton (Mean response $=1.65)$, the ratio could be further divided to 1 out of every 44 Edmonton-based ATB customers and 1 out of every 99 Calgary-based ATB customers.

In summary, results of this metric provide support that the EGP sponsorship had an impact in improving ATB brand prestige in current customers, more so in Edmonton than in Calgary, however.

Objective 8: ATB Internal Marketing (Motivate Staff): The metric for Objective 8 was developed in response to ATB's interest in leveraging the EGP sponsorship to

\footnotetext{
${ }^{43}$ This figure was calculated by dividing the number of respondents who felt that ATB's brand prestige had improved over the past two months (32) by the total number or respondents $(160)$. This figure was then multiplied by the ratio of ATB mentions to all mentions (12/157) to come up with the 1 in 66 figure (384/25120),
} 
motivate staff (i.e., internal marketing). Here, satisfaction is used as a proxy for motivation. The metric was developed using three data sources: (i) the annual ATB employee survey (provided by ATB), (ii) employee interviews and (iii) the employee ticket program. It is noted that this metric is not ideal but given the realities of permissions, it allows for an estimate of the effectiveness of the sponsorship. In addition to the ticket program, ATB employees ( 20 in total) were also able to get involved by volunteering for the Go-Kart track or MasterCard booths.

First, ATB's annual employee survey (completed in January 2006) found that most (91\%) ATB employees believe that ATB is a good corporate citizen and the majority (64\%) considers it to be a good place to work. These results suggest that ATB employees are satisfied with their work environment and believe strongly that ATB is doing a good job as a corporate citizen. However, there remains a significant proportion of staff (36\%) who do not consider ATB to be a good place to work.

Second, results from the post-event employee interviews (Data Collection \#6) provide three important contributions. First, six of the seven interviewees believe that ATB is a good place to work and all seven are satisfied with their employer. Two of the interviewees, however, noted that they have colleagues who are not happy with ATB; again showing that there is room for improvement. Also, with respect to the ATB-EGP sponsorship, very mixed views were provided, ranging from high levels of support for the sponsorship (three mentions by interviewees) to concerns about how the sponsorship was leveraged with employees (five mentions by interviewees). Certainly, the expression of these concerns notes that frustration as opposed to motivation may be what was achieved in some employees. Finally, when asked to assess the impact of the sponsorship, no 
employee was able to assign a quantitative value, although all interviewees (seven of seven) felt it was a good marketing idea and all but one (six of seven) indicated that they believe that most employees felt this way. In responding to this question, two of the interviewees reported that they believed that some employees felt it was an Edmontoncentric event.

Third, the ATB employee-ticket program was analyzed. ATB's Marketing Manager described the program:

we are communicating via email and the intranet to our staff about the sponsorship, we are recruiting volunteers, and we are allowing a limited number of staff (via open call) to purchase the discounted tickets... on the MasterCard side, they are giving away tickets to staff who sign up the most new M/C customers. And, of course, our in-branch collateral is meant to start conversations between customers and staff to go to the microsite and sign up for the customer contest (Rudan, 2006a).

Although two of the seven employee interviewees were not even aware the program existed, five of the interviewees knew of the program and responded that it was a resounding success. Three respondents even suggested that it should be expanded in 2007. As outlined in Data Collection Exercise \#7, the ticket program was a success with demand far outreaching supply. The ticket program must also be considered from a budget point of view as well. A cost of $\$ 21,167.02$ was incurred by ATB to cover the discounts provided to employees. Without an employee survey, it is not possible to assess the cost/employee affected however, given the positive qualitative results generated, it is reasonable to consider this a success. A few notes from employee interviews may help with future sponsorships: (i) "I think they all thought it was good...but the only thing I find is that we don't get enough notice to get tickets to make arrangements for people" (Employee, personal communication, August 1, 2006) and (ii) "I thought I got in on it but 
they didn't find my order...so then I would've had to get a regular one. I thought I had Sunday" (Employee, personal communication, July 30, 2006).

In summary, following the cancellation of the employee satisfaction survey, this alternative measure was implemented. Objective 8 was measured indirectly using three sources of data which provides support that the EGP sponsorship was generally effective in employee motivation (i.e., positive employee interviews and the sold-out ticket program), although the weakness of the measure must be noted.

Objective 9: ATB - Achieve Competitive Advantage: The ninth ATB objective was to create a competitive advantage in Alberta. In other words, they were seeking a way by which to differentiate themselves from their competition through reminding Albertans that they are a bank for Alberta only. The mass-market survey of 500 Albertans included a question to describe this. Specifically, respondents were asked if the fact that ATB sponsored the EGP while other Albertan banks did not led them to consider ATB as having an advantage over these other banks. Due to limits on the length of the questionnaire, only one question was asked. More than one-half of the respondents (51.2\%) reported that they either strongly disagree or disagree that advantage was achieved, a few (6.2\%) said 'do not know', and a small portion (16.6\%) said 'neither agree nor disagree'. This suggests that the sponsorship was not effective in achieving competitive advantage for ATB. However, approximately one-quarter of respondents were influenced positively (3.6\% of respondents strongly agreed and $22.4 \%$ agreed that advantage was achieved). Although these are relatively small percentages, some positive effect must be noted for the sponsorship. 
Deeper analysis provides more insight into those who do believe advantage was achieved. First, Edmonton respondents ranked the ability of the EGP to provide competitive advantage significantly higher than did Calgary respondents $(t=2.122$, $\mathrm{p}<.05)$. Second, respondents who had previously watched an entire Indy or CHAMP car race on television (some level of fandom) ranked the ability of the EGP to provide competitive advantage significantly higher than respondents who had not $(t=2.008$, $\mathrm{p}<.05$ ). Finally, and interestingly, respondents who were ATB customers ranked the ability of the EGP to provide a competitive advantage lower (with weak significance) than respondents who were not previously customers $(t=1.528, p<.1)$. Thus, one could infer that people who were not ATB customers, who live in Edmonton, and who are fans of auto-racing were most influenced.

\section{Objective 10: Establish ATB as major plaver in Alberta banking - with}

Customers: An additional ATB objective stemmed from the organization's goal to become a major player in the Alberta banking industry. Although this is similar in nature to achieving competitive advantage, it was articulated as a distinct goal by ATB as they believe that achieving competitive advantage through the sponsorship and being viewed as a major player in the banking market with customers and non-customers are not the same (Rudan, 2005b). Thus, the metric for measuring this objective involved survey questions specific to this objective in order to assess any increase in the number of current ATB customers who believe that ATB is a major player in the market. This was implemented using questions on the in-branch customer surveys (Edmonton and Calgary) and the pre-event microsite online survey (Albertan customers outside of Edmonton and Calgary). 
With respect to ATB customers outside of the two major Albertan cities, the preevent survey of ATB customers showed that 1675 of the 1787 (or 93.7\%) non-Calgary/ non-Edmonton respondents believed (yes or no question) that ATB is a major player in the Alberta banking market. Further analysis showed that those $(n=1578)$ who believed that ATB's sponsorship of the EGP significantly increased or somewhat increased their opinion of ATB were significantly more likely $(t=4.243, p<.001)$ to note that ATB is a major player in the market than those who noted that the sponsorship had no effect $(n=1896)$ or a decreasing effect $(n=10)$ on their opinion of ATB. This suggests, albeit imperfectly, that the EGP sponsorship played a role here.

In terms of the Edmonton and Calgary customers who were queried via the inbranch surveys, the majority (65.5\%) felt that ATB was already a major player in the Albertan banking market. Specific to the sponsorship, respondents were then asked if they believed that ATB's importance in Alberta's financial services industry had increased in the last two months. For the ATB customers $(n=162)$ in the sample, 57 (35\%) believed it had, $76(47 \%)$ said no and $29(18 \%)$ did not know. Consistent with previously reported results, respondents from Edmonton ranked ATB as a major player significantly more frequently (weak significance) than respondents from Calgary $(\mathrm{t}=1.630, \mathrm{p}<.1)$; once again suggesting the importance of the EGP in Edmonton. In total, the 57 respondents ( 31 from Edmonton, 26 from Calgary) mentioned 304 factors that influenced the increase in their support of ATB's importance in the FI sector the past two months. Of these mentions, ATB's customer service standards (50), ATB being Albertaonly (49), and the opening of new branches (26) were the most frequent, while the sponsorship of the EGP was the $4^{\text {th }}$ most mentioned factor with 23 mentions (15 from 
Edmonton, 8 from Calgary). If the influence of the EGP sponsorship is considered in the context of the 304 overall factors, one can estimate that the EGP sponsorship was responsible for $7.5 \%$ of the increase in the importance of ATB in the Albertan market over the two month period following the EGP sponsorship. Cross-tabulations revealed that two individuals exist in the sample of 162 ATB customers who (i) originally reported that ATB was not a major player in the Albertan banking market, (ii) then indicated that ATB's importance had increased in the past two months and (iii) noted that the sponsorship of the EGP was one of the reasons for their increased view of ATB's importance. Although this is a small number, it does demonstrate some success here.

In summary, the analysis of Objective 10 shows that the EGP sponsorship was responsible for an estimated $7.5 \%$ of the increase in opinions of the importance of ATB in the customers from Edmonton and Calgary, although response in Edmonton was significantly higher. Results from outside of Edmonton and Calgary were also positive with over $93 \%$ indicating that they feel that ATB is a major player in the Albertan FI market, although the impact of the sponsorship on this figure is uncertain.

\section{Objective 11: Establish ATB as major player in Alberta banking - with Non-}

Customers: ATB also sought to increase their position as a major player in the Albertan market with non-customers. This method looked at non-customers and their belief that ATB was a major player in the market. It was measured by asking Albertans (via questions on the mass market survey) if they believed if that the ATB sponsorship of the EGP helps demonstrate that ATB is a major player in the Alberta banking market. Of non-customers ( $\mathrm{n}=413), 63.7 \%$ agreed (227) or strongly agreed (36) that the EGP sponsorship was a factor in establishing ATB as a major player in the Alberta banking 
market. Further analysis of non-customers revealed that some groups were more likely than others to report that the EGP sponsorship helped demonstrate that ATB is a major player: (i) those under 45 years of age $(t=2.035, p<.05)$, (ii) those who were unable to correctly identify ATB as 'a full-service province wide Albertan financial institution' $(t=3.963, p<.001)$, (iii) those who had watched the EGP on TV ( $t=1.848, p<.1)$, and (iv) those who could be called fans (i.e., had previously watched an entire car race on TV) $(t=2.094, p<.05)$. Notably, no difference in Edmonton versus Calgary $(t=.456)$ is found here. The influence of the EGP sponsorship was greater in those young (under 45) noncustomers who were fans of auto racing, who saw the event on TV, and who previously were uncertain of the scope of ATB's operations.

\section{Objective 12: Re-Brand ATB as Full Service Financial Institution - with}

Customers: ATB also sought to use the EGP sponsorship as a means to re-position from a rural bank to a full service financial institution with its customers. The metric uses data from both the pre-event online surveys (customers outside of Calgary and Edmonton) and in-branch, post-event questionnaires (Calgary and Edmonton based customers).

For customers in rural or small city Alberta, the pre-event online survey included a two part question. Respondents were first asked to select which of the following best describes ATB Financial: 'a full-service Albertan bank', 'a Canadian bank from coast-tocoast', 'a small town Albertan bank', 'an urban banking institution with branches in all major Canadian cities', 'a British Columbia bank expanding into Alberta', or 'none of the above'. The desired response 'a full-service Albertan bank' was provided by $82.9 \%$ of the sample demonstrating a high level of awareness of a key aspect of the ATB brand. The most undesirable response ('a small town Alberta bank') was the next most common 
selection at $6.8 \%$. The remaining $10.3 \%$ either expressed that they did not know or responded with an incorrect answer. Respondents were then asked if the fact that ATB had decided to sponsor the EGP had changed their response to the question. Here, the vast majority (94.1\%) of ATB customers outside of Edmonton and Alberta believe that the EGP sponsorship had a limited effect in changing their reported opinions. Further analysis, however, reveals that the EGP sponsorship significantly influenced two groups of respondents to change their response to the question more than those who had provided the desirable response; namely those who previously defined ATB as a small town Albertan bank $(t=7.614, p<.001)$ or those who described ATB as a Canadian bank from coast to coast $(t=2.014, p<.05)$.

The in-branch surveys also enabled an analysis of Edmonton and Calgary based ATB customers. This metric involved a three stage question; one asking if the EGP sponsorship improved the prestige of the ATB brand, one asking if sponsoring the EGP helped demonstrate that ATB is a rural financial services institution and the other asking if sponsoring the EGP helped demonstrate that ATB is a financial services institution for all Albertans. Results here support the view that the EGP sponsorship was able to influence knowledge of the ATB brand. Analysis of the first question revealed that 72 (or 45\%) of ATB customers either strongly agreed or agreed that the EGP sponsorship helped increase the ATB brand while only $16(10 \%)$ disagreed or strongly disagreed. Descriptive results from the second question demonstrate that customers appear to view ATB as a rural financial services institution (which is opposite to what most noncustomers thought in Objective 11), as 69 (43\%) of ATB customers either strongly agree or agree that the EGP sponsorship helped demonstrate that ATB is a rural FI while 30 
(19\%) disagreed or strongly disagreed. Results from the third question show that 85

(53\%) of respondents agree or strongly agree that the EGP sponsorship helped

demonstrate that ATB is a FI for all Albertans, with only $19(12 \%)$ in disagreement. A correlation matrix was run with all three questions and the relationships between each of the variables was found to be significant $(p<.01)$ indicating a similarity of responses between the three questions. The details are presented in Table 51 below.

\section{Table 51: Correlation Matrix: Objective 12 Questions}

Correlations

\begin{tabular}{|ll|r|r|r|}
\hline & & $\begin{array}{r}\text { EGP SP on } \\
\text { ATB brand }\end{array}$ & $\begin{array}{r}\text { EGP SP = } \\
\text { rural FI }\end{array}$ & $\begin{array}{r}\text { EGP SP = for } \\
\text { all Albertans }\end{array}$ \\
\hline EGP SP on ATB brand & Pearson Correlation & 1 & $.484^{*+1}$ & $.531^{*-}$ \\
& Sig. (2-tailed) &. & .000 & .000 \\
& $\mathrm{~N}$ & 217 & 217 & 217 \\
\hline EGP SP = rural FI & Pearson Correlation & $.484^{* *}$ & 1 & $.687^{*}$ \\
& Sig. (2-tailed) & .000 &. & .000 \\
& $\mathrm{~N}$ & 217 & 217 & 217 \\
\hline EGP SP = for all Albertans & Pearson Correlation & $.531^{* *}$ & $.687^{*+1}$ & 1 \\
& Sig. (2-tailed) & .000 & .000 &. \\
& $\mathrm{~N}$ & 217 & 217 & 217 \\
\hline
\end{tabular}

** Correlation is significant at the 0.01 level (2-tailed).

A data reduction (principal component analysis) was then run on data related to the three questions with the first question (Eigen value $=2.259$ ) found to explain $75.3 \%$ of the variance and thus being selected to represent the three questions for further analysis.

It is important to note two issues around the data generated by this group of questions. First, in all three cases, there were high numbers of respondents who indicated 'Don't Know' perhaps indicating difficulty in understanding the questions or the challenge of attributing a promotion to a brand. Second, there were a number of contradictory responses including 11 respondents who noted 'strongly agree' that ATB is 
both a rural FI and a FI for all Albertans. This could be due to a lack of customer knowledge of the ATB brand or the wording of the questions where the first question may have been construed to mean that ATB provides services to rural Albertans but not necessarily only to rural Albertans.

In summary, all three (correlated) questions suggest that the EGP sponsorship played a role in re-branding ATB as a full service FI; particularly effective with noncustomers outside of Edmonton and Calgary who previously lacked knowledge about the ATB brand and with $45 \%$ of customers in both Edmonton and Calgary.

\section{Objective 13: Re-Brand ATB as Full Service Financial Institution - with non-}

Customers: The rationale for Objective 13 is the same as Objective 12 except that the target is non-ATB customers. This is measured primarily using data from the massmarket survey of 500 Albertans ( $n=413$ non-customers), with supporting data from the non-ATB customers ( $n=57)$ who responded to the in-branch survey.

Respondents to the mass market survey were asked to respond to the following questions after being made aware (aided recall) that ATB was a sponsor of the EGP: "when I think of ATB Financial, I think of a rural Alberta financial institution" and "when I think of ATB Financial, I think of a full-service, province wide financial institution". For the first question, a balanced distribution of opinions was found with 21 strongly disagreeing, 155 disagreeing, 156 agreeing and 17 strongly agreeing. However, for the second question, results for ATB as a full-service FI are very strong as $72.5 \%$ (298) of non-customers agree or strongly agree. A paired samples comparison of means between the two questions showed a strongly significant difference $(t=8.852, p<.001)$ 
between the two questions supporting that ATB's brand is recognized as they would like (i.e., as a full service FI) and not as a rural bank.

Further evidence of the effectiveness of the EGP sponsorship on the re-branding of ATB is provided by the 56 respondents of the in-branch surveys who indicated they were not customers of ATB. First, 26 (or $46 \%$ ) noted that they are likely to open an ATB account in the near future where 19 of the $26(73 \%)$ either agreed (11) or strongly agreed (8) that sponsoring the EPG improved the prestige of ATB's brand.

Objective 14: ATB Internal Marketing (Build Employee Pride): Following the cancellation of the employee survey by ATB, this objective was measured in the same way as Objective 8 (employee motivation). The identical metric and analysis is used (see Objective 8) which found that the EGP sponsorship was effective in increasing employee motivation (i.e., positive employee interviews and the sold-out ticket program).

Objective 15: ATB -Assess_Sponsorship Effectiveness: An objective of this sponsorship for ATB (and one of the reasons it came to be a part of this dissertation) was to evaluate the sponsorship as a promotional activity to support future business decisions. The fact that this evaluation was undertaken responds to this objective.

Objective 16: EGP-Revenue Generation: The objective of revenue generation to support the operation of its event was of primary importance for the EGP. The metric adopted here is an analysis of the budget and EGP marketing plan. First, it is noted that ATB agreed to a 2-year contract at the set fee of $\$ 410,000$ to be a gold sponsor of the event in 2006 and 2007. This met the EGP's revenue generation objective for a gold sponsor (Edmonton Grand Prix General Manager, 2006). The fact that ATB spent considerable additional resources (approximately $\$ 240,000$ ) and energy leveraging the 
sponsorship in 2006 considered by the Executive Director of the EGP to be "a very positive advantage" (Edmonton Grand Prix General Manager, 2006).

Objective 17: EGP - Develop Long-Term Partnerships: The EGP clearly articulated its desire to build long-term partnerships as a key objective in its sponsorships. In the case of the EGP-ATB sponsorship, this was assessed qualitatively using post-event interviews with key people in both organizations. A series of questions around the relationship were asked including satisfaction, objectives, issues, and servicing.

On the EGP (sponsee) side, interviews were conducted with the two individuals responsible for the sponsorship: (i) EGP General Manager, and (ii) EGP Sponsorship Consultant for the event, on August 1,2006. The General Manager overseas all operations of the EGP including the contract negotiations with ATB (Edmonton Grand Prix General Manager, 2006) while the Sponsorship Consultant was contracted by the EGP to manage and service all EGP sponsorships, including ATB. She outlined her role: "I am the primary sponsorship liaison for all sponsors...I was the primary contact working on the deliverables promised [to ATB]" (Edmonton Grand Prix Sponsorship Consultant, 2006).

On the ATB (sponsor) side, interviews were carried out with all ATB staff involved with the sponsorship including five (5) marketing staff, three (3) suite hosts, seven (7) employees and two (2) MasterCard representatives. All were conducted in the two week period following the event (July 24 to August 7, 2006) by telephone. The details and questions posed are outlined in Data Collection Exercises \#5 and \#8. Given the sensitive nature of the comments, the identities of the interviewees are kept confidential and, thus, their comments are not referenced in the following paragraphs. 
Interviewees from both sides reported satisfaction with the sponsor-sponsee relationship with some significant concerns expressed. The majority of the concerns were expressed by representatives of the sponsor, particularly with respect to EGP's attention to the deliverables promised in the contract and ATB's onsite needs. For example, one interviewee commented that "they [EGP] performed at 70-80\% of my expectations" and another similarly acknowledged that "we [ATB] got about 70 or $80 \%$ of the attention that we should of" and when pressed to explain said:

They [EGP] were generally very disorganized. So, it took quite a while to get answers from them...it felt a little like babysitting. You know, signage was put up late, booth locations were not what we wanted, that kind of stuff. So, it took a lot of extra effort on our part to get what we needed. It wasn't really a well oiled machine...in the end we were generally happy but we had to work harder [than expected] to get what we needed.

Another ATB interviewee responded similarly: "...there were things that they [EGP] didn't come through with but overall they provided what we agreed upon and did a pretty good job, so I'd probably say about $85 \%$ [performance on EGP's role in the sponsorship]." One interviewee summarized "I think that there were probably two or three sort of gaps that could have been avoided." When pressed to identify the problems, some interviewees refused while others eventually explained the issues. First, "there was a problem with family zone...logistic problem that they ran in to". When asked to explain, the interviewee responded that:

we were informed before that the family fun zone would include the rides and be an alcohol free area with all family stuff BUT it turned out that there was a beer tent beside and all rides were far away...so, I think we lost a lot of traffic from the Go-Kart track. It ended up being kind of a Go-Kart track with a few people around drinking beer. And, they'd committed to us that'd we'd be part of family fun zone. 
Second, three of the ATB interviewees mentioned signage; notably the lack of providing the committed signage, while another noted the lack of delivery on a promised television broadcast. Third, many stressed communication issues and the difficulty as the event approached in getting calls returned and deliverables acted upon. For example, one noted "I felt sometimes that we weren't necessarily the top of the list....often what was agreed on, wasn't happening or wasn't happening as was planned" while another reported that "Our contact at the Grand Prix seemed to have a lot of other things on the go and until crunch time we got $75 \%$ attention from EGP but when it came to crunch time...it became more like $50 \%$ of that, if that high."

When the EGP interviewees were asked by the researcher to respond about any problems with their relationship with ATB, the EGP General Manager (2006) reported no problems and the EGP Sponsorship Consultant (2006) responded:

...we had a great relationship. I do apologize for one thing...that being the broadcast tape...that is just a learning curve from my end dealing with computers and things like that until the race... working through webmail and getting messages. I think everything else went smoothly.

After indicating that she felt that the event was a success and that she felt that she had enough resources to deal effectively with 25 sponsors, the EGP Sponsorship Consultant (2006) provided her opinion on whether the ATB sponsorship was a success or not: "I hope it was. It is difficult for me to say as I wasn't part of negotiation side as I don't know what was promised and what was expected." She felt that ATB signage was highquality and well-displayed, that the Go-Kart track was very effective, and that ATB people onsite were well trained and friendly. Her only recommendation was that ATB needed to do more onsite promotion of the sponsorship to get the message out more to the 
people on site. When asked about the EGP side of the relationship and what could have been done differently, she indicated that:

I found that everything was delayed - especially from our end - due to the temporary site...I think that having a year under their belts and having more time to work through the program and take advantage of it should be better. Trying to rush a program through in 4 months was tough" (Edmonton Grand Prix Sponsorship Consultant, 2006).

When asked for specific recommendations, she provided a few: (i) "I would comment that they should include something with ticket mailers (gets recognition upfront)", (ii) "[they should be] having more people roaming the site and reinforcing the brand", and (iii) [they need] more 1 on 1 interaction with customers (Edmonton Grand Prix Sponsorship Consultant, 2006). Finally, she was asked about how the EGP Board of Directors felt about the current relationship with ATB. She indicated that "they are happy with ATB as a sponsor and the sponsorship programs that they [implemented]...they are happy with any sponsor who does activate and co-promote and they definitely feel that the ATB brand is a good fit" (Edmonton Grand Prix Sponsorship Consultant, 2006).

In summary, it is obvious that both sides view the relationship with concern and identified a number of issues (communication, delivery of promises, leveraging, etc.) which need to be resolved. However, it certainly appears that both sides are committed to improving the relationship in the future. Many of these concerns were viewed to be relatively minor in nature. Also, the Sponsorship Consultant (2006) pointed to the fact that ATB is one of many EGP sponsors. Further, the EGP representatives (Edmonton Grand Prix General Manager, 2006; Edmonton Grand Prix Sponsorship Consultant, 2006) commented that ATB was not a title or presenting sponsor which meant they were 
not top priority, however they reported that they would improve the sponsor servicing in the future towards building a long-term relationship with ATB.

\section{Objective 18: EGP - Build an affinity ${ }^{44}$ with Alberta Market (through ATB}

association): One of the key reasons why the EGP was interested in the ATB as a sponsor was its ability to provide an Alberta-focused message through the sponsorship (Edmonton Grand Prix General Manager, 2006). This was then translated into an objective for the EGP and was measured via two questions on the mass market survey. The first question asked if the respondent believed that the fact that ATB was a sponsor of the EGP made them prouder that the event is hosted in Alberta, while the second asked respondents if learning that ATB was sponsoring the EGP increased their belief that ATB cares about Albertans. On the first query, $48.8 \%$ either agreed or strongly agreed, while $22.8 \%$ disagreed or strongly disagreed. For the second question, a similar result was achieved with $43.4 \%$ either agreeing or strongly agreeing, while $29.2 \%$ disagreed or strongly disagreed. In fact, responses to the two questions were significantly correlated $(r=.517, p<.01)$. In both cases, evidence is provided that the sponsorship had some effect on the EGP objective of building an affinity with the Alberta market.

Deeper analysis provides limited additional insight into Albertans' affinity with the event as no influencing variables had an significant impact other than the fact that fans (those who had watched an entire car race previously on TV) believed more than non-fans $(t=1.939, \mathrm{p}=.053)$ that the sponsorship increased their pride that the EGP is held in Alberta. A similar difference $(t=2.047, \mathrm{p}<.05)$ occurred with the 'care' question. Thus, in summary, there is support that the sponsorship had an influence on increasing

\footnotetext{
44 'affinity' here refers to attachment between the EGP and Albertans
} 
Albertans' affinity with the event (via pride and care constructs) with an enhanced effect on those who were already fans of auto racing.

Objective 19: Effectively Service Sponsors: This objective is measured in a similar fashion to Objective 17 where, post-event, representatives of both the sponsor and the sponsee were interviewed to assess the relationship between ATB and the EGP. One aspect of this relationship is the servicing provided by the sponsor (EGP) to the sponsee (ATB). As noted in Objective 17, interviewees from ATB noted some problems with communication and service; which was also supported by one EGP interviewee. One particular question in those interviews asked respondents to evaluate the service provided by EGP to ATB, where three ATB interviewees responded that service was $70-80 \%$ of expectations.

Objective 20: Customer Acquisition (MasterCard Onsite Sign-up): During the event, there were 4 MasterCard booths with volunteers (ATB associates) circulating around the event grounds seeking to sign people up for ATB MasterCard. Provided they completed a form, the respondents received a giveaway $\mathrm{t}$-shirt. Maximizing the number of complete sign-ups was an important objective for ATB MasterCard.

ATB MasterCard officials provided the results of the sign-up campaign at the event. Over the course of the 3-day event, 699 people had signed up for a MasterCard, $52 \%$ of who were eventually approved for a card (i.e. 364 individuals). If we consider this in the context of their budget, we can calculate the cost per sign-up and the cost per sign-up leading to approved cardholder (i.e., potential new customer). The total cost to MasterCard for the sponsorship was $\$ 123,839$ (or $\$ 85,000$ fee plus $\$ 38,839$ leveraging). Dividing by the number of sign-ups (699) and approved cards (364) gives a cost per sign- 
up of $\$ 177.17$ and cost per approved cards of $\$ 340.22$. MasterCard representatives noted that this is an acceptable figure for them (Sperling, 2006).

ATB MasterCard also sought to acquire customers through the promotions launched on the pre-event microsite where it was noted that 869 visitors to the microsite did click on the link to the ATB MasterCard webpage. No tracking was done to determine if any of the 869 became cardholders. Further, MasterCard representatives verified that two additional EGP-related promotional contests led to 320 new approved cardholders; 195 from a regional branch contest and 125 from a call centre contest. No further details on these promotions were provided, although no additional costs were incurred (Sperling, 2006; Rudan, 2006b).

In summary, 684 new cardholders (approved) were acquired by MasterCard from the EGP sponsorship at a cost of $\$ 181.05$ each. This is considered to be a very good cost per approved cardholder sign-up by MasterCard officials (Sperling 2006).

Objective 21: MasterCard-Build Awareness: The co-sponsor ATB MasterCard had one promotional objective in addition to its goal of customer acquisition. This resulted from the fact that MasterCard International committed $\$ 45,000$ in resources to ATB MasterCard towards the EGP sponsorship in return for the inclusion of its logo in all related ATB promotions (Rudan, 2006b). The ability of the sponsorship to build awareness of ATB MasterCard with ATB customers and prospects was, thus, a further objective of the sponsorship. This was measured through questions on the in-branch surveys where respondents were asked whether sponsorship of the EGP increased their awareness of the ATB MasterCard product. Results indicate that the sponsorship had limited effect in building awareness of the ATB MasterCard as nearly half (49.6\%) of the 
responds either disagreed or strongly disagreed that the EGP sponsorship increased their awareness of MasterCard. However, almost one quarter of the respondents (22.7\%) agreed or strongly agreed, which may be considered significant considering the high preexisting levels of awareness that MasterCard has globally. A high level of awareness of MasterCard was demonstrated in the in-branch survey population in the metrics of each of Objectives 1, 2, and 3. An 'ATB Visa Card' (which does not exist) was used as an option as an influencing factor but was never chosen by a respondent. Further analysis found no significant differences between Calgary and Edmonton or between customers and non-customers.

\subsection{Data Analysis: Shirking Behaviours}

Concurrent to gathering the data for the objectives to be measured, the process of identifying potential shirking behaviours or activities was also undertaken. Note that in many cases, metrics for shirking could not be planned until the researcher became aware of the potential shirk and related information became available. The same combined format of presenting methods concurrent with results is adopted here for the nine potential shirking effects assessed.

Shirking Effect \#1: The contract between ATB and the EGP included a clause (2.2) allowing for a previous agreement with Capital City Savings (a direct ATB competitor) to sponsor the Pit Lane Club at the EGP. Given the importance of exclusivity in sponsorship, the fact that ATB was given exclusivity in the FI category, and the Capital City Savings sponsorship of the Pit Lane Club, this was classified as a shirking behaviour. The metric developed to determine its impact was a question on the mass 
market survey to determine the level of confusion created by the Capital City Savings sponsorship of Pit Lane. The question asked respondents $(n=500)$ to select the official FI sponsor of the EGP from a list of 5 options with an additional choice to select 'none of the above'. Results clearly show that some confusion was generated in both ATB customers and non-ATB customers. The vast majority, 343 (68.6\%), either did not know or reported 'none of the above'. After that, ATB was the most mentioned ( $n=71$ or $14.2 \%$ ), followed by RBC ( $n=57$ or $11.4 \%$ ), Capital City Savings ( $n=18$ or $3.6 \%$ ), Bank of Alberta (fictional) ( $n=6$ or $1.2 \%$ ), and Alberta Credit Unions ( $n=5$ or $1.0 \%$ ). In the context of these various levels of confusion (market, shirk, clutter) and noting the difficulty involved in attributing the lack of awareness to this particular shirk, this analysis suggests that some negative effect of the Capital City Savings Pit Row sponsorship is evident. If we analyze further the 18 respondents who selected Capital City Savings as the official FI sponsor of the EGP, it is observed (i) that being outside of Edmonton did not lead to more confusion as 11 of the 18 were Edmonton based (with 6 from Calgary and 1 from outside), (ii) that one of them attended the race in person, (iii) that 4 watched the EGP on television, (iv) that 11 of the 18 had household incomes under $\$ 100 \mathrm{k}$, and (v) that 13 of the 18 were female.

In addition to the overall finding that $3.6 \%$ of respondents selected Capital City Savings as official EGP FI sponsor, additional support that negative effects resulted is evident through the 87 respondents in the sample who were already ATB customers. Of these 87 ATB customers, 3 selected Capital City Savings as the official FI sponsor of the EGP. 


\section{Shirking Effect \#2: Similar to Shirking Effect \#1, Shirking Effect \#2 was}

discovered following a detailed review of the sponsorship contract. It involves another contracted issue where ATB was not provided the option to supply the onsite ATM machines during the event. It is considered a potential shirk as it is a behaviour potentially counter to ATB's interests. Given the 'white label' (i.e. generic, non-branded) style of machines typically used at such events, it is estimated that ATB could have made approximately $\$ 2$ per transaction had the machines been onsite. Expenses are unknown but would include the transport, delivery, maintenance and service of the machines. If we estimate (conservatively) that each attendee (total attendance was 171,391), on average, would use an onsite ATM machine 0.5 times/day during the event and that expenses are $\$ 1$ per transaction, lost revenue is estimated to be $\$ 42,848$.

Shirking Effect \#3: As noted previously, a potential shirking behaviour was identified during one of the post-event interviews where it was noted that ATB had been promised "signs at Go-Kart track but did not get half of them" (Rudan, 2006b). Qualitative feedback was sought from the various post-event interviews. ATB interviewees reported frustration with the lack of signage, although they did not express much concern about the potential marketing impact of the lack of signage, other than noting that any detraction would be most noticeable for the television audience. EGP interviewees expressed that they were not aware of the problem. Given the point that the television audience would be most affected (Rudan, 2006a), the sample of 52 Albertans who responded to the mass market survey who indicated that they had watched the EGP on television was looked at further. Of the 52, $12(23 \%)$ were current ATB customers. Interestingly, not one member of this group was able (unaided) to identify ATB as the 
official FI sponsor of the EGP, with 3 respondents selecting RBC and 9 reporting ' $I$ do not know'. Similarly, the non-ATB customers who had watched the EGP on television (40) were also confused about the identity of the official FI of the EGP, although $6(15 \%)$ were able to correctly identify ATB.

The summary point of this analysis is that, among television viewers, considerable confusion exists about sponsorship of the EGP. Although attributing a portion of this confusion to the loss of signage is impossible to show empirically in this research, it is likely that the lack of signage issue had some role in this confusion.

Shirking Effect \#4: Throughout the post-event interviews, a number of issues around the service efficiency provided by the EGP were identified by a number of ATB interviewees. Given that these were related to activities of the EGP or its suppliers, they were considered as potential shirks of ATB and included: (i) communication challenges for ATB personnel with EGP contacts, (ii) delayed delivery and slow servicing with the truss structure for the ATB sponsored Go-Kart track, (iii) production error on flags for the event, (iv) late delivery of signage and challenges with signage sub-contractor Stratotech, (v) late delivery of prizes for ATB retail contest, (vi) failure to finalize promised television commercial spot for ATB in time, and (vii) failure by the EGP to deliver post-event report to ATB (as of December 2006). Other than lost promotional benefits for ATB from the lost television commercial spot/signage errors and planning challenges for 2007 from the late report, these activities did not result in any significant detraction from the sponsorship although they did result in considerable aggravation, frustration and a loss of time for ATB employees. 
Shirking Effect \#5: As noted in Objective \#4, ATB had a goal to impact its highend customers and prospects with the EGP sponsorship. One particular aspect of that objective involved a significant investment to contract a high profile professional race car driver to visit the ATB hospitality booths on all three days of the EGP. Two ATB interviewees and the suite hosts all indicated that there may have been shirking behaviour (lateness, less time committed than contract, difficulty to find, etc.) on the part of the driver's team, which is assessed here. In addition to the $\$ 10,515$ invested in food, drinks, upgrades, invitations and giveaways for the hospitality suite, a fee of $\$ 5,500$ was paid to the driver for the visits. The assessment of the potential shirk is analyzed using qualitative data from the post-event interviews with the three Suite Hosts as the metric.

The Suite Host for one of the days described how the visit worked out on that day: "he [the driver] got there about 1:00 and was there for a good 35 minutes. He did a great job and spent time signing autographs as much as we wanted and also reviewed the track details and more about the cars...people were happy" (Suite Host_1, 2006). An attendee at the hospitality suite the same day echoes these positive comments: "he [the race car driver] was the best part of the sponsorship...very good" (Relationship Manager, personal communication, July 27, 2006).

The Suite Host of another day had a much different experience. Similar to the day described above, it was planned (per the contract) that the driver would come to the hospitality booth about 30 minutes after the race (arrive around 1:30pm). However, "today he came at $3[\mathrm{pm}]$ " (Suite Host, personal communication, July $30^{\text {th }}, 2006$ ), which as the Suite Host explains - was not ideal for the guests at the suite:

...it was planned that he would come after the race which finished at $1 \mathrm{pm}$ so we expected him at 1:30 or 2 ...but he came at 3 . Clients were excited. 
We had to eventually go and get him. It was frustrating from a client perspective. They [clients] were fine with it. It was no big deal, you know. Some of them waited and some of them left. Most of the clients actually left at that point. I told them that he'd be there in 20 minutes but we couldn't force them to stay. It was hot. Now, that was my biggest let down as the host as I had to explain why he wasn't there. You know, they were excited to meet him and things were designed for him. Now, we gave some pictures/signatures to those who'd left but it wasn't the same. (Suite Host_2, 2006)

This Suite Host also pointed out that continued calling to the driver and his agent was required to find him and encourage him to come right away, although she noted that the main negative was her frustration as it appeared that the lateness and short visit "had limited, if any, affect on the effectiveness of the sponsorship" (Suite Host_2, 2006).

The Suite Host on the third and final day of the EGP also had only positive things to say about the driver and his contribution to the sponsorship:

I think there is huge value in having the driver come to the suite. He was paid by ATB to come for an hour or so on all 3 days. He let customers know that we'd [ATB] paid for him when he was there. It is very valuable... his manager also came in before the driver to set up his visit which was nice. Food and drink was quality and great and we didn't run out. Taxi chits worked well and were appreciated [by attendees]. One lesson learned was on food... after the race, there was no one left [in the suite] to eat food so we lost some money. (Suite Host, personal communication, July $30^{\text {th }}, 2006$ )

In summary, 2 out of the 3 Suite Hosts reported that the driver fulfilled and exceeded the tenets of his contract while the 3 noted he was late but otherwise did what he was asked and that the negative effects were very limited. As such, it is reasonable to conclude that no shirking behaviour took place here.

Shirking Effect \#6: A sixth potential shirking effect related to the ATB-sponsored Go-Kart Track at the EGP was reported to the researcher in two of the post-event interviews. This promotion was included in the ATB-EGP sponsorship contract because 
of (i) its high profile and (ii) its planned location in the family zone (i.e. near rides, kids' events, etc.). The shirk resulted when the Go-Kart track ended up being located near the beer garden and far from the other kids' rides (Rudan, 2006b). Given the lateness of this change and the challenge of forecasting what benefits would have resulted from a location, as planned, near the kid's zone and away from the beer garden, the effects are estimated using the post-event interview transcripts. One of the ATB interviewees summarized:

We were informed before that the family fun zone would include the rides and be an alcohol free area with all family stuff but it turned out that there was a beer tent beside and all rides were far away and signage was weak. So, I think we lost a lot of traffic from the Go-Kart track. It ended up being kind of a Go-Kart track with a few people around drinking beer. And, they'd committed to us that'd we'd be part of family fun zone.... and there is no question that this impacted the effectiveness of the Go-Kart track.

During one of the post-event interviews, an ATB staff member used a map to show where the Go-Kart track was supposed to have been and where it actually ended up being and commented "I am positive that the location change was a negative issue for our promotions". Another interviewee referred specifically to the potential loss of promotional benefit for ATB: "personally, I think the Go-Kart thing was great...they should continue it...but in a better location... where it was, was not good for promotion". Although the actual impact could not be specifically measured, the results of the postevent interviews demonstrate that a loss of promotional capacity did occur to some degree.

Shirking Effect \#7: The seventh potential shirking effect was identified in a postevent interview with one of the Suite Hosts, who noted that the ATB announcements that were played over the public address system on site were incomprehensible (as were all 
announcements). Given the post-event timing of this shirk being identified; it was not possible to put a specific metric in place, although data from the Suite Host post-event interviews provide some input. Notably, two of the Suite Hosts commented specifically on the loss of promotional value: "they were a waste of time", and "one thing they should change is the public announcing system. We could never hear a word of what was being said".

Shirking Effect \#8: Two ATB employees raised sensitive internal ATB issues as potential shirks in the post-event employee interviews. First, they pointed out that the allocation of tickets in the employee ticket program likely detracted from ATB's internal marketing objectives (Objective 8 to motivate staff and Objective 14 to build employee pride). Second, they noted that the selection of guests in the ATB hospitality suite had likely detracted from the effectiveness of the hospitality suite (Objective 4-Impact Top $1 \%$ of customers). Based on these suggestions, both are considered potential shirking behaviours and their impact is assessed separately.

Results from the post-event ATB employee interviews were used to assess the employee ticket program, where three interviewees noted that communications from ATB to its staff failed to reach everyone. Specifically, two of the seven interviewees had not heard of the program, another believed it was an Edmonton-only offer, and 3 noted that they knew of colleagues who had wanted to attend but were unable to as tickets were sold out before they knew about the ticket program. This issue around communication must be taken in the context of an otherwise very successful program which sold-out quickly and got ATB staff widely excited about the sponsorship. 
Analysis of the employee interviews was used to review the potential shirking behaviour with respect to access to the hospitality suite. This is considered a potential shirk as the activities involved could undermine the sponsorship and one of its objectives. Suite_Host_1 (2006) described the issue: "we had some tactical struggles over who was invited" and another ATB official explained in detail that:

The original plan for the hospitality suite was to have 25 guests per day which were to include 8/day who were top customers with over $\$ 2,000,000$ in loans, 15/day from investor services clients and prospects and $2 /$ day to be a single ATB executive and his or her spouse. However, jealousy and politics came into play and the number of ATB executives and spouse grew to 6/day and some other ATB staff used some of the other ticket places for themselves or friends instead of for clients and prospects.

Some employees were disappointed that their clients were invited but they were not; and one noted "it is tough but we were not invited. We were allowed to send clients. So, we could buy tickets but we weren't invited." The same interviewee, however, noted that "my clients were happy - all of them enjoyed it - they were wined and dined. I sent 6 but would have liked to have been there myself'. In addition to the issue around ATB executives and staff attending, determining how many spots would be provided to guests became an issue, as noted by one of the Suite Hosts:

...the goal was to invite top-end clients to [allow ATB to] interact with top-end clients...that was very much achieved. I mean there were some invitation logistics. I thought that there were too many executive types there...maybe more relationship managers would have been ideal: the people who clients deal with on day to day. There may have been too many ATB employees as well. On my day, there was myself and there was 4 executive types and their guests...so 8 spots of 25 taken up by ATB employees. And that has to be looked at for sure. 
There was also some concern expressed around the invitation of spouses to the event as expressed by one of the Suite Hosts:

There is also debate about [inviting] spouses for each ATB person. For clients, I think it is necessary to invite a guest but for an ATB executive, there is good and bad...it is business so you don't need the guest but then again if you bring your spouse/guest, they can relate to the client's spouse/guest and talk while others are doing business. In general, I'd say yes but a small suite limits this and we need more clients there.

These four potential shirks - whether from actions of specific individuals or from ATB policy around the event - are amplified since only 48 (26 clients/prospects with 22 guests) of the 75 spots were taken by clients or prospects is an issue. This means that $36 \%$ (27) of the places were taken by ATB employees and their guests, for a ratio of less than 2:1 (1.78:1 to be exact) of Clients/Prospects:ATB representatives. If we reduce the sample to include only clients/prospects who meet the Top $1 \%$ definition (i.e., household income $>\$ 100,000$ ), the ratio drops to $1.28: 1$. From all accounts, these ratios are low and likely led to some hurt feelings and disappointed employees, clients and prospects.

Overall, the hospitality suite places are reported by interviewees to be a significantly more impactful issue detracting from the sponsorship than the employee ticketing program. In fact, the employee ticket program suffered only from the issues around any normal popular program so it is not deemed shirking behaviour. Considering the fact that a low percentage of places in the hospitality suite were occupied by ATB clients and prospects (not all of whom met the Top $1 \%$ criteria), it is reasonable to suggest that activities around hospitality suite 
invitations undermined the effectiveness of the sponsorship and Objective 4 in particular.

Shirking Effect \#9: A review of the transcripts of the post-event interviews with ATB MasterCard and ATB staff suggested that there may have been some cooperation issues between the sponsor and co-sponsor that potentially detracted from the effectiveness of the sponsorship. It was deemed a potential shirk as both sponsor and cosponsor were contractually linked to the sponsorship and an undermining of the deliverables on the contract would fit the definition of shirking behaviour. A deeper assessment of the interview transcripts and further communication with both ATB and MasterCard representatives revealed that there is not a specific shirk here but a larger organizational issue of how the ATB MasterCard unit fits in at ATB. One interviewee summarized the situation: " 3 years ago, we had more marketers at MasterCard -6 on our floor - than we have in ATB marketing and they only work on MasterCard and there is no collaboration between the units which makes no sense". When asked if this issue needed addressing, the interviewee articulated that 'I'm pretty confident that in 5 years that won't look the same...things are changing... all sponsorships small and large should come through 1 unit who have linkages with everybody [both MasterCard and ATB]".

Many additional comments were made by interviewees on the specific issues and challenges of the ATB - ATB MasterCard relationship. The comments can be grouped based on how they affect the sponsorship: (i) inefficient budgeting, (ii) mutually exclusive strategies, (iii) strained communications, and (iv) distinct and uncoordinated leveraging plans. In summary, no shirking behaviour specific to sponsorship is identified, however the larger issue of inefficient activity and competing interests between ATB 
marketing and ATB MasterCard is noted, as is the effect it had on the sponsorship. Results clearly point out the pressing need for ATB and ATB MasterCard to deal with this issue.

\subsubsection{Step 7: Generate and Interpret Outcomes and Impacts}

The process of developing and implementing this evaluation revealed a number of challenges in sponsorship evaluation research, with particular challenges stemming from decisions, resource and permission issues which are discussed in this section.

The process of making strategic decisions around the evaluation turned out to be considerably more complex than originally thought. In fact, seven individuals influenced how the evaluation developed. These individuals were representatives from ATB marketing, ATB legal, ATB research, EGP management, ATB MasterCard, the doctoral researcher and the doctoral research supervisor. Of particular note, approvals were necessary from lawyers and research experts on behalf of ATB in order for the evaluation to proceed.

With respect to permissions, ATB required the signing of NDAs by the researcher, the $\mathrm{PhD}$ supervisor and the $\mathrm{PhD}$ committee with versions of the NDA designed specifically for each by the ATB legal department. ATB's Vice-President of Marketing also interviewed the researcher in person on the research. Following these two steps, the researcher was allowed full disclosure and support. The EGP was more reluctant. Interviews came only after the event and following considerable communication from ATB and the researcher. Information from co-sponsor ATB MasterCard was full and complete. 
The process revealed that significant time and financial resources are needed to complete an evaluation. The researcher invested approximately 250 hours and the key ATB contact (Marketing Manager, Investor Services) put over 80 hours into the analysis, while at least another $10 \mathrm{ATB}$ staff members allocated at least 1 hour and up to 25 hours in some cases to the evaluation. It is estimated that the researcher and representatives from ATB, MasterCard and EGP dedicated a total of 430 hours of their time specifically to the evaluation. Budget costs were also significant and were shared by ATB, the author and the $\mathrm{PhD}$ supervisor with the total cost coming to $\$ 11,773.86$ as outlined in Table 52 below.

\section{Table 52: Evaluation Research Expenses}

\begin{tabular}{|l|c|c|}
\hline Expense & Amount & Paid By \\
\hline Researcher Visit to Edmonton - Hotel & $\$ 300$ & ATB \\
\hline Researcher Visit to Edmonton - Flight/Meals/Transportation & $\$ 1525.50$ & NOR \\
\hline Researcher Expenses for Interviews (long distance, tape, etc.) & $\$ 148.36$ & NOR \\
\hline In-Branch Surveys - Data Collection Salaries (80 hours @ \$15) & $\$ 1200$ & NOR \\
\hline In-Branch Surveys - Hotel, Travel and Incentives & $\$ 1100$ & ATB \\
\hline Mass Market Surveys (Alberta) - Research House Fee & $\$ 5000$ & ATB \\
\hline Mass Market Surveys (Alberta) - Research House Fee & $\$ 2000$ & JM \\
\hline Miscellaneous Costs - Research & $\$ 500$ & NOR \\
\hline & & \\
\hline TOTAL COST & $\$ 11,773.86$ & $*$ \\
\hline
\end{tabular}

In summary, the process model was run successfully. The final step of the process model involves generating the outcomes and impacts of the sponsorship vis-à-vis the 21 objectives and 9 shirking behaviours. It is a summary of the previous 30 sub-sections and is presented in Table 53 below. The summary includes a brief description of each 
objective/shirking behaviour, a researcher ranking ${ }^{45}$ on the level of attainment of the

objective (or 'detraction' in the case of shirking) and the results that support that ranking.

\section{Table 53: Summary Results}

\begin{tabular}{|c|c|c|c|}
\hline \multicolumn{2}{|c|}{ Objective } & \multicolumn{2}{|l|}{ Results } \\
\hline$\#$ & Description & $\begin{array}{l}\text { Objective } \\
\text { Obtained }\end{array}$ & Results of Analysis \\
\hline 1 & ATB Customer Acquisition - Edmonton & Limited & + 7 new customers \\
\hline 2 & ATB Customer Acquisition - Calgary & No & No effect \\
\hline 3 & ATB Customer Acquisition - Other & Partial & +34 new customers \\
\hline 4 & ATB Impact Top 1\% customers/prospects & Yes & $\begin{array}{l}\text { + } 26 \text { Top Customers \& Prospects } \\
\text { 'impacted'@ } \$ 1780 \text { each }\end{array}$ \\
\hline 5 & Increase Awareness (that ATB exists) & Yes & $+16.4 \%$ increase \\
\hline 6 & Increase Awareness (that ATB cares) & Yes & $+43.4 \%$ increase \\
\hline 7 & Improve ATB Brand Prestige (customers) & Partial & $\begin{array}{l}+1 \text { in } 66 \text { customers ( } 1 \text { in } 44 \mathrm{EDM} / 1 \text { in } \\
99 \mathrm{CAL} \text { ) influenced }\end{array}$ \\
\hline 8 & ATB Internal Marketing (motivate staff) & Yes & $\begin{array}{l}\text { + Sold-out ticket program } \\
\text { + Positive employee interviews }\end{array}$ \\
\hline 9 & ATB Achieve competitive advantage & Limited & $\begin{array}{l}+3.6 \% \text { of respondents impacted } \\
+ \text { Significantly greater impact on non- } \\
\text { customers, fans and Edmonton }\end{array}$ \\
\hline 10 & $\begin{array}{l}\text { Establish ATB as major player in Alberta } \\
\text { banking market - with customers }\end{array}$ & Partial & $\begin{array}{l}+ \text { Over } 90 \% \text { believe so already, } 3.5 \% \text { of } \\
57 \text { non-believers impacted }\end{array}$ \\
\hline 11 & $\begin{array}{l}\text { Establish ATB as major player in Alberta } \\
\text { banking market - with non-customers }\end{array}$ & Yes & $\begin{array}{l}+64.8 \% \text { of Albertans (strongly) agree } \\
\text { that EGP sponsorship helped } \\
+ \text { Significantly greater impact on } \\
\text { young, fans of sport and TV viewers }\end{array}$ \\
\hline 12 & $\begin{array}{l}\text { Re-brand ATB to full-service operation } \\
\text { from small town rural bank - customers }\end{array}$ & Yes & $\begin{array}{l}+45 \% \text { of customers noted that EGP } \\
\text { sponsorship aided re-positioning }\end{array}$ \\
\hline 13 & $\begin{array}{l}\text { Re-brand ATB to full-service operation } \\
\text { from rural bank - non-customers }\end{array}$ & Yes & $\begin{array}{l}+72.5 \% \text { agree or strongly agree that } \\
\text { ATB is full-service FI } \\
+ \text { Significant difference b/w those who } \\
\text { correctly chose and those who did not }\end{array}$ \\
\hline 14 & Internal marketing ATB - build pride & Yes & $\begin{array}{l}\text { + Sold-out ticket program } \\
+ \text { Positive employee interviews }\end{array}$ \\
\hline 15 & ATB: assess sponsorship effectiveness & Yes & + The occurrence of this evaluation \\
\hline 16 & EGP - revenue generation & Yes & $\begin{array}{l}+ \text { Target price achieved }(\$ 410 \mathrm{k}) \\
+ \text { ATB leveraging investment }(\$ 240 \mathrm{k})\end{array}$ \\
\hline 17 & EGP - develop long-term partnerships & No & $\begin{array}{l}\text { Numerous concerns to overcome, but } \\
\text { commitment to improve in } 2007\end{array}$ \\
\hline 18 & $\begin{array}{l}\text { EGP - build affinity with Alberta market } \\
\text { through association with ATB }\end{array}$ & Yes & $\begin{array}{l}+ \text { Strong effect }(50 \%) \text { in building pride } \\
\text { in Alberta-based event }\end{array}$ \\
\hline
\end{tabular}

${ }^{45}$ Given the varied nature of the 21 objectives and 9 shirking behaviours, coupled with the fact that many of the objectives were not constructed by ATB, MasterCard or EGP with measurable components, a 4-level ranking system (yes, partial, limited, and no) was used with ranking based on researcher assessment. The 4levels were defined as follows: yes (objective achieved as desired), partial (considerable but incomplete evidence of successful achievement of the objective), limited (low levels of success, often uncertain), no (no evidence of success). 


\begin{tabular}{|c|c|c|c|}
\hline 19 & EGP - effectively service sponsors & Limited & $+70-80 \%$ performance \\
\hline 20 & MasterCard - customer acquisition & Yes & +684 new clients via booths/contests \\
\hline 21 & Awareness of ATB MasterCard & Yes & $+22 \%$ increase due to sponsorship \\
\hline \multicolumn{2}{|c|}{ Shirk } & \multicolumn{2}{|l|}{ Results } \\
\hline \# & Description & Detraction & Results of Analysis \\
\hline 1 & Sponsor Conflict w/ Capital City Savings & Yes & - $3.6 \%$ of consumers confused \\
\hline 2 & No On-Site Product Sales & Partial & - Approx. $\$ 85,695$ in lost revenue \\
\hline 3 & Signage Problem & Yes & - Loss of TV promotional value \\
\hline 4 & Service Efficiency & Limited & $\begin{array}{l}\text { Inconvenience and minor loss of } \\
\text { promotional benefits }\end{array}$ \\
\hline 5 & Race Car Driver Investment & No & No shirking behaviour evident \\
\hline 6 & Go-Kart Track Location & Yes & - High loss of promotion capacity \\
\hline 7 & PA Announcements & Limited & - Minor loss of promotion capacity \\
\hline 8 & $\begin{array}{l}\text { Implementation of Ticket Program } \\
\text { Hospitality Suite invitations }\end{array}$ & $\begin{array}{l}\text { No } \\
\text { Yes }\end{array}$ & $\begin{array}{l}\text { No shirking behaviours evident } \\
\text { - Poor ratio of clients/prospects to } \\
\text { ATB reps }(1.7: 1)\end{array}$ \\
\hline 9 & MasterCard/ATB Cooperation & No & $\begin{array}{l}\text { No shirking behaviour evident, } \\
\text { although some larger issues identified }\end{array}$ \\
\hline
\end{tabular}

Methodologically, a number of recommendations were developed for future research from this sponsorship evaluation case study. First, in intimate data collection environments such as the hospitality suite survey, it is important to use a one-sided survey (some respondents missed the reverse side) and to include significant training of suite hosts on the survey given that they have many responsibilities during the day including the survey. Second, with respect to shirking behaviours, the need to include a round of pre-event interviews to determine potential sources of shirking would enable more quantitative assessments. This could be accomplished through qualitative forecasting techniques such as expert opinion or a focus group with people who were involved in a previous similar sponsorship. Third, when interviewing representatives of sponsors, sponsees, and intermediaries, it became evident that the need to do so in a private, comfortable setting with extra time to discuss 'key' issues should be included in the process model. Finally, the resource-intensive nature of evaluation was again highlighted; both in terms of financial cost $(\$ 11,600$ or $2.6 \%$ of the ATB sponsorship fee) 
and time commitment. The demands are considerable and may not be well understood when embarking on an evaluation.

\subsection{Recommendations to Participating Organizations}

Throughout the implementation of the process model in the ATB-EGP sponsorship evaluation case study, a number of recommendations specific to the sponsor (ATB), sponsee (EGP) and co-sponsor (ATB MasterCard) were developed. They are presented here for the benefit of the participating organizations and for the improvement of the process model.

Recommendations to $A T B$ : A number of specific recommendations are provided to ATB from the sponsorship evaluation case study. First, it is suggested that the relationship between ATB marketing and ATB MasterCard marketing be clarified and reorganized. The specific recommendation is to accelerate the previously discussed idea (Rudan, 2006a) of merging of the two units into one cohesive entity. Concurrent to accelerating the merger, it is further recommended (i) to balance the leveraging ratios of ATB Financial and ATB MasterCard to the EGP sponsorship to ensure an equal contribution towards maximizing the value of the sponsorship and (ii) to develop a coordinated plan for the 2007 EGP. Second, it is recommended that ATB implement a second evaluation exercise for the customer acquisition objectives in 12-18 months time to determine if longer-term impacts were generated where short-term outcomes were weak. Third, ATB should prioritize sponsorship for future awareness and branding objectives but NOT for future customer acquisition or competitive advantage objectives since results here show sponsorship to be effective in awareness/branding but not 
customer acquisition. Fourth, for the Hospitality Suite at the 2007 EGP, ATB should consider the following suggestions for action: (i) repeat the high profile race car driver visit but with a different star driver, (ii) reserve a larger suite and consider alternative suite layouts to increase numbers and improve the experience, (iii) review invitation policy to increase the ratio of customers and prospects to ATB representatives, (iv) reconsider the option for ATB executives and relationship managers to bring a guest with them, (v) ask EGP for better suite signage, (vi) ask EGP for improved bathroom facilities (both quality and location), (vii) ask EGP for more visitors passes (i.e. 4 for every 25 person suite) which are valid all day (not just after 2:30pm), and (vii) address a number of other minor issues identified in the post-event employee interviews (i.e., (a) improve delivery and inventory of food including no food on Sunday afternoon, (b) order less alcohol or lower prices in the booth, (c) eliminate or reduce gift bag, and (d) ask EGP if younger bands could be included for younger crowds). Fifth, considering the employee discount ticket program, the following three suggestions are offered for the 2007 EGP: (i) improving communication program so all ATB staff are aware of the program, (ii) implement a strategic ticket allocation system, and (iii) allocate more budget to expanding the number of tickets available in the program. Sixth, it is suggested that ATB (i) meet immediately with the EGP to express strong concern over the Capital City Savings sponsorship, (ii) demonstrate (using results from this evaluation) that such a conflicting sponsorship is detracting from the benefits of the ATB sponsorship, and (iii) negotiate for exclusivity or price reduction or position ATB for better negotiations if sponsorship is to continue beyond 2007. Seventh, it is recommend that ATB try to meet immediately with the EGP to discuss the on-site ATM machines as both a marketing and 
revenue-generation function for ATB. Eighth, ATB should meet immediately with the EGP to make sure the location of the Go-Kart track in 2007 is in the fan zone, near rides and away from beer tents. This effort should also include improved training (potentially in collaboration with Stratotech) of ATB Go-Kart track volunteers on (i) Go-Kart track operations, (ii) equipment needs and storage, (iii) accreditation, and (iv) volunteer operations (recruitment, breaks, nutrition, etc.). Ninth, it is suggested that ATB meet immediately with the EGP to discuss the 2007 signage plan for the Go-Kart track and put a monitoring plan in place to ensure compliance. Tenth, it is recommended that ATB meet immediately with the EGP and request a dedicated EGP staff contact during the event who will be reachable in 'crunch time'. Finally, ATB must deal with the service efficiency items identified under Shirking Element \#4, including (i) requesting an improved PA system for 2007, and (ii) researching and developing marketing tactics to work towards overcoming confusion with RBC as official FI sponsor.

Recommendations to EGP: Six recommendations for the EGP were identified from the sponsorship evaluation case study. First, it is suggested that the EGP implement a strategy to develop long-term partnerships with secondary level sponsors such as ATB that includes increased attention to the sponsor's needs and increased human resources allocated towards sponsor servicing. Second, the EGP should consider increasing the prices of sponsorship and then using these additional funds to help sponsors leverage the association by providing additional promotional value (signage, TV, radio, etc.), investing in co-promotions, and increasing its sponsor servicing capacity. Third, it is recommended that the EGP consider selecting a minimum number of sponsors with a provincial geographic focus (e.g. ATB and Alberta) to continue to build affinity between 
the event and Albertans. Fourth, it is suggested that the EGP revamp sponsor servicing during the event with improved communications and increased human resources. Fifth, it is recommended that EGP management review the drop in attendance over the past two years (there has been a decrease of 27,000 spectators from 2005 to 2006) in order to understand why this happened and to avoid it from happening again in 2007. Finally, it is recommended that the EGP respond positively to the many requests that will come their way from ATB as per recommendations to ATB above.

Recommendations to ATB-MasterCard: The sponsorship evaluation case study also provides five specific recommendations to ATB MasterCard (the co-sponsor). It is suggested that they (i) increase their presence on the ground to 6 or 8 smaller-sized booths with an increased number of volunteers to increase sign-ups, (ii) identify and locate sign-up volunteers in more strategic 'roaming locations' such as inside a beer tent or near lineups, (iii) develop a more cost-effective and appealing sign-up premium (in lieu of a t-shirt), (iv) consider more activities targeted at under-30 target markets, and (v) recognize the role that ATB played in building awareness of MasterCard and accelerate the process of merging their marketing functions with ATB. 


\subsubsection{Sponsorship Evaluation 2: Kanatek-Mount Everest Expedition Sponsorship}

The second sponsorship evaluation case study implemented as part of this dissertation is the 2005 Kanatek Expedition to Mount Everest. Like the ATB-EGP sponsorship, the presentation of this sponsorship evaluation case study follows the steps in Process Model D2. Note that Step 1, as presented here, is more detailed than for the ATB-EGP sponsorship evaluation case study due to the fact that the evaluation developed over a five year period of time and that an unexpected tragedy took place that drastically altered the nature of the evaluation. Although this tragedy limited the ability to fully evaluate the sponsorship, much learning around the evaluation process occurred and the risks inherent in implementing the process model were clarified.

\subsubsection{Step 1: Setting the Stage}

The Sponsee: In the summer of 2000, following his second major research expedition to the base camp of Mount Everest, Dr. Sean Egan, a University of Ottawa health sciences professor, decided that he wanted to summit the world's highest mountain. However, by the fall of 2001, his dream was in doubt due to his inability to acquire the necessary resources to finance his trek. Although he had approached numerous potential sources, including corporate sponsors, granting agencies, foundations, and his own University, the significant resources necessary to support such an endeavour were not readily available. It was at this point that Dr. Egan asked the author of this thesis (a former research assistant of his) to become involved in the project. In the fall of 2003, Harold Mah - event support manager for the city of Toronto - also joined the core organizing team, followed by Dr. Dave Valliere, Ryerson University Professor in 
Entrepreneurship and Strategy, in the fall of 2004 as Research Director for the expedition.

During the period from early 2000 to early 2004, a number of sponsors (approximately 125 (Egan, 2005a)) had been approached. Considerable interest was generated, however no deals were signed and the expedition date was delayed from spring 2004 (Dr. Egan's original goal (Egan, 2003a)) to spring 2005 with hopes that the extra year would enable the necessary resource generation. Dr. Egan noted (Egan, 2005a) that some positive energy had been created in late 2003 and early 2004 that kept him motivated. First, following a meeting with senior administration at the University of Ottawa, the University had allocated one of its Development Officers (Ric Cuthbertson) to help raise resources for the expedition. In the winter of 2004, Irving, Home Depot and Honda Canada were all sent detailed sponsorship proposals following an initial expression of interest by these organizations (Cuthbertson, 2004). Nothing materialized and Ric left the University shortly thereafter and was replaced by Tony Giampietro a few months later (Egan, 2005b). Second, Dr. Egan and his core organizing team had developed a number of resource-generating strategies that he felt could be successful (Egan, 2005b) although only limited success was ever achieved. These strategies included seeking internal and external research grants and opening up the expedition to other climbers, researchers and trekkers who would pay a premium towards supporting the expedition. As part of the efforts to attract researchers and trekkers, Dr. Egan spent considerable time attending related academic conferences on hypoxia, sport psychology, and mountaineering spreading the word about the expedition (Egan, 2005a). He received over 50 written expressions of interest from researchers from 12 different countries and 6 
would end up joining the trek (Egan, 2005a). Third, Ryerson University in Toronto had come on board as a partner institution on the research aspects of the expedition, with initial plans involving one (1) senior administrator, five (5) professors and two (2) research assistants to join the trek (Luk, 2004). Fourth, a colleague of Dr. Egan's who had been to Everest with him in 1998, Dr. Roger Broughton of the Medical School at the University of Ottawa, joined the team. As one of the world's top sleep researchers, Dr. Broughton immediately took an active planning and fundraising role, particularly with granting agencies (Egan, 2005b), although health reasons forced him to withdraw from the expedition in the fall of 2004 (Broughton, 2004b). Finally, Dr. Egan had successfully ridden his bicycle across Canada in the summer of 2004 generating media attention and building his fitness level.

The Sponsor: Founded in 1981, Kanatek is an Ottawa-based independent systems integrator specializing in data availability, networked storage, and backup and recovery solutions (www.kanatek.ca). Kanatek does business in the private sector, the public sector, and academic marketplaces and its customers include Nortel, Rogers, Government of Canada, Provincial Governments (Ontario and Quebec), Bank of Nova Scotia, CIBC, Bank of Canada, Siemens, Alcatel, Via Rail, and McGill University (Kell, 2004a). In the early 2000 s, Kanatek was seeking a way to (i) increase sales, (ii) send a positive message to its partners and (iii) increase employee satisfaction (Gardner, 2004a; Kell, 2004a) since things were starting to 'turn around' in their market after the crash of the high technology market in the late 1990's when Kanatek's "core industry was failing", the company had decreased in size by $50 \%$ and employee morale was low (Kell, 2005a). 
Throughout 2003 and 2004, Kanatek's President Terry Kell, who lived in the same town (Almonte, Ontario) as Dr. Egan, had heard of the expedition and had discussed it in-person with Dr. Egan who had proposed Kanatek sponsoring the expedition. He brought this idea to Kanatek's management team in late 2003 and, following a review of the potential business impacts, they decided not to pursue the opportunity (Kell, 2004b). However, they also decided to keep 'a close eye' on the development of the expedition and, following a second review of the opportunity in the spring of 2004, the Kanatek senior management team decided to sponsor the expedition (Kell, 2004b). It was noted that the decision to sponsor was "100\% a business decision" (Kell, 2004b). Following some additional discussion amongst the expedition and Kanatek, the contract was agreed to via email on June 10,2004 and the 2005 Kanatek Expedition to Mount Everest (KEME) was born.

\subsection{Identify Sponsorship}

This sub-section is presented in 4 parts; (i) Sponsorship Investigation, (ii) The Sponsorship, (iii) The Expedition, and (iv) Post-Expedition.

Sponsorship Investigation: Following the agreement in June of 2004 on the sponsorship contract, the sponsorship itself was investigated. This involved a review of the contract and regular communication with the President of Kanatek, the Leader of KEME and other expedition members (by email, by phone and in person). From these communications, it was observed that both the sponsor and the sponsee had specific articulated objectives (Egan, 2004a; Kell, 2004a). Both parties were willing to contribute to the evaluation (Egan, 2004a; Egan, 2004b; Kell, 2004a). This sponsorship is an 
example of a typical-sponsee sponsorship situation, where the sponsee sought out many sponsors (with limited success) and where the sponsor had many investment alternatives to achieve their objectives and selected this sponsee. Finally, it was determined that the KEME sponsorship meets all the dimensions of the working definition of sponsorship, as documented in Table 54 below.

\section{Table 54: KEME Sponsorship and Working Definition}

\begin{tabular}{|c|c|}
\hline Dimensions of Operational Definition & How met by KEME Sponsorship \\
\hline $\begin{array}{l}\text { One party (the sponsor) invests resources in } \\
\text { another party (the sponsee), where: } \\
\text { a. the sponsee provides promotional value in } \\
\text { return, and } \\
\text { b. the sponsor makes the investment in order to } \\
\text { achieve image-based, brand-based and/or media- } \\
\text { based objectives. }\end{array}$ & $\begin{array}{l}\text { Kanatek is investing significant resources (cash } \\
\text { and in-kind support) to become the title sponsor of } \\
\text { KEME where the expedition is providing Kanatek } \\
\text { with the opportunity for promotional value in } \\
\text { return. Kanatek has a variety of internal and } \\
\text { external marketing objectives it is seeking to } \\
\text { achieve. }\end{array}$ \\
\hline $\begin{array}{l}\text { The relationship between the sponsor and the } \\
\text { sponsee is a principal-agent relationship, where } \\
\text { the sponsee provides a service to the sponsor. }\end{array}$ & $\begin{array}{l}\text { Kanatek is taking the role of principal and has } \\
\text { contracted the Expedition as its agent to achieve a } \\
\text { variety of marketing objectives. }\end{array}$ \\
\hline $\begin{array}{l}\text { Joint sponsor-sponsee activities are part of the } \\
\text { sponsorship. }\end{array}$ & $\begin{array}{l}\text { The relationship between Kanatek and the } \\
\text { Expedition is such that most KEME activities are } \\
\text { joint activities. }\end{array}$ \\
\hline $\begin{array}{l}\text { Consumers (or members of the target market of } \\
\text { the promotion) are exposed to three specific } \\
\text { entities: the sponsor's brand, the sponsee's brand } \\
\text { and the sponsor-sponsee association. }\end{array}$ & $\begin{array}{l}\text { In addition to Kanatek and the Expedition (Dr. } \\
\text { Egan), the sponsorship focuses its promotions on } \\
\text { KEME via a variety of activities (e.g., blog, } \\
\text { conferences, media). }\end{array}$ \\
\hline $\begin{array}{l}\text { Consumers (or members of the target market of } \\
\text { the promotion) consider the sponsor of a given } \\
\text { sponsee to be a partner of that sponsee, and this } \\
\text { consideration lasts longer than the sponsorship } \\
\text { due to the goodwill or emotional ties that } \\
\text { consumers build over time. }\end{array}$ & $\begin{array}{l}\text { KEME promotes all of its sponsors as partners in } \\
\text { enabling Dr. Egan's summit quest and in } \\
\text { supporting the international research team. } \\
\text { Kanatek's technology support is particularly } \\
\text { noted. }\end{array}$ \\
\hline $\begin{array}{l}\text { The sponsor-sponsee association is exploited or } \\
\text { leveraged by one or both parties. }\end{array}$ & $\begin{array}{l}\text { Both the Expedition and Kanatek have extensive } \\
\text { plans to leverage the sponsorship. }\end{array}$ \\
\hline $\begin{array}{l}\text { The transfer of elements of the sponsee's image } \\
\text { to the sponsor is of interest to the sponsor. }\end{array}$ & $\begin{array}{l}\text { Kanatek seeks to demonstrate its ability to } \\
\text { function in an extreme environment, an element of } \\
\text { the Expedition. }\end{array}$ \\
\hline $\begin{array}{l}\text { The exclusivity of the sponsorship is of interest } \\
\text { to the sponsor. }\end{array}$ & As per the sponsorship contract. \\
\hline $\begin{array}{l}\text { Congruency (fit) between the sponsor and the } \\
\text { sponsee is important to both parties. }\end{array}$ & $\begin{array}{l}\text { Given that this is a typical-sponsee situation, } \\
\text { Kanatek had many options before determining } \\
\text { that this was best (fit) option. }\end{array}$ \\
\hline $\begin{array}{l}\text { Philanthropy is not the primary objective of the } \\
\text { sponsor (i.e. the investor has non-philanthropic } \\
\text { expectations from the sponsorship). }\end{array}$ & $\begin{array}{l}\text { Kanatek's decision to sponsor is "100\% a } \\
\text { business decision". }\end{array}$ \\
\hline
\end{tabular}


The Sponsorship: Following the contract signing and leading up to the event, the association between Kanatek and KEME took form mainly through a variety of associated events. First, on July 22 and 23, 2004, an important planning session was held in Toronto, Ontario involving all major stakeholders. Second, on September 14, 2004, Terry Kell chaired a sponsorship meeting in Toronto where the related activities of KEME were discussed. Third, the 2004 Kanatek Annual General Meeting (AGM) was held on October 1, 2004. The entire AGM (both content and organization) was organized around an Everest theme. Dr. Egan and the author of this dissertation attended and presented to 75 Kanatek staff, technology partners (i.e., Sun Microsystems, Hewlett Packard, StorageTek, Veritas Software, GE Access, Aventi, Quantum) and suppliers. The Everest-themed AGM was dubbed a success (Kell, 2004d; Gardner, 2004b). Finally, on March 1 and March 3, 2005, Kanatek ran two technology conferences related to the expedition (one in Toronto and one in Ottawa) around the Everest theme that targeted technology industry professionals.

Kanatek took a lead role in recruiting additional sponsors and supporting partners for KEME. These partners are listed in Table 55 below:

\section{Table 55: 2005 KEME Sponsors}

\begin{tabular}{|l|l|}
\hline Type of Sponsor & Sponsor \\
\hline Title Sponsor & Kanatek \\
\hline Supporting Sponsors and & HP, SkyWave Mobile Communications, Energizer, CV \\
Partners (in-kind and product & Technologies (Product: Cold FX), Rogers Television, Urban \\
contributions only) & Voyageur (equipment and clothing), Usana Health Sciences \\
& (vitamins), 1972 Team Canada Hockey, University of \\
& Ottawa, Ryerson University, Carleton University, \\
& Brown University (Rhode Island, USA), Peninsulat Private \\
& Sleep Laboratory, Sydney, Australia \\
\hline
\end{tabular}


Following the contract agreement, an aggressive media campaign was launched by Kanatek and the Expedition that included (i) media spots (TV, radio, newspaper), (ii) a blog managed by Kanatek that eventually hit an estimated 100,000 readers (Kell, 2005a; Kell, 2005b), (iii) industry conferences, (iv) a special hockey game played at Base Camp ("The World's Highest Hockey Game") that achieved considerable media attention (including a mention on the $\mathrm{CBC}$ evening news with Peter Mansbridge), (v) sponsorship from the famed '1972 Team Canada' hockey team, (vi) calls to elementary schools from the mountain by Dr. Egan, satellite feeds to the blog from the mountain, and (vi) the filming of a documentary (yet to be released as of December 2006).

The Expedition: The date for the trek was finalized and the team was developed after the sponsorship contract was signed. Following the final deadline for enrollment fees on November $30^{\text {th }}, 2004$, the team was finalized at 21 members, including one climber, 8 trekkers, and 12 researchers. The sole climber and expedition leader was Dr. Egan. He was also the only one to have previously been to Everest. The 12 researchers, included the author of this dissertation, as well as people from Carleton University, Ryerson University, the University of Ottawa, the University of Sydney Sleep Institute (Australia) and Brown University (USA). The trekkers included a camera crew (Rogers), sponsors, and hikers of varying abilities.

The multi-project, multi-party, multi-research expedition of 21 left for Everest in March and April of 2005. A support team of 48 people accompanied the trek; including 2 cooks, 8 kitchen helpers, 25 porters, 5 yak drivers, 7 Sherpa, 1 manager and 16 yaks. The three month agenda for KEME involved a general schedule, with some customizations organized for the various groups (researcher, climber, trekker, and media crew) based on 
their roles and the details of their work. An outline of the general schedule is provided in table 56 below

Table 56: 2005 KEME Planned Itinerary

\begin{tabular}{|c|c|}
\hline Date & Description \\
\hline March 24, 2005 & Depart Canada for Nepal \\
\hline March 26-29,2005 & $\begin{array}{l}\text { Katmandu - sport tourism research trek preparation, media stuff, } \\
\text { etc. }\end{array}$ \\
\hline March $30^{\text {th }}, 2005$ & Main expedition fly to Lukla, begin trek \\
\hline March $30^{\text {th }}$ to April 4 & Sport tourism research continues in Katmandu \\
\hline April 1-8, 2005 & Trek to Base Camp \\
\hline April 8-12, 2005 & Research activity at base camp, summit preparations \\
\hline April $12-16,2005$ & Researchers trek back to Katmandu \\
\hline April 12 to April $30^{\text {th }}$ & $\begin{array}{l}\text { Preparation, planning, ascents to various camps and summit } \\
\text { attempt of Everest (weather dependant) }\end{array}$ \\
\hline May $30^{\text {th }}, 2005$ & Sean Egan's return from Everest \\
\hline June, 2005 - June, 2007 & Leveraging plan to promote the sponsors and the expedition \\
\hline
\end{tabular}

From a business point of view (organization, fund-raising, marketing, etc.) and from a research/trekker point of view (all trekkers achieve their climbing goals, all research complete), the expedition was a resounding success that exceeded expectations (Kell, 2005b) until the tragic loss of Dr. Egan's life during his summit attempt on April 29, 2005. This tragedy significantly altered the sponsorship and its evaluation.

Post-Expedition: The loss of Dr. Egan was difficult emotionally for many of the team members (Kell, 2005b) and led to the cancellation of most of the planned marketing activities to leverage an expected summit attempt and the research output (Kell, 2005b). In fact, a series of post-event conferences, speaking engagements and other promotional activities (all outlined in the contract) were cancelled (Kell, 2005b). Furthermore, the tragedy and experience had a profound effect on Kanatek President Terry Kell leading him to drastically change his personal lifestyle (Gardner, 2005a), which reduced the ability to evaluate the sponsorship. This was principally driven by the fact that Terry Kell 
embraced Dr. Egan's messages of healthy living and removed himself from the day-today operations of Kanatek to focus on other aspects of his life (Gardner, 2006a; Kell, 2006b).

However, some of the objectives of the sponsorship were still addressed and new charitable efforts resulting from the tragedy were also developed; largely to honour Dr. Egan and extend his legacy (Gardner, 2006a). As of January 2007, a major ongoing fundraising effort to build a school at the 'Child Haven' Canadian orphanage just outside of Katmandu in Dr. Egan's name was approximately a year from completion. The effort was developed by the 'Ad-Astra' group ('ad astra' was an often-heard Dr. Egan quote meaning 'aim high'). The mission of Ad-Astra, which was started and managed by expedition team members, was to build the school to honour Dr. Egan and to promote many of the ideas that Dr. Egan believed in (www.adastra-aimhigh.com). As of December 1,2006 , approximately $\$ 140,000$ of the $\$ 150,000$ required had been raised from a variety of fund-raising and message-sharing activities, including (i) two annual charity golf tournaments in Ottawa that raised $\$ 70,000$ combined, (ii) an art show called "A Show of Love" in February 2006 held in Dr. Egan's hometown of Almonte which donated $50 \%$ of its proceeds, (iii) presentations and tributes at the 'Green Door Restaurant Evening' held in Ottawa on January $30^{\text {th }}, 2006$, (iv) a tribute to Dr. Egan in January 2006 in Sherbrooke, Quebec by Gabriel Filippi, who successfully climbed Everest in 2005, where all proceeds were donated to Ad Astra, (v) a unique fundraiser organized by Dr. Egan's nephew, Gordon Hassett, in Ireland where he grew his hair for 15 months and organized a 'shaveathon' where people sponsored him to shave it off, (vi) two Nepalese nights jointly organized by Expedition members and the Nepalese- 
Canadian community were held at a Nepalese restaurant in Toronto in the fall of 2005, (vi) an Ad-Astra Christmas Card drive in December 2005, (vii) a photography exhibit in Almonte, (viii) seminars given by expedition members to organizations around the Everest theme, (ix) a $40^{\text {th }}$ birthday party turned into a $\$ 4,000$ fundraiser by one expedition member, and (x) a campaign kick-off for Ad-Astra on June 2005 that included an auction of 250 items of expedition paraphernalia which generated over $\$ 20,000$.

\subsection{Build Relationships}

Prior to committing to the evaluation, it was confirmed that relationships were in place with the sponsor (Kanatek) and the sponsee (KEME). No intermediaries were identified as having significant influence on the sponsorship. The relationship on the sponsee side was considered very strong as the researcher was a core team member. On the sponsor side, Kanatek noted strong interest in the evaluation and the relationship developed over time. Full disclosure of information and support from both sides was strong between June 2004 and July 2006 . However, a change in management structure at Kanatek in 2006 included Terry Kell reducing his role in the day-to-day operations at Kanatek and the hiring of a new managing director to take over that responsibility. This, in turn, rendered the evaluation a low priority. 


\subsection{Cost-Benefit Pre-Test}

An informal cost-benefit pre-test was carried out by the author following the signing of the sponsorship contract. This involved (i) consideration of the reach of KEME, (ii) estimation of the size of the sponsorship (Kell, 2004b) and (iii) assessment of the potential impacts of the general objectives expressed or forecasted from the discussions to that point (Kell, 2004c; Egan 2004b). The results of this pre-test indicated that sufficient costs would be incurred and that benefit to both the sponsor and the sponsee was possible, supporting an evaluation.

\subsection{Decision}

Recorded officially in emails between the researcher and Kell (2004c) on September 24,2004 , the 'Go' decision for the evaluation was jointly made during a September 2004 visit to Kanatek headquarters by the researcher. As the Process Model prescribes, a number of steps had been carried out prior to the decision point to determine whether or not to evaluate the sponsorship. These steps were implemented in the spring and summer of 2004 in order to be certain that the process model was worth implementing. Given the relatively small size of the sponsorship and the close proximity of the researcher to the sponsorship, this was done on an ad-hoc basis (i.e., a less formal approach was sufficient given strong relationships and high levels of knowledge).

The decision to evaluate was revisited on four future occasions by both the researcher and the sponsor: (i) following the death of Dr. Egan, (ii) in March 2006 (Kell, 2006b) due to the slow process of dissertation research, (iii) in August 2006 following a change in management structure at Kanatek which put the evaluation process in doubt 
(Kell, 2006a), and (iv) in December 2006 by the researcher following 14 weeks of no response from Kanatek, at which point the decision was made to shelve the evaluation. On each of the four occasions, Kanatek representatives expressed interest in continuing with and completing the evaluation, however it became evident over time that the evaluation was becoming less and less of a priority.

\subsubsection{Step 2: Collect Data Concerning the Sponsorship}

The collection of data for this case study was a lengthy process that was impacted by a few unforeseen events, including (i) the length of dissertation research, (ii) the death of Dr. Egan and (iii) changes in management at Kanatek.

\subsection{Data Gathering}

Following the 'GO' decision of September 2004, background data collection began in an organized fashion as per Step 2 of the Process Model D2. In anticipation of the potential evaluation, however, data had been collected since June 2004. Data was gathered from both the sponsor and the sponsee only. Although no intermediaries (other sponsors, minor partners, suppliers) were determined to be significantly enough involved to be included in the evaluation, at the request of the sponsor (Kell, 2004c) Kanatek's relationship with one of the co-sponsors, HP, was included in the evaluation plan. The data collection process continued until the fall of 2006 and included obtaining and reviewing the documents as described in the following table. 
Table 57: Secondary Data Sources

\begin{tabular}{|c|c|c|}
\hline Document & Source \& Date & Rationale for Retrieval \\
\hline Expedition Business Plan & $\begin{array}{l}\text { Received February 10,2001 } \\
\text { from Expedition Management }\end{array}$ & $\begin{array}{l}\text { Identification of } \\
\text { objectives }\end{array}$ \\
\hline Expedition Budget & $\begin{array}{l}\text { Received February 10,2001 } \\
\text { from Expedition Management }\end{array}$ & $\begin{array}{l}\text { Identification of } \\
\text { objectives }\end{array}$ \\
\hline $\begin{array}{l}\text { Expedition Business Plan } \\
\text { (revised) }\end{array}$ & $\begin{array}{l}\text { Received July 30, } 2003 \text { from } \\
\text { Expedition Management }\end{array}$ & $\begin{array}{l}\begin{array}{l}\text { Identification of } \\
\text { objectives }\end{array} \\
\end{array}$ \\
\hline $\begin{array}{l}\text { Expedition Toronto 2-Day } \\
\text { Retreat Minutes }\end{array}$ & $\begin{array}{l}\text { Received September 14, } 2003 \\
\text { from Expedition Management }\end{array}$ & $\begin{array}{l}\begin{array}{l}\text { Identification of } \\
\text { objectives }\end{array} \\
\end{array}$ \\
\hline $\begin{array}{l}\text { Expedition Business Plan } \\
\text { Revised }\end{array}$ & $\begin{array}{l}\text { Received September 29, } 2003 \\
\text { from Expedition Management }\end{array}$ & $\begin{array}{l}\text { Identification of } \\
\text { objectives }\end{array}$ \\
\hline $\begin{array}{l}\text { Expedition 2-Day Retreat } \\
\text { (Kingston, ON) Minutes }\end{array}$ & $\begin{array}{l}\text { Received May 20, } 2004 \text { from } \\
\text { Expedition Management }\end{array}$ & $\begin{array}{l}\begin{array}{l}\text { Identification of } \\
\text { objectives }\end{array} \\
\end{array}$ \\
\hline Expedition Budget Revised & $\begin{array}{l}\text { Received March 30, } 2004 \\
\text { from Expedition Management }\end{array}$ & $\begin{array}{l}\begin{array}{l}\text { Identification of } \\
\text { objectives }\end{array} \\
\end{array}$ \\
\hline $\begin{array}{l}\text { Expedition Business Plan } \\
\text { Revised }\end{array}$ & $\begin{array}{l}\text { Received May 6, } 2004 \text { from } \\
\text { Expedition Management }\end{array}$ & $\begin{array}{l}\text { Identification of } \\
\text { objectives }\end{array}$ \\
\hline $\begin{array}{l}\text { Email contract agreement } \\
\text { drafted by Terry Kell }\end{array}$ & $\begin{array}{l}\begin{array}{l}\text { Received June 10, } 2004 \text { from } \\
\text { Kanatek }\end{array} \\
\end{array}$ & $\begin{array}{l}\begin{array}{l}\text { Identification of } \\
\text { objectives }\end{array} \\
\end{array}$ \\
\hline Expedition Research Plan & $\begin{array}{l}\begin{array}{l}\text { Received June 15, } 2004 \text { from } \\
\text { KEME }\end{array} \\
\end{array}$ & $\begin{array}{l}\begin{array}{l}\text { Identification of } \\
\text { objectives }\end{array} \\
\end{array}$ \\
\hline $\begin{array}{l}\text { Expedition Toronto 2-Day } \\
\text { Meetings Minutes }\end{array}$ & $\begin{array}{l}\text { Received July 23, } 2004 \text { from } \\
\text { KEME }\end{array}$ & $\begin{array}{l}\text { Identification of } \\
\text { objectives }\end{array}$ \\
\hline $\begin{array}{l}\text { Kanatek Expedition } \\
\text { Objectives Document }\end{array}$ & $\begin{array}{l}\text { Received September 4,2004 } \\
\text { from KEME }\end{array}$ & $\begin{array}{l}\begin{array}{l}\text { Identification of } \\
\text { objectives }\end{array} \\
\end{array}$ \\
\hline $\begin{array}{l}\text { Email response on } \\
\text { evaluation based questions }\end{array}$ & $\begin{array}{l}\begin{array}{l}\text { Received September 24, } 2004 \\
\text { from Kanatek }\end{array} \\
\end{array}$ & $\begin{array}{l}\text { Identification of } \\
\text { objectives }\end{array}$ \\
\hline $\begin{array}{l}\text { Everest Conference Call } \\
\text { Minutes }\end{array}$ & $\begin{array}{l}\text { Received November 12, } 2004 \\
\text { from KEME }\end{array}$ & $\begin{array}{l}\begin{array}{l}\text { Identification of } \\
\text { objectives }\end{array} \\
\end{array}$ \\
\hline $\begin{array}{l}\text { Expedition Team } \\
\text { Documents }\end{array}$ & Received January 29,2005 & $\begin{array}{l}\text { Identification of } \\
\text { objectives }\end{array}$ \\
\hline $\begin{array}{l}\text { Everest Blog Postings from } \\
\text { March } 2005 \text { to December } \\
2005\end{array}$ & Retrieved as posted & Information for evaluation \\
\hline
\end{tabular}

The documents noted in Table 57 were supplemented with considerable personal communication (including over 500 emails and approximately 100 phone calls/conference calls), notably: 
1. Various meetings, lunches, calls and emails with expedition leader Dr. Sean Egan (March 2000 to March 2005).

2. Various meetings, lunches, calls and emails with expedition Base Camp manager Harold Mah (Sep 2004 to Aug 2006).

3. Meeting with Sean Egan and Terry Kell, Ottawa, September 8, 2004.

4. Meetings with various Kanatek employees and partners at the 2004 Kanatek AGM.

5. Meeting at Kanatek Headquarters with Terry Kell (President) and Carol Gardner (Project Manager), June 7, 2005.

6. Various discussions during the expedition (March/April, 2005).

7. Meeting with Terry Kell in Ottawa, October 1, 2005.

8. Ryerson presentation on Everest on November 9, 2005; which included discussions with sponsors, researchers and expedition members.

9. Meetings with Terry Kell and Carol Gardner on February 10, 2006 at Kanatek Headquarters and over breakfast; which included two separate in-depth interviews and the sharing of various internal documents.

10. Meeting with Terry Kell in Ottawa on August 28, 2006.

It should also be noted that Kanatek did its due diligence on the evaluation in order to make sure that the process would meet their needs. This was evident via detailed discussions and follow-up in the spring and summer of 2004 leading up to the formal decision to evaluate in September 2004. Further, following the management change at Kanatek in 2006, the decision to evaluate was re-visited by the new management team where it was not identified as a top priority (Kell, 2006c). This led to the eventual 
decision to stop the data collection process in December 2006 due to a lack of response from the new management team.

\subsection{Attributes of the Sponsor-Sponsee Relationship}

The following attributes of the sponsor-sponsee relationship were observed as per the process model:

- Sponsorship Age: conceived in 2004, the researcher was involved at all stages of this sponsorship; pre-sponsorship, during the contract phase and following the expedition.

- Sponsee Type: this is an instance of a typical-sponsee (see section 2.1.2.5 for definitions of mega-sponsee and typical sponsee).

- Industry Effects: the industries of both sponsor and sponsee are described here:

- Systems Integrators: since the mid-1990's, this industry has been under considerable pressure with all players shrinking in size, including Kanatek and with a large number having exited the business altogether (Kell, 2005b). More precisely, Kell estimated that in the early 1990's, they had 25 direct competitors and that, today, there are about 8 (Kell, 2005b). The fact that the market was beginning to turn around in the early 2000's was an impetus for this sponsorship.

- Everest Expeditions: over 2300 people have reached the summit of Mount Everest over the past 30 years (BBC News, 2005), making the achievement of financial support (sponsorship or otherwise) for an expedition increasingly difficult as the novelty effect has worn off.

- Sponsorship Size: At $\$ 50,000$ (sponsorship fee), this is a small sponsorship ${ }^{46}$.

\footnotetext{
${ }^{46}$ The label of 'medium-sized' sponsorship is based on an author-created scale which views any sponsorship of under $\$ 10,000$ in value as very small; between $\$ 10,000$ and $\$ 100,000$ as small; from
} 
- Phase: At the date of writing (January, 2007), we are 21 months post-expedition.

- Resources: The Kanatek sponsorship is a combination of cash contribution, in-kind investments and related charity and other activities that will benefit both the sponsor and the sponsee. Approximately a quarter million Canadian dollars were invested.

- Level: Kanatek is the title sponsor of the expedition.

- Sponsor-Sponsee fit: Representatives from the sponsor and the sponsee confirm that there is a good strategic fit between Kanatek and KEME (Egan, 2004a, Kell, 2004b; 2004c) because Kanatek would be able to leverage KEME to achieve its objectives and $\mathrm{KEME}$ received the resources it needed from a quality sponsor.

- Leveraging: Both the sponsor and sponsee invested additional funds:

- Sponsor (Kanatek) - A review of sponsorship budgets and reports of senior staff (Gardner, 2005a; Kell, 2005b) supports that Kanatek leveraged the sponsorship significantly but strategically. In addition to the sponsorship fee of $\$ 50,000$, Kanatek estimates that it invested $\$ 250,000$ of cash and in-kind resources (including a $\$ 20,000$ contribution from co-sponsor HP) towards the sponsorship (Kell, 2005c) for a leveraging ratio of 5:1. An example of the strategic leveraging of KEME is the two related 'data-assault' industry conferences built around the expedition. These events had a total budget of $\$ 94,750$ but also generated $\$ 73,000$ in sponsorship from industry partners which reduced Kanatek's overall cost to $\$ 21,750$.

- Sponsee (KEME) - By virtue of research funding, self-investment, and other activities, the sponsee (i.e. climbers, researchers and non-sponsor-related trekkers as very large. 
on the expedition) invested approximately $\$ 300,000$ in additional resources. The composition of the $\$ 300,000$ is varied and from many sources, including individual researcher, trekker and climber fees.

- Pre-existing opinions: No significant pre-existing opinions were observed as expected with a first-time sponsorship (Egan, 2004a; Kell, 2004a).

- Target Market: The Expedition plan outlined seven stakeholders: climbers, researchers on the expedition, researchers for whom the expedition collects data, trekkers, sponsors, charities and media partners. These targets were identified as potential sources of funding, promotional value and/or a cause in need of support (Egan, 2004b). Kanatek's plan outlined 5 target markets: industry, staff, key partners and clients, key prospects and charity. These targets were identified as potential sources of business, promotional value and/or a cause in need of support (Kell, 2004b).

\subsubsection{Step 3: Articulate Objectives}

The third stage of the process model involves articulating the objectives to be evaluated. Following a review of the contract, sponsor input, and sponsee input, the articulation of objectives chart was first drafted in September 2004. The chart was then sent to Kanatek and Dr. Egan and, following the receipt of their continued feedback over the life of the sponsorship, the final version (August 29, 2006) is provided below in Table 58 and includes the formal and the implicit objectives obtained from the data collection. Specifically, objectives and their reach were obtained following review of (i) the sponsorship contract, (ii) marketing plans for each of sponsor, sponsee and co-sponsor, 
and (iii) in-depth interviews (transcripts) with the leaders of the sponsor and the sponsee.

It is important to note that objectives are presented as they were expressed in the contract, documentation or interview transcripts. This research did not involve the construction of the objectives.

Table 58: KEME: Articulation of Objectives, Reach, Activities and Outputs

\begin{tabular}{|c|c|c|}
\hline Data Source & Objective & Reach \\
\hline \multirow{3}{*}{$\begin{array}{l}\text { Contract (emailed on } \\
\text { June } 10,2004 \text { and agreed } \\
\text { to by sponsee same day). }\end{array}$} & \multirow{2}{*}{$\begin{array}{l}\text { To leverage the sponsorship into business } \\
\text { for Kanatek }\end{array}$} & Existing Customers \\
\hline & & New Customers \\
\hline & To raise Kanatek's profile in its market & Kanatek's target markets ${ }^{47}$ \\
\hline \multirow{5}{*}{$\begin{array}{l}\text { Kanatek Expedition Plan } \\
\text { (received September 4, } \\
\text { 2004) }\end{array}$} & $\begin{array}{l}\text { To support Dr. Egan successfully } \\
\text { summiting Mount Everest }\end{array}$ & Expedition \\
\hline & $\begin{array}{l}\text { To demonstrate the successful use of } \\
\text { technology in a hostile environment }\end{array}$ & Blog readers \\
\hline & $\begin{array}{l}\text { To support important scientific research by } \\
\text { Canadian Universities }\end{array}$ & Expedition researchers \\
\hline & $\begin{array}{l}\text { To organize the world's highest hockey } \\
\text { game }\end{array}$ & Expedition \\
\hline & $\begin{array}{l}\text { To raise money for the Child Haven } \\
\text { International orphanage }\end{array}$ & Child Haven International \\
\hline \multirow{5}{*}{$\begin{array}{l}\text { Sponsor Interviews } \\
\text { (Terry Kell on February } \\
7,2005 \text { and Carol } \\
\text { Gardner on February 10, } \\
2006 \text { ) }\end{array}$} & \multirow[t]{5}{*}{ To increase employee morale } & CEO \\
\hline & & Technology employees \\
\hline & & Administrative staff \\
\hline & & Sales team \\
\hline & & Contractors/Sub-contractors \\
\hline \multirow{4}{*}{$\begin{array}{l}\text { Sponsee Interviews } \\
\text { (Sean Egan, October 22, } \\
\text { 2000) \& Business Plan }\end{array}$} & To raise the resources necessary & $\begin{array}{l}\text { Sponsors, Granting Agencies, } \\
\text { Universities, Foundations }\end{array}$ \\
\hline & To provide a great and safe experience & Trekkers, Climbers, Researchers \\
\hline & To promote the benefits of active living & Mass market \\
\hline & To conduct applied academic research & Researchers \\
\hline
\end{tabular}

\subsubsection{Step 4: Establish Metrics}

Metrics and methods for each of the objectives in Table 58 were established and developed. Subsequently some were implemented and many cancelled due to the developments reported in the description of this case. Table 59 below outlines the metrics

${ }^{47}$ Kanatek (Kell, 2004c) defines its target market: "any organization that is managing large amounts of data so government (prov/fed), communications (service providers and tech developers), finance (schedule A banks, tier 2 financials, brokerage firms), and commercials (manufacturers, Pharma, insurance)" 
developed for each of the objectives. Due to the fact that several of the metrics were cancelled or altered during the evaluation, the objectives and their metrics are numbered 1 through 11 with reach only being considered for metrics or methods that were being assessed. A further table (Table 60) delves deeper into such metrics and combines them as certain methods are used to respond to more than one objective. It is important to note that the selection of metrics and methods to measure each objective was based on a collaborative decision-making process between the researcher, Kanatek and KEME vis-àvis resources available and the relative importance of the objective. 
Table 59: KEME Sponsorship Evaluation: Metrics and Methods

\begin{tabular}{|c|c|c|c|c|}
\hline Objective & $\#$ & Reach & Metric and Methods & Rationale for Selection \\
\hline \multirow{2}{*}{$\begin{array}{l}\text { To leverage the } \\
\text { sponsorship into business } \\
\text { for Kanatek }\end{array}$} & \multirow[t]{2}{*}{1} & Existing Customers & \multirow{2}{*}{$\begin{array}{l}\text {-Internal sales and market data from } \\
\text { Kanatek } \\
\text { - Survey of Kanatek sales staff }\end{array}$} & \multirow{2}{*}{$\begin{array}{l}\text {-Sales data is best way to measure } \\
\text { increases in current business while } \\
\text { opinions of sales staff best way to } \\
\text { forecast new business potential }\end{array}$} \\
\hline & & New Customers & & \\
\hline To raise Kanatek's profile & 2 & Kanatek's target market & -Industry survey & -Access to sample \\
\hline $\begin{array}{l}\text { To support Dr. Egan } \\
\text { successfully summiting } \\
\text { Mount Everest }\end{array}$ & 3 & Expedition & -Success of summit attempt & - Clear objective \\
\hline $\begin{array}{l}\text { To demonstrate the use of } \\
\text { Kanatek technology in a } \\
\text { hostile environment. }\end{array}$ & 4 & Blog readers & $\begin{array}{l}\text { - Online survey of blog readers } \\
\text { - Survey/testimonials of Expedition } \\
\text { members }\end{array}$ & $\begin{array}{l}\text {-Access to blog } \\
\text { - Low cost } \\
\text { - Sample of interested individuals }\end{array}$ \\
\hline $\begin{array}{l}\text { To organize the world's } \\
\text { highest hockey game }\end{array}$ & 5 & Expedition & $\begin{array}{l}\text { - Occurrence of hockey game } \\
\text {-Media output }\end{array}$ & - Clear objective \\
\hline $\begin{array}{l}\text { To raise money for the } \\
\text { Child Haven International } \\
\text { orphanage }\end{array}$ & 6 & Child Haven International & -Dollars raised & - Access to financial data available \\
\hline \multirow{5}{*}{$\begin{array}{l}\text { To increase employee } \\
\text { morale at Kanatek }\end{array}$} & \multirow[t]{5}{*}{7} & CEO & -CEO interview & \multirow{5}{*}{$\begin{array}{l}\text {-Willingness to give interview } \\
\text { - Support of Kanatek senior management } \\
\text { - Low cost } \\
\text { - Researcher connection }\end{array}$} \\
\hline & & Technology employees & \multirow[t]{4}{*}{-Employee survey (online) } & \\
\hline & & Administrative staff & & \\
\hline & & Sales team & & \\
\hline & & Contractors/Sub-contractors & & \\
\hline $\begin{array}{l}\text { Expedition: to raise the } \\
\text { resources necessary }\end{array}$ & 8 & $\begin{array}{l}\text { Sponsors, Granting Agencies, } \\
\text { Universities, Foundations }\end{array}$ & $\begin{array}{l}\text {-Achievement of sponsorship } \\
\text { revenue targets }\end{array}$ & - Access to financial data available \\
\hline $\begin{array}{l}\text { Expedition: to provide a } \\
\text { great and safe experience }\end{array}$ & 9 & Trekkers, Climbers, Researchers & $\begin{array}{l}\text { - Survey/testimonials of Expedition } \\
\text { members }\end{array}$ & $\begin{array}{l}\text {-Access to sample } \\
\text { - Willingness to participate high }\end{array}$ \\
\hline $\begin{array}{l}\text { Expedition: to promote the } \\
\text { benefits of active living }\end{array}$ & 10 & Mass market & -Mass market survey & $\begin{array}{l}\text { - Resources available } \\
\text { - Reach representative market }\end{array}$ \\
\hline $\begin{array}{l}\text { Expedition: to support } \\
\text { applied academic research }\end{array}$ & 11 & Researchers & $\begin{array}{l}\text { - Research output survey } \\
\text { - Survey/testimonials of Expedition } \\
\text { members }\end{array}$ & $\begin{array}{l}\text {-Access to research output } \\
\text { - Willingness of researchers to } \\
\text { participate high }\end{array}$ \\
\hline
\end{tabular}


Each of the metrics identified above is listed or merged with similar metrics into the list of data collection details below in Table 60 below. Note the status column where a number of the metrics were cancelled or altered due to the death of Dr. Egan or the management changes at Kanatek.

\section{Table 60: Data Collection Details}

\begin{tabular}{|c|c|c|c|}
\hline Metric & Description & Steps in Methodology & Status \\
\hline -Internal sales data & $\begin{array}{l}\text { Sales figures from the year } \\
\text { preceding expedition to the } \\
\text { year following }\end{array}$ & $\begin{array}{l}\text { Metric cancelled due to change in } \\
\text { management structure at Kanatek (i.e. } \\
\text { data not made available) }\end{array}$ & CANCELLED \\
\hline $\begin{array}{l}\text {-Survey Sales } \\
\text { Staff }\end{array}$ & $\begin{array}{l}\text { Determination of support of } \\
\text { expedition in building } \\
\text { business }\end{array}$ & $\begin{array}{l}\text { Metric cancelled due to change in } \\
\text { management structure at Kanatek. }\end{array}$ & CANCELLED \\
\hline -Industry survey & $\begin{array}{l}\text { Random survey of industry } \\
\text { firms to assess Kanatek } \\
\text { image changes }\end{array}$ & $\begin{array}{l}\text { - Metric cancelled due to death of Dr. } \\
\text { Sean Egan. }\end{array}$ & CANCELLED \\
\hline -Summit & Success of summit attempt & - Progression of expedition & COMPLETED \\
\hline $\begin{array}{l}\text { - Survey of blog } \\
\text { readers }\end{array}$ & $\begin{array}{l}\text { To assess technology } \\
\text { demonstration impact }\end{array}$ & $\begin{array}{l}\text { - Metric cancelled due to death of Dr. } \\
\text { Sean Egan } \\
\text { - Replaced with testimonials of } \\
\text { expedition members }\end{array}$ & COMPLETED \\
\hline $\begin{array}{l}\text { - Research output } \\
\text { survey }\end{array}$ & $\begin{array}{l}\text { Assessment of research } \\
\text { output generated }\end{array}$ & $\begin{array}{l}\text { Survey of researchers on expedition to } \\
\text { ascertain publications completed, in- } \\
\text { progress or planned }\end{array}$ & COMPLETED \\
\hline $\begin{array}{l}\text { - Survey of } \\
\text { researchers on } \\
\text { expedition }\end{array}$ & $\begin{array}{l}\text { Assessment of research } \\
\text { environment and } \\
\text { sponsor/sponsee support }\end{array}$ & $\begin{array}{l}\text { - Survey of researchers on expedition to } \\
\text { ascertain publications completed, in- } \\
\text { progress or planned }\end{array}$ & COMPLETED \\
\hline $\begin{array}{l}\text { - Hockey game } \\
\text { occurrence }\end{array}$ & $\begin{array}{l}\text { Did hockey game happen as } \\
\text { planned? }\end{array}$ & - Testimonials of expedition members & COMPLETED \\
\hline $\begin{array}{l}\text { - Hockey Game } \\
\text { Media Generated }\end{array}$ & $\begin{array}{l}\text { Assessment of promotional } \\
\text { value of hockey game }\end{array}$ & $\begin{array}{l}\text { - Metric cancelled due to change in } \\
\text { management structure at Kanatek. }\end{array}$ & CANCELLED \\
\hline $\begin{array}{l}\text { - Child Haven: } \\
\text { dollars raised }\end{array}$ & $\begin{array}{l}\text { Assessment of impact on } \\
\text { charity }\end{array}$ & $\begin{array}{l}\text { - Metric changed drastically following } \\
\text { death of Dr. Egan as it become the } \\
\text { prime focus of the team around the } \\
\text { building of a school at the orphanage in } \\
\text { his honour } \\
\text { - Metric now is the proportion of funds } \\
\text { raised to complete school }\end{array}$ & COMPLETED \\
\hline -CEO interview & $\begin{array}{l}\text { Assessment of CEO's (Peter } \\
\text { K.) opinion of the } \\
\text { sponsorship }\end{array}$ & $\begin{array}{l}\text { - Metric cancelled due to change in } \\
\text { management structure at Kanatek. }\end{array}$ & CANCELLED \\
\hline $\begin{array}{l}\text {-Employee survey } \\
\text { (online) }\end{array}$ & $\begin{array}{l}\text { Assessment of impact on } \\
\text { employee morale }\end{array}$ & $\begin{array}{l}\text { Metric cancelled due to change in } \\
\text { management structure at Kanatek. }\end{array}$ & CANCELLED \\
\hline $\begin{array}{l}\bullet \text { Achievement of } \\
\text { sponsorship } \\
\text { targets }\end{array}$ & Did sponsee achieve targets & $\begin{array}{l}\text { Comparison of dollars raised to budget } \\
\text { goals }\end{array}$ & COMPLETED \\
\hline
\end{tabular}




\begin{tabular}{|l|l|l|l|}
\hline $\begin{array}{l}\text {-Survey of } \\
\text { Expedition } \\
\text { members }\end{array}$ & $\begin{array}{l}\text { Satisfaction with experience } \\
\text { a year after the fact }\end{array}$ & - Survey of expedition members & COMPLETED \\
\hline $\begin{array}{l}\text {-Mass market } \\
\text { survey }\end{array}$ & $\begin{array}{l}\text { To determine the benefits of } \\
\text { promoting Sean's summit of } \\
\text { Everest at 63 }\end{array}$ & $\begin{array}{l}\text { - Metric cancelled due to death of Dr. } \\
\text { Sean Egan. }\end{array}$ & CANCELLED \\
\hline
\end{tabular}

\subsection{Observations on research process}

The process of developing and implementing this evaluation revealed a number of challenges in sponsorship evaluation, with particular challenges stemming from unexpected external events and permission issues. As seen in Table 60, a number of these research challenges emerged following the death of Dr. Egan on the mountain, as well as via management changes that occurred at Kanatek. Although all parties were aware of the risk, few planned for it, except for the marketing consultant working on the expedition who had a plan in place in case tragedy struck (Gardner, 2006). From a permission point of view, full access to all information and cooperation was provided by both the sponsor and the sponsee until the management changes were implemented at Kanatek and the sponsorship evaluation was dropped as a priority. In terms of budget, expenses for the evaluation were not high for a number of reasons: (i) Kanatek absorbed many of the costs as part of the expedition budget, (ii) the researcher was also an expedition member, (iii) the absence of any mass market based objectives, and (iv) the fact that some data collection exercises were cancelled.

\subsubsection{Step 5: Determine Metrics for Resources and Shirking}

Step 5 involves identifying the resources (inputs and activities) put in place by the sponsor and the sponsee. 


\subsection{Resources and Activities}

The sponsorship fees paid by Kanatek for title sponsorship of the 2005 Everest Expedition were $\$ 50,000$. As noted previously, the $\$ 50,000$ fee was leveraged by a five to one ratio (i.e., approximately $\$ 250,000$ of cash and in-kind contributions). Kanatek's two-year plan for leveraging the KEME sponsorship was termed 'The Kanatek Trek to Base Camp' and involved a number of coordinated activities including: (i) an invitation to key customers, partners and potential customers to come along as trekkers and partake in the experience, (ii) a technology demonstration at base camp over satellite link, (iii) a co-sponsorship program which sought to involve key suppliers and customers in KEME, (iv) technology conferences in Toronto and Ottawa (March 2005), (v) an event kick-off and launch (March 2005), (vi) technology conferences and dinners in Toronto, Ottawa and Montreal (November 2004), (vii) an expedition preparation meeting with trekkers, climbers and researchers (February 2005), (viii) an expedition send-off at the Ottawa and Toronto airports (March 2005), (ix) a welcome back reception for the expedition team (changed to a celebration of Dr. Egan around his funeral in May 2005), and (x) a minimum of four one-day Technology Conferences and Dinners in Ottawa, Montreal, and Toronto (planned for the fall 2005 but later cancelled). Kanatek also leveraged its activities strategically with co-sponsors generating $\$ 73,000$ in sponsorship from industry partners for the conferences and $\$ 20,000$ from HP for co-sponsorship of the expedition.

Kanatek, as title sponsor, also provided significant support to KEME, including (i) providing financial and in-kind support to the expedition, (ii) supporting the various 
research projects ${ }^{48}$, (iii) managing public relations and media events for KEME, (iv) developing and managing the KEME website, (iv) hiring of a base camp manager to support the summit bid, (v) supporting the participation of the Kanatek CEO on the trek, (vi) providing the necessary technology equipment for the trek including satellite links, (vii) providing data back-up services and equipment to the researchers, and (viii) organizing a hockey game at Base Camp, including providing and transporting the necessary equipment. In return, Kanatek required (i) the naming rights to the expedition, (ii) photos of the Kanatek flag (and that of co-sponsor HP) on the summit and at base camp, (iii) the right of refusal on any other sponsor, (iv) the right to bring in other sponsors, (v) the placement of the Kanatek logo (and that of HP) embroidered on clothing of all expedition team members, and (vi) the right to use the expedition to raise money for the charity of Kanatek's choice.

\subsection{Shirking}

The second aspect of Step 5 involves identifying the potential shirking behaviours. In this sponsorship evaluation case study, no evidence of shirking was observed or found. In fact, the opposite occurred, where the sponsor was more supportive, engaged and involved than expected. Their additional involvement included investing additional resources as the process went on, and driving the activities of the charity that was formed following the tragedy on the mountain.

\footnotetext{
${ }^{48}$ Note that Kanatek requested it be acknowledged on all resulting research papers.
} 


\subsubsection{Step 6: Collect and Analyze the Data (Results)}

This step involves implementing all of the metrics by first gathering the necessary data and, second, analyzing the generated results. Given that the effects of 11 objectives were measured using 14 data collection methods, the presentation of these results and analysis is lengthy and complex. In order to present the findings in a coherent way that outlines the process undertaken, 14 short sub-sections are presented comprised of (i) the methodological details of each of the 14 data collection exercises, and (ii) a summary results section and table of the data analysis for each of the 11 objectives.

\subsection{Data Collection Exercises}

The data gathering phase of Step 6 in Process Model D2 is described here with the presentation of the methodological details of each of the 14 data collection exercises.

Data Collection Exercise \#1: Internal Sales Data: In order to assess Objective \#1, Kanatek internal sales and market data, both pre- and post-expedition, was to be provided to the researcher. This was cancelled following the change in management structure at Kanatek. A memo outlining the data requested is attached at Appendix I.

Data Collection Exercise \#2: Survey Sales Staff: The survey was prepared as part of the metric for Objectives \#1 and \#7, but its implementation was cancelled following the change in management structure at Kanatek. A copy of the survey is attached as Appendix J.

Data Collection Exercise \#3: Industry Survey: Kanatek had agreed to provide the researcher with its database of clients and potential clients in its markets. A phone survey was planned to address Objective \#3 with each organization to assess if the KEME 
sponsorship had an effect on Kanatek's profile in these markets. This data collection exercise was cancelled following the tragedy.

Data Collection Exercise \#4: Summit: With respect to supporting the summit attempt (Objective \#4), Kanatek provided all resources requested by the sponsee ( $\$ 50,000$ cash, media support, equipment, clothing and communications). In terms of climbing progress, the expedition was a success at all levels until the tragedy which saw the expedition leader die during his preparations to summit the mountain. At the time, Dr. Egan was 3 weeks into the acclimatization phase and was going back and forth between base camp, camp 1 and camp 2. The objective of attaining the summit was not achieved. Data Collection Exercise \#5: Survey of Blog Readers: One of Kanatek's objectives, the purpose of objective 4 was to demonstrate the ability of technology to support the expedition both in its research and as part of its communications function. The plan was to create an online survey to query blog readers about Kanatek's ability to use technology on Everest and the effects (if any) of that ability on Kanatek's brand and market positioning. This data collection exercise was cancelled following the tragedy.

Data Collection Exercise \#6: Survey of Expedition Members: The survey of expedition members (Appendix $\mathrm{K}$ ) was planned to assess Objectives 9 and 11. Following the cancellation of the anticipated survey of blog readers, it was adapted to also assess Objective 4.

For Objective 4, expedition members were asked to comment on Kanatek's ability to demonstrate the use of technology in a 'hostile' environment via an open-ended question in the survey of expedition members. Of 21 expedition members, 8 responded to the optional open-ended question to provide detailed comments about the technology 
demonstration. Results are mixed, perhaps revealing the group's varied levels of technology knowledge or interest in the technology demonstration. One member summarized the situation:

Objectives of the IT demos were unclear. The technology was unreliable, and inadequate backup plans were in place. Protocol for access to the technology (who can use it, and for what purposes) was unclear. Kanatek spun the "recovery of iPaq data" situation into a version that was somewhat misleading. The VHF radio technology worked fine, but suffered from unclear communications protocols and roles/responsibilities during ascents.

This view was summarized by a few others. One responded: "from what I know (very little), technology did not seem to work well (less than expected)", while another said "the video uplinks did not work, from that perspective I was not thoroughly impressed". A fourth critical viewpoint (tempered with some positive comments) was also provided:

The technology was implemented to get sponsors signed up (\$\$) and was really an afterthought. It was obvious that Kanatek's management thought it was important, but the people working at Kanatek were not directly tasked with helping the effort. Only one or two really cared, and it showed. Had Sean not passed away, it would have been difficult to spin the technology to promote the effort and make the investment worthwhile. Having a backup satellite system (or cables) would have been a good idea. The sat phones, however, worked wonderfully and really gave a feeling of comfort and security. Calling my family from Everest Base camp was one of the highlights of the trip.

Interestingly, these four (4) critical viewpoints were offset by four (4) mostly positive comments, including "good setup of equipment, temperamental due to field condition", "very interesting and impressive", "overall I found the research and experiments fascinating", and "very good but we should have had a communication technologist on the trek".

The majority of the survey was designed to measure the satisfaction of expedition members with their experience (Objective 9). Of the 20 expedition members remaining 
alive, 15 responded to the questionnaire for a $75 \%$ response rate. They were asked a variety of Likert scale and open-ended questions, of which some address specifically the issues of safety and satisfaction. The 5-point Likert scales were structured with responses of very satisfied (1), satisfied (2), neither satisfied nor dissatisfied (3), dissatisfied (4), and very dissatisfied (5). When asked to describe their level of satisfaction with the safety provided, the mean response was a very positive 1.76 with no respondent indicating either dissatisfied or very dissatisfied. Overall satisfaction was asked at two points in time (post-expedition and at the date of completion). The effect of the tragedy on satisfaction was also measured. Levels of satisfaction both post-expedition and 'today' were exceptionally high with means of 1.31 and 1.38 , respectively. In both cases over $50 \%$ of the respondents indicated "very satisfied". When assessing the impact of Dr. Egan's death on their satisfaction, a different 5-point scale was used with a mean of 3.00 resulting (where 3 is 'no change). It should be noted that 3 individuals noted that they were more dissatisfied or much more dissatisfied following the tragedy. An additional open-ended question allowed respondents to further elaborate on their ideas around the expedition and how it might have been a better experience. Twelve responses were provided. Those with particular direction to the sponsorship are presented here. One respondent pointed out that "the role and specific expectations of the main sponsor could have been clearer. We did not know if the sponsor was satisfied or not, during and after the expedition". A second expedition member underlines their high level of satisfaction: "it was a wonderful, life-altering experience for which I will be eternally grateful". A third identifies the lack of medical support as a key issue:

Without the involvement of Dr. Keith [a researcher on the expedition who also happened to be a medical doctor], we would have had NO Medical 
personnel on this trip. This would have been a serious oversight. Given the doctor's contributions to the health and safety of several people, both on our expedition and outsiders, I consider medical personnel essential to this kind of travel.

One of the sponsors on the trek also pointed out a concern they had:

As a sponsor, it would be important on future trips to establish who gets the best spots for banners and promotional photos. Several times flags and banner of small sponsors and non-sponsors found their way into prominent positions early at key photographic sites with no recourse for removal. When a major sponsor pays thousands of dollars to be involved and cannot obtain the same visibility as a non-sponsor, there is an issue. These "visibility" issues should be taken care of up front.

An interesting dichotomy also emerged from two contradictory points. While one expedition member noted that "there was a very interesting dichotomy of science/researcher vs. adventure trekkers in the expedition and the camaraderie that was fostered between interest groups was simply fantastic", another critiqued that there were "too many agendas involved with the expedition...various research projects, technology and sports...should have just focused on three for the entire group".

An important objective of both the sponsor and the sponsee, Objective 11, was to create an environment that was conducive to research. Five of nine researchers responded to the open-ended question about the research environment. Four of them reported a very positive environment and one respondent suggested that the conditions were not ideal for the researcher's work. One respondent noted emphatically that "the expedition was an extraordinary opportunity to test theory under unique conditions", while another said that "doing high-altitude research in this way is very effective. Linking with other researchers provides a very supportive environment of people and equipment, and shared logistics" and added that the experience was "highly recommended!" The only negative respondent 
reported that "support wasn't really provided for my research, it was more of an afterthought, which was disappointing".

Data Collection Exercise \#7: Research Productivity: A survey of researchers on the expedition provided the following assessment of research output (as of October 2006). Results for eight of the nine researchers on the expedition (all except for Dr. Egan) are very impressive as outlined in Table 61 below.

\section{Table 61: Research Output To Date and Forecasted}

\begin{tabular}{|l|c|c|}
\hline \multicolumn{1}{|c|}{ Output } & Already Produced & Forecasted (Expected) in Future \\
\hline Publications (books/journal articles) & 4 & 14 \\
\hline Conference Proceedings & 12 & 4 \\
\hline Conference Presentations & 20 & 4 \\
\hline Projects Ongoing & N/A & 8 \\
\hline
\end{tabular}

\section{Data Collection Exercise \#8: Hockey Game Occurrence: The 'World's Highest}

Hockey Game', Objective 5, was a major undertaking by expedition team members. It was used both to improve the experience for expedition members and as a motivator for media attention. The Hockey Game was evaluated on two levels. First, 'did the event happen?' This was a key assessment given the considerable time and financial investment incurred to setup the hockey game, (design, build and bring the necessary equipment such as sticks, jerseys, nets, pucks up the mountain). This was achieved and the game took place on ice. Players from 6 countries were represented, referees managed the game, and significant media attention was generated (television, newspapers and radio). The second level of evaluation was to survey the expedition members on the success of the game. Based on their testimonials ( 9 provided), expedition members were very satisfied with the game and the benefits it provided. A sample of these views is 
provided here. Expedition members noted that the "hockey game was an amazing concept, executed well. High enjoyment factor and media value", "it was fun", and that it was "a great idea, a superb story". Another went into more detail:

The game was great. Professionally managed with fantastic equipment and rink, given the circumstances. Congratulations to the organizers. It had a huge impression on the other expeditions on the mountain. But the media impact back home was very minimal (it served only as a story hook for newspapers before we left). It should have been televised live, or at least the highlights and score reported. This fantastic opportunity was underleveraged.

A third expedition member's testimonial reveals an incredible personal experience:

Another highlight of the trip!!! The hockey game was a blast and a really needed diversion from the technology and politics...of base camp. So glad that Terry suggested it and really happy to have played in the highest game ever played. Considering that skating was not an option, and pucks would not have worked, I can't imagine how it could have been better. To play in the bright sunshine, under the khumbu glacier, with a Sherpa for a ref, and yaks walking through, was worth all the effort.

A few others, while still demonstrating satisfaction, pointed out some issues with having a game such as this as part of an expedition. One noted that "the link between the hockey game and the expedition was not clear for me (probably not also for media). However, it was well organized and I enjoyed the experience." Another cautioned that "playing any sport activity could have led to injury. Yes we received some media coverage because of the NHL strike so we received some media but the fact jerseys and sticks were sold for charity was very good. Unfortunately not for Child Haven". Finally, another expressed frustration that the event was not leveraged as it could have been: "hockey was outstanding, too bad nothing further was done with it. The momentum was lost and opportunities were not seized and the moment passed. This is a huge post expedition mistake especially when extensive amounts of money were invested". 


\section{Data Collection Exercise \#9: Hockey Game Media Generated: Kanatek}

articulated an objective (Objective 5) that was put on hold following the tragedy and cancelled following the change in management structure at Kanatek. However, an informal assessment of this objective is significant. For example, the game was mentioned by Peter Mansbridge on the CBC evening news, the Hockey Hall of Fame wanted a puck and various Ottawa media outlets provided coverage (Kell, 2005c).

Data Collection Exercise \#10: Funds Raised for Charity: From the beginning of the sponsorship (Egan, 2005a; Kell, 2005c), raising money for charity was an important goal of the expedition (Objective 6). As of December 1, 2006, 90\% of the money required to build the school in Dr. Egan's honour at the Child Haven orphanage in Katmandu, Nepal had been raised. A variety of activities (golf tournaments, theme nights, buy a brick, etc.) had been successful and plans to complete the fundraising were expected. In addition to the school, it is important to note that money was raised for Teen Ranch via the World's Highest Hockey Game (approximately $\$ 25,000$ ) and for Child Haven (pre-tragedy; approximately $\$ 10,000$ ).

Data Collection Exercise \#11: CEO Opinion: As part of Kanatek's objective to increase employee morale (Objective 7), an interview with the CEO of the organization was planned to acquire his opinion. This was cancelled following the change in management structure at Kanatek.

Data Collection Exercise \#12: Employee Online Survey: Employee opinion was also an important component of Kanatek's objective to increase employee morale through the expedition (also Objective 7). The survey was planned for distribution to management, sales staff, contractors, sub-contractors, administrative staff, and 
technology employees. This was cancelled following the change in management structure at Kanatek.

Data Collection Exercise \#13: Achievement of Sponsorship Revenue Targets: The sponsorship deal with Kanatek provided the resources sought by the expedition in its sponsorship plan. This was an important objective of the Expedition (Objective 8) and a necessary one to make the expedition a reality. This included $\$ 50,000$ in cash and $\$ 30,000$ in in-kind services.

Data Collection Exercise \#14: Mass Market Survey: One of the drivers of Dr. Egan's desire to summit Mount Everest was his hope to promote the benefits of active living to people of all ages. The data gathering plan called for an assessment of Objective 10 through a mass market survey (Ontario) of randomly selected respondents. This data collection exercise was cancelled following the tragedy.

\subsubsection{Step 7: Generate and Interpret Outcomes and Impacts}

The final step of the process model involves assessing the outcomes and impacts of this sponsorship evaluation case study on each of the 11 identified objectives. Given the major challenges facing this sponsorship (tragedy and sponsor management changes), the results of the evaluation were not completed as originally planned. However, as table 62 below summarizes, they provide significant insight into the importance of risk management in sponsorship and the importance of senior management support in sponsorship evaluation. 
Table 62: Summary Results: Outcomes per Objectives

\begin{tabular}{|c|c|c|c|}
\hline \multicolumn{2}{|c|}{ Objective } & \multicolumn{2}{|l|}{ Results } \\
\hline$\#$ & Description & $\begin{array}{l}\begin{array}{l}\text { Objective } \\
\text { Obtained }^{49}\end{array} \\
\end{array}$ & Results of Analysis \\
\hline 1 & To leverage the sponsorship into business & N/A & NOT EVALUATED \\
\hline 2 & To raise Kanatek's profile in its market & N/A & NOT EVALUATED \\
\hline \multirow[t]{2}{*}{3} & \multirow{2}{*}{$\begin{array}{l}\text { To support Dr. Egan successfully } \\
\text { summiting Mount Everest }\end{array}$} & Support: Partial & + Strong support of effort provided \\
\hline & & Summit: No & - Tragedy (summit not achieved) \\
\hline \multirow[t]{2}{*}{4} & \multirow{2}{*}{$\begin{array}{l}\text { To demonstrate the successful use of } \\
\text { technology in a hostile environment. }\end{array}$} & \multirow[t]{2}{*}{ Limited } & +4 positive testimonials \\
\hline & & & -4 negative testimonials \\
\hline 5 & To play the world's highest hockey game & Yes & $\begin{array}{l}+ \text { Game played \& media generated } \\
+ \text { Very positive testimonials }\end{array}$ \\
\hline 6 & $\begin{array}{l}\text { To raise money for Charity (pre-tragedy } \\
\text { plans for Child Haven and Teen Ranch + } \\
\text { post-tragedy plan for school in Dr. Egan's } \\
\text { name) }\end{array}$ & Yes & $\begin{array}{l}+ \text { \$'s for Teen Ranch \& Child Haven } \\
+ \text { Post-tragedy: } 90 \% \text { of funds for Egan } \\
\text { school at Child Haven (as of Dec 06) }\end{array}$ \\
\hline 7 & To increase employee morale & N/A & NOT EVALUATED \\
\hline 8 & To raise the resources necessary & Yes & + Kanatek provided full request \\
\hline \multirow[t]{2}{*}{9} & \multirow{2}{*}{$\begin{array}{l}\text { To provide a great and safe experience on } \\
\text { trek }\end{array}$} & \multirow[t]{2}{*}{ Partial } & + Very satisfied with safety and trek \\
\hline & & & - Tragedy (Dr. Egan's death) \\
\hline 10 & To promote the benefits of active living & N/A & NOT EVALUATED \\
\hline 11 & To support applied academic research & Yes & $\begin{array}{l}+36 \text { outputs produced already }(\mathrm{Oct} / 06) \\
+22 \text { future outputs expected } \\
+4 \text { of } 5 \text { testimonials positive }\end{array}$ \\
\hline
\end{tabular}

In summary, the results of the KEME case - although not complete - provide a number of important findings for this dissertation. These are discussed in detail in the conclusion (Chapter 7).

\subsubsection{Summary of Sponsorship Evaluation Case Studies}

Chapter 6 presented two sponsorship evaluation case studies. Each case study included a detailed report on the process of implementing the sponsorship evaluation and provided an evaluation of the sponsorship. The first example, the ATB-EGP sponsorship evaluation case study, was an example of a mega-sponsee situation and involved a complete evaluation of a very complex sponsorship. Extensive results are provided

\footnotetext{
${ }^{49}$ Adopting the same ranking system as developed for the ATB-EGP sponsorship evaluation (see Table 53), the achievement of each objective is measured using a 4-level ranking system (yes, partial, limited, and no) where the levels were defined as follows: yes (objective achieved as desired), partial (considerable but incomplete evidence of successful achievement of the objective), limited (low levels of success, often uncertain), no (no evidence of success). N/A is used to refer to objectives not measured.
} 
including recommendations for model implementation, for sponsorship evaluation and for each of the participating organizations (ATB, EGP and ATB MasterCard). The second example, the KEME sponsorship evaluation case study, was an example of a typical-sponsee situation that was plagued by uncontrollable external events, namely a tragedy on the expedition and a major change in management at the sponsor post-event. Although the sponsor adapted the sponsorship following the impact of the external events, it greatly reduced the value of the sponsorship evaluation to the participating organizations. The learning achieved from both case studies is discussed in Chapter 7. 


\subsection{Summary, Discussion and Conclusion}

The purpose of this dissertation was to apply Agency Theory to sponsorship evaluation and develop a way to conduct sponsorship evaluations in a meaningful, legitimate and reliable fashion. This involved constructing and validating a process model for sponsorship evaluation. The inspiration for the work came from the expressed need of practitioners and an identified gap in the sponsorship literature. Based on these motivations, the dissertation set out to accomplish its major objective of constructing the process model, as well as to address its four specific sub-objectives around the evaluation of sponsorships to support the development of the process model. In this regard, the dissertation reviewed the literature on sponsorship, evaluation, sponsorship evaluation and Agency Theory (i) to improve understanding of the sponsor-sponsee relationship, (ii) to take inventory of current practice, (iii) to articulate the barriers preventing good evaluation, and (iv) to outline the benefits of evaluation.

In pursuing the major objective and the four sub-objectives of this dissertation, a number of contributions to sponsorship theory, Agency Theory and evaluation theory were made, including contributions to practice (e.g., providing a validated, step-wise process model that addresses a specific need) and improvements to our understanding of theory and its application (e.g., the adoption of an Agency Theory framework for sponsorship evaluation).

A draft process model (version D1) was crafted based on the literature review on the topics of sponsorship, evaluation, Agency Theory, performance measurement and sponsorship evaluation. The draft model was then vetted through an iterative testing process that included two phases of extensive empirical work. First, the opinions of 14 
experts representing sponsors, sponsees and agencies were garnered through in-depth interviews to improve the process model (version D2) and to enhance the understanding of the sponsorship relationship and sponsorship evaluation. Second, two sponsorship evaluation case studies were undertaken to test Process Model version D2 and to further improve the Process Model (see version D3).

In an effort to articulate the contributions of this dissertation succinctly, this final chapter is organized in 6 sub-sections that provide a detailed summary of the research. These sections are (i) research conclusions from the sponsorship evaluation case studies, including an updated version of the process model, (ii) contributions to practice, (iii) contributions to theory and the literature, (iv) limitations of the research, (v) suggestions for future research and (vi) a conclusion.

\subsection{Research Conclusions: Sponsorship Evaluation Case Studies}

Building on the literature and on the opinions of expert interviewees, the results and analysis of the sponsorship evaluation case studies serve as a test of the process model. The case studies lead to learning about the implementation of the process model and to the identification of necessary changes. As such, this section of the dissertation is organized in three parts: (i) the summary findings from the two sponsorship evaluation case studies, (ii) the updated process model and (iii) the learning vis-à-vis the methods of implementing the process model. 


\subsubsection{Summary Findings}

The ATB-EGP sponsorship evaluation case study is an example of a successful implementation of the process model. All seven stages of the model were run to completion, final results were generated and recommendations were provided to the participating organizations. This sponsorship evaluation case study was an example of a mega-sponsee scenario where intermediaries were included in the evaluation. In total, 21 objectives and 9 shirking behaviours were assessed. These 30 measurement exercises provided feedback for an improved process model (as will be noted in section 7.1.2), methodological improvements (see section 7.1.3), and a better understanding of the array of objectives available in sponsorship (see section 7.3.4).

The KEME sponsorship evaluation case study is an example of a process model implementation that was successful in some regards but very unsuccessful in others. Most notably, two uncontrollable external factors (a tragedy and a change in management structure at the sponsor) led to the cancellation of a number of the planned data collection exercises, metrics and methods. Although this led to an incomplete evaluation of the 11 objectives of the sponsorship, a number of important contributions to the development of the process model were generated. For example, the need to consider the 'riskiness' of the sponsee was evident as was the importance of having a senior champion within the sponsor or sponsee to ensure that the evaluation is completed. These contributions are noted in sections 7.1.2 (updated process model), 7.1.3 (methodological improvements), and 7.3.4 (better understanding of objectives in sponsorship).

These conflicting case outcomes make for an important discussion point. On one hand, the ATB-EGP case was an example of a near-perfect implementation of the process 
model (funding, legal approval, organizational support, etc.) while the KEME case outlines how the implementation of a well-planned evaluation can be irreconcilably compromised due to uncontrollable factors. Although the compromised outcome of the KEME case could be viewed as a failure from an evaluation viewpoint, from a research point of view it provided for important learning about the process model and identified a number of improvements to the model (see section 7.1.2). Similarly, the near-ideal implementation of the ATB-EGP case provides future researchers with an example of the potential effectiveness of the process model and identifies specific details which require special attention or improvement (also as noted in section 7.1.2).

\subsubsection{Updated Process Model}

The final version of the process model (D3) is presented in Figure 12. It includes the changes made from version D2 coming directly from the results of the two sponsorship evaluation case studies. These changes are outlined in Table 63 below.

Table 63: Changes Made to Process Model Version D3 from Version D2

\begin{tabular}{|l|l|l|}
\hline$\#$ & Change & Rationale/Source \\
\hline 1 & $\begin{array}{l}\text { Include ambush tactics by the sponsor's } \\
\text { competitors in Step 5 (Assess Shirking) }\end{array}$ & $\begin{array}{l}\text { ATB case, non-exclusivity issue with } \\
\text { Capital City }\end{array}$ \\
\hline 2 & $\begin{array}{l}\text { Emphasize the importance of senior } \\
\text { management buy-in added to Step 1, Part 2 } \\
\text { (Build Relationship) }\end{array}$ & $\begin{array}{l}\text { KEME case, Kanatek management } \\
\text { change }\end{array}$ \\
\hline 3 & $\begin{array}{l}\text { Emphasize the importance of legal aspects } \\
\text { (e.g. signing NDA upfront, getting approval } \\
\text { of internal legal departments) in Step 1, Part } \\
\text { 2 (Build Relationship) }\end{array}$ & $\begin{array}{l}\text { ATB case, the diligence of the } \\
\text { sponsor's legal department to ensure } \\
\text { the company was protected must be } \\
\text { respected and considered early on to } \\
\text { prevent problems later in evaluation }\end{array}$ \\
\hline 4 & $\begin{array}{l}\text { Include time to complete the evaluation as } \\
\text { part of the Preliminary Assessment (Step 1, } \\
\text { Part 3) }\end{array}$ & $\begin{array}{l}\text { Both cases revealed the need to } \\
\text { broaden this early assessment of the } \\
\text { sponsorship to reduce risk }\end{array}$ \\
\hline
\end{tabular}




\begin{tabular}{|c|c|c|}
\hline 5 & $\begin{array}{l}\text { Change the title of Step 1, Part } 1 \text { to 'Pre- } \\
\text { Screen Sponsorship' from 'Identify } \\
\text { Sponsorship' to recognize the detailed } \\
\text { nature of the step }\end{array}$ & $\begin{array}{l}\text { Both cases revealed the importance of } \\
\text { fully understanding the sponsorship } \\
\text { and its attributes as early as possible. } \\
\text { This also reflects the fact that Step } 1 \\
\text { is primarily about setting up the } \\
\text { evaluation and determining if the } \\
\text { process model is worth implementing }\end{array}$ \\
\hline 6 & $\begin{array}{l}\text { Reword the sub-point about objectives in } \\
\text { Step } 1, \text { Part } 1 \text { to 'identify measurable } \\
\text { sponsor/ } \\
\text { Sponsee objectives' }\end{array}$ & $\begin{array}{l}\text { Both cases underlined the need to } \\
\text { have measurable objectives to work } \\
\text { with }\end{array}$ \\
\hline 7 & $\begin{array}{l}\text { Add a 'forecast potential shirks' box to } \\
\text { Steps } 2 \text { and } 3\end{array}$ & $\begin{array}{l}\text { ATB case, highlighted the importance } \\
\text { of pre-event research to forecast } \\
\text { potential shirking behaviours }\end{array}$ \\
\hline 8 & $\begin{array}{l}\text { Recognize sponsor, sponsee or intermediary } \\
\text { in-house research professionals as potential } \\
\text { external influences in Steps } 5,6 \text {, and } 7 \text {; and } \\
\text { note that these external influencers impact } \\
\text { all } 7 \text { Steps }\end{array}$ & $\begin{array}{l}\text { ATB case, the role of the ATB } \\
\text { research department underlined the } \\
\text { importance of engaging these groups } \\
\text { early on }\end{array}$ \\
\hline 9 & $\begin{array}{l}\text { Reword the inputs/activities box in Step } 5 \text { to } \\
\text { indicate that inputs and activities are } \\
\text { reported on and not measured in Step } 5\end{array}$ & $\begin{array}{l}\text { Both cases noted a wording problem } \\
\text { in } \mathrm{D} 2 \text { where resources are identified } \\
\text { and shirks are measured in Step } 5\end{array}$ \\
\hline 10 & $\begin{array}{l}\text { Add a sub-point on the attribution issue to } \\
\text { the Step } 4 \text { box that links to 'reach' including } \\
\text { a note that metrics and methods will be } \\
\text { designed to best deal with the issue }\end{array}$ & $\begin{array}{l}\text { Both cases, particularly ATB, noted } \\
\text { the importance of reach in the } \\
\text { articulation of objectives }\end{array}$ \\
\hline 11 & $\begin{array}{l}\text { Extend the reach box to demonstrate that the } \\
\text { concept is part of Steps } 3,4 \text { and } 5\end{array}$ & $\begin{array}{l}\text { Both cases revealed that reach is an } \\
\text { important consideration in these Steps }\end{array}$ \\
\hline 12 & $\begin{array}{l}\text { Move the attributes of the sponsor-sponsee } \\
\text { relationship from Step } 2 \text { and Step } 3 \text { to be } \\
\text { included in Step } 1\end{array}$ & $\begin{array}{l}\text { Both cases noted that such } \\
\text { information should be obtained as } \\
\text { early as possible }\end{array}$ \\
\hline 13 & $\begin{array}{l}\text { Add the word 'collaborative' in front of } \\
\text { selection in Box } 2 \text { of Step } 4\end{array}$ & $\begin{array}{l}\text { Both cases revealed the importance of } \\
\text { working with sponsors, sponsees and } \\
\text { intermediaries to develop and } \\
\text { implement metrics } \\
\end{array}$ \\
\hline \begin{tabular}{|l|}
14 \\
\end{tabular} & $\begin{array}{l}\text { Change the title of Step } 5 \text { from 'determine } \\
\text { metrics for resources and shirking' to } \\
\text { 'identify resources and determine metrics } \\
\text { for shirking' }\end{array}$ & $\begin{array}{l}\text { Both cases noted a wording problem } \\
\text { in } \mathrm{D} 2 \text { where resources are identified } \\
\text { and shirks measured in Step } 5\end{array}$ \\
\hline 15 & $\begin{array}{l}\text { Replace the word 'generate' with the word } \\
\text { 'summarize' in the title box of Step } 7 \text { to } \\
\text { better capture the essence of what the step } \\
\text { accomplishes }\end{array}$ & $\begin{array}{l}\text { Both cases demonstrated that this is } \\
\text { the case in Step } 7\end{array}$ \\
\hline
\end{tabular}


The changes noted in Table 63 are substantive in nature. They are based directly on experiences from the sponsorship evaluation case studies and improve the process model. Following the implementation of these suggested changes, the final version (D3) of the process model represents the core contribution of this dissertation. It contributes to both the literature and to practice. For the literature, it represents the first theory-based process model for the evaluation of sponsorship that is openly shared. It is hoped that this should lead to further testing of sponsorships, to the development of extensions of the process model (e.g. a model specific to Mega-events, a simplified version for implementation with small sponsorships, or a model designed for social marketing sponsorships), and to discussions on its validity both in its operation and its agency theory-based design. Theoretically, this work on the process model supports the distinction of sponsorship from advertising in the promotional mix, which will undoubtedly foster further discussion. For practitioners, the process model will provide both sponsors and sponsees with a tool for the assessment of their sponsorship-related activities. Further, the process model could be used to improve or to collaborate with the developers of other sponsorship evaluation models. As one practitioner noted: "I would like to vet the process model through my own [model for sponsorship evaluation]" (Sp_Exp_1). In addition, the adaptability of the process model to a wide variety of sponsorship situations benefits both academics and practitioners. One of the expert interviewees noted that the model's range goes from "a simple sponsorship... [that] starts with saying 'Joe, what would be important to you?' when Joe is the owner of a local convenience store asked by a group running a local event in the park to be a sponsor...to major sponsorships" (Int_2, 2006). 
Figure 12: Process Model of Sponsorship Evaluation: Process Model D3

\section{Process Model: Sponsorship Evaluation}

\begin{tabular}{|c|c|c|c|c|c|c|}
\hline $\begin{array}{c}\text { Step 1: } \\
\text { SETTING } \\
\text { THE } \\
\text { STAGE }\end{array}$ & $\begin{array}{c}\text { Step 2: } \\
\text { COLLECT } \\
\text { DATA } \\
\text { concerning } \\
\text { the }\end{array}$ & $\begin{array}{c}\text { Step 3: } \\
\text { ARTICULATE } \\
\text { OBJECTIVES }\end{array}$ & $\begin{array}{l}\text { Step 4: } \\
\text { ESTABLISH } \\
\text { METRICS }\end{array}$ & $\begin{array}{c}\text { Step 5: } \\
\text { IDENTIFY } \\
\text { RESOURCES } \\
\text { AND } \\
\text { DETERMINE }\end{array}$ & $\begin{array}{c}\text { Step 6: } \\
\text { COLLECT } \\
\text { DATA \& } \\
\text { ANALYZE }\end{array}$ & $\begin{array}{c}\text { StEP 7: } \\
\text { SUMMARIZE } \\
\& \\
\text { INTERPRET } \\
\text { OUTCOMES }\end{array}$ \\
\hline $\begin{array}{l}\text { 1. Pre-screen } \\
\text { sponsorship }\end{array}$ & sponsorship & & & $\begin{array}{l}\text { METRICS FOR } \\
\text { SHIRKING }\end{array}$ & & 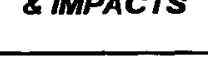 \\
\hline
\end{tabular}

*Must meet

definition

dimensions

*Identify

measurable

sponsor/see

objectives

*Sponsee: Mega

or Typical?

"Forecast

assess relevancy

*Describe

sponsorship

relationship and

its attributes (e.g.

size, phase,

industry, cash/in-

fit etc)

2. Build relationship achieve buy-in with \& legal, attain belief

in value to be

provided, and

articulate need for

evaluation with (i)

Agent, (ii) Principal

(iii) Others

3. Preliminary Assessment: cost-benefit pre-test + time

4. Decision: GO/NO GO

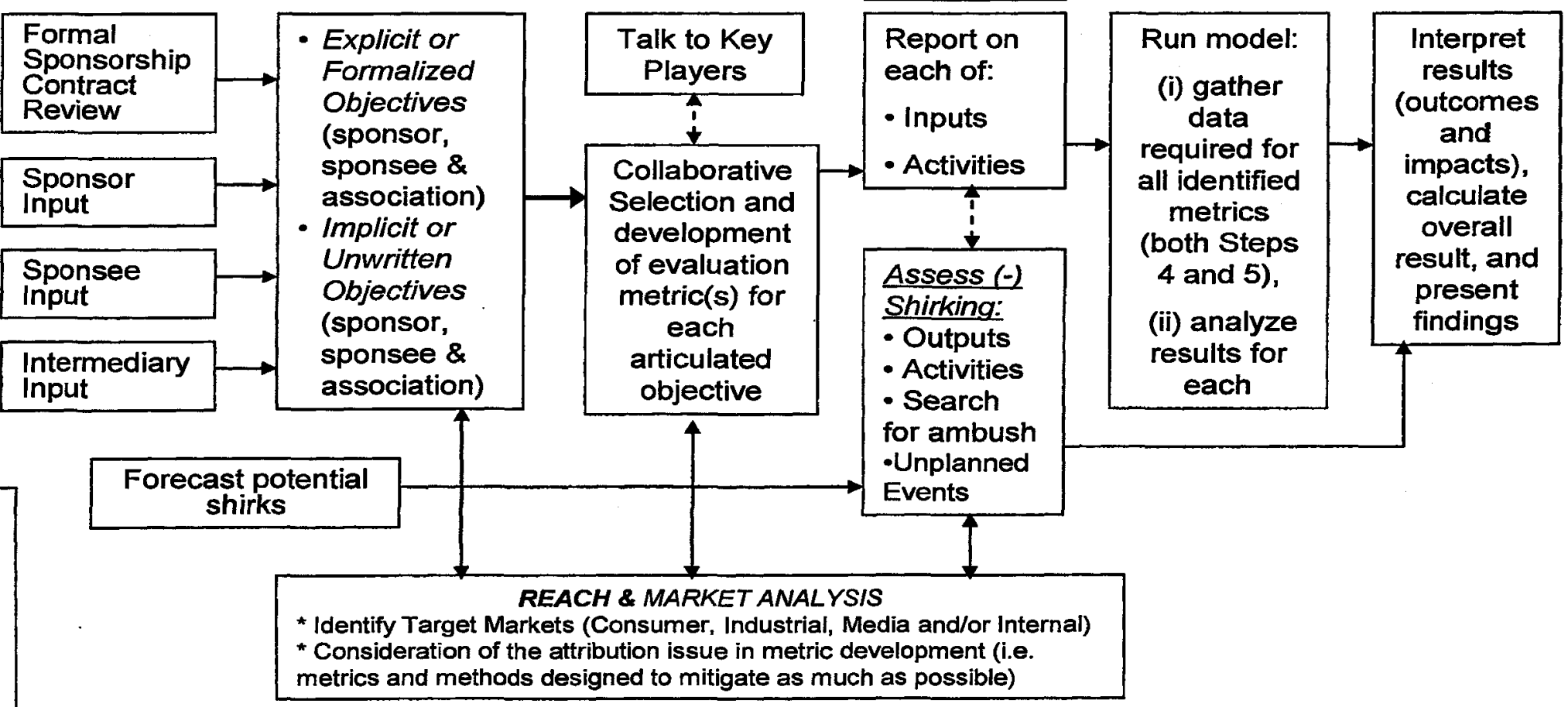

EXTERNAL INFLUENCERS (to be considered in all 7 Steps of the model) - Many external factors influence variables (e.g. sales, competition, economy, etc.) - Measuring behaviours

- Co-sponsoring effects and activities

-Involvement of in-house research professionals (sponsor/sponsee) encouraged 


\subsubsection{Methods and Implementation}

Methodologically, the implementation of the model in both sponsorship evaluation case studies was shown to be a risky, lengthy and resource-intensive research procedure. The changes suggested in process model version D3 (Figure 12) will help mitigate this risk. A number of additional recommendations are provided here to improve the implementation of the process model. For example, results from the sponsorship evaluation case studies support the recommendations (i) that evaluations be included in sponsorship contracts so that sufficient budgets for evaluation are allocated at the onset of a sponsorship, (ii) that researchers doing an evaluation prioritize the objectives to be measured in order to efficiently allocate metrics and methods to maximize the value of the evaluation, and (iii) that the necessary thought and planning goes into determining who collects the data for each objective to minimize any bias that may exist.

The results of the sponsorship evaluation case studies also highlight the learning about the implementation of the process model in addition to the 'how-to' description provided earlier with version D1. Specifically, seven directions for the future use of the process model were identified and each is explained briefly here. First, sponsorship evaluation researchers are directed to get a copy of the final version of the sponsorship contract(s) early and prior to making a decision on whether to proceed. In the ATB-EGP sponsorship evaluation case, a final version of the sponsorship contract was not received until the days prior to the event which resulted in the occurrence of two 'potentiallyavoidable' shirking behaviours due to the contract. Second, the important role of MasterCard in the ATB-EGP sponsorship demonstrates that a sponsorship evaluation researcher must make a concerted effort (as the process model notes) to determine and 
include all intermediaries and their objectives. Third, the definition of 'shirk' must be broadened to include behaviours that ambush the sponsorship or any of the objectives sought by any sponsor, sponsee or intermediary. Fourth, sponsorship evaluation researchers are encouraged to plan for the long-term nature of evaluation, both in terms of measurement and implementation. In the ATB-EGP case, the need to measure a number of the objectives (e.g., customer acquisition) again in 12-18 months demonstrates the long-term nature of some measurements, while results from the KEME case emphasize the long-term nature of implementation and the accompanying risks. Fifth, results from both sponsorship evaluation case studies support the need to have established senior contacts in all involved organizations. Sixth, particularly when researchers are not well versed in the dynamics of the sponsor's industry and the sponsee's industry, they must dedicate time to learn such. This point was evident with Kanatek, a B2B company, whose industry was a challenge to define and understand. Finally, the importance of accessing confidential qualitative data from all sides (sponsor, sponsee, intermediary) as early as possible was learned in the ATB-EGP case, where the lack of confidential input from the sponsee (i.e., not via the sponsor) until post-event limited the effectiveness of the evaluation.

The determination of metrics and methods to measure identified objectives is also noted as an important aspect of implementing the process model. The ATB-EGP and KEME case studies both included data collection instruments with weaknesses (e.g. retrospective questions in expert interviews and on surveys, alternate methods adopted for resource reasons) that are acknowledged. As noted in Version D3 of the process 
model, researchers need to prioritize objectives, metrics and methods vis-à-vis the resources (human, financial and time) available.

\subsection{Contributions to Practice}

As noted above, results from the sponsorship evaluation case studies support the decision making of sponsors, sponsees and intermediaries. Most importantly, these practitioners are provided with a process model for sponsorship evaluation. By providing a validated, 7-stage process model, this research addresses a need that was expressed by both practitioners (e.g., Mark Harrison, personal communication, October 27, 2002) and in the literature (Crompton, 2004a; Mullin, Hardy \& Sutton, 2000; Milne \& McDonald, 1999; Berrett, 1993). In this regard, it is of particular importance to note that the process model demonstrates that evaluation methods specific to sponsorship (i.e., distinct from those designed to evaluate advertising) are required as suggested by a variety of previous studies (e.g., Cornwell, Pruitt \& Clark, 2005; Belch \& Belch, 2001; Tripodi, 2001; Shimp, 1997; Cornwell, 1995). The fact that advertising and sponsorship function differently (Bloxam, 1998) is at the heart of this distinction and is supported in a number of ways by the process model which (i) considers the objectives of all parties (sponsors, sponsees, and intermediaries) in the evaluation, (ii) views the sponsorship relationship from the point of view of the consumer who typically is exposed to three distinct images - the sponsor, the sponsee and the association between them - where the sponsorship can support the transfer of images between the three, (iii) prioritizes objective specificity in its design, and (iv) has adopted Agency Theory as a framework that allows for clear understanding of the evaluation process. 
For practitioners, the process model will provide sponsors and sponsees, as well as agencies providing evaluation services, with a tool for the assessment of their sponsorships. The inclusion of the 'how-to' guide, the detailed steps with GO/NO GO decision points, and a graphical depiction of the model will facilitate and, ideally, encourage its use in practice. The fact that the model is also adaptable to any sponsorship situation should also be attractive to potential users as it distinguishes it from previous models in the literature (e.g., Cornwell, Pruitt \& Clark, 2005; Cornwell, 1995; Pope \& Voges, 1994; Irwin \& Asimakopoulos, 1992). It was also noted in the expert interviews, that the process model could be used to improve or collaborate with other models currently in use.

\subsection{Contributions to Theory and the Literature}

This dissertation involves applied research. As such, it is more about applying and understanding theory than it is about building theory. However, it does take some important steps in developing theory in sponsorship evaluation as insight is provided towards responding to the various challenges facing sponsorship (Weick, 1995) through the construction and testing of the process model for sponsorship evaluation (Swenson, 2001; Sutton \& Staw, 1995).

The research adopted an Agency Theory perspective to sponsorship evaluation and it developed a process model that was then tested through (i) expert interviews and (ii) two sponsorship evaluation case studies. Contributions were made to the literatures of Agency Theory, sponsorship, sponsorship evaluation and objectives. Each of these areas is discussed separately in the following four sub-sections. 


\subsubsection{Contributions to Agency Theory}

Agency Theory was adopted to provide the theoretical foundation for the dissertation where the sponsor-sponsee relationship is viewed as an instance of cooperative effort in a principal-agent relationship, where the sponsee/agent acts on behalf of the interests of the sponsor/principal (Bahli \& Rivard, 2003). As noted throughout this dissertation, contributions in this regard from Agency Theory to theory development are tri-directional as (i) the use of Agency Theory provided focus, structure and clarity to sponsorship evaluation, (ii) Agency Theory provided the framework for the Process Model supporting its development, and (iii) viewing sponsorship evaluation through an Agency Theory lens further developed the theory and its applicability to marketing practice.

Based on the direction of scholars (Bergen, Dutta, \& Walker, 1992; Eisenhardt, 1989), Agency Theory was selected from a set of relationship theories as the theoretical framework for this dissertation. The fact that Agency Theory was selected supports the work of Bergen, Dutta and Walker (1992) who noted that Agency Theory has a role to play in the marketing literature. In addition, the use of Agency Theory in an evaluation setting widens its range of its applicability beyond viewing relationships to evaluating the effectiveness of relationships. Adopting Agency Theory's unit of analysis - the contract as the basis of measurement within the evaluation is critical to this point. This is a significant contribution and one which fits with calls from the Agency Theory literature to expand the scope of its application (Eisenhardt, 1989) and could lead to additional research in the area. The finding that Agency Theory works well in the sponsor-sponsee 
relationship is also a contribution as it demonstrates that Agency Theory can work in complex, B2B relationships as well as its typical purview of employer-employee and Board-CEO relationships (Bergen, Dutta, \& Walker, 1992; Jensen, 1983; Jensen \& Fama, 1983; Jensen \& Meckling, 1976).

Agency Theory provided a lens by which to evaluate a sponsor's investment in a sponsee and the resulting relationship's ability to achieve both the sponsor's and the sponsee's specific objectives. As outlined in Chapter 4, this fills a gap in sponsorship evaluation by providing the theoretical framework sought by both academics and practitioners that will enable the effective and efficient measurement of sponsorship effectiveness.

Another important contribution of Agency Theory to sponsorship evaluation lies in the expansion of the definition of the contract to include both the tenets of the formal written contract and the understood but unwritten aspects of the relationship; namely the informal contract. In turn, this expanding definition leads to a broader consideration of objectives for evaluation and the identification of those objectives (the informal ones) that are often neglected in evaluation (see Newburn 2001; Sandler \& Shani, 1993). Further, the consideration of intermediaries and their objectives stems from Agency Theory and is an additional important contribution to sponsorship evaluation.

\subsubsection{Contributions to Sponsorship Theory}

In addition to the major contribution of the process model to the sponsorship evaluation literature, this dissertation sought to achieve 4 sub-objectives related to improving the understanding of the sponsorship relationship required to construct the 
process model. As such, the process of addressing these 4 sub-objectives represents the main contributions of this dissertation to the sponsorship literature. First, viewing the sponsor-sponsee relationship as a version of a principal-agent relationship was shown to have merit, particularly as a way by which to evaluate the relationship. In this regard, Agency Theory put the focus on the contract (explicit and implicit) as the unit of analysis which, in turn, put the focus on identifying and measuring only those objectives and shirking behaviours related to the contract (Bergen, Dutta, \& Walker, 1992; Eisenhardt, 1989). Second, the inclusion of performance evaluation theory in combination with Agency Theory to look at sponsorship evaluation was beneficial to the development of the process model, particularly in emphasizing the importance of reach (i.e., the target(s) sought for each objective) and separating the results by impacts and outcomes to recognize the influence of time and challenges of attribution and intent in measurement (Capko, 2003; Heslop \& Fadaie, 2002). In the ATB-EGP sponsorship evaluation case study, for example, the use of the concept of 'reach' led to the identification of 21 objectives as opposed to 18 , while for the KEME sponsorship evaluation case study, it allowed for the targets of two of the objectives to be further specified to 2 and 5 targets, respectively. Third, results from both sponsorship evaluation case studies provide considerable direction to sponsors, sponsees and intermediaries for future business/promotion decisions. For example, in the ATB-EGP sponsorship evaluation case, detailed and specific recommendations were provided to ATB, EGP and MasterCard. Fourth, the applied nature of the dissertation should be noted. Specifically that it recognizes that each sponsorship is unique and that it develops an adaptable 
process model for practitioners that was developed with the input of industry experts and tested on two 'real' cases of sponsorship.

In addition, this dissertation makes a strong contribution to the sponsorship literature by emphasizing analysis on the sponsee as an equal contributor to the sponsorsponsee relationship. Similarly, it also responds to Shank's (1999) suggestion and broadens the definition of the sponsee, including proposing the mega-sponsee/typical sponsee scenarios. Other authors had previously noted this as a weakness in the sponsorship literature (Cornwell \& Maignan, 1998) and some prior definitions of sponsorship had focused entirely on the sponsor (Dean, 1999; d'Astous \& Bitz, 1995).

Finally, the generalizability of the process model to any sponsorship is an important contribution to the sponsorship literature as it recognizes and emphasizes the principle that each sponsorship relationship is unique and that each should be evaluated accordingly. Although only two case studies have been tested to date, the resulting process model is adaptable to all potential sponsorship scenarios and will be improved as testing continues.

\subsubsection{Contributions to Sponsorship Evaluation Theory}

The most important contribution of this dissertation is its delivery of version D3 of the process model for sponsorship evaluation. Although the model cannot yet be referred to as theory, it provides impetus for future research and, over time and through additional testing could develop into theory. In terms of this contribution specific to the sponsorship evaluation literature, it represents the first theory-based process model for 
the evaluation of sponsorship that will be openly shared with the academic and business communities.

Considering the limited pre-existing theory in sponsorship evaluation (Walliser, 2003; Harvey, 2001; Meenaghan, 2001; Olkkonen, 2001), the overall impact of this work on sponsorship evaluation theory is considerable. A process model specifically designed for sponsorship evaluation has been carefully constructed from three bodies of literature and consultation with experts. Following a pre-test, it was then tested in two extensive and very different sponsorship evaluation case studies. Throughout this process, three versions of the model were presented with the resulting third draft (version D3) ready for use in practice and for continued testing and development by researchers. Continued testing, broadened application and structured assessment of each 'box' in the process model will also continue to improve and build much needed theory on sponsorship evaluation.

\subsubsection{Contributions to the Literature Related to Objectives}

Objectives, or goals, are of the utmost importance to this dissertation as the process model, in taking an Agency Theory approach, carries out a process of evaluation that is based on the implicit (informal) and explicit (formal) objectives of the sponsor, sponsees and relevant intermediaries. It is these objectives that form the basis for the metrics and methods that are implemented to measure the effectiveness of the sponsorship.

Practically, the results of the dissertation point to two important aspects of objectives that are noted in version D3 of the process model. First, the lack of clear, 
measurable objectives as a challenge in sponsorship evaluation is evident in both sponsorship evaluation case studies and is noted in the literature (Crompton, 2004a; Cornwell \& Maignan, 1998; Berrett \& Slack, 1995; Berrett, 1993). Version D3 of the process model notes this finding and specifies that an evaluation would not proceed unless proper objectives are provided. Second, and this is a finding exclusive to this dissertation, is that there is a need to prioritize objectives vis-à-vis the resources available to measure them (human, financial and time). Specifically, it is unlikely that the necessary resources for a complete evaluation would ever be available, thus decisions must be made to prioritize objectives, reach, metrics and methods. It is suggested that this would involve framing a set of possible of objectives for each sponsorship and then selecting metrics and methods based on the priority of objectives, the ability to measure and the cost of the research. This is noted in version D3 and is seen as an important contribution.

As noted in Appendix A, 61 different sponsorship objectives were identified in the literature. These objectives were many and included a vast array of objectives ranging from enhancing corporate image (Pope \& Voges, 1998) to increasing television coverage (Liu, Putler \& Weinberg, 2004; Erdogan \& Kitchen, 1998) to encouraging product sales (Crompton, 2004a) to entertaining clients (Pope \& Voges, 1998) to blocking competition (Irwin \& Sutton, 1994). The current research explored 32 different objectives (21 in the ATB-EGP sponsorship and 11 in the KEME sponsorship), including seven that were new (or newly adapted) to the literature including (i) impacting key prospects (top 1\%), (ii) improving brand prestige in current customers, (iii) re-branding ATB from being viewed primarily as a small town Alberta bank to a full-service provide-wide bank, (iv) 
demonstrating the successful use of technology in a hostile environment, (v) supporting important scientific research, (vi) organizing the world's highest hockey game, and (vii) promoting the benefits of active living. These additions to the objectives in the literature and their accompanying metrics and methods are a contribution to future research in sponsorship evaluation.

\subsection{Limitations of this Research}

It is also important to recognize the limitations of this dissertation, particularly with respect to the process model. Eight such limitations were identified. First, as noted in the literature review on sponsorship evaluation, the attribution by self-opinion in the context of multiple influences is very difficult to evaluate. There is no ideal solution, however metrics grounded in a clear objective that asks aided and unaided questions with options to select competing influences can allow for a reasonable estimate of the influence of a sponsorship on particular image, branding, or awareness objective. Second, the sponsorship evaluation literature review also stressed the challenges in measuring intent to behave (e.g., intent to purchase) since the respondents ability to express if the intent will actually turn into behaviour is difficult to ascertain. This research recognizes this weakness and refers to other sponsorship evaluation researchers (Crompton, 2004a) who also note this weakness but also stresses that in the absence of sales data, intent to purchase is the next best measure available. Third, the lack of measurable objectives by sponsors and sponsees was evident in both sponsorship evaluation case studies and limited the effectiveness of the evaluations as there were often no targets to measure against. This will be addressed in future implementations of Process Model D3 which 
now includes a requirement for measurable objectives in Step 1. This will involve the sponsorship evaluation researcher working with the sponsor(s) and sponsee presponsorship. Fourth, as noted in both sponsorship evaluation case studies, the resource implications (human and financial) of implementing the process model are significant and could potentially be a barrier to its implementation. The updated Process Model D3 includes an estimation of resources in Step 1 as an attempt to mitigate this risk which will allow the researcher to prioritize metrics and methods pre-sponsorship. Fifth, the length of the research process in the KEME and ATB-EGP cases underlines the challenge of time as a third resource challenge, in addition to financial cost and human resources risk, that sponsorship evaluation researchers need to consider. An assessment of time in the context of the Step 1 Cost-Benefit Test has been added to Process Model D3 to try to mitigate the time effect by seeking to advise a researcher not to embark on an evaluation that is unlikely to be completed. Sixth, the implementation of the two sponsorship evaluation case studies revealed that a challenge exists with respect to the clarity of roles between the sponsor and the sponsee as principal and agent, respectively. This challenge is commonly identified in the Agency Theory literature (Eisenhardt, 1989).

Methodologically, this resulted - in the ATB-EGP case - in some confusion at times over who was pursuing which objective and who was potentially shirking whom. It is important that sponsorship evaluation researchers use pre-sponsorship interviews to clearly articulate each entity and its objectives as Step 1 of the model advises. Seventh, the fact that drafts D1 and D2 of the process model did not consider the 'riskiness' of sponsees was a weakness that has been corrected in D3. This weakness was evident in the KEME sponsorship evaluation which was, for the most part, cancelled following the 
tragic death of Dr. Sean Egan. Finally, the generalizability of the findings from 14 expert interviews and 2 sponsorship evaluation case studies must be questioned. This weakness is enhanced by the fact that only 1 sponsorship evaluation case study was fully implemented and completed. This weakness, however, is mitigated considerably by the fact that the model is a process model that is designed to be adapted to each sponsorship that it is used to evaluate; based on the premise that all sponsorships are unique.

\subsection{A Future Research Agenda}

A number of avenues for future research are identified in this dissertation. First and of the most importance is the continued testing and updating of version D3 of the process model. Ideally this will include evaluations of a broad array of sponsorships (e.g., mega-sponsee/typical-sponsee, cash/in-kind, sponsors/sponsees of all sizes, social marketing sponsors/sponsees, etc.). The need to further explore risky sponsees is also noted from the KEME case. Additionally, it is recommended that future research include partial evaluations and the evaluations of single objectives in response to the resource challenges that were shown to typically affect evaluations. Finally, future research is suggested to further explore some of the key issues built into each of the boxes of the model, including assessing the specificity of the mega/typical sponsee scenarios, evaluating sponsorships with varying levels of collaboration with a champion, determining methods to better forecast shirking behaviours, and developing an improved method of determining metrics and methods for a given objective.

In order to scope a future research agenda, a number of hypotheses to be tested or explored are provided here: 
1. H1: That the Process Model will be applicable for sponsorships that include social marketing (i.e. behaviour change) objectives.

2. H2: That the Process Model can be adapted for use when limited resources (i.e. less than required for complete implementation) for evaluation are available to the researcher.

3. H3: That longitudinal study using the Process Model will provide enhanced evaluation of sponsorships.

4. H4: That the Process Model can be adapted to evaluate sponsorships that include sponsors, sponsees and intermediaries of all sizes (e.g. mega-sponsees, small sponsors, etc.).

5. H5: That the following concepts ('boxes') in the Process Model are further explored:

a. Shirking: developing a better understanding of how to account for both (i) behavioural and (ii) contractual shirking.

b. Shirking: developing improved measurement techniques.

c. Legal support for evaluation: further research on understanding its importance and achieving support for implementation.

d. Metric Development: that future research considers and develops other techniques to measure sponsorship-based objectives including (i) experimental design, (ii) observation, and (iii) focus groups.

6. H6: To support that Agency Theory is the best theoretical framework upon which to base the Process Model for sponsorship evaluation. 
7. H7: That the Process Model be compared to other industry-based models for sponsorship evaluation.

8. H8: That the Process Model is applicable in sponsorships (i) in all industries, (ii) of global, national, regional and local reach, and (iii) in all countries/regions of the world.

These 11 hypotheses outline a number of future research studies demonstrating the need for work in sponsorship evaluation and the role of this dissertation in encouraging future research.

\subsection{The Final Word}

One of the sponsorship experts summarized the overall impact of this dissertation by noting that "the key to the future of sponsorship lies in how to then re-package [the common need for evaluation] into some kind of general tool with wide application" (SSor_3). This research has taken a number of important steps in developing sponsorship evaluation theory towards this goal with the construction of a validated process model for sponsorship evaluation.

This research began by focusing on an important topic that was of high interest to both practitioners and researchers, as expressed in trade publications, the marketing literature and in-person to the author. This emphasis towards 'solving' the sponsorship evaluation challenge resulted in a two-stage, multi-method dissertation that has taken important steps - both theoretically and practically - to achieving its goal. The research process itself outlines both the difficulty and the interest in the topic. Three literatures, expert input, a pre-test and two in-depth case studies were required. Agency Theory 
provided the necessary framework. Corporate partners were intimately involved and invested significant resources in the process. The importance of time, resources, highlevel support of partners, and confidentiality was clear. Each iteration of the process model was better than the previous version, both practically and theoretically. 


\section{References}

Aaker, D.A. (1996). Measuring brand equity across products and markets. California Management Review, 38(3), 102-120.

Abratt, R., \& Grobler, P.S. (1989). The evaluation of sports sponsorships. International Journal of Advertising, 8(4), 351-362.

Abratt, R., Clayton, B.C., \& Pitt, L.F. (1987). Corporate objectives in sports sponsorship. International Journal of Advertising, 6, 299-311.

Aguilar-Manjarrez, R., Thwaites, D., \& Maule, J. (1997). Modelling sport sponsorship selection decisions. Asia-Australia Marketing Journal, 5(1), 9-20.

Aijo, T.S. (1996). The theoretical and philosophical underpinnings of relationship marketing: Environmental factors behind the changing marketing paradigm. European Journal of Marketing, 30(2), 8-18.

Alchian, A.A., \& Demsetz, H. (1972). Production, information cost and economic organization. American Economic Review, 62, 777-792.

Algozzine, B., Beattie, J., Bray, M., Flowers, C., Gretes, J., Howley, et al. (2004). Student evaluation of college teaching. College Teaching, 52(4), 134-142.

Ali, C., Cornwell, T.B., Nguyen, D., \& Coote, L. (2006). Exploring the usefulness of a consumer activity index in the sponsorship-linked marketing context. International Journal of Sport Marketing and Sponsorship, 7(2), 115-124. American Marketing Association (2004). A New definition of marketing. Marketing News, Sept. 15, 2004.

Amis, J. (2003). Good things come to those who wait: The strategic image and reputation at Guinness. European Sport Management Quarterly, 3(3), 189-214. 
Amis, J., Slack, T., \& Berrett, T. (1999). Sport sponsorship as distinctive competence. European Journal of Marketing, 33(4), 250-272.

Amis, J., Pant, N., \& Slack, T. (1997). Achieving a sustainable competitive advantage: A resource-based view of sport sponsorship. Journal of Sport Management, 11, 8096.

Anderson, E., \& Oliver, R. (1987). Perspective on behavior-based versus outcome-based salesforce control systems. Journal of Marketing, 51 (October), 76-88.

Andreff, W., \& Nys, J-F. (2002). Économie du sport. Paris : Presses universitaires de France.

Anne F., \& Chéron E.J. (1991). Mesure de l'efficacité du sponsoring : une analyse des effets intermédiaires sur l'audience directe de l'événement. Revue Française $d u$ Marketing, 131, 69-81.

Arani, A. (1992). How corporations take advantage of Olympic marketing opportunities. Sport Marketing Quarterly, 1(1), 7-12.

Arychuk, K (2006). Personal communication, July 27.

Armstrong, C. (1988). Sports sponsorship: A case study approach to measuring its effectiveness. European bulletin of Himalayan research, 16(2), 97-103.

Arrow, K.J. (1985). The Economics of Agency. Principals and Agents: The Structure of Business (Pratt, J., \& Zeckhauser, R., Eds.). Boston, USA: Harvard Business School Press, 37-51.

Arthur, D., Dolan, G., \& Cole, M. (1998). The benefits of sponsorship success: An analysis of the relationship between television exposure and the position of the motorcycle rider. Cyber-Journal of Sport Marketing, 2(2). 
Arthur, D., Scott, D., Woods, T., \& Booker, R. (1998). Sport sponsorship should... A process model for the effective implementation and management of sport sponsorship programs. Sport Marketing Quarterly, 7(4), 49-60.

Asimakopoulos, M.K. (1993). Sport marketing and sponsoring: The experience of Greece. Sport Marketing Quarterly 2(3), 44-48.

Bagozzi, R.P. (1975). Marketing as exchange. Journal of Marketing, 39, 32-39.

Bahli, B., \& Rivard, S. (2003). The information technology outsourcing risk: A transaction cost and agency theory-based perspective. Journal of Information Technology, 18, 211-221.

Barnes, James G. (2001). Secrets of customer relationship management: It's all about how you make them feel. New York: McGraw-Hill.

Barney, J. (1991). Firm resources and sustained competitive advantage. Journal of Management, 17(1), 99-120.

Barzel, Y. (1982). Measurement cost and the organization of markets. Journal of Law and Economics, 25(1), 203-225.

Basu, V., \& Lederer, A.L. (2004). An agency theory model of ERP implementation. Proceedings from the 2004 SIGMIS Conference on Computer Personnel Research: Careers, culture, and ethics in a networked environment, Tucson, USA, 8-13.

Basu, A., Rajiv, L., Srinivasan, V., \& Staelin, R. (1985). Salesforce compensation plans: An agency theoretic framework. Marketing Science, 4(Fall), 267-291.

BBC News (2005). Dozens reach Mount Everest summit, retrieved September 14, 2006, from http://www.bbc.co.uk. 
Bebchuk, L.A., \& Fried, J.M. (2003). Executive compensation as an agency problem. Journal of Economic Perspectives, 17(3), 71-92.

Belch, G.E., \& Belch, M.A. (2001). Advertising and promotion: An integrated marketing communications perspective (5 ed.). Boston, USA: McGraw-Hill.

Bendapudi, N., Singh, S.N., \& Bendapudi, B. (1996). Enhancing helping behavior: An integrative framework for promotion planning. Journal of Marketing, 60(July), $33-49$

Bennett, G., Henson, R., \& Zhang, J. (2002). Action sports sponsorship recognition. Sport Marketing Quarterly, 11(3), 174-185.

Bennett, P.D., Lamm, R.P., \& Fry. R.A. (1988). Marketing. Boston, USA: McGraw-Hill. Bennett, R. (1999). Sport sponsorship, spectator recall, and false consensus. European Journal of Marketing, 33(3/4), 291-313.

Bergen, M., Dutta, S., \& Walker, O.C. (1992). Agency relationships in marketing: A review of the implications and applications of agency and related theories. Journal of Marketing, 56(July), 1-24.

Berrett, T., \& Slack, T. (2001). A framework for the analysis of strategic approaches employed by non-profit sport organisations in seeking corporate sponsorship. Sport Management Review, 4, 21-45.

Berrett, T., \& Slack, T. (1999). An analysis of the influence of competitive and institutional pressures on corporate sponsorship decisions. Journal of Sport Management, 13, 114-138. 
Berrett, T. \& Slack, T. (1995). Approaches to corporate sponsorship in Canada's national sport organizations. A report submitted to Sport Canada. Faculty of Physical Education and Recreation, University of Alberta, Alberta, Canada.

Berrett, T. (1993). The sponsorship of amateur sport: Government, national sport organization, and the corporate perspectives. Leisure and Society 16, 323-46.

Bharadwaj, S.G., Varadarajan, P.R., \& Fahy, J. (1993). Sustainable competitive advantage in service industries: A conceptual model and research propositions. Journal of Marketing, 57(October), 83-99.

Bloxam, M. (1998). Brand affinity and television progamme sponsorship. International Journal of Advertising, 17(1), 89-98.

Boeing (2005). Sponsorship evaluation criteria, retrieved March 10, 2005, from http://www.boeing.com.

Borys, B., \& Jemison, D.B. (1989). Hybrid arrangements as strategic alliances: theoretical issues in organizational combinations. Academy of Management Review, 14(2), 234-249.

Bowey, S. (1998). Editorial. European Research, 16(2), 85.

Boyle, R., \& Haynes, R. (2000). Power game: Why sport matters to television. Power Play: Sport, The Media and Popular Culture, 2000, 67-88.

Bozeman, B., \& Papadakis, M. (1995). Company interactions with federal laboratories: what they do and why they do it. Technology Transfer, 20(4), 64-74.

Brassington, F., \& Pettit, S. (2000). Principles of marketing (2 ed.). Italy: Harlow, Financial Times Management. 
Brooks, C.M. (1994). Sports marketing: Competitive business strategies for sports. Englewood Cliffs, USA: Prentice Hall.

Brooks, C. (1990). Sponsorship: strictly business. Athletic Business, October, 59-62.

Broughton, R. (2004). Personal Communication, September 23.

Brown, T.J., \& Dacin, P.A. (1997). The company and the product: Corporate associations and consumer product reponses. Journal of Marketing, 61(1), 68-84.

Cannon, H., \& Riordan, E. (1994). Effective reach and frequency: Does it really make sense? Journal of Advertising Research, 34(2), 19-28.

Cantillon, P (1998). Evaluation: beyond the rhetoric. Journal of Evaluation in Clinical Practice, 5(3), 265-268.

Capko, Judy (2003). 5 steps to a performance evaluation system: keep your staff productive and motivated by conducting regular performance evaluations. Family Practice Management, 10(3), 43-48.

Carlsen, J., \& Taylor, A. (2003). Mega-events and urban renewal: The case of the Manchester 2002 Commonwealth Games. Event Management, 8, 15-22.

Chalip, L. \& Leyns, A. (2002). Local business leveraging of a sport event: Managing an event for economic benefit. Journal of Sport Management, 16(2), 132-158.

Collins, M. (1994). Global corporate philanthropy and relationship marketing. European Management Journal, 12(2), 226-233.

Copeland, R., Frisby, W., \& McCarville, R. (1996), Understanding the sport sponsorship process from a corporate perspective. Journal of Sport Management, 10(1), 32 48. 
Copeland, R. (1991). Sport sponsorship in Canada: A study of exchange between corporate sponsors and sport groups. Unpublished Master's Thesis, University of Waterloo, Canada.

Cornwell, T.B., Pruitt, S.W., \& Clark, J.M. (2005). The relationship between majorleague sports' official sponsorship announcements and the stock prices of sponsoring firms. Journal of the Academy of Marketing Science, 33(4), 401-412.

Cornwell, T., \& Coote, L. (2005). Corporate sponsorship of a cause: the role of identification in purchase intent. Journal of Business Research, 58(3), 268-276.

Cornwell, T.B., Pruitt, S.W., \& van Ness, R. (2001). The value of winning in motorsports: sponsorship-linked marketing. Journal of Advertising Research, 41(1), 17-31.

Cornwell, T.B., Roy, D.P., \& Steinard II, E.A. (2001). Exploring managers' perceptions of the impact of sponsorship on brand equity. Journal of Advertising, 30(2), 4151.

Cornwell, T.B., \& Maignan, I. (1998). An international review of sponsorship research. Journal of Advertising, 27(1), 1-21.

Cornwell, T.B. (1997). The use of sponsorship-linked marketing by tobacco firms: International public policy issues. The Journal of Consumer Affairs, 31(2), 238254.

Cornwell, T.B., Maignan, I., \& Irwin, R. (1997). Long-term recall of sponsorship sources. An empirical investigation of stadium and sport café audiences. AsiaAustralia Marketing Journal, 5(1), 45-57. 
Cornwell, T.B. (1995). Sponsorship-linked marketing development. Sport Marketing Quarterly, 4(4), 13-24.

Crane, F.G., Kerin, R.A., Hartley, S.W., Berkowitz, E.N., and Rudelius, W. (2006). Marketing (6 ed.). Toronto: McGraw-Hill.

Crimmins, J., \& Horn, M. (1996). Sponsorship: From management ego trip to marketing success. Journal of Advertising Research, 36(4), 11-21.

Crompton, J. (2004a). Conceptualization and alternate operationalizations of the measurement of sponsorship effectiveness in sport. Leisure Studies, 23(3), 267281.

Crompton, J.L. (2004b). Sponsorship ambushing in sport. Managing Leisure, 9, 1-12.

Crow, D., \& Hoek, J. (2003). Ambush marketing: A critical review and some practical advice. Marketing Bulletin, 14(1), retrieved May 3, 2005 from http://www.marketing-bulletin.massey.ac.nz.

Crowley, M.G. (1991). Prioritising the sponsorship audience. European Journal of Marketing, 25(11), 11-21.

Cuneen, J., \& Hannan, M.J. (1993). Intermediate measures of sponsorship advertising at an LPGA tournament. Sport Marketing Quarterly, 2(1), 47-56.

Cunningham, W.H., \& Taylor, S.F. (1995). Event marketing: State of the industry and research agenda. Festival Management and Event Tourism, 2, 123-137.

Cuthbertson, R. (2004). Personal communication, January 13.

Daneshvary, R., \& Schwer, R.K. (2000). The association endorsement and consumers intention to purchase. Journal of Consumer Marketing, 17(3), 203-213. 
D'Astous, A., \& Bitz, P. (1995). Consumer evaluations of sponsorship programmes. European Journal of Marketing, 29(12), 6-22.

Dean, D.H. (1999). Brand endorsement, popularity, and event sponsorship as advertising: Cues affecting consumer pre-purchase attitudes. Journal of Advertising, 28(3), 112.

Derbaix, C., \& Pham, M.T. (1991): Affective reactions to consumption situations: A pilot investigation. Journal of Economic Psychology, 12, 325-355.

Dimanche, F. (1996). Special events legacy: The 1984 Louisiana Worlds Fair in New Orleans. Festival Management and Event Tourism, 4(1), 49-54.

Doherty, A.M., \& Quinn, B. (1999). International retrial franchising: an agency theory perspective. International Journal of Retail \& Distribution Management, 27(6), 224-236.

Dolphin, R.R. (2003). Sponsorship: Perspectives on its strategic role. Corporate Communications: An International Journal, 8(3), 176-183.

Easton, S., \& Mackie, P. (1998). When football came home: A case history of the sponsorship activity at EURO 96. International Journal of Advertising, 17(1), 99114.

Egan, S. (2003a). Personal communication, September 24.

Egan, S. (2004a). Personal communication, August 3.

Egan, S. (2004b). Personal communication, December 20.

Egan, S. (2005a). Personal communication, January 11.

Eisenhardt, K.M. (1989). Agency theory: An assessment and review. Academy of Management Review, 14(1), 57-74. 
Eisenhardt, K.M., (1989b). Building theory from case study research. Academy of Management Review, 14 (4), 532-550.

Eisenhart, T. (1988). Sporting changes zap competitors. Business Marketing, 6, 92-97.

Erdogan, B.Z., \& Kitchen, P.J. (1998). Managerial mindsets and the symbiotic relationship between sponsorship and advertising. Marketing Intelligence \& Planning, 16(6), 369-374.

Ewing, J. (2004). Can Football be saved? Business Week, New York, July 19.

Fahy, J., Farrelly, F., \& Quester, P. (2004). Competitive advantage through sponsorship. European Journal of Marketing, 38 (8), 1013-1030.

Fama, E.F., \& Jensen, M.C. (1983). Separation of ownership and control. Journal of Law and Economics, 26, 301-325.

Fama, E.F. (1980). Agency problems and the theory of the firm. Journal of Political Economy, 88, 288-307.

Farrelly F., Quester, P., \& Burton, R. (1997). Integrating sports sponsorship into the corporate marketing function: An international comparative study. International Marketing Review, 14 (3), 170-182.

Feldman, J.M., \& Lynch, J.G. (1988). Self-generated validity and other effects of measurement on belief, attitude, intention, and behaviour. Journal of Applied Psychology, 73(3), 421-435.

Felt, J. (2003). How sports sponsorship can help your brand. Managing Intellectual Property, 125, 24-26.

Ferrand, A., \& Pages, M. (1996). Image sponsoring: a methodology to match event and sponsor. Journal of Sport Management, 10, 278-291. 
File, K.M., \& Prince, R.A. (1998). Cause related marketing and corporate philanthropy in privately held enterprise. Journal of Business Ethics, 17(14), 1529-1539.

Flynn, D.M. (1993). Sponsorship and the survival of new organizations. Journal of Small Business Management, 31(1), 51-62.

Furlong, R. (1994). Tobacco advertising legislation and the sponsorship of sport. Australian Business Review, 22, 159-162.

Gardiner, M., \& Shuman, P. (1988). Sponsorships and small businesses. Journal of Small Business Management, 44-50.

Gardner, C. (2004a). Personal communication, November 6.

Gardner, C. (2004b). Personal communication, October 1.

Gardner, C. (2006). Personal communication, February 10.

Getz, D. (2002). Editorial: On the nature and significance of event studies. Event Management, 7, 141-142.

Getz, D. (1998). New age, new name, new direction. Festival Management and Event Tourism, 5, 167-169.

Gianelloni, J-L. (1993). L'influence de la communication de l'evenement sur la structure de limage de l'entreprise. Recherche et Applications en Marketing, 8(1), 5-29.

Gierl, H., \& Kirchner, A. (1999). Emotionale bindung und imagetransfer durch sportsponsoring. Werbeforschung \& Praxis, 44(3), 32-35.

Gladden, J.M., \& Funk, D.C. (2002). Developing an understanding of brand associations in team sport: Empirical evidence from consumers of professional sport. Journal of Sport Management, 16, 54-81. 
Gladden, J., Milne, G., \& Sutton, W. (1998). A conceptual framework for assessing brand equity in Division I college athletics. Journal of Sport Management, 12(1), 1-19.

Gorney, B., \& Ness, R.G. (2000). Evaluating dimensions for full-time head coaches at NCAA Division II institutions. Journal of Personnel Evaluation in Education, 14(1), 47-65.

Grant, R. M. (1991). The resource-based theory of competitive advantage: Implications for strategy formulation. California Management Review, 33, 114-135.

Greene, J.C., \& McClintock, C. (1991). The evolution of evaluation methodology. Theory into Practice, 30, 13-21.

Grewal, D., \& Pechmann, C. (1998). American marketing association winter educators' conference proceedings: Marketing theory and applications, 9, Chicago, Illinois: American Marketing Association.

Grimes, E., \& Meenaghan, T. (1998). Focusing commercial sponsorship on the internal corporate audience. International Journal of Advertising, 17(1), 51-74.

Grohs, R., Wagner, U., \& Vsetecka, S. (2004). Assessing the effectiveness of sport sponsorships - An empirical examination. Schmalenbach Business Review, 56, 119-138.

Gronroos, C. (2004). The relationship marketing process: Communication, interaction, dialogue, value. Journal of Business \& Industrial Marketing, 19(2), 99-113.

Gross, A.C., Traylor, M.B., \& Shuman, P.J. (1987). Corporate sponsorship of art and sports events in North America. Proceedings from the General Sessions of the 40th ESOMAR Marketing Research Congress, Montreux, Switzerland, 535-561. 
Gummesson, E. (2004). Return on relationships (ROR): The value of relationship marketing and CRM in business-to-business contexts. Journal of Business \& Industrial Marketing, 19(2), 136-148.

Gwinner, K., \& Swanson, S. (2003). A model of fan identification: Antecedents and sponsorship outcomes. Journal of Services Marketing, 17(3), 275-294.

Gwinner, K.P., \& Eaton, J. (1999). Building brand image through event sponsorship: The role of image transfer. Journal of Advertising, 28(4), 47-57.

Gwinner, K.P. (1997). A model of image creation and image transfer in event sponsorship. International Marketing Review, 14(3), 145-158.

Hamel, G., \& Prahalad, C.K. (1994). Competing for the future. Boston, MA: Harvard Business School Press.

Hastings, G., (1984). Sponsorship works differently from advertising. International Journal of Advertising, 3, 171-180.

Harris, M., \& Raviv, A. (1979). Optimal incentive contracts with imperfect information. Journal of Economic Theory, 20, 231-259.

Harvey, B. (2001). Measuring the effects of sponsorships. Journal of Advertising Research, 41(Jan/Feb), 59-65.

Heslop, L., \& Fadaie, K. (2002). The 3Bs of impact assessment of technology transfer programs: Rationale, technique and a case example from the Canada Centre for Remote Sensing. International Journal of Technology Transfer and Commercialisation, 1(3), 217-248. 
Hirsch, P., \& Friedman, R. (1986). Collaboration or paradigm shift? Economics vs. behavioural thinking about policy? In J. Pearce \& R. Robinson (Eds.), Best Papers Proceedings: Academy of Management, Chicago, USA, 31-35.

Hoek, J., \& Gendall, P. (2002). When do ex-sponsors become ambush marketers? International Journal of Sports Marketing \& Sponsorship, 3 (4), 383-402.

Hoek, J. (1998). Sponsorship: An evaluation of management assumptions and practices. Marketing Bulletin, 10, 1-11.

Hoek, J., Gendall, P., Jeffcoat, M., \& Orsman, D. (1997). Sponsorship and advertising: A comparison of their effects. Journal of Marketing Communications, 3, 21-32.

Hoek J., Gendall P., \& Sanders J. (1993). Sponsorship management and evaluation: Are managers's assumptions justified? Journal of Promotion Management, 1(4), $1993,53-66$.

Hoffman, A. (1998). Two sides of the coin, corporate giving is business. Fund Raising Management, 29(1), 27-30.

Howard, D. R., \& Crompton, J. L. (1995). Financing sport. Morgantown, WV: Fitness Information Technology.

Hughes, H. (1993). Olympic tourism and urban regeneration. Festival Management and Event Tourism, 1(4), 157-162.

IEG Sponsorship Report (2006). 2006 sponsorship spending. IEG Sponsorship Report, 25.

IEG Sponsorship Report (2004). 2004 sponsorship spending. IEG Sponsorship Report, $23,1-3$. 
IEG Sponsorship Report (2003). 2003 sponsorship spending. IEG Sponsorship Report, $22,1-2$.

IEG Sponsorship Report (2000). 2000 sponsorship spending. IEG Sponsorship Report, 19, 4-5.

Ireland, R.D., \& Hitt, M.A. (1999). Achieving and maintaining strategic competitiveness in the 21 century: the role of strategic leadership. Academy of Management Executive, 13(1), 43-57.

Irwin, R.L., Lachowetz, T., Cornwell, T.B., \& Clark, J.S. (2003). Cause-related sport sponsorship: An assessment of spectator beliefs, attitudes and behavioural intentions. Sport Marketing Quarterly, 12(3), 131-139.

Irwin, R., \& Sutton, W. (1994). Sport sponsorship objectives: An analysis of their relative importance for major corporate sponsors. European Journal of Sport Management, l(2), 93-101.

Irwin, R. D. (1993). In search of sponsors. Athletic Management, 11-16.

Irwin, R.L., \& Asimakopoulos, M.K. (1992). An approach to the evaluation and selection of sport sponsorship proposals. Sport Marketing Quarterly, 1(2), 43 - 51.

ISBA (1998). A guide to sponsorship evaluation. London, UK: Incorporated Society of British Advertisers.

Issues in Sponsorship (2003). How big is the Canadian sponsorship pie? The Sponsorship Report. Retrieved September 29, 2004, from http://www.sponsorship.ca.

Jacobides, M., \& Croson, D.C. (2001). Informational policy: Shaping the value of agency relationships. Academy of Management Review, 26(2), 202-233. 
Jagre, E., Watson, J.J., \& Watson, J.G. (2001). Sponsorship and congruity theory: A theoretical framework for explaining consumer attitude and recall of event sponsorship. Advances in Consumer Research, 28, 439-45.

Jalleh, G., Donovan, R.J., Giles-Corti, B., \& Holman, C.D. (2002). Sponsorship: Impact on brand awareness and brand attitudes. Sport Marketing Quarterly, 8(1), 35-45.

Javalgi, R.G., Traylor, M.B., Gross, A.C., \& Lampman, E. (1994). Awareness of sponsorship and corporate image: An empirical investigation. Journal of Advertising, 23(4), 47-58.

Jeannet, J.-P., \& Hennessey, H. D. (1992). Global Marketing Strategies (2 ed.). Boston, MA: Houghton Mifflin Company.

Jensen, M. (1983). Organization theory and methodology. Accounting Review, 56, 319338.

Jensen, M., \& Meckling, W. (1976). Theory of the firm: Managerial behaviour, agency costs and capital structure. Journal of Financial Economics, 3, 305-360.

Jobber, D. (1998). Principles and practice of marketing (2 ed.). London: McGraw-Hill.

Johar, G.V., \& Pham, M.T. (1999). Relatedness, prominence, and constructive sponsor identification. Journal of Marketing Research. 36(3), 299-312.

John, G., Weiss, A., \& Weitz, B. (1987). An organizational coordination model of salesforce compensation plans: Theoretic analysis and empirical test. Journal of Law, Economics, and Organization, 3(Fall), 373-396.

Kahle, L., \& Homer, P. (1985). Physical attractiveness of the celebrity endorser: A social adaptation perspective. Journal of Consumer Research, 11(3), 954-961.

Kell, T. (2004a). Personal communication. October 22. 
Kell, T. (2004b). Personal communication. December 1.

Kell, T. (2004c). Personal communication. September 24.

Kell, T. (2004d). Personal communication. December 10.

Kell, T. (2005a). Personal communication. February 7.

Kell, T. (2005b). Personal communication. August 11.

Kell, T. (2005c). Personal communication. October 14.

Kell, T. (2006a). Personal communication. August 28.

Kell, T. (2006b). Personal communication. April 23.

Kell, T. (2006c). Personal communication. Nov 13.

Keller, K.L., (1993). Conceptualising, measuring, and managing customer-based brand equity. Journal of Marketing, 57 (1), 1-22.

Kinney, L., \& McDaniel, S. (1996). Strategic implications of attitude-toward-the-ad leveraging event sponsorships. Journal of Sport Management, 10(1), 250-261.

Kitchen, P.J. (1993). Marketing communications renaissance. International Journal of Advertising, 12(4), 367-386.

Kodish, B. (2003). General semantics: A general theory of evaluation. Concord, 60(3), 286-294.

Kolah, A. (2003). Maximizing the value of sponsorship. Sport Business Group Limited Publication.

Kotler, P. (1997). Marketing Management (9 ed.). New Jersey: Prentice Hall.

Kover, A.J. (2001). Editorial: The sponsorship issue. Journal of Advertising Research, 41(Jan-Feb), 5 . 
Kuzma, J., \& Shanklin, W. (1994). Corporate sponsorship: A framework for analysis., Dubuque, USA: Brown \& Benchmark.

Kuzma, J.R., Shanklin, W.L., \& McCally, J.R. (1993). Number one principle for sporting events seeking corporate sponsors: Meet benefactor's objectives. Sport Marketing Quarterly, 2(3), 27-32.

Lachowetz, T., McDonald, M., Sutton, W.A., \& Hedrick, D.G. (2003). Corporate sales activities and the retention of sponsors in the National Basketball Association (NBA). Sport Marketing Quarterly, 12(1), 19-26.

Lachowetz, T., \& Irwin, R. (2002). FedEx and the St. Jude Classic: An application of a cause-related marketing program (CRMP). Sport Marketing Quarterly, 11(2), $114-116$.

Lancaster, G., \& Massingham, L. (1993). Essentials of marketing. London, UK: McGraw- Hill.

Lardinoit, T., \& Quester, P. (2001). Attitudinal effects of combined sponsorship and sponsor's prominence on basketball in Europe. Journal of Advertising Research, 41(Jan-Feb), 48-58.

Lascu, D., Giese, T.D., Toolan, C., Guehring, B., \& Mercer, J. (1995). Sport involvement: A relevant individual difference factor in spectator sports. Sport Marketing Quarterly, 4(4), 41-46.

Law, A., Harvey, J., \& Kemp, S. (2002). The global sport mass media oligopoly: The three usual suspects and more. International Review for the Sociology of Sport, 37, 279-302. 
Lee, J.K. (2005). Marketing and promotion of the Olympic Games. The Sport Journal, 8(3), retrieved from http://www.thesportjournal.org.

Lee, M.S., Sandler, D.M., \& Shani, D. (1997). Attitudinal constructs towards sponsorship. International Marketing Review, 14(3), 159-169.

Liu, Y., Putler, D.S., \& Weinberg, C.B. (2004). Is having more channels really better? A model of competition among commercial television broadcasters. Marketing Science, 23(1), 120-133.

Ludwig, S., and Karabetsos, J.D. (1999). Objectives and evaluation processes utilized by sponsors of the 1996 Olympic Games. Sport Marketing Quarterly, 8 (1), 11-19.

Luk, P. (2004). Personal communication. May 31.

Lyberger, M.R., \& McCarthy, L. (2002). An analysis of volume consumption, consumer interest and perceptions of sport sponsorship as they related to the Super Bowl. International Journal of Sports Marketing and Sponsorship, 1 (Dec/Jan), 429447.

Lyberger, M., \& McCarthy, L. (2001). An assessment of consumer knowledge of, interest in, and perceptions of ambush marketing strategies. Sport Marketing Quarterly, $10(2), 130-137$.

Mack, R.W. (1999). Event sponsorship: An exploratory study of small business objectives, practices, and perceptions. Journal of Small Business Management, $37(3), 25-30$.

Madrigal, R. (2001). Social identity effects in a belief-attutide-intentions hierarchy: Implications for corporate sponsorship. Psychology \& Marketing, 18(2), 145-165. 
Marshall, D., \& Cook, G. (1992). The corporate sports sponsor. International Journal of Advertising, 11, 307-324.

Mason, D.S. (1999). What is the sports product and who buys it? The marketing of professional sport leagues. European Journal of Marketing, 33(3/4), 402-418.

McCarthy, L. M., \& Irwin, R. I. (2000). An examination of the rationale and motives for corporate purchase of stadia and arena naming rights. The Cyber-Journal of Sport Marketing, 4(2/3).

McCarthy, L. M., \& Irwin, R. I. (1998). Names in lights: Corporate purchase of sport facility naming rights. The Cyber-Journal of Sport Marketing, 2(3).

McCarville, R.E., Flood, C.M., \& Froates, T.A. (1998). The effectiveness of selected promotions on spectators' assessments of a non-profit sporting event sponsor. Journal of Sport Management, 12, 51-62.

McCarville, R.E., \& Copeland, R.P. (1994). Understanding sport sponsorship through exchange theory. Journal of Sport Management, 8, 102-114.

McCook, K., Turco, D., \& Riley, R. (1997). A look at the corporate sponsorship decision-making process. Cyber-Journal of Sport Marketing, 1(3).

McCracken, G. (1989). Who is the celebrity endorser? Cultural foundations of the endorsement process. Journal of Consumer Behaviour, 16(3), 310-321.

McCarthy, L., \& Lyberger, M. (2001). An assessment of consumer knowledge of interest in, and perceptions of ambush marketing strategies. Sport Marketing Quarterly, Vol. 10, No. 4, pp. 130-137. 
McDaniel, S. (1999). An investigation of match-up effects in sport sponsorship advertising: The implications of consumer advertising schemas. Psychology \& Marketing, 16 (2), 163-184.

McDaniel, S.R., \& Mason, D.M. (1999). An exploratory study of influences on public opinion towards alcohol and tobacco sponsorship of sporting events. Journal of Services Marketing, 13(6), 481-499.

McDaniel, S.R., \& Kinney, L. (1998). The implications of recency and gender effects on consumer response to ambush marketing. Psychology \& Marketing, 15(4), 385403.

McDonald, C. (1991). Sponsorship and the image of the sponsor. European Journal of Marketing, 25(11), 31-38.

Meenaghan, T. (2002). From sponsorship to marketing partnership: The Guinness Sponsoring of the GAA All-Ireland Hurling Championships. Irish Marketing Review, 15(1), 3-15.

Meenaghan, T. (2001). Understanding sponsorship effects. Psychology and Marketing, $18(2), 95-122$.

Meenaghan, T., \& Shipley, D. (1999). Media effect in commercial sponsorship. European Journal of Marketing, 25(11), 39-56.

Meenaghan, T. (1998). Current developments and future directions in sponsorship. International Journal of Advertising, 17, 3-28.

Meenaghan, T. (1994). Point of view - Ambush marketing: Immoral or imaginative practice? Journal of Advertising Research, September/October, 77 - 88. 
Meenaghan, T. (1991a). Sponsorship - legitimising the medium. European Journal of Marketing, 25(11), 5 - 10.

Meenaghan, T. (1991b). The role of sponsorship in the communications and marketing mix. International Journal of Advertising, 10 (1), 35-47.

Meenaghan, T. (1983). Commercial sponsorship. European Journal of Marketing, Special issue, 1-73.

Meerabeau, E., Gillet, R., Kennedy, M., Adeoba, J., Byasss, M., \& Tabi, K. (1991). Sponsorship and the drinks industry in the 1990s. European Journal of Marketing, 25(11), 39 - 56.

Melkers, J.E., \& Cozzens, S.E. (1997). A review of performance measurement in state science and technology-based economic development programs. In S.A. Rood (Ed.), Technology Transfer: How Do We Know What Works? Proceedings of the Technology Transfer Metrics Summit (pp.109-117). New Mexico: Technology Transfer Society.

Mendez, H.Y. (1999). Virtual signage: The pitfalls of 'now you see it, now you don't.'" Sport Marketing Quarterly, 8 (4), 15-21.

Meredith, L. (1993). A customer evaluation system. The Journal of Business and Industrial Marketing. 8(1), 58-73.

Messmer, M. (2004). Developing effective performance reviews. Strategic Finance, 85(9), 13-14.

Meyer, H. (1999). When the cause is just. Journal of Business Strategy, 20(6), 27-31.

Milne, G. R., \& McDonald, M. A. (1999). Sport Marketing: Managing the exchange process. Sudbury, Mass.: Jones and Bartlett. 
Miyazaki, A.D., \& Morgan, A.G. (2001). Assessing market value of event sponsoring: Corporate Olympic sponsorships. Journal of Advertising Research, 41(1), 9-16.

Moore, J.N., Pickett, G.M., \& Grove, S.J. (1999). The impact of a video screen and rotational-signage systems on satisfaction and advertising recognition. Journal of Services Marketing, 13(6), 453-468.

Moorthy, K.S. (1987). Managing channel profits: comment. Marketing Science, 6(Fall), 375-379.

Morgan, R.M., \& Hunt, S.D. (1994). "The commitment-trust theory of relationship marketing. Journal of Marketing, 58(July), 20-38.

Mount, J., \& Niro, B. (1995). Sponsorship: An empirical study of its application to local business in a small town setting festival. Management and Event Tourism, 2, 167175.

Mullin, B., Hardy, S., \& Sutton, W. (2000). Sport marketing (2 ed.). Champaign, IL: Human Kinetics.

Mullin, J. (1997). Performance-based corporate philanthropy: How 'giving smart' can further corporate goals. Public Relations Quarterly, 42(2), 42-48.

Nelson, P. (1974). Advertising as information. Journal of Political Economy, 82(July/August), 729-754.

Newburn, T. (2001). What do we mean by evaluation? Children and Society, 15, 5-13.

Nicholls, J.A.F., Roslow, S., \& Dublish, S. (1999). Brand recall and brand preference at sponsored golf and tennis tournaments. European Journal of Marketing, 33(3/4), $365-386$.

Oakley, A. (1998). Public policy experimentation: Lessons from America. Policy Studies, 
19(2), 93-114.

Ogilvie, C. (2006, December 4). Sponsorship, a challenge, not charity: It's about legacies, brand association and being Canadian. The Vancouver Province. p.A4.

O'Hagan, J., \& Harvey, D. (2000). Why do companies sponsor arts events? Some evidence and a proposed classification. Journal of Cultural Economics, 24, 20524.

Ojala, C.F., \& Edmondson, B. (1987). Businesses that sponsor women's sports gain loyal customers. American Demographics, October, 35-37.

Olkkonen, R. (2001). Case study: The network approach to international sport sponsorship arrangement. Journal of Business and Industrial Marketing, 16(4), 309-329.

O'Reilly, N., \& Madill, J. (2007). The World Anti-Doping Agency: The role of social marketing. Journal of Nonprofit and Public Sector Marketing, 17(1/2).

O'Reilly, N., \& Rahinel, R. (2006). Forecasting the importance of media technology in sport: The case of the televised ice hockey product in Canada. International Journal of Sport Marketing and Sponsorship, 8(1).

O’Reilly, N., Nadeau, J., Seguin, B., \& Harrison, M. (2007). In-stadium sponsorship evaluation of a mega-sponsee: The 2004 Grey Cup. International Journal of Sport Marketing and Sponsorship, 8(2).

Otker, T. (1988). Exploitation: The key to sponsorship success. Marketing and Research Today, 16(2), 77-86.

Otker, T., \& Hayes, P. (1987). Judging the efficiency of sponsorship: Experience from the 1986 Soccer World Cup. European Research, 15(4), 3-9. 
Palumbo, G. (2001). Trial procedures and optimal limits on proof-taking. International Review of Law and Economics, 21(3), 309-327.

Parker, K. (1991). Sponsorship: The research contribution. European Journal of Marketing, 25(11), 22-30.

Edmonton Grand Prix General Manager (2006). Personal communication. Aug 1.

Edmonton Grand Prix Sponsorship Consultant (2006). Personal communication. Aug 1.

Patton, M. (1980). Qualitative evaluation methods. London: Sage.

Perrow, C. (1986). Complex organizations. New York, USA: Random House.

Peteraf, M. A. (1993). The cornerstones of competitive advantage: A resource-based view. Strategic Management Journal, 14, 179-191.

Petty, R.E., \& Cacioppo, J.T. (1986). Communication and persuasion: Central and peripheral routes to attitude change. New York: Springer Verlag.

Pham, M.T., \& Johar, G.V. (2001). Market prominence biases in sponsor identification: Processes and consequentiality. Psychology and Marketing, 18(2), 123-143.

Pham, M.T. (1992). Effects of involvement, arousal, and pleasure on the recognition of sponsorship stimuli. Advances in Consumer Research, 19, 85-93.

Picard, P. (1987). On the design of incentive schemes under moral hazard and adverse selection. Journal of Public Economics, 33, 305-332.

Pitts, B., \& Slattery, J. (2004). An examination of the effects of time on sponsorship awareness levels. Sport Marketing Quarterly, 13(1), 43-54.

Polonsky, M.J. \& Speed, R. (2001). Linking sponsorship and cause related marketing. European Journal of Marketing, 35(11/12), 1361-1385. 
Pope, N., \& Voges, K. (2000). The impact of sport sponsorship activities, corporate image, and prior use on consumer purchase intention. Sport Marketing Quarterly, 9(2), 96-102.

Pope, N. (1998). Consumption values, sponsorship awareness, brand and product use. Journal of Product and Brand Management, 7(2), 124-135.

Pope, N. K., \& Voges, K. (1998). Awareness of sponsorship and corporate image: An investigation replicated. Journal of Marketing Communication, 5(1), 17-28.

Pope, N. K., \& Voges, K. (1997). An exploration of sponsorship awareness by product category and message location in televised sporting events. Cyber-Journal of Sport Marketing, 1(1), 16-27.

Pope, N. K., \& Voges, K. (1994). Sponsorship evaluation: Does it match the motive and the mechanism? Sport Marketing Quarterly, 3(4), 38-45.

Pound, R.W. (1996). The Importance of Commercialism for the Olympic Movement. International Olympic Committee: Olympic Message Sources of Financing Sports, 3, 10-13.

Quester, P., \& Thompson, B. (2001). Advertising and promotion leverage on arts sponsorship effectiveness. Journal of Advertising Research, 41(Jan-Feb), 33-47.

Quester, P., Burton, R., \& Farrelly, F. (1998). Organizational power games: Decisions in sports sponsorship investment. Marketing Management, 7 (1), 6-15.

Quester, P., \& Farrelly, F. (1998). Brand association and memory decay effects of sponsorship: the case of the Australian Formula One Grand Prix. The Journal of Product and Brand Management, 7(6), 539-550. 
Quester, P.G. (1997a). Sponsorship returns: the value of naming rights. Corporate Communications: An International Journal, 2(3), 101-108.

Quester, P.G. (1997b). Awareness as a measure of sponsorship effectiveness: The Adelaide Formula One Grand Prix and evidence of incidental ambush effects. Journal of Marketing Communications, 3, 1-20.

Rajaretnam, J., (1994). The long-term effects of sponsorship on corporate and product image: Findings of a unique experiment. Marketing and Research Today, February, 62-74.

Redfern, S. (1998). The evaluation boom: is it new? Journal of Clinical Nursing, 7, 389391.

Rees, P., \& Gardiner, H. (2003). Best value, partnerships and relationship marketing in local government. International Journal of Nonprofit and Voluntary Sector Marketing, 8(2), 143-152.

Rifon, N.J., Choi, S.M., Trimble, C.S., \& Li, H. (2004). Congruence effects in sponsorship. Journal of Advertising, 33(1), 29-42.

Rodebaugh, T.L. (2005). The factor structure of the DSM-III-R personality disorders: an evaluation of competing models. International Journal of Methods in Psychiatric Research, 14(1), 43-55.

Rodgers, S. (2003). The effects of sponsor relevance on consumer reactions to internet sponsorships. Journal of Advertising, 32(4), 66-76.

Rosenberg, N.J., \& Siegel, M. (2001). Use of corporate sponsorship as a corporate marketing tool: a review of tobacco industry sponsorship in the USA, 1995-1999. Tobacco Control, 10, 239-246. 
Ross, S. (1973). The economic theory of agency: The principal's problem. American Economic Review, 63, 134-139.

Rowley, J. (2004). Partnering paradigms? Knowledge management relationship marketing. Industrial Management \& Data Systems, 104(2), 149-157.

Rowley, J. (1998). Promotion and marketing communications in the information marketplace. Library Review, 47(8), 383-387.

Rudan, K. (2005a). Personal Communication, December 4.

Rudan, K. (2005b). Personal Communication, December 9.

Rudan, K. (2006a). Personal Communication, February 11.

Rudan, K. (2006b). Personal Communication, February 12.

Rudan, K. (2006c). Personal Communication, July 31.

Rudan, K. (2006d). Personal Communication, May 10.

Rudan, K. (2006e). Personal Communication, November 16.

Ruth, J.A., \& Simonin, B.L. (2003). Brought to you by Brand A and Brand B: investigating multiple sponsors' influence on consumers' attitudes towards sponsorsed events. Journal of Advertising, 32(3), 19-30.

Sacks, P. (1997). Standardized testing: Meritocracy's crooked yardstick. Change, 29(2), 24-32.

Sandler, D.M., \& Shani, D. (1998). Ambush marketing: Is confusion to blame for the flickering of the flame? Psychology \& Marketing, 15(4), 367-383.

Sandler, D.M., \& Shani, D. (1993). Sponsorship and the Olympic Games: The consumer perspective. Sport Marketing Quarterly, 2(3), 38-43. 
Sandler, D.M., \& Shani, D. (1989). Olympic sponsorship vs. 'ambush' marketing: Who gets the gold? Journal of Advertising Research, 11(Aug/Sept), 9-14.

Sappington, D. (1991). Incentives in principal-agent relationships. Journal of Economic Perspectives, 3(2), 45-66.

Scherer, J., \& Sam, M. (2005). Sporting sign wars: advertising and the contested terrain of sporting events and venues. International Journal of Sport Management and Marketing, 1(1/2), 17-36.

Schwarz, N. (1999). Self-reports: How the questions shape the answers. American Psychologist, 54(2), 93-105.

Scott, J.C. (1998). Seeing Like a State. New Haven, USA: Yale University Press.

Scott, D., \& Suchard, H. (1992). Motivations for Australian expenditure on sponsorship: An analysis. International Journal of Advertising, 11, 325-332.

Scriven, M. (1998). The new science of evaluation. Scandinavian Journal of Social Welfare, 7, 79-86.

Seguin, B., Lyberger, M., O’Reilly, N., \& McCarthy, L. (2005) Internationalizing ambush marketing: The Olympic brand and country of origin. International Journal of Sport Sponsorship and Marketing, 6(4).

Seguin, B., Teed, K., \& O’Reilly, N. (2005). National sport organizations and sponsorship: An identification of Best Practices. International Journal of Sport Management and Marketing, 1(1/2), 69-83.

Shank, M.D. (2005). Sports marketing: A strategic perspective (3 ed.). Upper Saddle River, NJ: Prentice Hall. 
Shank, M.D. (2002). Sports marketing: A strategic perspective (2 ed.). Upper Saddle River, NJ: Prentice Hall.

Shank, M.D. (1999). Sports marketing: A strategic perspective. Upper Saddle River, NJ: Prentice Hall.

Shanklin, W., \& Kuzma, J. (1992). Buying that sporting image: What senior executives need to know about corporate sports sponsorship. Marketing Management, Spring, 59-64.

Shannon, R., \& Turley, L.W. (1997). The influence of in-arena promotions on purchase behavior and purchase intentions. Sport Marketing Quarterly, 6(4), 53-62.

Shannon, J.R. (1996). The new promotion mix: A proposed paradigm, process, and application. Journal of Marketing Theory and Practice, (4)1, 56-68.

Shaw, B., \& Post, F.R. (1993). A moral basis for corporate philanthropy. Journal of Business Ethics, 12, 745-751.

Shilbury, D., \& Berriman, M. (1996). Sponsorship awareness: A study of St. Kilda Football Club supporters. Sport Marketing Quarterly, 1(1), 27-33.

Shimp, T.A. (1997). Advertising, promotion, and supplemental aspects of integrated marketing communications (4 ed.). Fort Worth, USA and London, UK: Dryden Press.

Sia, T.L., Lord, C.G., Blessum, K.A., Ratcliff, C.D., \& Leppter, M.R. (1997). Is a rose always a rose? The role of social category exemplar change in attitude stability and attitude-behavior consistency. Journal of personality and social psychology, 72(3), 501-514. 
Siegel, M. (2001). Counteracting tobacco motor sports sponsorship as a promotional tool: in the tobacco settlement. American Journal of Public Health, 7, 1100-1106.

Slack, T. (1997). Understanding sport organizations: The application of organization theory. Champaign, USA: Human Kinetics.

Slack, T., \& Bentz, L. (1996). The involvement of small businesses in sport sponsorship. Managing Leisure, 1, 175-184.

Sleight, S. (1989). Sponsorship: What it is and how to use It. Bershire, England: McGraw-Hill.

Smith, C. (1994). The new corporate philanthropy. Harvard Business Review, 72(3), $105-$ 116.

Sparks, R. (1997). Tobacco-control legislation, public health and sport sponsorship. AsiaAustralian Marketing Journal, 5(1), 59-70.

Speed, R., \& Thompson, P. (2000). Determinants of sports sponsorship response. Journal of the Academy of Marketing Science, 28(2), 226-238.

Sperling, C. (2006). Personal Communication, July 27.

Sperling, C. (2006b). Personal Communication, December 1.

Sport Business News (2006). London 2012 Sponsorship Interest Soars. August 9, 2006. Retrieved from http://www.sportbusiness.com.

Stake, R.E. (1995). The art of case study research. Thousand Oaks, California: Sage. Statistics Canada (2007). Provincial and territorial highlights: 2001 Census. March 10, 2007. Retrieved from http://www.statscan.ca.

Stipp, H. (1998). The impact of Olympic sponsorship on corporate image. International Journal of Advertising, 17(1), 75-87. 
Stipp, H., \& Schiavone, N.P. (1996). Modeling the impact of Olympic sponsorship on corporate image. Journal of Advertising Research, 36(4), 5-21.

Stotlar, D.K. (1993). Sponsorship and the Olympic winter games. Sport Marketing Quarterly, 2(1), 35-43.

Stotlar, D.K., \& Kadlecek, J.C. (1993). What's in it for me? Athletic Business, April, 3236.

Stotlar, D.K., \& Johnson, D.A. (1989). Assessing the impact and effectiveness of stadium advertising on sport spectators at division I institutions. Journal of Sport Management, 2(2), 100-114.

Strauss, B., \& Friege, C. (1999). Regaining service customers. Journal of Service Research, 1(4), 347-361.

Suite_Host_1 (2006). Expert interview, Edmonton, AB, July 27, 2006.

Suite_Host_2 (2006). Expert interview, Edmonton, AB, July 31, 2006.

Sutton, R.I., \& Staw, B.M. (1995). What theory is not. Administrative Science Quarterly, 40, 371-384.

Swenson, D. (2001). How to evaluate a theory. Management Department, The College of St. Scholastica, Duluth, MN, web publication.

Tenner, A.R., \& DelToro, I.J. (2000). Process redesign. Upper Saddle River, New Jersey: Prentice Hall.

Thorelli, H.B. (1986). Networks: between markets and hierarchies. Strategic Management Journal, 7, 37-51. 
Thwaites, D., Aguilar-Manjarrez, R., \& Kidd, C. (1998). Sports sponsorship development in Canadian companies: Issues and trends. International Journal of Advertising, $17,29-49$.

Thwaites, D., \& Carruthers, A. (1998). Practical applications of sponsorship theory: Empirical evidence from English rugby clubs. Journal of Sport Management, 12, 203-219.

Thwaites, D. (1995). Professional football sponsorship: Profit or profligate? International Journal of Advertising, 14(2), 149-164.

Townley, S., Harrington, D., \& Couchman, N. (1998). The legal and practical prevention of ambush marketing in sports. Psychology \& Marketing, 15(4), 333-348.

Tripodi, J. (2001). Sponsorship - a confirmed weapon in the promotional armoury. International Journal of Sports Marketing and Sponsorship, March/April, 1-20.

Turner, P. (1999). Television and the internet convergence: Implications for sports broadcasting. Sport Marketing Quarterly, 8(2), 43-51.

Ukman, L. (1995). IEG's complete guide to sponsorship. Chicago: International Events Group.

VANOC. (2006). Mint named as official sponsor of VANOC. Vancouver: VANOC Communications.

Valliere, D. (2004). Personal Communication. September 3.

Vavra, T.G. (1995). Aftermarketing: How to keep customers for life through relationship marketing. Chicago: Irwin Professional Publishing.

Waller, D.S. (2004). Developing an account-management lifecycle for advertising agency-client relationships. Marketing Intelligence \& Planning, 22(1), 95-112. 
Walliser, B. (2003). An international review of sponsorship research: extension and update. International Journal of Advertising, 22 (1), 5-40.

Walliser, B,. \& Nanopoulos, P. (2000). Qui a gagné la coupe du monde 1998? Déterminants et importance de lassociation durable des sponsors à l'événement. Proceedings of the 16 Congress of the French Marketing Association (AFM), May, 723-734, Montreal.

Walliser, B. (1994). Les determinants de la memorisation des sponsors. Revu Francaise du Marketing, 150, 83-95.

Webb, J., \& Carter, S. (2001). Sponsorship activities and the small firms sector. Managing Leisure, 6(3), 168-179.

Webb, D.J., \& Mohr, L.A. (1998). A Typology of Consumer Responses to Cause-Related Marketing: from Skeptics to Socially Concerned. Journal of Public Policy and Marketing, 17(2), 226-238.

Wegerif, R. (1998). The social dimension of asynchronous learning networks. Journal of Asynchronous Learning Networks, 2(1), 34-49.

Weick, K.E. (1995). What Theory is Not, Theorizing is. Administrative Science Quarterly, 40, 385-390.

Westerbeek, H.M., \& Smith, A. (2002). Location Dependency and Sport Sponsors: A Factor Analytic Study. Sport Marketing Quarterly, 11(3), 140-150.

Westerbeek, H.M. (2000). Is sponsorship dependent on geographic location of the sport facility? Journal of Marketing Communications, 6(1), 53-68. 
Westerbeek, H.M., \& Shilbury, D. (1999). Increasing the focus on 'place' in the marketing mix for facility dependent sport services. Sport Management Review, 2(1), $1-24$.

Wilkinson, D.G. (1993). Sponsorship marketing: A practical reference guide for corporations in the 1990's. Toronto: The Wilkinson Group.

Williams, D.W. (2003). Measuring government in the early twentieth century. Public Administration Review, 63(6), 643-659.

Williamson, O. (1988). Corporate finance and corporate governance. Journal of Finance, 43(3), 567-591.

Willis, R. (2005). Testing times. History Today, 55(8), 38-39.

Wilson, G.A. (1997). Does sport sponsorship have a direct effect on product sales? The Cyber-Journal of Sport Marketing, 1(4).

Witcher, B., Craigen, J. G., Culligan, D., \& Harvey, A. (1991). The links between objectives and function in organizational sponsorship. International Journal of Advertising, 10, 13-33.

Wolton, C. (1988). Arts sponsorship: Harmony or discord? European Research, 16(2), 87-94.

Wong, C.K., Wong, W., \& Yeung, C.H. (2001). Student behaviour and performance in using a web-based assessment system. Innovations in Education and Teaching International, 38(4), 339-346.

Woods, S.M. (1993). Attracting foreign sponsorship for American events: The myth. Sport Marketing Quarterly, 2(2), 43-45. 
Woodside, A.G., \& Wilson, E.J. (2003). Case study research methods for theory building. Journal of Business \& Industrial Marketing, 18(6/7), 493-508.

Worthen, B.R., \& Sanders, J.R. (1991). The changing face of educational evaluation. Theory Into Practice, 30(1), 3-13.

Wright, R. (1988). Measuring awareness of British football sponsorship. European Research, 16(2), 104-108.

Yin, R.K. (2003). Applications of case study research (2 ed.). London: Sage.

Yin, R.K. (1994). Case study research. Thousand Oaks, USA: Sage

Zikmund, W.G. \& d'Amico, M. (1998). Marketing. Mason, USA: South-Western Thomson Learning. 


\section{APPENDIX_FOOTNOTE: Summary of Evaluation Application}

Since the early 1800 's, formal evaluation in education has been observed in various forms through the testing of students skills, and assessments of teacher effectiveness (Willis, 2005; Redfern, 1998; Worthen \& Sanders, 1991). Today evaluation is viewed as fundamental to the learning process (Algozzine, Beattie, Bray, Flowers, Gretes, Howley, Mohanty, \& Spooner, 2004; Cantillon, 1998) with sophisticated research on such aspects as measurement techniques (e.g., Wong, Wong \& Yeung, 2001; Sacks, 1997) and technology (e.g., Priluck, 2004; Wegerif, 1998) dominating that literature. In business, formal evaluation plays a key role in various feedback-driven business functions such as consumer behaviour, human resources, financial planning and market forecasting (e.g., Tenner \& DelToro, 2000). In government and public policy, formal evaluation is important since "information about the effectiveness of public services is hard to come by using any other means" (Oakley, 1998) and since such information is necessary in order to ensure that policy is suitable for, and preserves, the prosperity of, citizens (Williams, 2003; Newburn, 2001). In the legal system, evaluation is inherent as a trial itself could be described as a formal evaluation (Palumbo, 2001). The field of psychology employs a number of evaluative methods to assess human behavior and thought (e.g., Rodebaugh, 2005). In marketing, the evaluation of consumers on a variety of measures (e.g., satisfaction, intent to purchase, pricing, brand awareness, post-purchase opinion, etc.) is carried out in a variety of ways (e.g., customer surveys, comment cards, online surveys, etc.), which impacts an organization's marketing mix (Meredith, 1993). Similarly, in human resources, the formal evaluation of employees enables organization decisions on staffing, strategy and 
operations (Messmer, 2004; Capko, 2003; Slack, 1997). Formal evaluation is also fundamental to the scientific method, and the medical sciences, since it involves the processes of analyzing observations and comparing them back to previous studies and experiments. (Scriven, 1998). Finally, in sport, athletes and teams of athletes are constantly being evaluated against themselves and the performances of others, prior to competition and post competition, and in such forms as physical training (improvement, following program, etc.), medical (doping, health, injury prevention, etc.) mental training (motivation, confidence, etc.), and team-building (morale, cohesiveness, etc.), all towards a larger plan of athletic goals (Gorney \& Ness, 2000).

This appendix provides a synopsis of the vast reach of evaluation and an outline of the many areas where it has been applied. This is useful for this dissertation which seeks to understand, develop and advance evaluation in sponsorship. 
APPENDIX A: List of Sponsorship Objectives

\begin{tabular}{|c|c|c|}
\hline$\#$ & Sponsor Objective & Example(s) of Source(s) \\
\hline 1 & Enhance corporate image & $\begin{array}{l}\text { Pope \& Voges, 1998; } 2000 \\
\text { Stipp, } 1998 \\
\text { Bennett, } 1999 \\
\text { Cornwell \& Maignan, } 1998 \\
\text { Stipp \& Schiavone, } 1996 \\
\text { Brooks, } 1994 \\
\text { Pope, 1998 } \\
\text { Seguin, Teed \& O'Reilly, } 2005 \\
\text { Irwin \& Asimakopoulos, } 1992 \\
\text { Kitchen, } 1993 \\
\text { Meenaghan, 1991b } \\
\text { Kuzma, Shanklin \& McCally, } 1993 \\
\text { Stotlar \& Kadlecek, 1993 } \\
\text { Erdogan \& Kitchen, 1998 } \\
\text { Witcher, Craigen, Culligan \& Harvey, } 1991\end{array}$ \\
\hline 2 & Enhance product positioning & $\begin{array}{l}\text { Pope \& Voges, } 1998 \\
\text { Irwin \& Asimakopoulos, } 1992 \\
\text { Irwin \& Sutton, } 1994 \\
\end{array}$ \\
\hline 3 & Increase brand equity & $\begin{array}{l}\text { Gladden, Milne \& Sutton, } 1998 \\
\text { Gladden \& Funk, 2002 } \\
\text { Milne \& McDonald, } 1999 \\
\text { Crimmins \& Horn, } 1996 \\
\end{array}$ \\
\hline 4 & Increase share price of sponsor & $\begin{array}{l}\text { Cornwell, Pruitt \& Clark, } 2005 \\
\text { Cornwell, Roy \& Steinard, } 2001 \\
\text { Cornwell, 1995 }\end{array}$ \\
\hline 5 & $\begin{array}{l}\text { Achieve media exposure or media } \\
\text { equivalency }\end{array}$ & $\begin{array}{l}\text { Lee, 2005 } \\
\text { Crompton, 2004a } \\
\text { Brooks, 1994 } \\
\text { Kitchen, 1993 } \\
\text { McCook, Turco \& Riley, } 1997 \\
\text { Kitchen, 1993 } \\
\text { Erdogan \& Kitchen, } 1998 \\
\text { Bennett, 1999 } \\
\text { Sandler \& Shani, } 1993 \\
\end{array}$ \\
\hline 6 & $\begin{array}{l}\text { Enhance current advertising } \\
\text { campaign }\end{array}$ & Stotlar \& Kadlececk, 1993 \\
\hline 7 & Access a specific target market & Pope \& Voges, 1998 \\
\hline 8 & $\begin{array}{l}\text { Achieve goodwill with target } \\
\text { market(s) of interest }\end{array}$ & $\begin{array}{l}\text { Cornwell \& Maignan, } 1998 \\
\text { Pope, } 1998 \\
\text { Bennett, } 1999 \\
\text { Irwin \& Asimakopoulos, } 1992\end{array}$ \\
\hline 9 & Enable effective communication & Brooks, 1994 \\
\hline 10 & Television coverage & Kitchen, 1993 \\
\hline
\end{tabular}




\begin{tabular}{|c|c|c|}
\hline & & Erdogan \& Kitchen, 1998 \\
\hline 11 & Radio coverage & $\begin{array}{l}\text { Kitchen, } 1993 \\
\text { Erdogan \& Kitchen, } 1998\end{array}$ \\
\hline 12 & Corporate affiliation with sport & Stotlar \& Kadlececk, 1993 \\
\hline 13 & Encouraging public relations & $\begin{array}{l}\text { Lee, } 2005 \\
\text { Bennett, } 1998\end{array}$ \\
\hline 14 & Access to events & Stotlar \& Kadlececk, 1993 \\
\hline 15 & $\begin{array}{l}\text { Media exposure through signage } \\
\text { within the venue }\end{array}$ & Stotlar \& Kadlececk, 1993 \\
\hline 16 & Ticket access & Stotlar \& Kadlececk, 1993 \\
\hline 17 & Exclusivity with a sponsee & $\begin{array}{l}\text { Seguin, Teed \& O’Reilly, } 2005 \\
\text { Stotlar \& Kadlececk, } 1993\end{array}$ \\
\hline 18 & Create competitive advantage & $\begin{array}{l}\text { Rowley, } 1998 \\
\text { Kitchen, } 1993 \\
\text { Erdogan \& Kitchen, } 1998 \\
\text { Bennett, } 1998\end{array}$ \\
\hline 19 & Provide hospitality opportunities & $\begin{array}{l}\text { Lee, } 2005 \\
\text { Brooks, } 1994 \\
\text { Kitchen, } 1993 \\
\text { Ludwig \& Karabetsos, } 1999\end{array}$ \\
\hline 20 & $\begin{array}{l}\text { Encourage product/service sales or } \\
\text { ticket sales or intent to purchase }\end{array}$ & $\begin{array}{l}\text { Crompton, 2004a } \\
\text { Cornwell, 1995 } \\
\text { Brooks, 1994 } \\
\text { Copeland, Frisby \& McCarville, } 1996 \\
\text { Irwin \& Asimakopoulos, } 1992 \\
\text { Ludwig \& Korn, 1999 } \\
\text { Kitchen, 1993 } \\
\text { Erdogan \& Kitchen, } 1998 \\
\text { Hoek, 1998 } \\
\text { Pope \& Voges, } 2000 \\
\text { Bennett, 1999 } \\
\text { Shank, 2005 } \\
\text { Shank, 2002 }\end{array}$ \\
\hline 21 & Counter Bad Publicity & Bennett, 1999 \\
\hline 22 & To leverage a Fad or Fashion trend & \begin{tabular}{|l|} 
Kitchen, 1993 \\
Exdogan \& Kitchen, 1998 \\
\end{tabular} \\
\hline 23 & Exposure at event-site & Brooks, 1994 \\
\hline 24 & Increase market share & $\begin{array}{l}\text { Cornwell, } 1995 \\
\text { Irwin \& Asimakopoulos, } 1992 \\
\end{array}$ \\
\hline 25 & $\begin{array}{l}\text { Employee motivation, production, } \\
\text { loyalty and morale }\end{array}$ & $\begin{array}{l}\text { Pope \& Voges, } 1998 \\
\text { Garner \& Shuman, } 1988 \\
\text { Cornwell, } 1995 \\
\text { Kitchen, } 1993 \\
\text { Pope, 1998 } \\
\text { Irwin \& Sutton, 1994 } \\
\text { Irwin \& Asimakopoulos, } 1992 \\
\end{array}$ \\
\hline
\end{tabular}




\begin{tabular}{|c|c|c|}
\hline & & $\begin{array}{l}\text { Erdogan \& Kitchen, } 1998 \\
\text { Bennett, } 1999\end{array}$ \\
\hline 26 & Improve promotional efficiency & Rowley, 1998 \\
\hline 27 & Client entertainment & Pope \& Voges, 1998 \\
\hline 28 & Provide incentives for sales force & Pope \& Voges, 1998 \\
\hline 29 & Influencing politicians & Bennett, 1999 \\
\hline 30 & $\begin{array}{l}\text { Creating a good impression with } \\
\text { shareholders }\end{array}$ & Bennett, 1999 \\
\hline 31 & Meets management interest & Pope \& Voges, 1998 \\
\hline 32 & Conduct research and development & Pope \& Voges, 1998 \\
\hline 33 & Support new product development & Ludwig \& Korn, 1999 \\
\hline 34 & Achieve exclusivity & Ludwig \& Korn, 1999 \\
\hline 35 & Create loyal customers & $\begin{array}{l}\text { Ludwig \& Korn, } 1999 \\
\text { Bennett, } 1999\end{array}$ \\
\hline 36 & $\begin{array}{l}\text { Build product awareness or } \\
\text { company image in target market(s) }\end{array}$ & \begin{tabular}{|l|} 
Crompton, 2004a \\
Ludwig \& Korn, 1999 \\
Pope, 1998 \\
Irwin \& Asimakopoulos, 1992 \\
Bennett, 1998 \\
\end{tabular} \\
\hline 37 & Personal Interest of CEO & Seguin, Teed \& O'Reilly, 2005 \\
\hline 38 & Expand sponsor's marketing mix & Stotlar \& Kadlececk, 1993 \\
\hline 39 & Play a leadership role in industry & Seguin, Teed \& O'Reilly, 2005 \\
\hline 40 & Large TV audience & Liu, Putler \& Weinberg, 2004 \\
\hline 41 & Leverage promotional investments & Seguin, Teed \& O'Reilly, 2005 \\
\hline 42 & $\begin{array}{l}\text { As part of an internal marketing } \\
\text { platform }\end{array}$ & Seguin, Teed \& O'Reilly, 2005 \\
\hline 43 & $\begin{array}{l}\text { Create a favourable environment for } \\
\text { future (long-term) sales }\end{array}$ & $\begin{array}{l}\text { Cornwell \& Maignan, } 1998 \\
\text { Cornwell, } 1995 \\
\text { Rowley, } 1998 \\
\end{array}$ \\
\hline 44 & Build reputation & $\begin{array}{l}\text { Seguin, Teed \& O'Reilly, } 2005 \\
\text { Mason, 1999; Asimakopoulos, } 1993\end{array}$ \\
\hline 45 & Increase brand awareness & $\begin{array}{l}\text { Crompton, 2004a } \\
\text { Mullin, Hardy \& Sutton, } 2000 \\
\text { Erdogan \& Kitchen, 1998 } \\
\text { Irwin \& Asimakopoulos, } 1992 \\
\text { Cornwell \& Maignan, 1998 } \\
\text { Kitchen, 1993 }\end{array}$ \\
\hline 46 & $\begin{array}{l}\text { Build relationships through } \\
\text { improved reputation }\end{array}$ & \begin{tabular}{|l|} 
Jobber, 1998 \\
Garner \& Shuman, 1988 \\
Cornwell, 1995; 1997 \\
Irwin \& Asimakopoulos, 1992
\end{tabular} \\
\hline 47 & Good corporate citizen & $\begin{array}{l}\text { Pope, } 1998 \\
\text { Irwin \& Asimakopoulos, } 1992\end{array}$ \\
\hline 48 & High profile media coverage & Liu, Putler \& Weinberg, 2004 \\
\hline 49 & Penetrate new industry & Seguin, Teed \& O'Reilly, 2005 \\
\hline
\end{tabular}




\begin{tabular}{|c|l|l|}
\hline 50 & Increase quarterly earnings & Seguin, Teed \& O'Reilly, 2005 \\
\hline 51 & Reaching specific target markets & $\begin{array}{l}\text { Jobber, 1998 } \\
\text { Shimp, 1997 } \\
\text { Brassington \& Pettit, 2000 }\end{array}$ \\
\hline 52 & Improving community relations & $\begin{array}{l}\text { Jobber, 1998 } \\
\text { Pope, 1998 } \\
\text { Irwin \& Asimakopoulos, 1992 } \\
\text { Irwin \& Sutton, 1994 } \\
\text { Kitchen, 1993 } \\
\text { Erdogan \& Kitchen, 1998 } \\
\text { Irwin \& Sutton, 1994 } \\
\text { Bennett, 1998 }\end{array}$ \\
\hline 53 & $\begin{array}{l}\text { Creating entertainment } \\
\text { opportunities }\end{array}$ & $\begin{array}{l}\text { Jobber, 1998 } \\
\text { Erdogan \& Kitchen, 1998 }\end{array}$ \\
\hline 54 & $\begin{array}{l}\text { To complement other elements of } \\
\text { the marketing mix }\end{array}$ & $\begin{array}{l}\text { Crowley, 1991 } \\
\text { Farrelly, Quester \& Burton, 1997 }\end{array}$ \\
\hline 55 & $\begin{array}{l}\text { To gain access to specific target } \\
\text { media }\end{array}$ & $\begin{array}{l}\text { Crowley, 1991 } \\
\text { Farrelly, Quester \& Burton, 1997 }\end{array}$ \\
\hline 56 & $\begin{array}{l}\text { To facilitate (awareness/acceptance) } \\
\text { business relationships OR trade } \\
\text { relationships in specific supply } \\
\text { chains }\end{array}$ & $\begin{array}{l}\text { Garner \& Shuman, 1988 } \\
\text { Cornwell, 1995 } \\
\text { Pope, 1998 }\end{array}$ \\
\hline 57 & $\begin{array}{l}\text { Attract capital investment (build } \\
\text { awareness and interest) }\end{array}$ & $\begin{array}{l}\text { Garner \& Shuman, 1988 } \\
\text { Cornwell, 1995 }\end{array}$ \\
\hline 58 & Inform and educate the market & Rowley, 1998 \\
\hline 59 & Encourage donations & Hoek, 1998 \\
\hline 60 & Block Competition & Irwin \& Sutton, 1994 \\
\hline 61 & Sponsor recall & Crompton, 2004a \\
\hline
\end{tabular}




\section{APPENDIX B: Script for Expert Interviews}

\section{Background Questions: Interviewee Expertise}

1. Please state your name, position and work experience for the record?

2. Approximately how many sponsorships have you worked on in any capacity (volunteer, professional, contract, etc.) during the last 2 years?

3. Do you consider yourself to be an expert in sponsorship?

4. In working on a sponsorship, both during negotiations to sign a contract and during the implementation of the contract itself, what kinds of things are you typically involved in?

Background Questions: Sponsorship Issues in the Literature

1. For you and your work, what is your working definition of sponsorship?

2. Do you consider sponsorship to be an effective promotional tool?

3. In working on a sponsorship, both during negotiations to sign a contract and during the implementation of the contract itself, what kinds of things are you typically involved in?

4. Is sponsorship different from advertising? If so, how? Research Objective 1: Understand the Sponsor-Sponsee Relationship

Based on your experience in industry and with sponsorships, please respond to the following questions. If you do not have a specific answer to the question, please respond based on your general experience in business.

1. Think of a recent sponsorship you've been involved with and describe how that sponsorship was initiated?

a. Follow-up: "Would this be typical of how sponsorship relationships begin in general?"... if not, tell us about some of the other ways this can happen?

2. We're interested in the way that the sponsor-sponsee relationship works and we'd like to ask a few questions about that:

a. Thinking again of that recent sponsorship:

i. Once a contract is signed, how often do the sponsor and sponsee communicate?

ii. Typically, is there a formal contract involved? If yes, please describe the process.

iii. Once contract is signed, does sponsor monitor the sponsee in any way? [**if explanation is required** By monitoring, I mean 'did the sponsor spend time and resources observing the sponsee to make sure their investment was used properly.]

3. What are the three most important things that a sponsor typically wants out of a sponsorship relationship?

4. What are the three most important things that a sponsee typically wants out of a sponsorship relationship?

5. In your experience, how often are intermediaries often used:

6. In all the sponsorships you deal with, is exclusivity important? How often (percentage) is exclusivity is important? Under what conditions (i.e. size of sponsorship, competitiveness of market) is exclusivity important? 
7. In all the sponsorships you deal with, when is leveraging important? How often (percentage) is leveraging important? Under what conditions (i.e. size of sponsorship, competitiveness of market) is leveraging important?

8. How is a sponsor-sponsee relationship normally terminated? What role, if any, do intermediaries play in the termination of a sponsorship?

Research Objective 2: Understand Current Practice in Sponsorship Evaluation

1. Of the $\mathrm{X}$ sponsorships that you mentioned involvement with, how many were evaluated? In your overall experience, what proportion of sponsorships are actually evaluated?

2. Do you have any specific experience in the evaluation of sponsorship? If so, please explain?

3. What current sponsorship evaluation practices or tactics are you aware of? Please list them all.

4. What are your competitors doing vis-à-vis sponsorship evaluation?

5. Do typical sponsees and mega-sponsees evaluate sponsorship differently?

6. How do you see sponsorship evaluation practice evolving in the future?

Research Objective 3: Articulate Barriers to Evaluation, Fears around Evaluation and the Benefits of Evaluation

1. Do you believe that sponsorship can be evaluated effectively?

2. From your experiences, why does senior management of sponsors and/or sponsees decide to evaluate a given sponsorship?

3. From your experiences, does a positive evaluation effect future funding decisions and/or resource allocations by sponsors or sponsees?

4. From your experiences, does a negative evaluation effect future funding decisions and/or resource allocations by sponsors or sponsees?

5. What barriers to effective sponsorship evaluation have you experienced? What other barriers exist?

6. Do any fears exist around sponsorship evaluation for sponsors and sponsees?

7. What benefits does a well-done evaluation provide to sponsors and sponsees?

8. Are there any barriers, fears and/or benefits that develop from the external environment or market related factors?

9. Is it common for both the sponsor and the sponsee to be fully supportive of an evaluation?

Research Objective 4: Understand the Timing of Evaluation

The following questions refer to the 'when' around sponsorship evaluation.

1. Of the sponsorship evaluations that you have been involved with, when was the concept of evaluation typically first discussed: pre-contract, during the contract or post contract?

2. Can evaluation be done effectively post-contract? If so, how?

3. From your experiences, what can you recommend to the sponsor to insure sponsee compliance with the sponsor's expectations with respect to timing?

Feedback on Process model

1. Show and explain the draft Process model to the expert and ask for feedback 


\section{APPENDIX C: Online, Pre-Event Survey}

1. How did you learn about the ATBGrandPrix.com web site?

-.- Choose One ---

In-Branch Poster

Search Engine

From a Friend or Colleague

By an E-mail Invititation

Radio Advertisement

Newspaper Advertisement

Banner on ATB.COM Web Site

None of the Above

2. When you think of ATB Financial as a financial institution, what comes to mind?

Very high quality

High quality

Average quality

Low quality

Very low quality

Nothing, I'd never heard of it before

3. Has ATB Financial's sponsorship of the Grand Prix changed your opinion of ATB?

Significantly increased

Somewhat increased

No change

Somewhat decreased

Significantly decreased

4. Before being exposed to ATB's sponsorship of the Grand Prix, did you know about ATB?

Yes, and I knew about ATB's products and services as well

Yes, but I really didn't understand ATB's products and services

No.

5. In your mind, is the Grand Prix an appropriate event for ATB Financial to sponsor?

Yes, it is the best choice for ATB Financial

Yes, but there may have been better choices

I'm not sure

No, although it will still be effective for ATB Financial

No, it is a very poor choice for ATB Financial 
6. Does the fact that ATB Financial is a sponsor of the Grand Prix make you more likely to visit an ATB branch in the near future?

Very unlikely

Unlikely

Maybe

Likely

Very Likely

7. Does the ATB sponsorship of the Grand Prix alter the chance of you switching from your current bank to ATB Financial?

Significantly increased

Somewhat increased

No change

Somewhat decreased

Significantly decreased

N/A, I'm already an ATB customer

8. Do you consider ATB Financial to be a major player in the Alberta banking market?

Yes

No

9. Which of the following BEST describes ATB Financial?

A full-service Albertan bank

A Canadian bank from coast-to-coast

A small town Albertan bank

An urban banking institution with branches in all major Canadian cities

A British Columbia bank expanding into Alberta

None of the above

10. Was your answer to Question \#9 (directly above) changed due to the ATB Grand Prix sponsorship?

Yes

No

Please enter any comments or suggestions you have concerning our Grand Prix sponsorship, the contest, or the ATBGrandPrix.com web site: 


\title{
APPENDIX D: In-Branch questionnaire
}

Hello, my name is Lisa/Lucas representing ATB. We are currently conducting a survey of our customers to determine your views on some of our activities. Please be assured that we are not trying to sell anything and that your answers will remain anonymous. Would you mind giving us a few minutes of your time?

If YES, provide incentive

If NO, thank them kindly and await next customer

***INTERVIEWER NOTE: IF RESPONDENT ASKS, THE

SURVEY TAKES APPROXIMATELY 7 MINUTES***

1. Are you presently a customer of ATB Financial?

Yes $\quad 1$ GO TO Q.3

No $\quad 2$

2. Are you likely to open an account with ATB Financial in the very near future?

Yes 1 GO TO Q.12

No 2 GO TO Q.12

3. Which of the following best describes your situation:

ATB Financial is

1 The only financial institution I work with

2 One of two financial institutions I work with

3 One of three or more financial institutions I work with

4. Is this your home ATB branch?
YES 1
NO 2 (If NO, ask what their branch is:

5. Are you a new customer to ATB in the last 2 months?

YES 1

NO 2

6. Have you significantly increased your holdings or loans with ATB in the last 2 months?

YES 1

NO 2

\begin{abstract}
***NOTE TO INTERVIEWER - IF INTERVIEWEE ANSWER "YES" TO EITHER OR BOTH OF \#5 and \#6 ABOVE, CONTINUE WITH QUESTION \#7 IF THEY ANSWERED "NO" TO BOTH, THEN SKIP TO QUESTION \#8***
\end{abstract}

7. You indicated that you have (joined ATB)/(increased your holdings with us) in the last two months. Of the following list, please indicate which reason or reasons - you may select as many as you like - which had at least some effect on your decision (to start)/(increase) your business with ATB? *READ EACH AND ALLOW THEM TO ANSWER AFTER EACH ONE*
a. Seen or heard ATB advertising
b.I wanted to switch to a local bank
c. Proximity of branch to my home.

$\begin{array}{ll}\mathrm{Y} & \mathrm{N} \\ \mathrm{Y} & \mathrm{N} \\ \mathrm{Y} & \mathrm{N}\end{array}$


d.Proximity of branch to my work. $\quad \mathrm{Y} \quad \mathrm{N}$

$\begin{array}{llll}\text { e. The fact that ATB sponsored the Edmonton Grand Prix } & Y & N\end{array}$

f. The fact that ATB sponsored the Calgary stampede $\quad Y \quad N$

g. The quality of products we offer $\quad Y \quad N$

h.A specific product we offer $\quad \mathrm{Y} N \mathrm{~N}$

i. I have a friend or family member who works at ATB $\quad Y \quad N$

j. A current sales promotion we are running $\quad \mathrm{Y} N \mathrm{~N}$

k.TB's customer service standards $\quad \mathrm{Y} N \mathrm{~N}$

1. Since I sat in one of ATB's hospitality suites at the Edmonton Grand Prix

m. The ATB Visa Card

$\mathrm{Y} \quad \mathrm{N}$

n. The ATB Master Card $\quad Y \quad N$

1.Other: _— $\quad \mathrm{Y}$ N

2.Other: $\quad$ Y $\quad \mathrm{N}$

3.Other: $\quad \mathrm{Y} N \mathrm{~N}$

8. How do you rate the 'prestige' of the ATB brand relative to other financial institutions?

Very High High Average Low Very Low

9. Has your opinion of the prestige of the ATB brand improved in the last 2 months?

YES

NO (SKIP TO QUESTION 10)

a. If yes, can you identify as many of the following reasons as you like which had at least some affect on your opinion of the prestige of the ATB brand improving? *READ EACH AND ALLOW THEM TO ANSWER AFTER EACH ONE*

$\begin{array}{llll}\text { a. } & \text { Seen or heard ATB advertising } & \mathrm{Y} & \mathrm{N} \\ \text { b. } & \mathrm{Y} & \mathrm{N} \\ \text { c. } & \text { Prow branches opening } & \mathrm{Y} & \mathrm{N} \\ \text { d. } & \text { The fact that ATB sponsored the Edmonton Grand Prix } & \mathrm{Y} & \mathrm{N} \\ \text { e. } & \text { The fact that ATB sponsored the Calgary Stampede } & \mathrm{Y} & \mathrm{N} \\ \text { f. } & \mathrm{Y} & \mathrm{N} \\ \text { g. } & \mathrm{Y} & \mathrm{N} \\ \text { h. } & \text { I specific product we offer } & \mathrm{Y} & \mathrm{N} \\ \text { i. } & \text { A current sales promotion we are running } & \mathrm{Y} & \mathrm{N} \\ \text { j. } & \text { ATB's customer service standards } & \mathrm{Y} & \mathrm{N} \\ \text { k. } & \text { The ATB Visa Card } & \mathrm{Y} & \mathrm{N} \\ \text { l. } & \text { The ATB Master Card } & \mathrm{Y} & \mathrm{N} \\ \text { m. } & \mathrm{Y} & \mathrm{N} \\ \text { n. } & \text { Other: } & \mathrm{Y} & \mathrm{N} \\ \text { o. } & \text { Other: } & \mathrm{Y} & \mathrm{N}\end{array}$

10. Do you view ATB as a major player in the Alberta Financial Services market?

Yes Somewhat No 
11. Do you believe that ATB's importance in Alberta's financial services industry has increased in the last 2 months?

$$
\text { Yes } \quad \text { No (GO TO QUESTION 12) }
$$

a. If yes, please identify why you believe that ATB is more of a major player in the financial services market by selecting as many of the following factors which had at least some affect on your opinion? *READ EACH AND ALLOW THEM TO ANSWER AFTER EACH ONE*

$\begin{array}{llcl}\text { a. } & \text { The fact that ATB is an Alberta-only organization } & \mathrm{Y} & \mathrm{N} \\ \text { b. } & \mathrm{Y} & \mathrm{N} \\ \text { c. New branches opened } & \mathrm{Y} & \mathrm{N} \\ \text { d. Its line of products and services } & \mathrm{Y} & \mathrm{N} \\ \text { e. Its sponsorship of the Edmonton Grand Prix } & \mathrm{Y} & \mathrm{N} \\ \text { f. Its sponsorship of the Calgary Stampede } & \mathrm{Y} & \mathrm{N} \\ \text { g. I know an ATB employee } & \mathrm{Y} & \mathrm{N} \\ \text { h. A current ATB sales promotion } & \mathrm{Y} & \mathrm{N} \\ \text { i. ATB's customer service standards } & & \\ \text { j. ATB's advertising } & \mathrm{Y} & \mathrm{N} \\ \text { k. The ATB Visa Card } & \mathrm{Y} & \mathrm{N} \\ \text { l. The ATB Master Card } & \mathrm{Y} & \mathrm{N} \\ \text { m. Other: } & \mathrm{Y} & \mathrm{N} \\ \text { n. Other: } & \text { Other: } & \mathrm{Y} & \mathrm{N}\end{array}$

12. As you may or may not know, ATB was the official Financial Institution of the 2006 Edmonton Grand Prix. Please tell me whether you strongly agree, agree, neither agree nor disagree, disagree or strongly disagree with each of the following statements.

a) Sponsoring the 2006 Edmonton Grand Prix improved the prestige of ATB Financial's brand

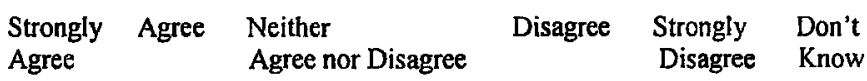

4

3

2

1 
b) Sponsoring the 2006 Edmonton Grand Prix helped demonstrate that ATB Financial is a rural financial services institution

$\begin{array}{llllll}\begin{array}{l}\text { Strongly } \\ \text { Agree }\end{array} & \text { Agree } & \begin{array}{l}\text { Neither } \\ \text { Agree nor Disagree }\end{array} & \text { Disagree } & \begin{array}{l}\text { Strongly } \\ \text { Disagree }\end{array} & \begin{array}{l}\text { Don't } \\ \text { Know }\end{array} \\ 5 & 4 & 3 & 2 & 1 & 9\end{array}$

c) Sponsoring the 2006 Edmonton Grand Prix helped demonstrate that ATB Financial is a financial services institution for all Albertans

$5 \quad 4$

d) The Sponsorship of the 2006 Edmonton

Grand Prix increased my awareness of the ATB MasterCard product.

e) ATB's sponsorship of the 2006 Edmonton Grand Prix increased my desire to do more business with ATB

f) The fact that ATB Financial sponsored the Edmonton Grand Prix makes me more likely to use more of ATB's services

5

g) Sponsoring the 2006 Edmonton Grand Prix helped demonstrate that ATB Financial is a major player in the Albertan financial services industry

13. May we confirm which age group you belong to? READ

$\begin{array}{ll}18-24 & 1 \\ 25-34 & 2 \\ 35-44 & 3 \\ 45-54 & 4 \\ 55-64 & 5 \\ 65 \text { or older } & 6\end{array}$

14. And finally, in 2005, was your total household income, before taxes... ${ }^{*}$ READ LIST*

Less than $\$ 50 \mathrm{k}$

$\$ 50 \mathrm{k}$ to less than $\$ 100 \mathrm{k}$

$\$ 100 \mathrm{k}$ to less than $\$ 150 \mathrm{k}$

$\$ 150 \mathrm{k}$ to less than $\$ 250 \mathrm{k} \quad 4$

$\$ 250 \mathrm{k}$ or more 5

DO NOT READ

Don't know/Refused

15. RECORD:

$\begin{array}{ll}\text { Male } & 1 \\ \text { Female } & 2\end{array}$

16. RECORD: Time of Day

$\begin{array}{ll}\text { Morning } & 1 \\ \text { Noon-Hour } & 2 \\ \text { Afternoon } & 3\end{array}$


17. RECORD: Day of Week

$\begin{array}{ll}\text { Monday } & 1 \\ \text { Tuesday } & 2 \\ \text { Wednesday } & 3 \\ \text { Thursday } & 4 \\ \text { Friday } & 5 \\ \text { Saturday } & 6\end{array}$

18. RECORD FROM SAMPLE:

\section{Edmonton Branch $\quad 1$ \\ Calgary Branch 2}

Those are all my questions for today. Thank you very much for your time, I do really appreciate it. Have a nice day/evening! 


\section{APPENDIX E: Hospitality Suite Survey}

\section{ATB - Grand Prix Edmonton Survey}

Dear Hospitality Sulte Attendee,

The following questionnaire is designed to give us valuable foedback on your experience It will only take 2 minutes of your time. Your participation is woluntary and anonymous, No personal identifying information is sought and you may decline to participate at any time

Thank you

\section{Questions:}

1. Please mate your experience at the Grand Prix today (circle)

$\begin{array}{lllll}\text { Poor } & \text { Föi } & \text { Good } & \text { Vely good } & \text { Excellent } \\ 1 & 2 & 3 & 4 & 5\end{array}$

2. Considering your experience today so far, would you come back next year? (circle)

$$
\begin{array}{ll}
\text { Yes } & 1 \\
\text { No } & 2
\end{array}
$$

3. Are you curfently a client of ATB? (circle)

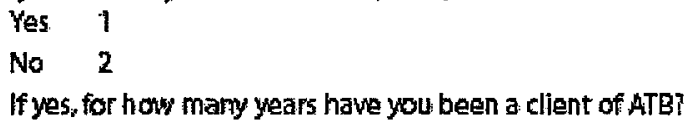

4. Do you consider ATB to be your primary financial institution? (circle)

$$
\begin{array}{ll}
\text { Yes } & 1 \\
\text { No } & 2
\end{array}
$$

5. Do you receive financial services from financial institutions other than ATB? (cincle)

$$
\text { Yes } 1
$$

No 2

a. If yes, how many additional financial institutions?

b. If yes, approximately what percentage of your financial services is done with ATB?

6. What is your anmual household income \{cinclel?

$\begin{array}{ll}<\$ 60,000 & 1 \\ \$ 60,000-\$ 1,00,000 & 2 \\ >\$ 100,000 & 3\end{array}$

7. Please respond to the following questions by cirding a response from 1 to 5 ; where 1 is 'strongly disagree, 2 is 'disagree'; 3 is'neither agree nor disagree'; 4 is'agree'; and 5 is 'strongly agree'.

a. My experience at the Grand Pro (thus farl will increase the amount of business that I do with ATB.

$\begin{array}{llllll}\begin{array}{l}\text { Strongly } \\ \text { disagree }\end{array} & \text { Disagree } & \begin{array}{l}\text { Neither agree } \\ \text { nordisagrea }\end{array} & \text { Agree } & \begin{array}{l}\text { Strongly } \\ \text { agree }\end{array} & \text { N/A } \\ 1 & 2 & 3 & 4 & 5\end{array}$


b. Ay experience at the Grand Prix ithus fort has improved my overall opinion of ATB as an ofganization.

\begin{tabular}{|c|c|c|c|c|}
\hline $\begin{array}{l}\text { Strongly } \\
\text { disagree }\end{array}$ & Disagree & $\begin{array}{l}\text { Neither agree } \\
\text { nor disagree }\end{array}$ & Agree & $\begin{array}{l}\text { Strongly } \\
\text { agree }\end{array}$ \\
\hline 1 & 2 & 3 & 4 & 5 \\
\hline
\end{tabular}

c. My experience at the Grand Prix (thus far) will encourage me to tell others positive information about ATB.

$\begin{array}{llllll}\begin{array}{l}\text { Strongly } \\ \text { disagree }\end{array} & \text { Disagree } & \begin{array}{l}\text { Neither agree } \\ \text { nor disagree }\end{array} & \text { Agree } & \begin{array}{l}\text { Strongly } \\ \text { agree }\end{array} & \text { N/A } \\ 1 & 2 & 3 & 4 & 5\end{array}$

d. ATB's sponsorship of the Edmonton Grand Prix has positively impacted my opinion of ATB as a financial institution.

$\begin{array}{llllll}\begin{array}{l}\text { Strongly } \\ \text { disagree }\end{array} & \text { Disagrae } & \begin{array}{l}\text { Neither agree } \\ \text { nor disagree }\end{array} & \text { Agree } & \begin{array}{l}\text { Strongly } \\ \text { agree }\end{array} & \text { W/A } \\ 1 & 2 & 3 & 4 & 5\end{array}$

e. ATBs sponsorship of the Edmonton Geand Prix has positwely impacted my desire to deal with ATB.

$\begin{array}{llllll}\begin{array}{l}\text { Strongly } \\ \text { disagree }\end{array} & \text { Disagree } & \begin{array}{l}\text { Neither agree } \\ \text { nor disagree }\end{array} & \text { Agree } & \begin{array}{l}\text { Strongly } \\ \text { agree }\end{array} & \text { N/A } \\ 1 & 2 & 3 & 4 & 5\end{array}$

Thank you. Your feedback is greatly appreciated. 


\section{APPENDIX F: Hospitality Hostess/Host Interview Template}

Date: XXX

Form: Telephone

Time: XX minutes

1. Please state your position and work experience for the record?

2. How many sponsorships have you worked on in your life, including as a volunteer?

3. What is your working definition of sponsorship?

4. What is your role in the ATB-Edmonton Grand Prix sponsorship?

5. Can you describe the crowd demographically?

6. Would you consider the hospitality suite to be a success?

7. Do you consider the hospitality suite to be a success for ATB?

8. At the hospitality Was the ATB logo easily viewable and well presented?

9. What else did you do?

10. How did they respond?

11. Anything else? 


\section{APPENDIX G: Mass-market questionnaire}

Hello, my name is....from TREND Research, a professional market research company in Alberta. We are conducting a survey on general topics that are of interest to Albertans. Please be assured that we are not trying to sell anything and your answers will remain anonymous.

\section{***INTERVIEWER NOTE: IF RESPONDENT ASKS, THE SURVEY TAKES APPROXIMATELY 6 MINUTES***}

A. May I speak to the person in the household who is 18 years of age or older, and who has had the most recent birthday?

$\begin{array}{lll}\text { Yes, on the phone } & 1 & \text { CONTINUE TO Q.1 } \\ \text { Yes (other member of household) } & 2 & \text { REPEAT INTRO \& GO TO Q.1 } \\ \text { Not available } & 3 & \text { SCHEDULE CALLBACK } \\ \text { Refused } & 4 & \text { DISCONTINUE \& THANK }\end{array}$

B. Are you or anyone in your household employed by a financial institution, market research or advertising company?

$\begin{array}{lll}\text { Yes } & 1 & \text { THANK \& TERMINATE } \\ \text { No } & 2 & \text { CONTINUE }\end{array}$

1. Have you ever attended an Indy, NASCAR or CHAMPCAR race as a spectator?

$\begin{array}{ll}\text { YES } & 1 \\ \text { NO } & 2\end{array}$

2. Have you ever watched an entire Indy, NASCAR or CHAMPCAR race on TV?

$\begin{array}{ll}\text { YES } & 1 \\ \text { NO } & 2\end{array}$

3. In late July of this past summer, the Edmonton Grand Prix Champ-Car Race took place in Edmonton. Did you...*READ THE FOLLOWING*
a. Attend the event in person?
b. Watch it on TV?
c. Follow it on either the radio or the internet? 112

4. While there are several sponsors for the 2006 Edmonton Grand Prix, to the best of your knowledge, which of the following was the title sponsor (by title sponsor we mean that the sponsors name is included in the event name)? *READ THE FOLLOWING LIST*

\begin{tabular}{ll} 
EDMONTON TOURISM & 1 \\
MOLSON & 2 \\
TRAVEL ALBERTA & 3 \\
FORD & 4 \\
THE BRICK & 5 \\
WEST_EDMONTON_MALL & 6 \\
NONE OF THE ABOVE & 7 \\
*DO NOT READ*: & \\
\hline Don't know & 8
\end{tabular}


5. Which of the Following was the official Financial Institution of the 2006 Edmonton Grand Prix? *READ THE FOLLOWING LIST*

\begin{tabular}{ll} 
Royal Bank of Canada & 1 \\
ATB Financial & 2 \\
Alberta Credit Unions & 3 \\
Capital City Savings & 4 \\
The Bank of Alberta & 5 \\
None of the above & 6 \\
*DO NOT READ* & \\
\hline Don't know & 7
\end{tabular}

6. ATB Financial was in fact the official financial institution of the 2006 Edmonton Grand Prix. Are you currently a customer of ATB Financial?

$\begin{array}{ll}\text { YES } & 1 \\ \text { NO } & 2\end{array}$

7. Based on your impressions or perceptions, which phrase best describes ATB Financial? *RANDOMIZE \& READ*

A full-service province wide Albertan financial institution

A Canadian financial institution from coast-to-coast

A small town Albertan financial institution

An urban financial institution with branches in all major Canadian cities but not in smaller towns and other areas

A Calgary financial institution expanding to Edmonton

*DO NOT READ*:

Don't know/ I have no idea what ATB Financial does

\section{INTERVIEWER NOTE: IF RESPONDENT SAYS THAT THEY HAVE NOT DONE BUSINESS WITH ATB FINANCIAL, READ:}

"Even if you have not done business with ATB Financial, base your answers on what you have seen or heard about the company. If you truly do not have an impression, don't know is an acceptable answer."

8. Now, I am going to read you a list of statements about sponsorships. For each of the following statement, please tell me whether you strongly agree, agree, neither agree or disagree, disagree or strongly disagree with it. *RANDOMIZE \& READ*

$\begin{array}{lclccc}\begin{array}{l}\text { Strongly } \\ \text { Agree }\end{array} & \text { Agree } & \begin{array}{l}\text { Neither } \\ \text { Agree nor Disagree }\end{array} & \text { Disagree } & \begin{array}{c}\text { Strongly } \\ \text { Disagree }\end{array} & \begin{array}{c}\text { Don't } \\ \text { Know }\end{array} \\ 5 & 4 & 3 & 2 & 1 & 9\end{array}$


b) After learning that ATB Financial was

$\begin{array}{llllll}\begin{array}{l}\text { Strongly } \\ \text { Agree }\end{array} & \text { Agree } & \begin{array}{l}\text { Neither } \\ \text { Agree nor Disagree }\end{array} & \text { Disagree } & \begin{array}{c}\text { Strongly } \\ \text { Disagree }\end{array} & \begin{array}{l}\text { Don't } \\ \text { Know }\end{array} \\ & & & & \end{array}$
sponsoring the Edmonton Grand Prix, my belief that they care about Albertans increased.

$\begin{array}{llllll}5 & 4 & 3 & 2 & 1 & 9\end{array}$

c) In my opinion, the ATB sponsorship of the Edmonton Grand Prix helps demonstrate that ATB is a major player in the Alberta banking market

d) When I think of ATB Financial, I think of a

full-service, province wide financial institution.

e) ATB being one of the sponsors for

Edmonton Grand Prix made me prouder that the

event is hosted in Alberta

f) The fact that ATB Financial sponsored the

Edmonton Grand Prix makes me more likely to

[open an account at ATB OR use more of

ATB's services]. **Interviewer to ask one or

the other based on response to $Q 7$ above: open

if not a client, use more if already a customer of $A T B^{* *}$

g) When I think of ATB Financial, I think of a rural Alberta financial institution.

$5 \quad 4$

h) The fact that ATB Financial sponsored the

Edmonton Grand Prix while other Albertan

banks did not led me to view ATB as having an

advantage over these other banks.

9. May if confirm which age group you belong to? READ

$\begin{array}{ll}18-25 & 1 \\ 25-35 & 2 \\ 35-45 & 3 \\ 45-55 & 4 \\ 55-65 & 5 \\ 65 \text { or older } & 6\end{array}$

10. And finally, in 2005, was your total household income, before taxes...*READ LIST*

Less than $\$ 50 \mathrm{k}$

1

$\$ 50 \mathrm{k}$ to less than $\$ 100 \mathrm{k} \quad 2$

$\$ 100 \mathrm{k}$ to less than $\$ 150 \mathrm{k} \quad 3$

$\$ 150 \mathrm{k}$ to less than $\$ 250 \mathrm{k} \quad 4$

$\$ 250 \mathrm{k}$ or more

5

DO NOT READ

Don't know/Refused

9

11. RECORD:

$\begin{array}{ll}\text { Male } & 1 \\ \text { Female } & 2\end{array}$


12. RECORD FROM SAMPLE:

$\begin{array}{lr}\text { Metro Edmonton } & 1 \\ \text { Metro Calgary } & 2 \\ \text { Other cities } & 3 \\ \text { Other towns/rural areas } & 4\end{array}$

Those are all my questions for today. Thank you very much for your time, I do really appreciate it. Have a nice day/evening! 


\section{APPENDIX H: Post-Event Employee Interview Template}

Date, Location, Time:

Record Gender:

1. Please state your name and position at ATB for the record, including the business unit that you work for?

2. How many years have you worked for ATB?

3. Do you consider ATB to be a good place to work?

4. Are you satisfied with how you are treated at ATB?

5. Are most employees satisfied with the working environment at ATB?

6. How would you rate the performance of the ATB marketing group over the past year?

7. Do you feel that the work of the marketing group has any effect on employee morale, employee retention or employee pride in the firm (please respond to all three)?

8. If yes, what specific activities led to this view?

9. If yes, did the ATB-EGP Sponsorship contribute?

10. Can you allocate a percentage?

[Now a few questions about the recent ATB-EGP Sponsorship]

11. How did you feel when you heard that ATB was going to sponsor the EGP?

12. What was the general feeling at the office when the ATB-ECG sponsorship was announced?

13. Did you attend the event?

14. Were you aware that ATB offered a staff discount program on tickets?

15. Did you take advantage of this offer?

16. Was it a popular offer?

17. Now that the event has passed, do you feel that it was a good marketing initiative for ATB to sponsor the EGP?

a. Is this general consensus?

18. Did the sponsorship make you proud to be an ATB employee?

19. Did the sponsorship raise employee morale around the office? 


\section{APPENDIX I: Internal Data Request, Kanatek Staff}

\section{MEMO: Data Request \#I}

To. Tenty Kell

From: Norm O'Reilly

Terry,

As discussed can you please provide the following?

Thanks,

Norm

\section{Sales Data:}

I'm assuming that your year-end is April $30^{\text {th }}$. If so, can you please provide me with the following? If not, we can adapt for your year-end.

1. For the year May 1, 2003 to April $30^{\text {th }}, 2004$
a. Total Revenue:
b. Total Profit/Loss:
c. Total Number of Customers as of April $30^{\text {th }}, 2005$ :
d. Number of new customers signed over the year:
e. Number of large customers signed over the year:
f. Number of customers lost over the year:
g. Number of large customers lost over the year:

2. For the year May 1, 2004 to April $30^{\text {th }}, 2005$
a. Total Revenue:
b. Total Profit/Loss:
c. Total Number of Customers as of April $30^{\text {th }}, 2005$ :
d. Number of new customers signed over the year:
e. Number of large customers signed over the year:
f. Number of customers lost over the year:
g. Number of large customers lost over the year:

3. For the year May 1,2005 to April $30^{\text {th }}, 2006$
a. Total Revenue:
b. Total Profit/Loss:
c. Total Number of Customers as of April $30^{\text {th }}, 2006$ :
d. Number of new customers signed over the year:
e. Number of large customers signed over the year:
f. Number of customers lost over the year:
g. Number of large customers lost over the year:

4. Since May 1, 2006, have any major sales or deals been signed where the expedition played a role (no matter how large or small) in that signing? If so, can you provide details on this (those) deal(s)?

5. As of today (September XX, 2006), how many customers does Kanata have?

\section{Employee Data:}


Can you please provide me with the following?

6. At June 10, 2004:

a. How many employees did Kanatek have?

b. How large (budget and number of employees) was the sales force including contracts?

7. At April $30^{\text {th }}, 2005$ :

a. How many employees did Kanatek have?

i. For the change from June 10, 2004:

1. How many new employees joined

2. How many employees left

b. How large (budget and number of employees) was the sales force including contracts?

i. For the change from June 10, 2004:

1. How many new employees joined

2. How many employees left

c. Any changes at senior management level?

8. As of today (Sept XX, 2006):

a. How many employees did Kanatek have?

i. For the change from April $30^{\text {th }}, 2005$ :

1. How many new employees joined

2. How many employees left

b. How large (budget and number of employees) was the sales force including contracts?

i. For the change from April $30^{\text {th }}, 2005$ :

1. How many new employees joined

2. How many employees left

c. Any changes at senior management level?

9. Any historical (pre-June 10,2004) that you may have on number of employees and/or size of sales force and/or senior management structure. 


\section{APPENDIX J: Kanatek Staff Survey}

\section{Sales Staff/Contractor Questionnaire}

The following survey is designed to help Kanatek evaluate some recent promotions it has implemented to increase business. Please take the 2-3 minutes required to complete the following.

Please note that your responses will be kept anonymous and only summary results will be shared with Kanatek management.

1. How long have you been working for (or with) Kanatek?

$\begin{array}{ll}1 & \text { I joined in the last year (i.e. since September 1, 2005) } \\ 2 & \text { I joined between March 1, } 2005 \text { and September 1, 2005 } \\ 3 & \text { I joined between June 10, } 2004 \text { and February 28, 2005 } \\ 4 & \text { I joined before June 10, } 2004\end{array}$

2. Which of the following best describes your situation: Kanatek is:
$5 \quad$ My full-time employer
6 My part-time employer
7 A client who I do contract work for

3. Kanatek has a number of promotional activities designed to support increased business and support the sales function of the organization. In general, are you satisfied with the ability of these activities to support your efforts to increase sales?

$\begin{array}{ll}\text { VERY SATISFIED } & 1 \\ \text { SATISFIED } & 2 \\ \text { NEITHER SATISFIED NOR DISSATISFIED } & 3 \\ \text { DISSATISFIED } & 4 \\ \text { VERY DISSATISFIED } & 5\end{array}$

4. As you are aware, Kanatek was the title sponsor of a recent expedition to Mount Everest. Were you satisfied with this sponsorship's ability to support your efforts to increase sales?

$\begin{array}{ll}\text { VERY SATISFIED } & 1 \\ \text { SATISFIED } & 2 \\ \text { NEITHIER SATISFIED NOR DISSATISFIED } & 3 \\ \text { DISSATISFIED } & 4 \\ \text { VERY DISSATISFIED } & 5\end{array}$

5. Specific to Kanatek's sponsorship of the recent expedition to Mount Everest, how many new deals were signed where it had some effect?

0

1 or more (Please indicate how many:

6. If you indicated 1 or more for question $\# 5$, please estimate the importance of the sponsorship in enabling you to sign the new client (please respond once for each client).

$\begin{array}{ll}\text { VERY IMPORANT } & 1(\#:-) \\ \text { IMPORTANT } & 2(\#:-3) \\ \text { MINOR IMPORTANCE } & 3(\#: \square)\end{array}$




\section{VERY SMALL IMPACT $\quad 4\left(\#: \_\right)$}

7. Specific to Kanatek's sponsorship of the recent expedition to Mount Everest, how many current deals were renewed where the sponsorship made some contribution to the renewal?

0

1 or more (Please indicate how many:

8. If you indicated 1 or more for question \#7, please estimate the importance of the sponsorship in enabling you to re-sign the client (please respond once for each client).

$\begin{array}{ll}\text { VERY IMPORANT } & 1(\#: \\ \text { IMPORTANT } & 2(\#: \\ \text { MINOR IMPORTANCE } & 3(\#: \square) \\ \text { VERY SMALL IMPACT } & 4(\#: \square\end{array}$

9. Specific to Kanatek's sponsorship of the recent expedition to Mount Everest, how many current clients increased their business with Kanatek where the sponsorship made some contribution to the increase?

0

1 or more (Please indicate how many:

10. If you indicated 1 or more for question \#9, please estimate the importance of the sponsorship in enabling you to re-sign the client (please respond once for each client).

$\begin{array}{ll}\text { VERY IMPORANT } & 1(\#: \square) \\ \text { IMPORTANT } & 2(\#: \square) \\ \text { MINOR IMPORTANCE } & 3(\#: \square \\ \text { VERY SMALL IMPACT } & 4(\#: \square\end{array}$

11. Given your answers above, can you summarize by estimating in Canadian dollars how much impact the sponsorship of the Mount Everest had on Kanatek sales?

$\$$

12. Do you have any ongoing sales discussions where the Expedition played a role?

$\begin{array}{ll}\text { YES } & 1 \\ \text { NO } & 2\end{array}$

13. Do you still use or plan to use the Expedition in future sales pitches?

YES 1

NO 2




\section{APPENDIX K: Expedition Member Survey}

The following survey is designed to help evaluate the expedition 16 months after the fact. Please take the 2 minutes (approximate) required to complete the following.

NOTE: Please BOLD your answers to questions below or fill in text box where applicable. Also, note that your responses will be kept anonymous and only summary results will be shared.

1. Which of the following best describes your situation on the 2005 expedition (pick one):

$\begin{array}{ll}8 & \text { Climber } \\ 9 & \text { Researcher } \\ 10 & \text { Trekker }\end{array}$

2. Looking back, I would describe my level of satisfaction with the safety provided on the expedition as:

$\begin{array}{ll}\text { VERY SATISFIED } & 1 \\ \text { SATISFIED } & 2 \\ \text { NEITHER SATISFIED NOR DISSATISFIED } & 3 \\ \text { DISSATISFIED } & 4 \\ \text { VERY DISSATISFIED } & 5\end{array}$

3. Looking back, I would describe my level of satisfaction with the overall experience of the expedition as:

VERY SATISFIED

SATISFIED 2

NEITHER SATISFIED NOR DISSATISFIED 3

DISSATISFIED

VERY DISSATISFIED

4. Following the news of Dr. Egan's death, my level of overall satisfaction became:

$\begin{array}{ll}\text { MUCH MORE SATISFIED } & 1 \\ \text { MORE SATISFIED } & 2 \\ \text { NO CHANGE } & 3 \\ \text { MORE DISSATISFIED } & 4 \\ \text { MUCH MORE DISSATISFIED } & 5\end{array}$

5. Today, I would describe my level of overall satisfaction became:

$\begin{array}{ll}\text { VERY SATISFIED } & 1 \\ \text { SATISFIED } & 2 \\ \text { NEITHER SATISFIED NOR DISSATISFIED } & 3 \\ \text { DISSATISFIED } & 4 \\ \text { VERY DISSATISFIED } & 5\end{array}$

6. (Optional) Please provide any insights you have into how the expedition could have been a better experience? Please provide comments for both the expedition and the title sponsor. 
7. Please provide your opinions of the technology demonstrations that took place from the mountain (satellite connection, data-back-up, communication home, etc.)?

8. Please provide your opinions of the hockey game played on the mountain (quality of setup, enjoyment, media value, etc.)?

The remainder of the survey is for those who were involved in research. If this is not you, you are finished! Thank you.

9. For your work, please provide numbers for each of the following that have resulted due to a contribution (no matter how small) from work done during the expedition:

b. The number of publications:

c. The number of conference proceedings:

d. The number of presentations:

e. The number of projects currently in progress:

f. The number of additional publications expected in the future:

g. The number of additional conference proceedings expected in the future:

h. The number of additional presentations expected in the future:

10. How would you rate your level of satisfaction with the research support provided by the expedition?

$\begin{array}{ll}\text { VERY SATISFIED } & 1 \\ \text { SATISFIED } & 2 \\ \text { NEITHER SATISFIED NOR DISSATISFIED } & 3 \\ \text { DISSATISFIED } & 4 \\ \text { VERY DISSATISFIED } & 5\end{array}$

11. How would you rate your level of satisfaction with the research support provided by the title sponsor of the expedition?

$\begin{array}{ll}\text { VERY SATISFIED } & 1 \\ \text { SATISFIED } & 2 \\ \text { NEITHER SATISFIED NOR DISSATISFIED } & 3 \\ \text { DISSATISFIED } & 4 \\ \text { VERY DISSATISFIED } & 5\end{array}$

12. Please provide your opinions the 2005 Kanatek Everest Expedition to Mount Everest as an environment for research? 


\section{APPENDIX L: Current Sponsorship Industry Trends}

\begin{tabular}{|c|c|c|c|}
\hline \multicolumn{2}{|c|}{ Current Trend } & \multirow{2}{*}{$\begin{array}{l}\text { Description } \\
\text { When a non-official sponsor } \\
\text { positions itself, through its } \\
\text { promotions, as the official sponsor } \\
\text { of an event. } \\
\end{array}$} & \multirow{2}{*}{$\begin{array}{l}\text { Source } \\
\text { Meenaghan (1998) }\end{array}$} \\
\hline 1 & Ambush Marketing & & \\
\hline 2 & New media technology & $\begin{array}{l}\text { Various technology enabled } \\
\text { sponsorship tactics (e.g., virtual } \\
\text { signage, iTV, HDTV, etc.) }\end{array}$ & $\begin{array}{l}\text { Mendez (1999); Moore, } \\
\text { Pickett \& Grove (1999); } \\
\text { Turner (1999); Shannon \& } \\
\text { Turley (1997) }\end{array}$ \\
\hline 3 & Advertising clutter & $\begin{array}{l}\text { Cutting through the cluttered } \\
\text { market place. Note this article } \\
\text { views sponsorship as a sub-set of } \\
\text { advertising. }\end{array}$ & $\begin{array}{l}\text { Ojala \& Edmunston (1987) } \\
\text { is an example of targeting } \\
\text { women }\end{array}$ \\
\hline 4 & Sponsorship conflicts & $\begin{array}{l}\text { Battles over exclusivity and } \\
\text { sponsorship often end up in the } \\
\text { courtroom }\end{array}$ & Meyer (1999) \\
\hline 5 & Broadcast regulations & $\begin{array}{l}\text { Broadcast sponsorship and rights } \\
\text { to valuable properties has } \\
\text { skyrocketed in cost. }\end{array}$ & Meyer (1999) \\
\hline 6 & The need for evaluation & $\begin{array}{l}\text { Strongly articulated by both } \\
\text { practitioners and academics. }\end{array}$ & Berrett (1993) and others. \\
\hline 7 & $\begin{array}{l}\text { Ban on industry (i.e., } \\
\text { tobacco) sponsorships }\end{array}$ & $\begin{array}{l}\text { Tobacco companies unable to } \\
\text { sponsor sport as part of their } \\
\text { marketing mix. }\end{array}$ & $\begin{array}{l}\text { Rosenberg \& Siegel } \\
\text { (2001); Siegel (2001); } \\
\text { McDaniel \& Mason (1999) }\end{array}$ \\
\hline 8 & Insurance & $\begin{array}{l}\text { Sponsees and sponsors accessing } \\
\text { insurance becoming more difficult } \\
\text { and costly }\end{array}$ & Author addition. \\
\hline 9 & $\begin{array}{l}\text { Official and unofficial } \\
\text { corporate hospitality }\end{array}$ & $\begin{array}{l}\text { Leveraging tactics expanding and } \\
\text { increasing in sophistication }\end{array}$ & $\begin{array}{l}\text { Ludwig \& Karabetsos } \\
\text { (1999) }\end{array}$ \\
\hline 10 & $\begin{array}{l}\text { Merchandising and } \\
\text { licensing and other } \\
\text { forms of Leverage }\end{array}$ & $\begin{array}{l}\text { Sponsors and sponsees are } \\
\text { seeking to get more out of } \\
\text { investments and leverage as many } \\
\text { ways as possible. }\end{array}$ & $\begin{array}{l}\text { Seguin, Teed \& O'Reilly } \\
(2005)\end{array}$ \\
\hline 11 & $\begin{array}{l}\text { Media conglomerates are } \\
\text { consolidating the } \\
\text { industry and reducing } \\
\text { opportunities for } \\
\text { sponsorship. }\end{array}$ & $\begin{array}{l}\text { Large media organizations buying } \\
\text { and selling sport properties and } \\
\text { differentiating horizontally and } \\
\text { vertically }\end{array}$ & $\begin{array}{l}\text { Law, Harvey \& Kemp } \\
(2002)\end{array}$ \\
\hline 13 & $\begin{array}{l}\text { Contra (or in-kind) } \\
\text { sponsorship }\end{array}$ & $\begin{array}{l}\text { Contributing in-kind resources } \\
\text { more attractive to sponsors and } \\
\text { possible in sponsee-rich } \\
\text { environment }\end{array}$ & $\begin{array}{l}\text { Fahy, Farrelly \& Quester } \\
(2004)\end{array}$ \\
\hline 14 & Multi-sponsor format & $\begin{array}{l}\text { Co-branding, co-sponsoring, } \\
\text { sponsor's co-leveraging, etc. all } \\
\text { becoming more popular }\end{array}$ & Meenaghan (1998) \\
\hline
\end{tabular}




\section{APPENDIX M: Int_2 Description Of Own Evaluation Model}

So, the way we start is that we start with assessing all the sponsor benefits, we take a look at the reach of each one of those benefits - eyeballs, audience exposure, audience reach, each one of those things - and we apply a value to that to come up with a total tangible value of that property. Then, we look at it and say OK what are the intangible assets of the property? So, then the second level is the intangible and we go through an assessment of where we look at what are the intangible elements that are added to that to come up with a total value of that property. So, for example, if somebody had a bunch of quantitative assets that we added together and it come up to $\$ 10,000$ and they were offering product exclusivity - so we put a range of anywhere from $25 \%$ to $50 \%$ on product exclusivity - so, let's say it was a really exclusive property, you know they were shutting out all of their competitors and everybody else, and we gave it a $50 \%$. So, that $\$ 10,000$ now becomes $\$ 15,000$ in value and we add in a number of other key factors and we come up with the total value of the sponsorship. OK? Now, we use a common asset evaluation for public events and this shows you what we do and how we lay out different things. So, in ID and in event program, a mogul ID can range anywhere from a $1 / 4$ of a cent to 5 cents. There are some variables here that shows you how it can work...for example, a value on a sing at an entrance to an event is a lot different value that a sign that is along a walkway at an event that has a lot of other moguls on it. I mean who looks at the sign with 4 or 5 moguls...nobody does but do you look at the sign at the entrance to the event...the odds are that you are going to see it. So, we place the highest value on signs where they are behind a stage where you are staring at it for a half an hour. Those are the signs with the highest value. So what we do is to keep the tangible assets consistent we work with the numbers and we change the values - we don't try to think about how many people will see that sign along the walkway and we don't try to think about how many people will see that entrance sign, we say there is 20,000 people attending so the entrance sign has a value of 4 cents/impression whereas the sign along the way has a value of 1 cent/impression...so, we're taking into account that it probably won't be seen like the one at the entrance. These values are based on my experiences. So, we've done is that we've looked at around 300 sponsorship properties at least and we've come up with averages of what things are worth and then we say based on this, this is where basic tangible assets come in at. So, what I'm going to give you here is the chart that shows you how this works and how these things apply. So what we do when we do this is....and this is sort of standard to what we do...we talk about the methodology or what we do with the company, then we talk about the types of things that we look at from an intangible perspective. So, you can see the prestige of the property, is it a worthwhile cause, does it have media potential, impact on the audience, does it have networking opportunities, is it adaptable to geographic considerations, what is the ease of activation, how exclusive is it, what is its ability to stimulate sales. So, 
you can see how - in this case here - that the tangible value is $\$ 10,000$ so we then assessed these other key [intangible] elements as being really important and we put them and we came up with $\$ 18,500$. Well, this $\$ 10,000$ is based on our stuff and the rest of it is based on experience, instinct, what other people are paying in the market, all that kind of stuff. This is where it gets fuzzy. We're starting with a quantitative number to start with....and we're saying purely on a quantitative level - forget the associative value of this - what is this worth from a pure media perspective. Then we add up. As you can see here, we have everything from websites, to ID on tickets, to logos, to PA announcements... You know if with something like this when you are looking at something like advertising on a publication to do with the sponsorship. If they are selling ads for $\$ 2,500$ and you are actually getting money $\$ 2,500$ to sell those ads, and you give up and ad as part of the benefit, then you should have a $\$ 2,500$ value. So, whenever there are rate cards established for things, those are the values we put on it. So, that is kind of that point. 